\title{
Sincerity in Politics and International Relations
}

Edited by

Sorin Baiasu and Sylvie Loriaux 


\section{Sincerity in Politics and International Relations}

This edited volume examines the concept of sincerity in politics and international relations in order to discuss what we should expect of politicians, within what parameters they should work, and how their decisions and actions could be made consistent with morality.

The volume features an international cast of authors who specialize in the topic of sincerity in politics and international relations. Looking at how sincerity bears on political actions, practices, and institutions at national and international level, the introduction serves to place the chapters in the context of ongoing contemporary debates on sincerity in politics and international theory. Each chapter focuses on a contemporary issue in politics and international relations, including corruption, public hypocrisy, cynicism, trust, security, policy formulation and decision-making, political apology, public reason, denial and self-deception, and will argue against the background of a Kantian view of sincerity as unconditional.

Offering a significant comprehensive outlook on the practical limits of sincerity in political affairs, this work will be of great interest to students and scholars alike.

Sorin Baiasu is Professor of Philosophy at Keele University, UK. Apart from articles and chapters, he authored Kant and Sartre: Re-discovering Critical Ethics (2011), and edited and co-edited several collections.

Sylvie Loriaux is Assistant Professor of Political Theory at Laval University, Canada. She contributed articles to various journals, including Moral Philosophy and Politics and the European Journal of Political Theory. 


\section{Routledge Advances in International Relations and Global Politics}

119 Exercising Human Rights Gender, agency, and practice Robin Redhead

120 State Responses to International Law Who complies? Kendall Stiles

121 Regional Integration and Democratic Conditionality How Democracy Clauses Help Democratic Consolidation and Deepening Gaspare M. Genna and Taeko Hiroi

122 Profits, Security and Human Rights in Developing Countries Global Lessons from Canada's Extractive Sector in Colombia Edited by James Rochlin

123 The Politics of Place and the Limits to Redistribution Melissa Ziegler Rogers

124 Apology and Reconciliation in International Relations

The Importance of Being Sorry Edited by Christopher Daase, Stefan Engert, Michel-André Horelt, Judith Renner, and Renate Strassner
125 The United States and Turkey's Path to Europe Hands across the Table Armă̆an Emre Çakır

126 Western Muslim Reactions to Conflicts Abroad Conflict Spillovers to Diasporas Juris Pupcenoks

127 U.S. Security Cooperation with Africa

Political and Policy Challenges Robert J. Griffiths

128 Russia's Relations with Kazakhstan

Rethinking Post-communist Transitions in the Emerging World System Yelena Nikolayevna Zabortseva

129 Reinventing Regional Security Institutions in Asia and Africa

Power shifts, ideas, and institutional change

Kei Koga

130 Sincerity in Politics and International Relations Edited by Sorin Baiasu and Sylvie Loriaux 


\title{
Sincerity in Politics and International Relations
}

\author{
Edited by \\ Sorin Baiasu and \\ Sylvie Loriaux
}

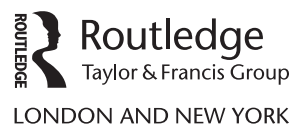


First published 2017

by Routledge

2 Park Square, Milton Park, Abingdon, Oxon OX14 4RN

and by Routledge

711 Third Avenue, New York, NY 10017

Routledge is an imprint of the Taylor \& Francis Group, an informa business

(C) 2017 selection and editorial matter, Sorin Baiasu and Sylvie Loriaux; individual chapters, the contributors

The right of Sorin Baiasu and Sylvie Loriaux to be identified as authors of the editorial matter, and of the individual authors as authors of their contributions, has been asserted by them in accordance with sections 77 and 78 of the Copyright, Designs and Patents Act 1988.

All rights reserved. No part of this book may be reprinted or reproduced or utilised in any form or by any electronic, mechanical, or other means, now known or hereafter invented, including photocopying and recording, or in any information storage or retrieval system, without permission in writing from the publishers.

Trademark notice: Product or corporate names may be trademarks or registered trademarks, and are used only for identification and explanation without intent to infringe.

\section{British Library Cataloguing in Publication Data}

A catalogue record for this book is available from the British Library

Library of Congress Cataloging in Publication Data

Names: Baiasu, Sorin, editor. | Loriaux, Sylvie, editor.

Title: Sincerity in politics and international relations / edited by Sorin

Baiasu and Sylvie Loriaux.

Description: Abingdon, Oxon; New York, NY: Routledge is an imprint of the Taylor \& Francis Group, an Informa Business, [2017] | Series:

Routledge advances in international relations and global politics | Includes bibliographical references and index.

Identifiers: LCCN 2016038010| ISBN 9780415704175 (hbk) |

ISBN 9780203762257 (ebk)

Subjects: LCSH: Political science-Philosophy. | International relations-

Philosophy. | Sincerity-Political aspects. | Kant, Immanuel,

1724-1804-Political and social views.

Classification: LCC JA71.S483 2017 | DDC 320.01/9-dc23

LC record available at https://lccn.loc.gov/2016038010

ISBN: 978-0-415-70417-5 (hbk)

ISBN: 978-0-203-76225-7 (ebk)

Typeset in Times New Roman

by Wearset Ltd, Boldon, Tyne and Wear 


\section{Contents}

Notes on contributors vii

Introduction 1

SYLVIE LORIAUX

\section{PART I}

Publicity 15

1 Political deception: lowering the bar 17

GLEN NEWEY

2 The role of public reason's principle of sincerity 32 ENRICO ZOFFOLI

3 Speaking on morality's behalf: when one should be silent and why

MARK EVANS

4 What can we learn about political corruption from Kant's conceptions of honesty, publicity and truthfulness?

DORON NAVOT

\section{PART II}

Rhetoric

5 The political rhetoric of administrative ethics:

Obama vs. the cynics 
vi Contents

6 A Kantian rhetoric of sincerity: politics, truth and truthfulness

PAMELA SUE ANDERSON

7 Making sense: the possibility of truthfulness in politics ESTHER ABIN

8 On doubt and otherness: deconstructing power and dissent SIMONE CHELI

\section{PART III}

Institutions

9 Political dissimulation à la Kant: two limits of the sincerity requirement

SORIN BAIAS U

10 Pretending peace: provisional political trust and sincerity in Kant and Améry

MARGUERITE LA CAZE

11 Governing by trust: sincerity as a procedural fairness norm ZSOLT BODA

12 Truth-telling and right-speaking in European integration politics: from theory to practice and back CATHERINE GUISAN 


\section{Contributors}

Esther Abin (Ph.D., Keele University) is Research Associate in the Department of Philosophy, University of Lille 3, and teacher in philosophy and ethics. She is currently working on a book drawn from her thesis Rationality and Morality in Political Theory: a paradigm shift.

Pamela Sue Anderson is Professor of Modern European Philosophy of Religion, University of Oxford; and Fellow in Philosophy, Regent's Park College, Oxford, UK. She received her doctorate from the University of Oxford in 1989 and an honorary doctorate from Lund University in 2009. Anderson has published numerous articles in modern European philosophy, since completing her Oxford DPhil, part of which was published in Ricoeur and Kant (1993). She also developed the groundwork for a new field: feminist philosophy of religion, publishing A Feminist Philosophy of Religion: the Rationality and Myths of Religious Belief (1998); Feminist Philosophy of Religion: Critical Readings, coedited with Beverley Clack (2004); New Topics in Feminist Philosophy of Religion: Contestations and Transcendence Incarnate (2010); Kant and Theology, co-authored with Jordan Bell (2010); Re-visioning Gender in Philosophy of Religion: Reason, Love and Epistemic Locatedness (2012). She is a Guest Editor of Sophia: International Journal of Philosophy and Traditions, special issue on 'Feminist Philosophy of Religion' (2014); she is also a Guest Editor of Text Matters: A Journal of Literature, Theory and Culture, special issue on 'Revisioning Ricoeur and Kristeva' (2014); In Dialogue: With Michèle Le Doeuff (London: Bloomsbury, forthcoming 2017). Currently, she is working on a monograph, Enhancing, Vulnerable Life, Love, Relationality and Affection, for a John Templeton Project on 'Enhancing Life'.

Sorin Baiasu is Professor of Philosophy at Keele University and Director of the Keele-Oxford-St Andrews Kantian (KOSAK) Research Centre. He is the author of Kant and Sartre: Re-discovering Critical Ethics (2011) and editor or coeditor of Politics and Metaphysics in Kant (2011), Kant on Practical Justification: Interpretive Essays (2013), Comparing Kant and Sartre (2016) and The Kantian Mind (forthcoming 2017). He guest edited or co-edited special issues of the Journal of International Political Theory (2007), Kantian Review (2011 and, forthcoming, 2016), Kant-Studien (2016) and Philosophia (2016 and 
forthcoming 2017). Currently, he is completing two monographs: one on Kant's idea of a guarantee for perpetual peace, and one on desert and justice.

Anders Berg-Sørensen is Associate Professor in Political Theory and Head of Studies at the Department of Political Science, University of Copenhagen. He has over the last decade done research on the contestation of the religionpolitics relationship in European public discourse and political thinking historically and actually. The focus has been on the political doctrine of secularism regulating the religion-politics relationship, the formation of secularism in early modern political thought and the transformation of secularism in contemporary political theory. Furthermore, he is carrying out research on political ethics and real politics engaging democratic theory and political theory of realism. He is currently working on a book manuscript with the preliminary title, Light and darkness in European post-war government: Democratic compromises of legitimacy, accountability and transparency. The project brings together the literature on compromises in democratic theory and the political history of democratic institutions constituted in post-war Europe with the aim at controlling the government's exercise of power.

Zsolt Boda is Senior Research Fellow and Director of the Institute of Political Science, at the Centre for Social Sciences of the Hungarian Academy of Sciences. He is editor-in-chief of Politikatudományi Szemle, the political science journal of the Hungarian Academy of Sciences. He researched and published extensively both in Hungarian and English on issues of institutional trust, public policy and governance.

Simone Cheli is Professor of General Pedagogy at the School of Human Health Sciences, University of Florence, and Director of Research at the Psychooncology Unit, Oncological Department of Florence. He received his degree in Clinical and Community Psychology at the University of Florence and his specialization degree in Psychotherapy at the Institute of Constructivist Psychology in Padua. His primary scientific interests include the epistemological foundations of psychology and education, and the development of different psycho-oncological interventions (with a specific focus on the application of the Third Wave of Cognitive-Behavioral Therapy) for patients, caregivers, professionals and organizations. He is currently president of the Tages Charity, a non-profit organization devoted to improving a scientifically and ethically based approach to the well-being of both persons and communities.

Mark Evans is Reader in Politics, Department of Political and Cultural Studies in the College of Arts and Humanities, Swansea University, UK. He is the author of Self-Realization: Politics and the Good Life in Modern Times (Nova 2007), and the editor of The Edinburgh Companion to Contemporary Liberalism (Edinburgh University Press 2001), Ethical Theory in the Study of International Politics (Nova 2004), Just War Theory: A Reappraisal (Edinburgh University Press 2005) and War, Terror and Ethics (Nova 2008). He has published numerous articles on liberalism, human rights, just war theory and, most recently, on 
jus post bellum and the morality of post-conflict reconstruction on which he is currently writing a book.

Catherine Guisan, PhD, is Visiting Assistant Professor in the Department of Political Science, University of Minnesota, Minneapolis. She has taught in five European universities also, including European University, Saint Petersburg, Russia as a Fulbright Scholar. She is the author of Un sens à l'Europe: Gagner la Paix (1950-2003) (Odile Jacob 2003) and A Political Theory of Identity in European Integration: Memory and policies (Routledge 2012). Her research interests include the role of memory in European Union identity formation, the responses of civil society during international political crises, and theorizing the politics of reconciliation.

Marguerite La Caze is Associate Professor in Philosophy at the University of Queensland. Her publications include Wonder and Generosity: Their Role in Ethics and Politics, (SUNY 2013), The Analytic Imaginary (Cornell 2002), Integrity and the Fragile Self, with Damian Cox and Michael Levine (Ashgate 2003) and articles on the work of Hannah Arendt, Simone de Beauvoir, Jacques Derrida, Sigmund Freud, Luce Irigaray, Immanuel Kant, Michèle Le Dœuff, Jean-Paul Sartre and Iris Marion Young.

Sylvie Loriaux is Assistant Professor of Political Theory at Laval University, Canada. Her research focuses on modern and contemporary political philosophy, global ethics and theories of justice. She has contributed articles to various journals, including Moral Philosophy and Politics, European Journal of Political Theory and Critical Review of International Social and Political Philosophy. She is currently working on a research project that explores territorial rights issues.

Doron Navot is a lecturer in the School of Political Sciences at the University of Haifa, Israel. He received his BA and MA degrees in political science from Tel Aviv University and his $\mathrm{PhD}$ from the Hebrew University. His writings include Political Corruption in Israel (2012) and articles about political corruption and the Israeli political system published in, among others, Constellations, Governance, Political Studies Review, Public Integrity and Public Management Review.

Glen Newey is Professor of Practical Philosophy in the Instituut voor Wijsbegeerte, Leiden University. He is the author of books and articles on political philosophy and ethics, including Virtue, Reason and Toleration (1999), Hobbes and 'Leviathan' (2008) and Toleration in Political Conflict (2013).

Enrico Zoffoli received his doctoral degree from the Technical University of Darmstadt (2013) after studying philosophy at the University of Bologna. Since then he has been working full-time as a freelance translator with special focus on legal and political theory. 



\title{
Introduction
}

\author{
Sylvie Loriaux
}

To be sincere or truthful means above all to mean what we say. This does not entail that we have to say everything we think. Sincerity differs from candour: it does not require people to disclose all their feelings to others, to tell them all the details of their past or present lives, or to make all their political or religious opinions public. ${ }^{1}$ Sincerity is perfectly compatible with people keeping secrets, withholding information, or more broadly, being entitled to privacy. The concept of 'sincerity' is perhaps best defined in terms of its contrary, that is, untruthfulness. At its core is the idea that although there is no duty to speak and even less to say everything we think, from the moment we say something we ought to mean it, that is, we ought to believe in its veracity. Of course, we can be wrong about the facts: some of the things we say may, as a matter of fact, prove to be false. But what matters from a sincerity perspective is that, at the time we express these things, we also believe them to be true. That is, we are not allowed to try to deceive others or to try to 'make [others] believe what we ourselves do not believe' (Bok 1999: 13). This rules out the telling of lies to others - which consists of making 'intentionally misleading statements', that is, making statements that we hold to be false with the intention that they be believed to be true (Bok 1999: 14; Mahon 2009: 203) - but also other less flagrant ways of misleading others as, for example, purposively exaggerating or concealing certain aspects of a given state of affairs to gain some control over others' beliefs and actions. $^{2}$

Untruthfulness is generally looked on as being morally reprehensible. Certainly, some benign forms of intentional untruths are largely tolerated, indeed fully accepted. This is for instance the case with jokes and white lies (such as accepted expressions of politeness). But these untruths usually do not deceive anyone and do not even invite others to believe them to be true (Mahon 2003: 102-3). It is also worth noting that the vast majority of people would not like to be suspected of having lied, let alone to be called 'liars'. While there are quite a few character flaws that they are prepared to acknowledge - such as avarice, jealousy, greed or impulsiveness - untruthfulness seems to call into question their very integrity and respectability. Conversely, even those who believe they have good reasons to lie to others would not like to be told lies by others (Bok 1999: 23). 


\section{S. Loriaux}

From a philosophical point of view, there are two main ways of accounting for the moral condemnation of untruthfulness: consequentialism and deontologism. Consequentialist approaches will typically place the emphasis on the potential harmful outcome of an untruthful action or practice. Even if they admit that certain instances of untruthfulness can have clearly positive consequences (as when the telling of a lie is predicted to save a large number of innocent people) and therefore be permissible, indeed obligatory, they will also take note of the fact that a general acceptance or a too frequent resort to untruthfulness is likely to have a corrupting effect on society as a whole. By contrast, deontological approaches will underscore the intrinsically and hence unconditionally immoral character of untruthfulness. For a deontologist, there is a moral duty to be truthful to others and the fact that a particular instance of lying would most likely result in serious harm being avoided does not generate any exception to that duty.

It is precisely this idea that forms the essence of Immanuel Kant's famous essay On a supposed right to lie from philanthropy (1797). Kant discusses in it the 'murderer-at-the-door' example: suppose (a) your friend X has taken refuge in your house, (b) a murderer who is pursuing her asks you whether $\mathrm{X}$ is in your house, and (c) you cannot evade an answer of 'yes' or 'no'. The question that Kant raises is the following: do you have the right to lie to the murderer in order to save your friend's life? A question that Kant also formulates in more general terms as follows: can philanthropy - that is, the love of human beings, which is a duty to which we are all bound - generate a right to lie? And Kant's answer is irrevocable: 'Truthfulness in statements that one cannot avoid is a human being's duty to everyone, however great the disadvantage to him or to another that may result from it' (SRL 612 [8: 426]).

\section{Kantian sincerity in politics}

As can be expected, Kant's position has been the subject of a great deal of criticism. ${ }^{3}$ Yet, some commentators have also tried to explicate it or to make sense of it, especially by bringing into relief its alleged 'political' nature. In support of their interpretation, they refer to Kant's claim that 'what is under discussion [in this essay] is a duty of right' (SRL 612 [8: 427]). That is, they stress that the 'murderer-at-the door' example is not concerned with truthfulness in the ethical sense of a duty to oneself. Kant's unconditional condemnation of untruthfulness in On a supposed right ... does not rest on the idea that a liar commits a crime against herself, or more specifically, on the idea that a liar makes herself into a 'mere deceptive appearance of a human being' - something which, according to Kant, is even less valuable than a thing - and thus annihilates her dignity as a human being (DV 552-3 [6: 429]). It is instead a matter of right, that is, a matter of several persons being able to affect each other by their actions and whose external freedoms must be made to coexist in accordance with a universal law (DR 387 [6: 230]).

At first sight, however, the claim that the duty of truthfulness is to be regarded as a duty of right seems to generate more confusion than clarification. One reason 
for this is that, in Kant's view, a chief respect in which duties of right differ from ethical duties is their enforceability or their being duties to the performance of which one can be coerced. As he puts it: 'All duties are either duties of right (officia iuris), that is, duties for which external lawgiving is possible, or duties of virtue (officia virtutis s. ethica), for which external lawgiving is not possible' (MM 394-5 [6: 239]); and an external (or juridical) lawgiving is a lawgiving that, unlike an ethical lawgiving, admits an incentive other than the idea of duty itself, namely, an external constraint (MM 383-4; 6: 219-20). Yet, the idea that a person might be forcibly compelled to tell the truth - or more precisely, that she might legitimately be punished by law for not having told the truth - may seem to some extent counterintuitive. After all, if we concede (as most of us would) that freedom of expression is an important condition of self-government, then it seems we should also accept to grant others the right to say not only things with which we disagree, but also things they themselves do not believe to be true ( $\operatorname{Raz} 2009: 266)$. As a great defender of freedom of expression, Kant concurs with this line of thought and recognises individuals' innate right

to do to others [...] such things as merely communicating [their] thoughts to them, telling or promising them something, whether what [they] say[] is true and sincere or untrue and insincere (veriloquium aut falsiloquium); for it is entirely up to them whether they want to believe [them] or not.

(DR 394 [6: 238])

To be sure, certain kinds of lies are as a matter of fact subject to external constraint. Suffice it to think of cases of defamation, in which a person damaged another's reputation by spreading false accusations, or of cases of fraudulent contracts, in which a person lied about the quality of the good she sold to another. Kant refers to these kinds of lies as lies 'in a jurist's sense' (SRL 612 [8: 426]) or 'in the sense bearing upon rights' (DR 394 [6: 239]). What they have in common is that they aim to deprive another of what rightfully belongs to her (DR 394 [6: 239]); and the reason they may be subject to legal sanctions is precisely that their wrongness consists in the wrongness of intending to violate another's rights (Mahon 2009: 218). Yet, this line of reasoning hardly applies to the 'murderer-at-the-door' example. As my lie to the murderer does not infringe on the rights of the friend that I intend to save nor on the rights of the murderer who compels me to answer his question, it cannot be treated as a lie in the jurist's sense of the word. If anyone can be said to violate another's rights, it seems it must be the murderer himself, not the liar.

Another way of approaching the juridical character of the 'lie-to-themurderer' example focuses on the idea that one cannot be legally punished for not having told lies to another. It is indeed worth noting that, however repugnant Kant's verdict may be, most of us would agree that a civil court cannot punish us for having refused to lie to another even if the information we so delivered enabled a murderer to find and kill an innocent victim. Kant accounts for this by arguing that truthfulness cannot be considered a 'free deed'. We cannot be held 
legally responsible and hence punished for the death of our friend because, truthfulness being an unconditional duty, we are 'not at all free to choose' whether or not to tell a lie (SRL 612 [8: 427]; 614 [8: 428]). ${ }^{4}$

But for most of those who emphasise the 'political' nature of On a supposed right to lie from philanthropy, the enforceability and imputability issues are not the primary issues. The key for understanding the substance of Kant's position lies instead in the way he addresses a claim made (presumably against him) by Benjamin Constant, according to which 'The moral principle "it is a duty to tell the truth" would, if taken unconditionally and singly, make any society impossible' (SRL 611 [8: 425]). ${ }^{5}$ In complete contrast to Constant, Kant argues that it is precisely the recognition of a right to lie that would make any society impossible. As we will see now, two main interpretations can and have been proposed to make sense of Kant's reply, each bringing to light one particular aspect of the importance of truthfulness in the political realm.

\section{A critique of exceptionalism in politics}

The first interpretation centres on the proper relationship between right and politics (Benton 1982; Wood 2008: 249), and more precisely, on Kant's claim that 'Right must never be accommodated to politics, but politics must always be accommodated to right' (SRL 614 [8: 429]). This claim echoes an argument he develops more extensively in Perpetual Peace: not only are principles of right always compatible with political society (contrary to what Constant affirms), but they also provide its only possible justification (PP 338-47 [8: 370-80]). The state finds its raison d'être in individuals' duty to enter a 'rightful condition' or civil society, that is, to determine and to secure their rights by submitting to coercive public laws. It is therefore the very concept of a duty of right that should guide politicians in their decision-making, not the end they aim to achieve - even if this end is also a duty such as the preservation of civil society. As Kant specifies, it would be self-defeating for politicians to pursue this end by treating it as 'problem of political prudence' or a 'technical problem' - too much empirical knowledge would be needed and the outcome of their decisions would always remain uncertain. It is only by acting in accordance with principles of right that politicians can expect to preserve civil society. This does not mean that principles of right must be applied in politics without attention to context: Kant agrees with Constant that intermediate principles' will sometimes need to be introduced to specify how general principles of right are to be instantiated in particular circumstances (SRL 613-4 [8: 427-9]). ${ }^{6}$ Nor does it mean that prudence has no role to play in politics: Kant recognises that too much haste can be self-defeating and that it may sometimes be preferable to postpone the implementation of a principle of right until favourable conditions are obtained (PP 321 [8: 347]; PP 340-1 [8: $372-3]$ ). But in neither case is there any justification for replacing principles of right by principles of political prudence or for legitimating exceptions to principles of right in the name of preserving society. 
Yet, this is precisely what Constant does when considering the duty of truthfulness: he argues that the duty to tell the truth presupposes that our interlocutors have a right to the truth and then identifies circumstances in which this duty simply ceases to apply (such as in 'murderer-at-the door' cases). In this regard, he does not differ from Kant's 'moralising politicians', who justify their transgressions of principles of right by invoking the incapacity of human nature to do what is morally required (PP 341 [8: 373]). Like them, he fails to see that by subordinating right to politics, one not only makes the achievement of one's political ends uncertain, but one also contributes to perpetuating transgressions of right. It is precisely the fact that politicians allow themselves exceptions to moral rules for supposedly worthy ends which 'does make possible much of what is utterly intolerable in our actual political life' (Wood 2008: 251).

Kant also suspects that behind politicians' attempts to undermine the unconditionality of principles of right lies a 'concern [...] to go along with the power now ruling (so as not to neglect their private advantage)' (PP 341 [8: 373]). It is in this spirit that Robert Benton brings into relief the historical background against which the discussion between Constant and Kant takes place, namely, the climate of opposition that arose during the French Revolution between the Directory and the Jacobins (Benton 1982: 139). According to him, Kant read Constant's pamphlet as an opportunistic reaction against the more democratic principles supported by the Jacobins (such as universal suffrage and equality of wealth), and more particularly, as an attempt to undermine basic principles of right to win the favours of the Directory.

Undoubtedly, this first line of interpretation underscores a recurrent concern in Kant's political writings, but it leaves two important issues unaddressed. The first is that even if we assume that politics must always be accommodated to right, it remains to be clarified why the duty to be truthful to others must be considered a duty of right in the first place. As already indicated, this view seems difficult to square with Kant's recognition of a right to tell or promise others things that are untrue or insincere as long as doing so does not infringe on the rights of any particular person. The second issue that needs to be elucidated concerns the 'political' dimension of a lie to a would-be murderer: even if we assume that politicians who permit themselves lying declarations for supposedly worthy ends often act from self-interested motives, it remains that the case of an ordinary individual lying to save an innocent's life can hardly be described as a case of political opportunism. How could such an isolated and altruistic instance of lying be said to corrupt political life? It is with these questions in mind that we turn to the second interpretation.

\section{Untruthfulness as a wrong to 'humanity in general'}

This interpretation places the emphasis on Kant's claim that a liar, even if she does no wrong to anyone in particular, nevertheless does wrong 'in general' or to 'humanity generally' (SRL 612 [8: 426]). The liar is said to transgress the postulate of public right, which requires all individuals who can mutually affect 


\section{S. Loriaux}

each other to enter and to remain in a rightful condition. In so doing, she does wrong 'formally' or 'in the highest degree' because she violates the 'right of human beings as such' - even if she does no wrong 'materially' or does not violate the rights of any particular person (DR 452; 6: 308).

A significant part of this interpretation deals with the duty of truthfulness owed by and/or to public officials. Politicians and statesmen who are untruthful in their public capacity are said to do wrong to 'humanity generally' because they can no longer be seen as representing any public authority. While the point of establishing public institutions is to subject interacting external freedoms to the governance of public coercive laws, public officials who are untruthful to their people can act only in their own name, not in the name of the public at large, and are therefore privatising public institutions (Wood 2008: 248; Varden 2010: 414-5). They contribute to the destruction of the rightful condition because they act in a way that is inconsistent with the possibility of representing any people whatsoever (Loriaux 2014: 208-9).

Similarly, insofar as those who are untruthful to public officials are untruthful not to private persons, but to representatives of the public authority, they must be seen as doing wrong to everyone and no one in particular or as committing a 'formal' rather than a 'material' wrong (Varden 2010: 414). A different way of making the same point is to regard right as a 'practice' which requires that declarations be made at various points and which presupposes truthfulness in declarations as one of its basic rules (Wood 2008: 243, 247-9). Those who lie to a judge or to a policeman violate the 'right of human beings as such' because they act on a principle whose universalisation would discredit the entire legal system. This remains the case even when they can reasonably foresee that their lies would prevent the condemnation of a person they know to be innocent. What we find here then is the idea that certain kinds of lies may be punished by law even if they did not entail the violation of a particular person's rights and even if they prevented an innocent from being unduly harmed.

Two points should be borne in mind, however. The first is that Kant regards the duty of truthfulness as an unconditional duty and hence as a duty that is owed not only by or to public officials, but between all human beings whatever their function within political society. This again raises the question of how to account for the 'political' dimension or 'formal' wrongness of lies told by and to 'ordinary' individuals. A possible answer is that the recognition of a right to lie in 'murderer-at-the-door' cases would most likely end up contaminating political life and authorising lies by and to public officials whenever it is believed this could avoid some serious harm or injustice (Loriaux 2014: 207; Wood 2008: 248-9). The underlying idea is not so much that any instance of untruthfulness can be expected to have an adverse effect on public trust and thereby on the smooth running of political society, but more fundamentally, that behind any 'exceptional' instance of untruthfulness lies a maxim that is inconsistent with the very possibility of a rightful condition.

These considerations bring us to another important point: the duty of truthfulness is owed between all human beings not only irrespective of their function 
within political society but also irrespective of their sharing a political society. There are indeed two ways in which the postulate of public right can be transgressed and a formal wrong committed as a result: either by undermining an existing rightful condition or by preventing a rightful condition from arising, that is, by perpetuating the state of nature (Weinrib 2008: 150). As we will see now, this has important implications for truthfulness in the international sphere.

\section{Kantian sincerity in international relations}

Domestic and international politics seem to be characterised by two different attitudes toward lying. While domestic lying is generally considered morally wrong - not only by Kantians, but also by consequentialists who point to the corrupting effects of untruthfulness on social and political life in general - international lying or lying that occurs between representatives of different states tends to be largely accepted. ${ }^{7}$ This difference is usually accounted for by referring to the anarchic character of the international sphere: the absence of a superior political authority to which states could turn to secure their rights is assumed to have implications as regards the content or even the very existence of moral duties between states. Given that states have the primary duty to protect the national interest and that other states cannot be trusted not to encroach on that interest, they must be authorised to do whatever is necessary to preserve themselves, even if this implies transgressing traditional moral rules.

To some extent, Kant concurs with this line of reasoning. As he puts it: 'No one is bound to refrain from encroaching on what another possesses if the other gives him no equal assurance that he will observe the same restraint toward him' (DR 452; 6: 307); yet 'a human being (or a nation) in a mere state of nature denies me this assurance and already wrongs me just by being near me in this condition' (PP 322; 8: 349). It is to this kind of considerations that he appeals when granting states a (provisional) right to wage war against states whose power has become threatening even if they have not committed any act of aggression (MM 484; 6: 346). Like individuals, states must be assumed to have a natural tendency to try to dominate each other as soon as they have the power to do so; they cannot be required to wait until facts have provided confirmation of this tendency before being authorised to defend themselves (DR 452 [6: 307]; PP 322 [8: 349]). On this point, the parallel with Thomas Hobbes' claim that no one can be obliged to make himself into a prey for others seems striking (Hobbes 1991: 92 [65]; 96 [68]; 110 [79]).

Unlike Hobbes, however, Kant emphasises the persistence of a certain type of moral rules even in the midst of war. He insists that, even though it is difficult to conceive of laws in a lawless condition, there is a duty not to resort to acts of self-defence whose maxim cannot be universalised without undermining trust between states and thereby destroying any prospect of international peace. While states are (provisionally) authorised to use force against those who threaten them, they may never make use of dishonest or 'dishonourable stratagems' such as using their subjects as spies (in which, Kant notes, 'use is made only of 


\section{S. Loriaux}

others' dishonesty') or for spreading false reports, breaking their agreements (for instance, a surrender agreement) or inciting to treason within the enemy state (Kant 1996: 320 [8: 346]; 485 [6: 347]; 487 [6: 349]).

So here again, we find the idea that untruthfulness is a violation of the postulate of public right: state leaders who are untruthful in their mutual dealings do wrong 'in the highest degree' or 'formally' (although they may do each other no 'material' wrong) because they act on a principle that contradicts the very possibility of an interstate rightful condition. It thus appears that the principle of truthfulness is not only a principle that admits no exception, but is also a principle whose application may never be postponed until more favourable circumstances are obtained. The principle of truthfulness is 'of the strict kind'; it is a principle that must be applied immediately, whatever the circumstances in which one finds oneself, even at the risk of one's life (Kant 1996: 320-1 [8: 346-8]; 485 [6:347-8]; 487 [6:349-50]). While the malevolence of human nature and the lack of assurance that is peculiar to the state of nature may authorise states to use force against each other, they may never authorise them to deceive each other. The reason is that some trust must remain if states are ever to leave the state of nature and be secured in their rights.

\section{Engaging Kantian sincerity: publicity, rhetoric and institutions}

This volume comprises 12 chapters and is divided into three parts. Part I centres on the relationship between sincerity and publicity. It starts by showing the importance of an utterance's publicly accepted meaning when determining whether to qualify this utterance as a lie (Newey). It then addresses the role of sincerity in theories of public reason (Zoffoli) and in successful moral criticism (Evans), as well as the appropriateness of appealing to Kant's principle of publicity when conceptualising the phenomenon of political corruption (Navot). Part II explores the rhetoric of sincerity from four different angles: as opposed to cynicism (Berg-Sórensen), as distinguished from candour (Anderson), as faithfulness to what makes sense in our lives (Abin), and as a meaningful choice (Cheli). Part III focuses on the role played by sincerity in building, shaping, and maintaining institutions. As a first step, it regards lying as form of inauthenticity which can also be found in social institutions (Baiasu). It then investigates the extent to which sincerity can be considered necessary for political trust, and thereby, for rebuilding society after a breakdown of trust (La Caze) and for governing capacities (Zsolt). It ends with a reflection on the place of sincerity in European institution building (Guisan).

\section{Part I Publicity}

Philosophical writing usually sets a high bar for lying. This high-bar approach also tends to focus on mendacity to the exclusion of other forms of deception, the consensus being that lying is especially bad or wrong. In Chapter 1, Glen Newey 
questions this approach via a critique of Chisholm and Feehan (1977). He notes that the high bar that they set for lying relies on a stringent account of assertion: many deceptive communications are not assertions, and so not lies. Newey criticises this account of assertion via a critique of its associated account of speakerintention. In his view, it is only because a given utterance has an accepted communicative meaning that the deceiver can achieve his aim. Analysis of deception should therefore focus on the target-belief of the speaker, not the means of inducing it: deception essentially involves the induction of a false target-belief. He proposes the following pragmatic test for deception: a speaker prima facie deceives if a reasonable person would take the speaker to aim at a target-belief $p$, and there is good reason to think that the speaker believes $\mathrm{p}$ to be false.

Chapter 2 shifts the attention to the role played by considerations of sincerity in contemporary liberal theories of public reason. As Enrico Zoffoli explains, an important debate in this field concerns the question of whether public justification should draw exclusively on shared or public reasons - this is the dominant 'consensus' model of public reason - or whether citizens should be allowed to converge on a given law for different private reasons - the so-called 'convergence' model of public reason, which is supported inter alia by Gerald Gaus. Zoffoli's main purpose in this chapter is to refute Jonathan Quong's claim that convergence models are inconsistent with public reason's principle of sincerity and that they should therefore be resisted. While acknowledging that convergence indeed seems problematic from the standpoint of sincerity, Zoffoli argues, first, that Quong's principle of sincerity does not necessarily justify consensus, and second (and more strongly), that we should avoid ranking and selecting competing conceptions of public reason on the basis of principles of sincerity.

Following G.A. Cohen's article 'Casting the First Stone: Who Can, and Who Can't, Condemn The Terrorists?', Mark Evans investigates in Chapter 3 the idea that one's condemnatory moral voice can be 'silenced' in certain kinds of situations, especially when one is similarly guilty of that which one condemns and when one has some degree of responsibility for that which one condemns. Evans rejects the claim that these phenomena are merely instances of 'hypocrisy' as an inadequate account of 'silencing' and proposes instead a 'commissive' account of moral discourse: 'silencing' occurs when putative moral critics lack a sufficiently sincere commitment to respecting morality themselves, thereby failing to acquire the personal moral authority necessary for the criticism to be successful. The chapter describes successful moral discourse in terms of an ongoing quest for moral knowledge and self-knowledge on the part of sincere moral discursants.

As Doron Navot points out in Chapter 4, prominent scholars such as Dennis F. Thompson and Mark E. Warren conceptualise the phenomenon of political corruption in modern democracies as a violation of Kant's principle of publicity. This principle essentially holds that an action is wrong when its maxim cannot be made public without contradiction; its application to political life can therefore be expected to prevent politicians from making laws that treat human beings as mere means since citizens would refuse being instrumentalised and would accordingly oppose the enactment of this kind of laws. However, Navot identifies three 
difficulties with this strategy. First, the consequences of a law may be misunderstood, whether because of the law's complexity or because the law may de facto result in people being instrumentalised although this was not its intended effect. Second, people may be manipulated into corruption, lose sensitivity to their being instrumentalised or even choose being instrumentalised (they may, for instance, vote for politicians known or strongly suspected to be corrupt). In other words, corruption may go hand in hand with publicity. Third, and more broadly, Navot questions the value of Kantian constructivism when it comes to elucidating fundamental political concepts such as justice or corruption.

\section{Part II Rhetoric}

Chapter 5 draws on Barack Obama's political rhetoric, as expressed in his first inaugural address and in his 'Ethics Commitments' of January 2009. Anders Berg-Sørensen questions the opposition on which this rhetoric is based between Obama's public commitment to basic ethical values (such as transparency, accountability or impartiality) and the Bush administration's alleged 'cynicism'. More specifically, he raises the question of whether cynicism is a moral and political departure that one has to, and can, repudiate (as Obama suggests) or whether it is an inevitable feature of political-administrative life. He opts for the latter and argues, using the terminology of Judith Shklar, that cynicism can be considered 'an ordinary vice'. The crucial question, according to him, then becomes what kind of cynicism we can live with and what kind we cannot accept. To address it, he provides a historical-conceptual analysis of cynicism and emphasises the crucial role played by personal ethics: vices not only flaw our character, but also provide incentives for ethical cultivation. He ends his chapter with some reflections on whether ethical cultivation represents a purely disruptive power or also includes a transformative political power.

In Chapter 6, Pamela Anderson explores the rhetoric of 'sincerity' as 'truthfulness' in the context of a letter exchange between Kant and Maria von Herbert, a young woman who had read Kant's moral philosophy. According to Anderson, Kant's reply to Maria makes it clear that, in his view, we should not demand of any human agent complete candour or complete open-heartedness on matters of truth. Instead his advice is to maintain a sincere commitment to truthfulness which allows a certain leeway - or reticence - when it comes to telling the truth. Of course, Kant continues to maintain that we should not lie; however, his reply challenges the simplicity of his moral view. Anderson argues that his reply is consistent with a critical distinction for human subjects, found in Kant's Religion within the Boundaries of Mere Reason, between the rhetoric of 'being truthful' as being 'sincere' with the right degree of 'reticence' and 'telling the whole truth' or candour. This Kantian distinction allows us to communicate only what is true without disclosing everything we know.

The question Esther Abin addresses in Chapter 7 is whether it is possible to retain the idea of truthfulness in politics while distancing oneself or even abandoning that of truth. Or more specifically: is it possible to be truthful in 
politics while adapting to situations whereby standards of truth are either hidden or simply unknown? Instead of taking truth as a normative standard of morality in politics, she examines the extent to which one can be truthful by being faithful to what makes sense to a political community at a certain time in a certain place. Central to her reflection is Bernard Williams' view that the ideas of truth and of truthfulness matter in what they are "significant in our lives" (Williams 2002). Abin also wishes to depart from the dichotomy that opposes the 'dirty hands' of politics to an ideal of political sincerity and transparency. Her interest lies instead in identifying the kind of rational and moral thinking that may render the virtue of truthfulness consistent with the temporal and contingent aspects of politics.

Simone Cheli also seeks to overcome the standard dichotomy between ethical and non-ethical values. His reflection in Chapter 8 builds on the premise that politics usually confronts us with both an ethical and an epistemological antithesis: on the one hand, we find an idealistic approach according to which there is only one truth and one unquestionable definition of right and wrong; on the other hand, we find a more Machiavellian approach which denies that any univocal truth could ever be reached and which refuses to take ethical considerations into account. Cheli's purpose is to bring into relief the communicative and ethical biases that plague these approaches and to pave the way for a possible third way by exploring the role of epistemological doubt in dealing with political disagreement. From his constructivist point of view, we create the so-called 'reality' by narrating our vision of the world and connecting this narrative with others. Reflecting about ethics means reflecting on the reasons why, say, being sincere or deceitful to others can be seen as meaningful choices for the person in question. It means calling into question our own and other persons' ethical assumptions and acknowledging that doubt may open the way toward otherness.

\section{Part III Institutions}

Sorin Baiasu introduces an account of political dissimulation, which he claims is Kantian in character. The paradoxical nature of the enterprise is motivated by two limitations on the obligation to be truthful, which Kant asserts as justified. The first limitation is a permission not to be truthful, when an agent does not have to communicate; the second limitation is an obligation to dissimulate, when an agent plays a role in a public institution. Both these limitations and especially the second one go against the standard view of Kant as defending a strict requirement to be truthful and sincere in all situations. Chapter 9 further examines the extent to which such limitations can be justified in a Kantian context. The claim is that the first limitation is justified as an implication of the negative nature of the justification provided by the Categorical Imperative; the second limitation is defended as an epistemic condition necessary for the rightful condition. If correct, the chapter claims to successfully square the circle of providing an account of political dissimulation which is genuinely Kantian in nature. 


\section{S. Loriaux}

Marguerite La Caze's main interest in Chapter 10 is in political trust as a necessary condition for rebuilding society after a civil war. She starts by considering the role played by considerations of trust in Kant's moral and political philosophy, with a special focus on how trust relates to the duty not to lie and to the duty to establish and maintain a rightful condition. She then turns to Jean Améry's idea of 'trust in the world' to argue that political trust presupposes not only Kantian justice and respect (and hence non-deception), but also help and care between persons. Drawing on these preconditions of trust, she then addresses the concrete question of how trust is to be restored in a situation such as post-genocide Rwanda. She suggests that sincerity may not be the most important consideration in this regard: it may sometimes be more helpful to act 'as if' we believed others and the world to be worthy of our trust, than mean what we say and believe in the way we act.

Chapter 11 points to a closer relationship between sincerity and trust, however. According to Zsolt Boda, sincerity in political communication is a procedural fairness norm and as such is a condition both for trust building and for governing capacities. While politicians often seem to believe that disclosing too much information or unveiling their true intentions might make them weaker, sometimes the opposite may be the case. Valid and fair communication can create trust, and thereby, foster allegiance to political decisions, increase citizens' willingness to cooperate with authorities and facilitate policy implementation. Zsolt argues that a lack of sincerity in political communication undermines the perception of fairness, which in turn has a negative impact on the leadership potential of politicians and on the governing capacities of the government. A case of Hungarian politics is analysed in this respect.

In the last chapter, Catherin Guisan brings to light the kind of discourse ethics and practices that moved the EU constitutional process forward. In doing so, she has two main purposes. The first is to challenge the widespread thesis that European founders were neo-functionalists primarily motivated by technocratic concerns, by bringing into relief their concern for both intelligibility and truth-telling. Her second purpose is show how EU politics exemplifies the relevance of Habermas' theory of communication action (especially his discussion of truth-telling, truthfulness, right-speaking and intelligibility), but also the difficulties of its implementation. With regard to the latter, she suggests that Habermas has paid insufficient attention not only to the importance of individual and small group agency for initiating right-speaking or for returning to truth-telling and truthfulness, but also to the fact that truth-telling and right-speaking have a 'taxing aspect'.

\section{Notes}

1 On the distinction between truthfulness and candour, see for instance: Carson (2010: 257-65) and Mahon (2003: 114-17).

2 It must be noted that the proper definition and relationship between 'deception' and 'lying' has been a subject of dispute. Thomas Carson argues, for instance, that to be considered a lie, a statement must be false in addition to being untruthful or believed to 
be false by the speaker (Carson 2010: 15-18). He also rejects the view that lying requires that the liar intends to deceive others (Carson 2010: 20-3). For yet other conceptions of lying and deception, see among others: Fried (1978); Williams (2002); Chisholm and Feehan (1977).

3 See for instance: Hofmeister (1972); Korsgaard (1996); Paton (1992).

4 Actually, Kant goes much further than that as he also adds that liars are legally accountable for all the consequences of their lie, however unpredictable they may be. Applied to the 'murder-at-the-door' example, this means that if we lie to the murderer and, unbeknown to us, our friend leaves our house and is killed by the murderer who, as a result of our lie, also left our house, then we may be prosecuted and punished for our friend's death.

5 This claim first appeared in Constant's pamphlet Des réactions politiques (1796). In it, Constant referred to 'a German philosopher, who goes so far as to maintain that it would be a crime to lie to a murderer who asked us whether a friend of ours whom he is pursuing has taken refuge in our house' (quoted in: SRL 611; 8: 425). Kant read the German translation of this pamphlet, which appeared the following year in the journal Frankreich im Jahr 1797, Part VI, No. I, and was told by the journal editor that he was the 'German philosopher' whom Constant had in mind.

6 One example is provided by the principle that we must be subject only to laws that we have given to ourselves: this general principle of right can be directly applied only in small societies; in large societies, its application requires the adoption of an intermediate principle according to which citizens can contribute to law-making through a representative system (ibid.).

7 The fact that international lying is generally accepted behaviour does not mean, however, that it is more common behaviour than domestic lying. According to a study by John Mearsheimer, there have been very few interstate lies and a major reason for this state of affairs is, paradoxically, the low level of trust that characterises international relations. Political leaders seldom lie to each other because their statements are unlikely to be believed by other countries unless they can be verified, which means that the prospect of getting away with international lying is relatively small (Mearsheimer 2011).

\section{Bibliography}

Benton, R. J. 1982. 'Political expediency and lying: Kant vs Benjamin Constant'. Journal of the History of Ideas 43: 1, 135-44.

Bok, S. 1999. Lying, Moral Choice in Public and Private Life. New York: Vintage Books.

Carson, T. L. 2010. Lying and Deception. Theory and Practice. Oxford: Oxford University Press.

Chisholm, R. and Feehan, T. 1977. 'The intent to deceive'. Journal of Philosophy 74, 143-59.

Fried, C. 1978. Right and Wrong. Cambridge, MA: Harvard University Press.

Hobbes, T. 1991. Leviathan. R. Tuck (ed). CUP.

Hofmeister, H. E. M. 1972. 'Truth and truthfulness: a reply to Dr. Schawrz'. Ethics 82, 262-7.

Kant, I. 1996. Practical Philosophy. M. J. Gregor (Tr. and ed.). CUP.

Korsgaard, C. M. 1996. 'The right to lie: Kant on dealing with evil'. In Creating the Kingdom of Ends. Cambridge: Cambridge University Press, pp. 133-58.

Loriaux, S. 2014. 'Deception, Right, and International Relations: a Kantian Reading'. European Journal of Political Theory 13: 2, 199-217. 


\section{S. Loriaux}

Mahon, J. E. 2003. 'Kant on lies, candour and reticence'. Kantian Review 7, 102-33.

Mahon, J. E. 2009. 'The truth about Kant on lies'. In C. Martin (ed.) The Philosophy of Deception. Oxford: Oxford University Press, pp. 201-24.

Mearsheimer, J. J. 2011. Why Leaders Lie. Oxford: Oxford University Press.

Paton, H. J. 1992. 'An alleged right to lie: a problem in Kantian ethics'. In Immanuel Kant: Critical Assessments. London: Routledge, pp. 210-25.

Raz, J. 2009. The Authority of Law, 2nd edn. Oxford: Oxford University Press.

Varden, H. 2010. 'Kant and lying to the murderer at the door.... One more time: Kant's legal philosophy and lies to murderers and Nazis'. Journal of Social Philosophy 41: 4, 403-21.

Weinrib, J. 2008. 'The Juridical Significance of Kant's "Supposed Right to Lie", Kantian Review 13: 1, 141-70.

Williams, B. 2002. Truth and Truthfulness: An Essay in Genealogy. Princeton, NJ: Princeton University Press.

Wood, A. W. 2008. 'Lies'. In Kantian Ethics. New York: Cambridge University Press, pp. $240-58$. 
Part I

Publicity 



\title{
1 Political deception \\ Lowering the bar
}

\author{
Glen Newey
}

\section{The problem}

My concern is with verbal deception. I focus on the role played by philosophical assumptions underlying politicians' strategies for evading this charge. The assumptions concern the moral ranking of lying as worse than non-mendacious deception, and the nature of assertion. The moral ranking arises from casuistical writing on deception. ${ }^{1}$ I shall argue that undue normative weight is given to the speech-act of assertion, compared with other ways that speakers communicate.

The casuistical tradition focuses on the speaker and his mental states, rather than the hearer. The flaws in it stem from a failure to acknowledge the essentially communicative nature of deception, including the hearer's 'uptake'. Politicians insist that they have been 'misunderstood' - that the uptake belied their intentions. They lay claim to epistemic authority over their own internal states primarily over what they intended to say - which trumps the hearer's uptake.

I treat deceptive speech as communicative. I offer a reasonableness test to decide what the speaker communicates, by asking what it would be reasonable to think that he was inviting the hearer to believe: a reasonable person's interpretation is usually a reliable guide to the speaker's intentions. What a speaker says he intended is distinguishable from what he actually intended, which is built up from publicly available evidence. We can frame hypotheses of greater or lesser plausibility on the basis of this, even though these fall short of infallibility.

The test faces various problems. But by the end it should be clearer what is involved in charges of political deception. In trying to see how charges of deception can be made to stick, we may learn when this cannot be done, and what might be lost if it could.

\section{Dodging charges of deception}

It is necessary for lying that a speaker utter $\mathrm{p}$ with the primary intention that some who hear it will thereby form a belief, which the speaker regards as not true - be it the truth-value of $\mathrm{p}$ itself or an attitude of the speaker related to it.

This leaves numerous matters unresolved in the analysis of lying, including these five dimensions: 
(a) The dupe - is this confined to the interlocutor, or may it include a broader audience?

(b) The utterance - must it be, in principle, truth-apt, or may it include other discourse, such as questions?

(c) The target belief - must this be at least a belief in the truth-apt content of what is uttered, assuming that some such content exists?

(d) The speech-act - must this be confined to assertion? Can the speaker's deceptive intention include entailments and conversational implicatures of what is said?

(e) Truth-valuation - must the speaker believe the truth-assessable content to be false, or merely not believe it to be true?

The account of lying can be narrowed by answering 'Yes' to all these questions, as do Chisholm and Feehan. As their examples show, Chisholm and Feehan think that an utterance is not assertoric, and so not mendacious, if the answer to any of the above questions is 'No'. Where a speaker is suspected of deception, people may disagree about the circumstances of utterance; how the utterance is to be understood; and what, in general, is to be classified as a lie: each dimension above allows for tightening definitions so that the utterance comes out as nonmendacious.

When they aim to dodge charges of lying, politicians can call on two kinds of philosophical rigourism: first, distinguishing the propositional content which is asserted from the understanding or 'uptake' of it by hearers; ${ }^{2}$ second, distinguishing between lying and 'mere' misleading talk. ${ }^{3}$

These two positions are related as follows: the casuistical tradition makes lying a specially bad form of deception, so the test for lying is made stringent by requiring false assertion, not merely false 'implicatures'. The special badness of lying follows from the claim that assertion incurs specially stringent obligations.

\section{The standard account}

\section{Exposition}

Chisholm and Feehan's theory (hereafter 'CF') sets a high bar for a given speech-act to count as lying, and proposes a significant moral distinction between the wrongness of lying and other forms of deception. Its formal definitions of statement, assertion and lying are cantilevered. Lying is a form of assertion, and assertion is a form of statement. Their definition of 'statement' runs:

D1 L states $p$ to $D=$ df . (1) L believes that there is an expression $E$ and a language $\mathrm{S}$ such that one of the standard uses of $\mathrm{E}$ in $\mathrm{S}$ is that of expressing the proposition p; (2) L utters E with the intention of causing D to believe that he, L, intended to utter $\mathrm{E}$ in that standard use.

This definition of 'statement' then yields a definition of 'assertion': 
D2 L asserts $\mathrm{p}$ to $\mathrm{D}={ }^{\mathrm{df}}$. $\mathrm{L}$ states $\mathrm{p}$ to $\mathrm{D}$ and does so under conditions which, $\mathrm{L}$ believes, justify $\mathrm{D}$ in believing that he, L, not only accepts $\mathrm{p}$, but also intends to contribute causally to D's believing that he, L, accepts $\mathrm{p}$.

Finally, this definition of 'assertion' yields a definition of 'lies':

D3 $L$ lies to $D=d f$. There is a proposition $p$ such that (i) either $L$ believes that $p$ is not true or $\mathrm{L}$ believes that $\mathrm{p}$ is false and (ii) $\mathrm{L}$ asserts $\mathrm{p}$ to $\mathrm{D}$.

L will believe, according to D2, that the appropriate 'conditions' will 'justify' the hearer in holding the beliefs mentioned. When the conditions for justification are obtained, L believes that the hearer has the 'right to expect' that the speaker believes the proposition. When L's utterance satisfies D1 to D3 - the utterance qualifies as an assertion, and $\mathrm{L}$ either believes that the proposition asserted by means of the utterance is false, or at least that it is not true, he lies.

\section{Assertion and standard use}

CF is the most analytically sophisticated version of the standard model of lying. It draws a sharp line between the propositional content of what is asserted, and the hearer's understanding of that utterance; and upholds the distinction between lying and 'mere' deception.

CF's rigourism surfaces in their problem case \#6. This asks whether a speaker lies in asserting that the weather will be fine tomorrow, if he neither believes nor disbelieves this, CF judges that he does not lie, as the proposition is 'not such that he believes it to be false (or not to be true)' as is required by D3 - he simply has no relevant beliefs. When they ask whether L lies with respect to the proposition that $\mathrm{L}$ believes that the weather will be fine tomorrow, they again conclude that he does not, as 'according to our definitions, he hasn't asserted that'. As the belief claim is absent from the assertum, it is not asserted, according to D2, and so L cannot have lied about it.

So CF restricts assertoric content to what is explicitly said. They admit that L's 'assertion that the weather will be good would normally suggest, or "contextually imply" that he, [the speaker] believes that the weather will be fine tomorrow', but insist that on their definition of assertion, this has not been asserted. Saying that $\mathrm{p}$ is obviously not the same as saying 'I believe that p'. Nor does ' $p$ ' entail 'I believe that $p$ '. Does ' $x$ said p' entail ' $x$ said that he believed that $p$ '? Irony, joking or quoting bar this entailment. Still, a non-contingent connection holds between L's uttering $\mathrm{p}$, and his telling the hearer that he believes $\mathrm{p}$, where the context is one in which utterances in assertoric form are to be taken seriously, and 'telling the hearer' amounts to 'giving the hearer to understand'. Usually the non-ironic, non-joking, etc., utterance of 'p' amounts to an avowal.

What is communicated goes beyond utterances' propositional content. In the above example, the fact that ' $L$ said p' fails to entail ' $L$ said he believed that $p$ ' is, as far as this goes, beside the point. There is a pragmatic contradiction in 
saying p, and saying also 'I don't believe p'. Compare someone who says, 'The weather will be fine. I don't believe that the weather will be fine', and responds, when challenged: 'Why are you puzzled: $\mathrm{p}$ and 'I don't believe p' are clearly distinct propositions?'.

The problems arise from overlooking the communicativeness of deception. Analysis cannot limit itself to the speaker's viewpoint: successful communication requires a common medium of exchange. The beliefs a hearer would reasonably form go beyond the entailments of the assertum. They are key to deciding whether the speaker has lied to or otherwise deceived him. In the weather example, the speech cannot be grasped without knowing that when L says, 'The weather will be fine' in D2-type conditions, hearers will take this to convey L's belief that the weather will be fine. The pragmatic contradiction point made earlier helps explain this. If an utterance is taken in a certain way, then it is usually reasonable to assume that the utterance was intended to be so taken.

If declarations are generally taken to convey L's belief that $p$, it is reasonable to assume that $p$ was uttered with the intention of conveying L's belief that $p$. This also shows why D3 is inadequate. If $\mathrm{L}$ utters $\mathrm{p}$, conveying the belief that the weather will be fine, he communicates something false to the hearer, regardless of whether $\mathrm{L}$ actively disbelieves or has no beliefs about $\mathrm{p}$. For he gives the hearer to understand that he believes $\mathrm{p}$.

Further problems face CF's account of statement. As D1 says, L states p to the hearer only if $\mathrm{L}$ believes that a standard use of the expression he utters, in the relevant language, is to express $\mathrm{p}$. It follows that $\mathrm{L}$ states $\mathrm{p}$ if he believes that he has uttered an expression a standard use of which is to express $p$, and intends the hearer to believe that he uttered the expression with that standard use. L has stated $p$ even if he has a false belief about the expression's standard use.

The condition contains a scope ambiguity. Does somebody who fails to express the proposition he intended succeed in stating $\mathrm{p}$ ? It seems that a speaker may intend to state p, but fail. When John F. Kennedy said, 'Ich bin ein Berliner' in Berlin in 1963, it was suggested that the standard use in German of these words was to express the proposition 'I am a doughnut'. ${ }^{4}$ If the standard use of 'Ich bin ein Berliner' in German is to express that proposition, Kennedy stated that he was a doughnut. It is unlikely that that is what Kennedy intended to state. Presumably he intended to state 'I am a Berliner', thereby expressing solidarity with West Berliners after the erection of the Wall. But he would have succeeded in stating that, in German, only if a standard use of the words he uttered in German was to express the proposition 'I am a Berliner', and this Kennedy failed to do.

To state $\mathrm{p}$, then, the speaker, in intending to state $\mathrm{p}$, must utter an expression one of whose standard uses in the relevant language actually is to express p. L's success will not depend on his beliefs alone but on the standard use of the expression, and therefore cannot be said to state p: L, as in the Kennedy example, may believe falsely that he is stating p. Hence CF's definition in D1 gives conditions for saying ' $\mathrm{L}$ believes he states $\mathrm{p}$ to $\mathrm{D}$ ', rather than, as they claim, ' $L$ states $p$ to $D$ '. What the speaker in fact states depends on what the standard use of ' $p$ ' is. 
Contrary to D1, then, uttering an expression such that one of its standard uses is, one believes, to express $\mathrm{p}$, is not sufficient for stating $\mathrm{p}$. What is needed in addition is that this belief is correct - that one of the standard uses of the expression really is to express $\mathrm{p}$. What it is for one of the standard uses of an expression to express $\mathrm{p}$ therefore cannot depend on what the speaker stipulates, as Humpty Dumpty argues to Alice..$^{5}$ It is possible trivially to define 'language' so that there is a language containing an expression a standard use of which is to express $\mathrm{p}$, and then $\mathrm{L}$ can count as stating $\mathrm{p}$ in this language. But this will not normally be a natural language of the speaker's target audience. What L can state to a hearer via an expression depends on its standard use, which is how a reasonable and competent speaker of the language would take it.

CF seem to be led astray by focussing on the speaker's attitudes to p. Deception would be impossible without shared meanings that deceivers exploit. In their problem case \#5, a standard use of 'My leg isn't bothering me too much today' is to express the proposition 'My leg is hurting to some significant extent today' - were it not, L would not be able to use it to deceive the hearer by getting him to believe this latter proposition. They argue that L is not lying, because his

utterance does not fulfil the conditions of our definition of 'assert': the false proposition that his utterance suggests ('implicates' or 'contextually implies') is not a proposition that is signified or intended by a standard use in English of the expressions that he utters. ${ }^{6}$

This suggests that CF cannot hold the line between standard use and implicature: implicatures figure among the standard uses of expressions that deceivers exploit. D1 holds that what matters is that L believes he is using the expression in a standard sense, not whether it really does: thus a number of examples (including the leg example) which they treat as non-mendacious deception will come out on their definitions as full-blown lies. The notion of a 'standard use' proves to be a Trojan Horse for the theory. They rely on their view of what the standard use of expressions really is, whereas L relies on the utterance's having a standard use to promote deception. It is significant that the pressure to do so makes itself felt in the problem cases, where they have to consider not merely what is asserted, but what is communicated in acts of deception. ${ }^{7}$

\section{Normativity}

For $\mathrm{CF}$, the normativity of assertion consists in the fact that when a speaker $\mathrm{L}$ asserts $\mathrm{p}$, he believes that he justifies the hearer in believing that he, L, accepts $\mathrm{p}$. This then explains how the hearer is wronged by being lied to. They argue that assertion, unlike other methods of inducing false belief, creates a legitimate expectation in the hearer that she will be told the truth about L's beliefs.

Why is it thought wrong to lie? And why is lying thought to be worse, other things being equal, than other types of intended deception? The answer would 
seem to be this. It is assumed that, if a person $\mathrm{L}$ asserts a proposition $\mathrm{p}$ to another person $\mathrm{D}$, then $\mathrm{D}$ has the right to expect that $\mathrm{L}$ himself believes $\mathrm{p}$. And it is assumed that L knows, or at least that he ought to know, that, if he asserts $p$ to $\mathrm{D}$, while believing himself that $\mathrm{p}$ is not true, then he violates this right of D's. But analogous assumptions are not made with respect to all other types of intended deception. ${ }^{8}$

Lying works by the assertion of something that the speaker does not believe true. In other cases of deception, the hearer has no legitimate expectation that the speaker believes what he communicates to the hearer. CF's account of lying supports the intuition that other forms of deception, such as misleading, are less bad than lying; only lying, as an abuse of assertion, is a breach of faith.

In CF the linkage between assertion and the special wrongness of lying is effected by the notion of assertoric justification: a speaker asserts $\mathrm{p}$ to a hearer only if the speaker believes that the hearer is justified in holding the beliefs referred to in D2. This gives rise to the legitimate expectations that lying breaches. L utters $p$, believing that its standard use is to state p. It is then inferred that when $\mathrm{L}$ thinks the hearer is justified in believing that $\mathrm{L}$ accepts $\mathrm{p}$, the hearer has a legitimate expectation that $\mathrm{L}$ accepts $\mathrm{p}$. But in the Kennedy example, the speaker's belief that the hearers are so justified will be false: the hearer is not justified in believing that the speaker accepts $p$, owing to the non-entailment of ' $\mathrm{D}$ is [really] justified in believing, etc.' from ' $\mathrm{L}$ believes $\mathrm{D}$ is justified in believing, etc.'.

The inference that when $\mathrm{L}$ asserts $\mathrm{p}$, the hearer has the right to believe that $\mathrm{L}$ accepts $\mathrm{p}$, fails. It does not follow that the hearer has the right to believe that $\mathrm{L}$ accepts $\mathrm{p}$ on the grounds that $\mathrm{L}$ believes that the hearer is justified in believing it. This latter belief of L's may itself be unjustified; in some cases the hearer will not even believe that $\mathrm{L}$ accepts $\mathrm{p}$. If the hearer is not justified in believing that $\mathrm{L}$ accepts $p$, it will not follow that he has the right to expect that $L$ accepts $p$, as when $\mathrm{L}$ has false beliefs about the proposition he has expressed. Of course, the usual grounds for believing that a speaker accepts $\mathrm{p}$ is that L makes an utterance, a standard use of which is to express $p$, in appropriate circumstances. But these grounds will not hold in cases of 'mis-speaking'.

This point goes beyond the misunderstandings so far considered. What a speaker communicates to a hearer depends on semantic, pragmatic and contextual factors. But insofar as the hearer has justified beliefs about the content, or the speaker's belief about the content, justification depends on how the communication will be taken, rather than solely on what the speaker believes. What a hearer is entitled to infer from a speaker's utterance depends on what the utterance is standardly taken to mean. Such inferences are not indefeasible. But that suggests limits of a strict-entailment model in the face of strongly contextual and pragmatic features.

What about an augmented version of CF's first condition?

$\mathrm{D}{ }^{*} \mathrm{~L}$ states $\mathrm{p}$ to $\mathrm{D}={ }^{\mathrm{df}}(1) \mathrm{L}$ believes that there is an expression $\mathrm{E}$ and a language $\mathrm{S}$ such that one of the standard uses of $\mathrm{E}$ in $\mathrm{S}$ is that of expressing 
the proposition p; (2) L utters E with the intention of causing D to believe that he, L, intended to utter E in that standard use; (3) one of the standard uses of $\mathrm{E}$ in $\mathrm{S}$ is indeed that of expressing the proposition $\mathrm{p}$.

The change is the non-relativisation of the 'standard use' of the expression to L's beliefs. Still, there is no reason to think that 'the standard use' of an expression must be taken as narrowly as CF. Standard uses of expressions often blur the line between strict entailment and implicature; if not, the deceiver would not be able to exploit this fact.

Brendan tells his traditionalist mother that he stayed at Brenda's until $9 \mathrm{pm}$, when in fact he stayed all night. Brendan knows that 'I left Brenda's at 9 pm' is not an entailment, but only an implicature of 'I stayed at Brenda's until 9 pm'. It is moot whether a standard use of this latter sentence is to express the proposition 'I left Brenda's at 9 pm'. Perhaps one might decide that it is not, so Brendan has not stated this. It seems hard to believe, though, that there is a significant moral difference between Brendan's stating this and his 'merely' stating 'I stayed at Brenda's until $9 \mathrm{pm}$ '. Has Brendan asserted that he left Brenda's at $9 \mathrm{pm}$ ? For the line of argument I am offering here, what matters for moral evaluation is whether it is said with deceptive intent.

Some implicatures operate at a semantic remove from what is explicit. It is not always clear what can reasonably be inferred from an utterance. Even so, the fact that a language is used for communicative purposes licenses norms about what it is reasonable to think that it means in specific contexts of use. What a hearer is justified in believing generally depends on what a reasonable person would think that the speaker was inviting the hearer to believe. What is communicated, and so what a hearer is justified in believing, depends on how the hearer takes the communication.

I will not offer a rival set of conditions to CF. One point at issue in cases of deception, including lying, is whether a speaker has really said that $p$, and it is doubtful whether any decompositional account can explicate the notion of really saying something. Many utterances that they treat as misleading may be lies, given less restrictive responses to the queries raised above in 2(a)-(e); but there is reason anyway to doubt that lying in general is worse than misleading. What matters for moral assessment is intentional deception, and the person who is (knowingly) misled is deceived as surely as someone who is lied to.

I take as basic the notion of a speaker's saying something to deceive, where 'saying' excludes irony, jokes, quotation, etc. Deceptive intent is basic, so that deciding whether a speaker was 'saying' that $\mathrm{p}$ depends on whether he intended to induce a false belief. That means imputing certain intentions to the speaker. Judgements about intentions can be wrong, but their fallibility does not show that the speaker has final authority over his avowals. The frames for judging a speaker's intentions are multiform and contextual. They include information about whether or not $\mathrm{p}$ is something that the speaker might want to say: for example, 'I did not have sexual relations with that woman, Miss Lewinsky'. This utterance might be thought semantically transparent. However, as the Starr 


\section{G. Newey}

Report shows, this did not stop President Clinton and his lawyers from attempting to redefine 'sexual relations' to exclude acts in which he and Lewinsky had engaged. ${ }^{9}$

Deception essentially involves the induction of false belief. The deceiver aims at a belief - the target-belief - which is false. The inference I draw from this is that the intended induction of false belief as such is what is prima facie wrong, but also that there may be situations in which the deception is justified. If deception as such - the intended induction of false belief - is wrong, the earlier rationale for a sharp line between lying and non-mendacious deception disappears. This justification will rest on assent, particularly from those who are deceived. But there is no reason to think that the conditions for assent cannot be met. An important class of cases in which this assent can be forthcoming lies in actions that agents concert politically.

Consider the following argument.

1. Lying and other speech-acts, such as misleading, generally thought of as non-mendacious, are species of the genus intentional deception.

2. In intentional deception, the liar intends to induce a false belief in her victim.

3. Intending to induce a false belief in one's victim makes the victim's agency a mere means to the liar's ends.

So (from 1, 2, and 3)

4. Lying and other deceptive speech-acts, such as misleading, make the victim's agency a means to the deceiver's ends.

5. It is always prima facie wrong to make a person's agency a mere means to one's ends.

So (from 4 and 5)

6. Lying, like other deceptive speech-acts, such as misleading, is prima facie wrong.

The challenge to the high-bar view is to ask why other kinds of deception lack the wrongness of lying. One strategy identifies the victim as complicit in her deception in cases of non-assertoric deception. Hearers have to go beyond the strict entailments of the assertum, and so implicate themselves in the induction of false belief. This response needs fuller discussion, but I confine myself here to two remarks. First, the fact that a second party - even if that party is the victim herself - is complicit in wrongdoing does not obviously mitigate the wrongness of the act or alter its explanation. Second, as with some other kinds of deception, the deceiver's aim is to catch the victim off-guard, by-passing her capacity for judgement. Reliance on standard uses of language is one way of achieving this. 


\section{Testing deception}

A hearer may misunderstand what she is told. But in many acts of deceptive speech the hearer understands exactly what the speaker intends. Verbal deception relies on an understanding common to speaker and hearer, and it is this which offers the opportunity for a pragmatic test of deception.

In controversies over political lying, as noted earlier, dispute often concerns what the words uttered meant. It is often said that it must be wrong to reduce the meaning of what a speaker says to his intentions in saying it, as a speaker may (as in Freudian slips) say something that he does not mean to say. On a widely held view, my intentions cannot be known, or known 'directly' by anyone except myself, nor your intentions by anyone but you, etc. This means that the deceptive speaker can always insist that his or her utterance has been 'misunderstood', when the hearer forms false beliefs as a result.

What I can communicate by a given expression is determined by what my audience takes it to mean. This need not be a 'standard use' of the expression: it may be a local idiom, slang, and so on. Still, successful communication requires an understanding of the expression common to speaker and hearer. This will constrain the uses to which the speaker can put it, and this constrains what a speaker can intend to say when using it. That it is understood in a certain way by the hearer is evidence that the speaker intends to be so understood. This is particularly clear with highly conventionalised utterances.

So a guide to a speaker's intentions is given by what the hearer takes the utterance to mean. The deceptive speaker cannot usually claim privileged access to his own thoughts to insist that he has been 'misunderstood'. The test set out below aims to provide a means to construct the speaker's intentions: the attributed intention is the result of the test, with some supplementary conditions. But the test does not take a stance on what intentions really are. It calls on evidence to construct hypotheses about what a speaker intended to communicate by means of a given utterance, and to determine whether the speaker intended to deceive.

The approach advocated here focuses, accordingly, on the hearer's uptake, and on the speaker's intentions.

\section{Interpretative reasonableness (IR)}

In general, the beliefs, if any, which a speaker $\mathrm{S}$ intends the hearer $\mathrm{H}$ to hold as a result of S's making an utterance to $\mathrm{H}$, are those which a reasonable and fully informed observer $\mathrm{R}$ would think that $\mathrm{S}$, in the circumstances, was inviting $\mathrm{H}$ to hold.

The aim of IR is to use hearer uptake as the basis for imputing intention to a speaker. Not that it is 'analytic' that intention equates with whatever hearers understand a speaker to have meant; but analyticity may not be the most helpful basis for assessing this test. When politicians claim that their words have been 'taken out of context', or misinterpreted, they cast doubt on IR as a test of 
speaker-intention. But speakers must appeal to an alternative publicly avowable meaning of their words.

Why not just say:

In general, the beliefs which a speaker $\mathrm{S}$ intends the hearer $\mathrm{H}$ to hold as a result of S's making an utterance to $\mathrm{H}$ are those which, in the circumstances, $\mathrm{H}$ would reasonably think that $\mathrm{S}$ was inviting $\mathrm{H}$ to hold?

It may be reasonable to think that a hearer is being invited to believe something, even though the hearer herself would not be reasonable in thinking this - for example because the deception depends on ignorance. Subliminal messages provide an illustration: to work, the hearer should not think that she is being invited to believe $\mathrm{p}$ at all, reasonably or otherwise. Similarly, deception clearly does not require a recognition by the intended dupe of the deceiver's intention to deceive.

So far, IR merely offers a basis for deciding what it is that a speaker has said. What is required for deception? I suggest the following.

\section{Deception}

A speaker $\mathrm{L}$ intends to deceive hearer $\mathrm{H}$ if $\mathrm{L}$ invites $\mathrm{H}$ to form a belief that $\mathrm{p}$, and $\mathrm{L}$ believes that $\mathrm{p}$ is false.

IR should not have the consequence that a speaker working, as it were, within the knowledge-community's assumptions counts, when tested by IR, as deceiving a hearer; the beliefs held by members of the community may be regarded by an observer as simply false. Contrast this with the quite different situation in which a speaker is outside the knowledge-community, but opportunistically uses arguments credible to members of it, to induce false beliefs. By contrast, it is over-demanding to brand as illicitly deceptive arguments based on claims that the speaker himself does not accept, to induce a hearer to believe something true - what Augustine called 'counter-deception'. Illicit deception aims at a false target-belief, rather than, as in the counter-deception case, using a lemma the speaker believes false to induce a belief that he thinks true. This can be amplified as follows:

\section{Ulterior-aim deception}

A speaker $\mathrm{L}$ intends finally to deceive a hearer $\mathrm{H}$ if $\mathrm{L}$ invites $\mathrm{H}$ to form a belief that $\mathrm{p}, \mathrm{S}$ believes that $\mathrm{p}$ is false, and there is no further belief $\mathrm{p} *$ that $\mathrm{L}$ believes to be true, and intends $\mathrm{H}$ to form as a result of forming $\mathrm{p}$.

This formula is hearer-relativised. The hearer may hold beliefs such that a reasonable person would think the speaker is inviting her to believe p. IR does not stipulate whether these beliefs themselves are reasonable. Nor does it require that the inferential norms on the basis of which the hearer forms new beliefs must themselves be reasonable. ${ }^{10}$ It seeks only to decide whether the speaker was 
inviting the hearers to form certain beliefs, and this may need to deploy inferential norms. More generally, determining deception depends on the speaker's aim, as judged by a reasonable observer, rather than the quality of the hearer's inferential route to it.

However, this is still not quite right, as malevolent deceivers intentionally induce true beliefs to make their imposture plausible. A con-man may add various true elements to the mise-en-scène to compound its verisimilitude, as when Iago points out to Othello that Desdemona had tricked her father by marrying him. ${ }^{11}$ One possibility again is the norm of counter-suggestibility, which may be used for deceptive effect. Hence the formula needs to say that the final aim of the speaker is to induce false belief.

\section{Final-aim deception}

A speaker $\mathrm{S}$ intends to deceive a hearer $\mathrm{H}$ as her ulterior aim if $\mathrm{S}$ invites $\mathrm{H}$ to form a belief that $\mathrm{p}, \mathrm{S}$ believes that $\mathrm{p}$ is false, and $\mathrm{S}$ intends that $\mathrm{H}$ forms any further belief $p^{*}$ (whether true or not) as a result of H's accepting $p$, only to get $\mathrm{H}$ to believe that $\mathrm{p}$.

This excludes benevolent false-lemma deception. There is a target-belief at which the speaker aims, which he believes is false, and any further beliefs are induced solely as part of the project of inducing that false belief.

It is too strong to require that the conception of justification be relativised to the beliefs which the hearer ideally would have if it were fully informed and rational. The speaker may aim to exploit the hearer's ignorance, so what the hearer justifiably believes cannot be gauged from the beliefs she would justifiably have if she knew all the facts. If she did know that not-p, then she would not justifiably believe that $\mathrm{p}$. On the other hand, she may be particularly well informed about something and so would justifiably, from what the speaker says, acquire beliefs which another less knowledgeable audience would not hold. So we need relativisation to the speaker's view of the hearer's knowledge, to decide whether deception has been attempted. This is allowed for by the third-personal stance of IR.

Competent speakers of the language usually qualify as reasonable for the purposes of IR. This extends too to the speaker. Interlocutors usually know whether they are communicating with competent language-users, and when not. Competent users can judge when expressions are being used in a non-standard way.

The test does not show whether, if a speaker attempts deception, this attempt is justified: that remains an open question, whose closure depends on an account of wrongness, such as the one sketched earlier. One reason for this is that there is no obvious argument that leads from the claim that a reasonable person would think that the hearer was being invited to form a certain belief, that the audience has any rights in the matter. Perhaps the hearer has authorised the speaker to deceive her for certain purposes. ${ }^{12}$

IR aims to hoist the deceiver with his own petard. If a speaker addresses a hearer with deceptive intent then he will have to convey this by using language 
in a way which the hearer will readily understand. Hence the fact that an utterance is reasonably interpreted in a certain way offers strong - although not indefeasible - evidence that it was intended to be so interpreted. The test does not state how, practically, it is to be implemented. Clearly there are various ways, more or less elaborate, in which it might be given practical effect. As such it exemplifies 'imperfect' procedural justice, in Rawls' sense of the term (Rawls, 1999): that is, it does not (and could not) specify procedures which infallibly produce the 'right' outcome - in this case, a procedure which ensured that a reasonable person would think that a speaker had invited a hearer to believe $p$ when and only when the speaker had intended the hearer to believe this.

Consider the following example, taken from the Hutton Inquiry into the events surrounding the death of Dr David Kelly, a government weapons adviser in the prelude to the 2003 Iraq war. ${ }^{13}$ On the BBC Radio 4 Today programme on 29 May 2003, a journalist, Andrew Gilligan, alleged that the Government 'probably knew' that its claim in its dossier of September 2002, Iraq's Weapons of Mass Destruction, that Iraq possessed WMD capable of deployment within 45 minutes, was false. ${ }^{14}$ In July 2003 Kelly emerged as the source for Gilligan's allegation, and Ministry of Defence press officers were given draft Question and Answer material prepared for use when briefing journalists about the source. ${ }^{15}$ The Q \& A material contains the following passage.

\section{$\mathrm{MoD} / 1 / 0065$}

Q: Were $[s i c]$ No 10 involved in this announcement?

A: The decision to issue a statement was made by the MoD.

The drafting of this exchange is such as to give the impression that the answer to the question posed is 'No'. The MoD briefing aims to get the questioner to a false conclusion, via a false inference. The decision to issue a statement was made by the MoD; so the decision to issue a statement was not made by No. 10; so No. 10 was not involved in this announcement; so the answer to the question is 'No'. That is, a reasonable person would conclude from the MoD proforma that No. 10 was not involved in the announcement. However, transcripts from the Hutton Inquiry hearings show that this is untrue. ${ }^{16}$

\section{Coda: democratic politics}

A constitutive problem facing public-interest defences of political lying is how the public can judge the public interest when it is deprived of the truth. Misapplication of standards of truth-telling may debase the coin of political discourse. The problem certainly goes wider than truth-telling. There is good reason to think that at least mild disaffection among the populace at large is endemic in democratic life; accountability mechanisms also fuel disaffection and expose politicians as untrustworthy. But democratic credibility is not helped by setting a high bar for mendacity, and then bemoaning the dishonesty of politicians who trim to stay beneath it. 


\section{Appendix: The Prime Minister's aeroplane interview, 22 July 2003}

After Kelly's suicide, the Prime Minister told reporters on 22 July 2003 that it was 'completely untrue' that he had authorised the naming of Dr Kelly. Asked whether he had authorised anyone in Downing Street or the MoD to release Kelly's name, the PM replied 'emphatically not ... I did not authorise the leaking of the name of David Kelly'.

However, in his Inquiry testimony given on 28 August 2003, the PM said when asked about the Government's decision to publicise the fact that a source had come forward:

my concern was to get that information not concealed but, as it were, out there so that no-one could say afterwards: look, this is something that you people were trying to cover up or conceal from a House of Commons Committee. ${ }^{17}$

Elsewhere in his evidence to the Inquiry the PM acknowledged that if on reinterview it was clear that [Kelly] was in all probability the source then we were going to have to disclose that'. ${ }^{18}$ The reason why the name was 'out there', then, was that the Government, led by the PM, had instigated the process of putting it into the public domain.

Sir Kevin Tebbit, the Permanent Secretary at the MoD, testified to the Inquiry that a meeting in Downing Street chaired by the PM resolved to authorise disclosure:

a policy decision on the handling of this matter had not been taken until the Prime Minister's meeting on the Tuesday [8 July 2003]. And it was only after that that any of the press people had an authoritative basis on which to proceed. ${ }^{19}$

This incidentally shows the falsity of the impression given by MoD/1/0065, quoted earlier. Thus:

1. the PM authorised disclosing both to the House of Commons Foreign Affairs and Intelligence and Security committees, as well as to journalists via the MoD press office, that a source had come forward; ${ }^{20}$

2. the PM knew that a foreseeable consequence of this was that the source would be identified. ${ }^{21}$

It was thus not 'emphatically not' the case, nor 'completely untrue', that the PM had authorised the naming of Kelly, as he had initiated a process which foreseeably resulted in Kelly's name becoming public. This is true regardless of whether the PM truthfully testified ${ }^{22}$ that he had not seen the Q\&A briefing.

A reasonable person would have thought that the public was justified in inferring, in line with $\mathrm{MoD} / 1 / 0065$, that the PM had not participated in the process by 
which Kelly's name became public. This is a false inference. It strains credulity that the PM did not recall, two weeks after the key meetings, that he had met advisers to discuss how to handle the emergence of the likely source for the Gilligan story. Hence there is no good reason to think that by 22 July the PM believed that he had played no part in the decision to name Kelly.

\section{Notes}

1 See for example, Aristotle 1926, Book II; St. Augustine, de Mendacio and Contra mendacium in Augustine 1948; Aquinas 1947, 2a2ae 110-113. For assertion, see Grice 1989, esp. ch. 5, 'Utterer's Meaning and Intentions' and ch. 6, 'Utterer's Meaning, Sentence-Meaning, and Word-Meaning'.

2 Chisholm and Feehan 1977 (152ff) argue that what is said by a speaker in cases of lying is the assertum, that is what is asserted, which is identified with the propositional content of the speaker's token utterance.

3 Chisholm and Feehan 1977 (155, problem case \#5) take this view, along with a long tradition of moral commentary on lying which includes Augustine in the de Mendacio; Aquinas in the Summa Q.110; Kant (1997), and others.

4 Although German native speakers I have consulted differ on whether 'Ich bin ein Berliner' really translates as 'I am a doughnut'.

5 Carroll 2010: 57.

6 Chisholm and Feehan 1977: 156.

7 I am thinking specifically of discussions of free speech, where theories often discount the context and cost of communication for a purely expressive view of speech. See Newey 2009.

8 Chisholm and Feehan 1977: 153.

9 Starr 1998.

10 On related matters, see Gaus 1996.

11 Othello, III 3, 238.

12 On this point see my 'Political Lying: a defense', Public Affairs Quarterly 11: 2 (1997), 93-116.

13 Hutton Inquiry: www.the-hutton-inquiry.org.uk/.

14 BBC documentary submissions: www.the-hutton-inquiry.org.uk/content/bbc/bbc_1_ 0004to0017.pdf.

$15 \mathrm{MoD}$ documentary submissions: www.the-hutton-inquiry.org.uk/content $/ \mathrm{mod} / \mathrm{mod}{ }_{-}$ 0062to0065.pdf.

16 See the Hutton inquiry transcripts online, and in particular the testimony of Sir Kevin Tebbit, then Permanent Secretary at the Ministry of Defence: http://webarchive. nationalarchives.gov.uk/20090128221550/www.the-hutton-inquiry.org.uk/content/ transcripts/hearing-trans 48 .htm.

17 Blair transcripts www.the-hutton-inquiry.org.uk/content/transcripts/hearing-trans22. htm: p72, 11. 20-4.

18 Blair transcripts www.the-hutton-inquiry.org.uk/content/transcripts/hearing-trans22. htm: p65, 11. 21-3.

19 Tebbit transcripts www.the-hutton-inquiry.org.uk/content/transcripts/hearing-trans 40. htm: p58, 11. 3-7.

20 Blair transcripts www.the-hutton-inquiry.org.uk/content/transcripts/hearing-trans22. htm.

21 Blair transcripts www.the-hutton-inquiry.org.uk/content/transcripts/hearing-trans22. $\mathrm{htm}$.

22 Blair transcripts www.the-hutton-inquiry.org.uk/content/transcripts/hearing-trans22. htm: p77, 1. 18. 


\section{Bibliography}

Aquinas, St. Thomas. Summa Theologica. New York: Benziger Bros.

Aristotle. 1926. Nicomachean Ethics, ed. H. Rackham. New York: Loeb.

Augustine. 1948. Euvres de Saint Augustin II: problèmes moraux, ed. G. Combès. Paris: Desclée de Brouwer \& Cie.

Carroll, L. 2010. Alice's Adventures In Wonderland. New York: Cosimo Books.

Chisholm, R. and Feehan, T. 1977. 'The intent to deceive'. Journal of Philosophy 74: 3, $143-59$.

Gaus, G. A. 1996. Gaus, Justificatory Liberalism: An Essay on Epistemology and Political Theory. Oxford: Oxford University Press.

Grice, P. 1989. Studies in the Way of Words. Cambridge, MA: Harvard University Press.

Kant, I. 1997. Lectures on Ethics, ed. Jerome B. Schneewind. Cambridge: Cambridge University Press.

Newey, G. 1997. 'Political lying: a defense'. Public Affairs Quarterly 11: 2, 93-116.

Newey, G. 2009. 'Denial denied: freedom of speech'. Amsterdam Law Journal 2: 2, 63-70.

Rawls, J. 1999. A Theory of Justice, rev. edn. Oxford: Oxford University Press.

Starr, K. 1998. The Starr Report: the Findings of Independent Counsel Kenneth W. Starr on President Clinton and the Monica Lewinsky Affair. New York: Public Affairs. 


\title{
2 The role of public reason's principle of sincerity
}

\author{
Enrico Zoffoli
}

\section{Overview of the argument}

My concern in this chapter is the idea (and ideal) of sincerity within the so-called doctrine of public reason. Very roughly, the doctrine of public reason holds that the exercise of political power ought to be adequately justified to the addressees of the law, understood as free and equal, self-legislating moral persons. Now because the practice of public reason involves exchanging reasons for and against the exercise of political power, it seems uncontroversial that an adequate theory of public reason should to some extent be concerned with the way in which citizens deliberate. In particular, many think, it would be desirable if citizens committed to the ideal of public reason respected some sincerity requirement while discussing political issues with one another. After all, public reasoning aims at bona fide justification. Hence, the arguments citizens put forward in support of their political proposals should not lapse into rhetorical attempts at persuasion. In fact, as Rawls's principle of legitimacy explains, "our exercise of political power is proper only when we sincerely believe that the reasons we would offer for our political actions are sufficient [...] and we also reasonably think that other citizens might also reasonably accept those reasons" (Rawls 1997: 578, italics mine). Again, then, it seems obvious to assume that public reasoning should be wedded to some principle of sincerity, which has been explicitly defended, although in slightly different variants, by public reason liberals such as John Rawls (1997), Gerald Gaus (1996), Jonathan Quong (2011), Micah Schwartzman (2011), Gerald Postema (1995) and Thomas Nagel (2003).

In this chapter I argue, however, that public reason liberals have overestimated the importance of the ideal of sincerity within public justification. If taken seriously, so my argument, the sincerity requirement would lead to neglect and downplay a core aspect of the doctrine of public reason, in that it would skew the very idea of a commitment to justify political proposals to others. Despite its intuitive appeal, then, sincerity can at best remain a prima facie desideratum connected with the ideal of public reason, without, however, enjoying the status of a strict requirement on public reason.

My argument unfolds in the following steps. First, I argue that honoring the ideal of justificatory sincerity involves respecting what Jonathan Quong has 
called the principle of justificatory sincerity (hereafter: PJS). Then I follow Quong in claiming that PJS offers grounds for rejecting a peculiar conception of public reason, which Fred D'Agostino has called a "convergence" model of public reason. However, I also argue that PJS has problematic implications, which risk undermining the very commitment to public justification. Next I consider two possible ways out of these problems. I conclude, however, that these solutions fail to reconcile PJS with the commitment to publicly justify.

\section{The principle of justificatory sincerity}

In defining the sincerity requirement, Quong assumes for simplicity that our constituency of public justification is limited to two reasonable parties (let us call them Andy and Bea). If our parties are committed to some liberal principle of legitimacy such as Rawls's, according to Quong, then they should agree on what he terms PJS:

Principle of justificatory sincerity (PJS): Andy can support proposal X only if he reasonably believes that (a) he is justified in endorsing $X$, that (b) Bea is justified in endorsing $\mathrm{X}$ and that (c) Bea is justified in accepting the arguments he has offered in support of $\mathrm{X}$ (and vice versa for Bea's proposals). ${ }^{1}$

As I see it, PJS fully captures the ideal of justificatory sincerity on which many public reason liberals place primary emphasis. To begin with, condition (a) seems necessary to any tenable account of justificatory sincerity. Unless Andy reasonably believes that $\mathrm{X}$ is justified to him, his arguments for $\mathrm{X}$ are insincere. Requirement (b) is implicit in Rawls's claim that the reasons we offer to others must be "sufficient." For to believe that X is justified to others simply is to believe that they have sufficient reason to accept it. Finally, requirement (c) restates what Rawls's principle of legitimacy says about the importance of giving others reasons that they could reasonably accept. Thomas Nagel concurs, arguing that "the sense of justice should lead us to try, in good faith, to offer to our fellow citizens grounds for the exercise of collective power that we believe they ... have reason to accept" (Nagel 2003: 66). In a similar vein, Gaus stresses, very plausibly, that "justifying your ... principles to others does not simply involve giving others reasons that they will accept, but in some way advancing reasons that you think are good reasons for them to accept" (Gaus 1996: 139).

There are, however, other important considerations that lend plausibility to PJS. First, PJS resists the radical and arguably controversial claim that Andy's meeting conditions (a) to (c) is a sufficient condition for $\mathrm{X}$ to be legitimately imposed on Bea. However important it may be, sincerity is not the only value at stake in public justification. It thus follows that Andy might be required not to support X despite his sincere and reasonable belief that $\mathrm{X}$ is justified to all. PJS makes room for this possibility, in that it holds that Andy's sincere and reasonable belief that $\mathrm{X}$ is publicly justified is only a necessary condition. 


\section{E. Zoffoli}

Moreover, PJS is promising because it only demands that Andy's beliefs about the legitimacy of his proposals be "reasonable." This last point is crucial. To see its significance, consider Schwartzman's definition of sincerity. In his view, "[i]f A says that p, A is sincere if and only if (i) A intends to say that p and (ii) A believes that p" (Schwartzman 2008: 992). To avoid unnecessary complications, let us assume that condition (i) will always obtain in the context of public justification. By stipulation, the members of our constituency will never utter "unintentional" statements. Still, they might say things that they do not actually believe, in which case they would be obviously insincere, as condition (ii) suggests. This is important. Openly (and intentionally) stating what you actually happen to believe is a necessary and sufficient condition for you to be sincere. Sincerity, in other words, is not a deontic notion, in that it does not refer to what people ought to believe, or to what they would believe if they took the trouble to carefully think things through.

At this point, though, a worry arises. Because sincerity is about actually held beliefs, PSJ would seem to speak in favor of "populist" justificatory conceptions, according to which a law is not publicly justified unless it gains the unanimous assent of all actual citizens. But this is an extreme and clearly implausible position. As Gaus says, "[p]eople can withhold their assent because of obstinacy, selfishness, laziness, perversity, or confusion. That an obstinate Betty simply refuses to assent to any of Alf's moral demands cannot demonstrate that Alf has failed to publicly justify them" (Gaus 1996: 121). ${ }^{2}$ In modeling the members of our constituency of public reason, then, we need to introduce at least some minimal degree of idealization. We must assume, that is, that what Andy and Bea sincerely (i.e., actually) believe about X deserves to be taken seriously only because they are conceived of as suitably idealized members of the public.

Still, those who cherish the value of sincerity should be wary of pushing this point too far. The more we idealize the members of our constituency, the more we demand that their real counterparts in flesh and blood accept reasons and proposals which they sincerely reject. This is why the qualification "reasonably" is so important in Quong's formulation of PJS. As we should avoid raising the bar of idealization too much, it is sufficient that Andy's beliefs be "reasonable." It is sufficient, that is, that Andy recognize the fact of reasonable pluralism and that he be free from gross defects of reasoning. This is a modest standard, which can be realistically met by most actual citizens. Hence, sincerely held beliefs are irrelevant if and only if they are unreasonable.

In sum, PJS seems to be a widely acceptable and robust principle of sincerity for three reasons. First, it captures nicely the idea that proponents of coercive legislation should offer reasons to others in a sincere way. Second, it does not claim that sincerity is a sufficient condition for legitimacy. Finally, it embodies a crucial "reasonableness" clause.

\section{Sincerity, consensus and convergence}

To become clearer on the implications of PJS, it is useful to expand a bit on the ideal of public reason. As I said at the outset, the ideal of public reason requires 
that the laws to which we are subjected be justified to us as free and equal, selflegislating moral agents. As Fred D'Agostino rightly points out, however, this general ideal presents itself as a multiply ambiguous "concept," which is open to different interpretations or "conceptions" of it. In particular, D'Agostino distinguishes between two families of justificatory conceptions, which he groups under the headings of "consensus" and "convergence" (D'Agostino 1996: 30-1). Essentially, "consensus" conceptions hold that public justification ought to draw exclusively on sharable or public reasons, while "convergence" models of public justification allow for the possibility that a given policy or proposal can be justified by different non-shareable or private reasons stemming from different comprehensive doctrines, which may happen to converge or overlap in support of it.

The overwhelming majority of theorists of public reason endorse consensus. They insist that "[t]o the extent that they claim to be valid for all, ought sentences must be justified to all with the same reasons" (Forst 2002: 194). ${ }^{3}$ Some, however, resist this dominant view. In particular, Gerald Gaus and Vallier argue that "for a law to be justified every citizen must have some conclusive reason to accept it: they need not all have the same reason" (Gaus and Vallier 2009: 51). The idea behind Gaus's convergence model is, of course, Rawls' intuition that a fully legitimate conception of justice should be able to gain an "overlapping consensus" of comprehensive doctrines. But while Rawls is notoriously unclear about the justificatory role of the overlapping consensus, Gaus maintains that the search for convergence points is "immensely important" to the achievement of public justification (Gaus 2011: 336). ${ }^{4}$

Now according to Quong, convergence should be resisted because it allows citizens to violate PJS. ${ }^{5}$ Quong's worries arise from the following scenario. Suppose Andy accepts a given proposal X for some comprehensive reason $R_{A}$, while he argues that Bea has her own comprehensive reason $R_{B}$ to endorse $X$. In this case, Andy would put forward what Gaus calls a "convergence argument," which seeks "to show that we have different reasons for endorsing X, though we all have some reasons for endorsing it" (Gaus 2003: 190-1). Rawls himself admits of this kind of reasoning, which he terms "reasoning from conjecture." If we reason "from conjecture," we "argue from what we believe, or conjecture, are other people's basic doctrines, religious or secular, and try to show them that, despite what they might think, they can still endorse a reasonable political conception" (Rawls 1997: 594). However, Quong is convinced that arguments of this kind are a blatant example of insincere justification. Consider again our case. By stipulation, Andy "does not believe that $R_{B}$ justifies $X$," so how could he sincerely say to Bea " $R_{B}$ is a reason for you to accept $X$ "? Robert Audi (1991: 47) makes a similar point when he asks: "Why should others be moved if I am not? ... [I]f the reason is adequate, why does it not move me?". It thus seems that Andy's convergence argument falls foul of requirement (c) of PJS, as Andy does not think $R_{B}$ is a good reason for Bea. Moreover, should Andy be unable to offer any reasons to $B$ ea other than $R_{B}$, he would most probably violate requirement (b) as well, as he could hardly think that $\mathrm{X}$ is justified to Bea after all. Quong concludes that PJS bars the use of convergence arguments in public reason. 
Of course, convergence theorists could protest that this reading is too narrow. Quong seems to imply that if Andy "conjectures" based on beliefs he rejects, he simply tries to get Bea to believe what he wants her to believe, without, however, providing her with reasons that he sincerely believes are good reasons for her to accept. Surely it is hard to disagree with Bryan Garsten when he says that reasoning from conjecture "sounds strikingly like a sympathetic portrayal of a rhetorical argument, in that it recommends beginning with a particular audience's opinions and trying to use those opinions as a basis of persuasion" (Garsten 2006: 186). However, we should make a crucial distinction between arguing from premises that we believe to be plainly crazy or irrational (a), and arguing from premises that we deem wrong yet not unreasonable (b). What sets apart (b) from (a) is that in case (b) we can believe that, in the light of their reasonable belief systems, our interlocutors are justified in holding the premises from which we argue, although we reasonably reject such premises.

We can therefore stipulate that Andy thinks $R_{B}$ is a good reason from Bea's perspective (and vice versa). In fact, Gaus argues that Andy would not be "objectionably insincere" if he could see $R_{B}$ as an "intelligible and relevant" consideration which Bea could endorse from her perspective after engaging in a sufficient degree of deliberation (Gaus 2011: 289). Still, "intelligibility and relevance" may not be sufficient, for Andy could grant that Bea's religious views are intelligible and relevant but unable to warrant rational belief. Yet to sincerely claim that $R_{B}$ justified $X$ to Bea, Andy must believe that $R_{B}$ is not merely a tolerable mistake, but rather a proper justificatory reason.

Now Quong aptly notes that to make sure that Andy is sincere in this sense, we should assume that Andy endorses some moderately relativistic epistemology such as Gaus's. Very roughly, Gaus rests on the assumption that "a rational belief system is to be analyzed in terms of the relations among its members (reasons and beliefs) and not with reference to the idea of truth" (Gaus 1996: 42). But as reasoners typically start with different sets of beliefs and inferential norms, they may be epistemically justified in holding different and largely conflicting belief systems. Reasonable pluralism thus turns into "relativism of reasons": it becomes possible that "people can have systems of beliefs that contain different norms of inference and belief acceptance and still be able to recognize each other's systems as rational" (Gaus 1996: 40). Therefore, if Bea's belief system commits her to acknowledging that $R_{B}$ is a reason for endorsing $X$, then Andy should see the inference from $R_{B}$ to $X$ as epistemically warranted from her perspective (and vice versa for Andy's private reason $\mathrm{R}_{\mathrm{A}}$ ).

As Quong stresses, however, this is an unlikely scenario, given that "many reasonable citizens ... do not think that doctrines that conflict with their own are justifiable. They view those other doctrines as both false and unjustifiable" (Quong 2011: 270). Consider again the example of religious doctrines, which is particularly germane to the point Quong wants to make. As an atheist socialist, Andy will probably believe that religion is an irrational illusion, so how could he take it to be a source of justification? Conversely, religious people often regard religious and secular doctrines that differ from their own as unjustifiable, 
although of course "intelligible and relevant." For instance, many Catholics do not believe that - say - skeptical, utilitarian and Muslim doctrines are anything more than reasonably endorsable errors. Also, perfectionists (both religious and secular) typically deny that people who fail to grasp the evident truth about human flourishing can be seen as rational in Gaus's sense. In sum, Quong's interpretation seems to better reflect what many people believe in good faith about the epistemic status of other people's non-public doctrines.

At this point, we must bear in mind what I called the "reasonableness clause" of PJS, according to which sincerely held beliefs must be reasonable. Now Gaus seems to imply that being reasonable means in some way recognizing that others have "justified beliefs" which we do not share (Gaus 2011: 292). If we accept this interpretation of the reasonable, then we have little reason to worry about Quong's empirical claim that many citizens do not view other citizens' doctrines as justified. Quite simply, we could dismiss this common view as not fully reasonable. As a result, we could grant that PJS is an important principle and yet deny that convergence permits insincerity, because fully reasonable persons view other citizens' doctrines as justified in Gaus's sense. Quong, however, resists this "epistemic" account of the reasonable. In fact, he sides with Rawls in refusing to tie the ideal of public reason to anything more demanding than a "deliberately loose" conception of the reasonable (Rawls 1993: 59). As Rawls says, reasonable doctrines and views need not be "open to rational appraisal or evidentially supportable" (Rawls 1997: 592). Reasonable persons, for Rawls, accept the burdens of judgment and the correspondent fact of reasonable disagreement. They view reasonable disagreement as a bare "fact" about liberal democracies: they recognize that over certain issues pervasive disagreement is "the inevitable long-run result of the powers of human reason at work within the background of enduring free institutions" (Rawls 1993: 4). Rawls thus maintains that, although the doctrine of the "burdens of judgment" has "epistemological elements," being reasonable "is not an epistemological idea" (Rawls 1993: 62). And this is so because epistemology is itself a controversial branch of philosophy, over which reasonable disagreement reigns. We can see others' doctrines as epistemically justified, but it is not unreasonable to simply tolerate others' views as innocuous mistakes. All Andy must do to qualify as reasonable is accept disagreement as an unavoidable consequence of the free exercise of reason under liberal principles.

Now the important point is that the Rawlsian account of the reasonable seems more in tune with PJS because, as we stressed above, in an important respect sincerity is not a deontic notion. Therefore, we should favor conceptions of public reason that exclude as few actually (i.e., sincerely) held beliefs as possible. If the members of our idealized constituency of public reason endorsed some fully fledged epistemic theory such as Gaus's, our model would barely reflect what most actual citizens sincerely believe. And yet sincerity is about actually held beliefs. The upshot is that we have to assume that the members of our constituency are reasonable in Rawls' sense simply because relatively few citizens are reasonable in Gaus's sense. Relatively few citizens, that is, would 
sincerely believe that norms backed by overlapping private reasons only are justified to all.

Moreover, Gaus himself seems sometimes to grant that citizens cannot be actually expected to endorse his epistemic theory, and hence to view other citizens' doctrines as justified. Gaus has distinguished between the "perspective of philosophical reflection" and the "perspective of real moral agents" (Gaus 2011: 264). Epistemic pluralism, in his view, is necessary to delineate a model of public justification from the perspective of one theorizing about justice. But if we employ this epistemic theory, as political theorists we do not thereby assume, far less demand, that the agents modeled by the theorist actually accept it. Rather, we simply lay out the epistemic framework within which public justification can occur. But if we admit that epistemic pluralism need not itself be agreed on, then PJS compels us to maintain that convergence allows citizens to engage in insincere public reasoning.

\section{Public reason and epistemology}

Thus far, I have argued that PJS establishes a case against convergence, for two interrelated reasons. The first is that sincerity is not a deontic notion, in the sense that it has nothing to do with what people ought to believe. Hence, the more our justificatory model departs from what most citizens actually believe, the more we permit or even demand insincerity. Second, most citizens disagree over epistemology. The upshot is that if we endorse PJS, we ought to favor conceptions of public reason that do not presuppose any kind of epistemology. Importantly, these two questions are inextricably intertwined. If a consensus model presupposed some controversial epistemological doctrine, then it would score almost as poorly as convergence with respect to PJS. In other words, PJS does not rank convergence below consensus in general, but only below "political" consensus conceptions such as Rawls', which are typically committed to epistemic restraint. As reasonable people disagree over epistemology, political liberals such as Quong, Rawls, Larmore and Macedo insist that a suitable conception of public reason must be neutral on controversial epistemic doctrines. Quong thus claims that "[p]olitical liberalism cannot affirm or deny the truth of Gaus's epistemic theory because that theory conflicts with what some reasonable citizens believe about the epistemic status of other people's non-public doctrines" (Quong 2011: 270). Following Rawls, Quong rejects justificatory accounts such as Gaus's, which rely on tethering public justification to controversial epistemic theories. Again, though, PJS requires political liberals to reject any kind of epistemology, not just Gaus's.

But while this sort of epistemic restraint, in conjunction with PJS, undermines the convergence view of public reason, it also makes PJS vulnerable to a crucial objection, which I take to be serious enough to compel us to deny PJS (or at least to consider sincerity as a mere desideratum, as opposed to a strict requirement cast in the form of a principle of sincerity binding on deliberators). The problem is that it is hard to see how any doctrine of public reason can be freestanding 
with respect to epistemology in general, as key concepts such as "reason," "justification" and "shareability" are deeply epistemological. This is not to deny, of course, that justificatory reasons are primarily moral, in the sense that they speak for or against ought-statements regulating behavior. But moral reasons, qua reasons, also have an epistemic dimension: they can be more or less able to support the belief for which they are reasons. So, for instance, if Andy says to Bea "Please lend me some money because I have none," he may well have given a moral reason to her. But to conclude that Bea should be convinced by that reason, we need to assess its epistemic weight. We need to verify, that is, whether or not that moral reason rationally commits her to believing that she should actually help him out. Again, all this is a roundabout way of saying that (moral) reasons for or against ought-statements (in our case: pieces of coercive legislation) need to be justified. Thus the moral and epistemological aspects of reasons cannot come apart. Rather, we need a moral epistemology to make sense of the idea of public justification.

To say that $\mathrm{X}$ is publicly justified to all is to say that all have some reason $R$ to accept X. And this, in turn, is tantamount to saying that Andy's affirming X on the basis of $R$ is not epistemically flawed. By the same token, to say that $R$ is a shareable reason justifying $\mathrm{X}$ is to say that all citizens are committed to regarding $R \rightarrow X$ as justificatory. So how can political liberals do away with epistemology? One response could consist in equating shareability with unanimous actual endorsement. If people reasonably disagree over epistemology, we cannot admit of any gap between people's actually shared beliefs and justificatory public reasons. For if we did admit that these two categories come apart, we should inevitably employ an epistemic theory to bridge the gap between the reasons we all actually affirm and the reasons that we ought to share. Clearly, though, the fact that Andy stubbornly insists on rejecting a reason that is justified to all cannot show that that reason is not shareable. Moreover, it is questionable whether there really are such things as "actually shared" reasons, to wit, reasons that are actually affirmed by all, ranging from Nazis to Maoists.

Of course, Rawlsians could retort that political liberalism is not committed to such a radical populist conception, but only to a populist conception that is concerned with the beliefs of reasonable people. But this revised populist view accomplishes little, for the simple fact that "reasonableness" is not an epistemic property of beliefs, but a moral attitude of persons, which means that reasonable people might hold flawed beliefs. In any event, Rawls rejects populism. In his view, we can certainly advocate reasons and values that are not actually shared as long as we reasonably believe that they could be shared by others. He claims, for example, that public reason asks us to "conduct our fundamental discussions in terms of what we regard as a political conception ... based on political values everyone can reasonably be expected to endorse..." (Rawls 1993: 241). ${ }^{6}$ Quong agrees. Rather than drawing on actually shared reasons we should appeal to reasons that we can share: "In a large and diverse liberal society, public reason ... requires that the reasons we offer to one another in political debate be reasons that we can all share" (Quong 2011: 273, italics mine). But this raises an obvious 
question: "Reasons we can all share" under which conditions? This is a purely epistemic question. If shareability and actual unanimous acceptance come apart, as Rawls and Quong rightly believe, we must explain which epistemic standards a reason must live up to in order to deserve the assent of all.

Quong could reply in two ways. First, he could grant that shareability is an epistemic concept and yet contend that a "loose" political epistemology can suffice. Second, he could insist that public justification may work even in the absence of an epistemic theory because the concept of shareability need not be spelled out in epistemic terms. In both cases he would eschew a controversial definition of shareability to retain a good deal of actual consensus about the nature of the concept.

\section{Epistemic neutrality?}

Let us consider the first strategy. Quong could argue that political liberalism must be neutral on controversial epistemological doctrines, and not on epistemology as such. Reasonable citizens, he could claim, can and should obviously master some basic epistemic tools. As Rawls stresses, reasonable people accept both commonsense reasoning and the non-controversial conclusions of science. ${ }^{7}$ With this move, the political liberal apparently catches two birds with one stone. On the one hand, he can resist the radically populist view that the reasons we can share come down to the reasons we actually share. On the other hand, the political liberal can avoid the charge of relying on a controversial epistemology, as commonsense epistemology is implicitly shared by all reasonable citizens.

Still, there are three major problems with this view. First, significant evidence shows that commonsense reasoning is typically flawed by shortcuts, fallacies, pitfalls and heuristics. ${ }^{8}$ This comes as no surprise. If our epistemology must conform to what citizens actually believe, then it is hard to see how it could yield results that differ much from a sheer populist view. In a way, political liberalism can avoid populism only by resorting to a populist epistemology. Second, the claim that commonsense reasoning is an adequate epistemic theory because people are likely to accept it is weirdly counterintuitive. Overwhelming evidence shows that commonsense reasoning is often flawed, but now we are told that the mere fact that many average reasoners are likely to commit errors of reasoning shows that commonsense reasoning is sound. Finally, there is a more subtle problem with the view that the content of moral epistemology must in some way reflect people's beliefs about epistemology. Let $T$ be an epistemic theory assessing the epistemic status of reasons and beliefs. Now if we accept the view that commonsense reasoning is a sound epistemic theory because it is widely acceptable, we are committed to the view that $T$ is a sound epistemic theory (if and) only if, all reasonable citizens have a justified belief that $T$ is a sound epistemic theory.

Now claiming that justification in general should depend on citizens' beliefs may be a legitimate position, but to defend it one must already presuppose that citizens' beliefs are grounded in good reasons. Otherwise, to determine whether 
citizens are justified in endorsing $T$, we would need a further epistemic theory $T^{*}$ that explains whether their endorsing $T$ is justified. But of course, all this implies that only an agreement on $T^{*}$ among (reasonable) citizens could justify $T^{*}$. But how can we know if they have good reasons for endorsing $T^{*}$ ? Again, we need a further point of reference cast in the form of a deeper epistemic theory $T^{* *}$, and so on ad infinitum. To stop this infinite regress, one must assume that citizens' deliberation is bound by an epistemological theory whose validity is not itself dependent on the outcome of deliberation. At this point, defenders of PJS could perhaps claim that $R$ is shareable if, and only if, all citizens deliberating under conditions specified by $T$ would share $R$. But this view would take us back to square one. We need an epistemic theory $T$ to determine which reasons count as justificatory, and this theory must be independent of what reasonable citizens believe about epistemology.

Perhaps Quong could claim that Gaus's epistemic pluralism is only one epistemic theory among others, a theory over which it is possible to disagree. So why not endorse the following view of shareability? $R$ is a shareable/public reason for $L$ if, and only if, all reasonable epistemic doctrines hold that $R$ is a shareable/public reason for $L$. This view does not deny that shareability is an epistemic concept, as it does not deny that one needs some epistemic account of justified belief to determine whether a given reason is public. However, this view need not be seen as an epistemic thesis; in fact, it actually looks more like a thesis that accounts for different, conflicting epistemic theories: as long as $R$ is public according to all epistemic theories, political liberals can assume that $R$ is shareable, without, however, having to endorse any such theory; that is to say, they can argue that $R$ is public because, regardless of the epistemic theory one happens to affirm, one is committed to endorsing $R$. This view has the virtue of giving an account of shareability that is sensitive to the fact of reasonable disagreement over epistemology. As long as all epistemic theories converge in defining $R$ as public, then $R$ is the object of a "meta-convergence," so to speak. If this meta-convergence on $R$ occurs, then political liberals can maintain that $R$ is shareable without having to affirm any controversial epistemology. Political liberals could both give an epistemic definition of shareability and refrain from affirming or denying any of the epistemic theories which, by means of metaconvergence, jointly define what counts as a shareable reason. ${ }^{9}$

There are, however, two obvious problems with this "meta-convergence view" of shareability. The first problem is that it would essentially take us back to a populist conception of public reason. Recall that reasonable citizens may affirm implausible views of epistemology such as commonsense-theories. But of course, political liberals could hardly discriminate against flawed views and beliefs, as to do so they should take sides in the thorny issue (on which, again, they wish to remain agnostic) of what constitutes a justified belief. Given their commitment to epistemic neutrality, political liberals who may be attracted to the metaconvergence view of shareability should give a say to implausible epistemic theories. This is a populist approach in disguise: $R$ is shareable if all epistemic theories (including, alas, implausible ones) would regard $R$ as public. 
The second problem with this view is that it is inconsistent with consensus, as some epistemic theories may reasonably insist that comprehensive reasons are crucial to justifying the law. Consider again Gaus's theory, according to which the justificatory strength of a reason depends on the structure of one's belief system. Now those who accept Gaus's theory could insist that their comprehensive reasons may be necessary to (fully) justify the law to them. Conversely, as Gaus points out (2011: 38-42), these citizens might insist that, to them, public reasons may not be strong enough to justify the laws to which they are subjected. In other words, these citizens would require a "convergence" model of public justification. Now it is hard to see how defenders of the meta-convergence view of shareability can avoid this implication. If theories such as Gaus's must have a say when it comes to determining which reasons are public, it is not clear why their adherents should not insist that such reasons may not be sufficient to justify the law. The upshot is that political liberals may indeed live up to their commitment to epistemic neutrality, provided they accept the meta-convergence view of shareability (and are willing to lapse into some populist approach to public justification). But if they do, they are committed to rejecting consensus models of public reason.

\section{The idea of reasonableness}

Thus far, I have taken for granted that shareability is an epistemic concept, but now Quong could try denying this assumption. Above, I argued that "reasonableness" is not an epistemic property of beliefs but a moral characteristic of persons. Now in some places Quong appears to steer a middle way between these two views, arguing that reasonableness is indeed (also) a quality of beliefs, but not an epistemic property of justified beliefs. That is, beliefs (and not only persons) are reasonable, and yet reasonable beliefs need not be epistemically justified. On Quong's definition, a "reasonable belief" is "any belief held by a reasonable person that is arrived at through an exercise of theoretical reason, which is to say that it is arrived at 'in a more or less consistent and coherent fashion" " (Quong 2011: 231). However, reasonable beliefs may fall short of full epistemic warrant because "[y]ou do not have to be subjectively justified in holding a belief in order for that belief to be a reasonable one" (Quong 2011: 232). Now according to Quong, political liberals can only demand that beliefs be "reasonable". Consequently, Quong might claim that $R$ is a public reason for $L$ if and only if the belief that $R$ is a shareable reason is not unreasonable.

If we start from the assumption that the vast majority of actual citizens are reasonable, PJS would lead to rank consensus models based on this latter view of shareability over convergence. But once again, this seems a reason to reject PJS, rather than a reason to reject convergence. As Quong explicitly concedes that reasonable beliefs may have poor epistemic credentials or be altogether unjustified, political liberalism permits epistemically flawed reasons to shape the outcome of public reasoning. But if this is so, then political liberalism hardly counts as a justificatory conception. How can we achieve public justification if we start from the assumption that justificatory reasons may fail to warrant rational belief? 
Political liberals would probably be dissatisfied with this conclusion, arguing that to place too much emphasis on the epistemic dimension of justification is to downplay other relevant aspects of an adequate theory of liberalism. As it is desirable to work out a theory of public reason whose results can be widely seen to be reasonable, we should be wary of expunging too many actually held beliefs from the justificatory process. This is certainly one of the political liberals' main concerns, so it is not implausible to interpret along these lines their reluctance to inject too much epistemic substance into the justificatory model.

I do not mean to belittle this urge. My point is simply that if we reject epistemology, we cannot plausibly defend a theory of public justification. Consider what Macedo says about the importance of appealing to widely shared reasons: "[A]t its most basic level, public justification has dual aims." On the one hand, "it seeks reflective justification (good reasons)"; but on the other hand, "it also seeks reasons that can be widely seen to be good by persons such as they are" (Macedo 1990: 281). This claim strikes me as admitting that for political liberals justification is just a desideratum, which, however important, may be traded off against other values, such as the achievement of a good deal of actual consensus on political principles. Of course, as Gaus has repeatedly insisted, his epistemic theory presupposes a low level of idealization: justification is about the reasons that average reasoners have, and not about the "objective" reasons that there are (Gaus 2011: 232-260). Still, insofar as we reject this sort of epistemology (or any sufficiently plausible epistemology), we lower the bar of idealization too much, thus losing sight of the reasons that deliberators have.

\section{Conclusion}

At the outset, I noted that sincerity seems a prima facie compelling requirement of public reason, as it seems obvious to assume that citizens should endeavor to justify their proposals to others in a sincere way. I further claimed that if we cherish the value of sincerity, we ought to accept what Quong calls PJS. Next I distinguished between "consensus" and "convergence" models of public reason, arguing that the former fare better than the latter with respect to PJS. In particular, I claimed that PJS requires ranking consensus over convergence because PJS, being a principle of sincerity, is concerned with citizens' actual beliefs. I also argued, however, that this sort of reliance on actually held beliefs (in conjunction with a Rawlsian "political" commitment to epistemic neutrality) raises a number of problems, which essentially threaten the fundamental commitment to publicly justify. Specifically, I argued that no theory of public justification can get off the ground in the first place in the absence of some kind of epistemic theory of justified belief. Insofar as it requires neutrality on epistemology, then, PJS ends up putting obstacles in the path of public justification, and should be resisted for that reason. I conclude that although sincerity may well be a desirable virtue of deliberators, it should not be turned into a strict requirement binding on public justification. 


\section{E. Zoffoli}

\section{Notes}

1 I have slightly simplified Quong's original formulation of PJS.

2 For other arguments against populism see Estlund 2008 (184-206) and Eberle 2002 (202-7).

3 For an overview of consensus models see Zoffoli 2013: 20-3. To be sure, many public reason liberals embrace the so-called "wide view" of public reason, which allows citizens to introduce their comprehensive views into debate at any time, provided supporting public reasons are offered in due course In the end, though, the wide view of public reason comes down to a sheer consensus view, as it holds that a law's having an adequate (though perhaps only forthcoming) shareable justification is a necessary and sufficient condition for that law to be publicly justified. See Rawls 1997: 591-4.

4 For other defenses of the convergence view of public reason see Stout 2004 and Zoffoli 2013.

5 Postema (1995) and Schwartzman (2011) also believe that sincerity requires reliance on public or shareable reasons.

6 Moreover, in his later works Rawls argued for the so-called "wide view" of public reason. Here the link between shareability and actual unanimous endorsement is even more tenuous.

7 See J. Rawls 1993: 139.

8 For more on this see Gilovic, Griffin and Kahneman (eds) 2002 and Gaus 1996: 131-6.

9 Elsewhere, I argued that this view is the best option for "political liberals" committed to "epistemic neutrality" (Zoffoli 2012).

\section{Bibliography}

Audi, R. 1991. "Religious commitment and secular reason: a reply to Professor Weithman." Philosophy \& Public Affairs 20, 66-76.

D’Agostino, F. 1996. Free Public Reason - Making It Up As We Go. Oxford: Oxford University Press.

Eberle, C. 2002. Religious Conviction in Liberal Politics. New York: Cambridge University Press.

Estlund, D. 2008. Democratic Authority. Princeton: Princeton University Press.

Forst, R. 2002. Contexts of Justice - Political Philosophy Beyond Liberalism and Communitarianism, trans. J. Farrel. Berkeley, CA: University of California Press.

Garsten, B. 2006. Saving Persuasion: A Defence of Rhetoric and Judgement. Harvard UP.

Gaus, G. 1996. Justificatory Liberalism - An Essay on Epistemology and Political Theory. New York: Oxford University Press.

Gaus, G. 2003. Contemporary Theories of Liberalism, London: SAGE.

Gaus, G. 2011. The Order of Public Reason - A Theory of Freedom and Morality in a Diverse and Bounded World. New York: Cambridge University Press.

Gaus, G. and Vallier, K. 2009. "The roles of religious conviction in a publicly justified polity: The implications of convergence, asymmetry and political institutions." Philosophy \& Social Criticism 35, 51-76.

Gilovich, T., Griffin, D. and Kahneman, D. (eds). 2002. Heuristics and Biases: The Psychology of Intuitive Judgment. Cambridge, MA: Cambridge University Press.

Macedo, S. 1990. "The politics of justification." Political Theory 18: 2, 280-304.

Nagel, T. 2003. "Rawls and liberalism." In S. Freeman (ed.), The Cambridge Companion to Rawls. Cambridge: Cambridge University Press. 
Postema, G. J. 1995. "Public Practical Reason: Political Practice.” In I. Shapiro and J. W. De Crew (eds), Nomos XXXVI: Theory and Practice. New York: New York University Press, pp. 345-85.

Quong, J. 2011. Liberalism Without Perfection. New York: Oxford University Press.

Rawls, J. 1993. Political Liberalism (expanded edition 2005). New York: Columbia University Press.

Rawls, J. 1997. "The idea of public reason revisited.” In S. Freeman (ed.), Collected Papers. Cambridge, MA: Harvard University Press, pp. 573-615.

Schwartzman, M. 2008. "Judicial sincerity.” Virginia Law Review 94, 987-1027.

Schwartzman, M. 2011. "The sincerity of public reason.” Journal of Political Philosophy 19: 4, 375-98.

Stout, J. 2004. Democracy and Tradition. Princeton: Princeton University Press.

Zoffoli, E. 2012. "The place of comprehensive doctrines in political liberalism: On some common misgivings about the subject and function of the overlapping consensus." Res Publica 18: 4, 351-66.

Zoffoli, E. 2013. Beyond Consensus. Public Reason and the Role of Convergence. Baden Baden: Nomos. 


\title{
3 Speaking on morality's behalf When one should be silent and why
}

\author{
Mark Evans
}

\section{Introduction}

In 'Casting the First Stone: Who Can, and Who Can't, Condemn The Terrorists?', G.A. Cohen draws attention to a feature of moral judgment which has received comparatively little attention in analytical moral philosophy (Cohen 2013). He claims that one's condemnatory 'moral voice' - one's position as an articulator of what morality says in criticism of someone - is 'silenced', robbed of at least some of its weight or force, in two types of situation even when what one says in those situations is indeed what morality has to say about them. They are:

[1] where one is responsible for something relevantly similar to that for which one is criticising the other person. Cohen offers three labels for the 'silencing' riposte that could be offered by the latter: 'look who's talking', 'pot calling the kettle black' and tu quoque ('you, too!'; 'you're guilty of the same thing!'). (Hereafter I shall call this the tu quoque response.)

[2] where the critic has significant direct responsibility for causing that which he is condemning. No snappy name is at hand to characterise the reply warranted from the other person, not least because the nature of the critic's 'direct responsibility' - and hence the wording of the reply itself - differs between the various relevant situations. Cohen's list of responses to which one might be rightfully subject in this kind of instance includes: 'you started it!'; 'you made me do it!'; 'you ordered me to do it!'; 'you asked me to do it'; 'you left me no reasonable alternative'; and 'you gave me the means to do it' (Cohen 2013: 123). (I will call this, in its general form, the 'coresponsibility' response.)

In neither situation is morality's validity undermined, as the criticism which the critic is said not to be entitled to make is in itself justified. But it matters greatly who gives voice to morality's judgments, for one lacks the moral authority to do so when one is rightfully liable to one (or more) of these moral rejoinders. A morally criticisable person, when criticised by someone who is morally impugnable in one, or both, of these ways can pertinently deflect their criticism by responding 'you have no right to condemn me!'. 
$T u$ quoque and co-responsibility ripostes against critics could also have force when the criticism in question is not over specifically moral matters. But when the criticism is a moral criticism, it is peculiarly troubling. There is something about the presumption of such a critic in the relationship that he is purporting to have, qua critic, to morality that gives 'silencing' its particular force. So it seems reasonable for us to propose that any adequate conception of morality's nature must be able to account for the 'silencing' feature in moral condemnation's illocutionary force. Cohen's discussion does not stretch this far in its ambitions (Cohen 2013: 121). The present chapter, then, seeks to make some (not full) headway in this regard. Its analysis culminates in what many might think to be a highly demanding, puritanical rendering of the pragmatics of moral discourse but that may indeed be what we must accept to take morality seriously.

\section{Hypocrisy}

I begin by noting that part of the explanation of silencing is a conceptual feature which not all moral philosophies necessarily share, and which may mean some of them might avoid the 'silencing' puzzle altogether. It is, however, a very prominent and influential feature, explicated as follows: though they are variously configured along consequentialist and deontological lines, the type of the theory which is of concern here embraces a characteristic Enlightenment conceptualisation of the 'moral point of view'. This is said to be, in principle, 'agent-independent' in the following way: valid moral judgments about what is right and wrong, or good and bad, are posited as objective in the sense of their being independent of the attitudes or dispositions of any particular agent. The validity of the judgment in question does not depend on who is making it: the claim that $\mathrm{X}$ was wrong to do $\mathrm{Y}$ to $\mathrm{Z}$ holds regardless of whether it is $\mathrm{Z}$, or you, or me, or God, or - in a confessional moment $-\mathrm{X}$ who says so. In this sense morality can be said to have 'its own point of view'. Such objective impartiality or, more pertinently in this context, impersonality must, then, be distinguished from what can be called 'the agent-relativity of moral authority' that 'silencing' exposes: one's authority to pass moral judgment on someone is crucially determined by one's personal moral standing with respect to who and what is being condemned.

Now, one might think that all that Cohen has described are simply instances of hypocrisy, presenting no great difficulty in accounting for 'silencing'. Hypocrisy, we might think, is just plain bad, one of the most obvious of moral failings (a judgment that reflects the peculiarly strong contempt in which, as Judith Shklar notes [Shklar 1984: 45], the hypocrite is nowadays held by so many): the hypocrite's fault is that he is a dissembler who pretends to be what he is not.

There are three reasons, however, why the 'hypocrisy' diagnosis will not do. First, what makes hypocrisy morally wrong when it is morally wrong - for it is not always so, or, at least, not always worse than being unhypocritical - is part of what needs explaining. For on one level, the charge of hypocrisy could look like being one merely of inconsistency (almost as if it were a logical flaw), or 
lack of integrity, bemoaning the agent's moral 'disunity': a matter of disjunction between one's own true convictions and one's publicly declared or exhibited convictions. Such disjunction is usually said to be proof of an insincerity of commitment to one's avowed principles, and this is where many would say its specific vice is located.

But clearly it would be morally better, in some sense, for certain people not to be true to their own principles. There are occasions on which it is justified and perhaps necessary to act in ways that run counter to one's moral beliefs. The private racist is a hypocrite if he practises superficial public toleration - but better this than to discard the public pretence. And if we say that there is still a moral flaw with the private racist, as he ought to be a private as well as public anti-racist, the question of hypocrisy is nevertheless not powering the main thrust of our criticism. He should be a private as well as public anti-racist because he should be completely anti-racist, not because he should not be a hypocrite.

Second, if the 'inconsistency' of a hypocritical avowal is what gives rise to 'silencing', then removal of that inconsistency would remove the disqualification of moral authority. But someone who says 'I know I've done the same as you but you shouldn't have done that!' doesn't obviously preserve the authority of their moral voice simply because they admit their own failing. To be sure, there may be occasions on which concessions of tu quoque or co-responsible liability restore an authority originally lost by whatever has given arise to that liability. But not any breezy old admission will let one off the hook; the deceit that is present when there is no such admission may be removed, yet that is not always sufficient to avoid being 'silenced'.

Third, 'silencing' is often manifest even when there is no disjunction between an individual's criticism and his principles. It is not always the case that a 'silenced' agent is a hypocrite in the strict sense of not actually applying to himself a principle that he professes. Imagine a militia group has captured a town and its leader offers the mayor a choice: to spare his own life the mayor can select 100 women and children for execution, or he can spare the lives of everyone else in the village if he accepts execution for himself. The mayor chooses to spare his own life, and 100 other people are accordingly murdered. The militiaman then says to the mayor, 'You coward! You chose the wrong option. Morality requires you to have sacrificed yourself'. He then adds, and he means this quite sincerely (because in his own perversely dutiful way he is not himself afraid of death), 'I would have willingly given my own life to spare the women and children'. In condemning the mayor, then, the militiaman is not criticising him for acting in a way that he would also have done in like circumstances: he is prepared unhypocritically to practice what he is preaching in this instance.

Note that it is not the case that it is inappropriate for anyone to criticise the mayor's choice. We could still say that, objectively, he made the wrong choice. Terrible though the choice forced upon him was for him, that it posed demonstrably non-equivalent evils significantly qualifies the genuinely tragic nature of his dilemma and opens up the space for agent-independent moral critique. 
Using this example, here, then, is a sketch of the 'silencing' diagnosis: we could say that the militiaman is 'silenced' not because he wouldn't have done what morality requires in situations such as that confronting the mayor but because he is not more generally committed to morality at all. He has no business pretending to be concerned about whether the mayor does what morality requires because his own actions show that he is not genuinely bothered about whether the mayor lives according to morality's requirements or not. We might still want to say that there is hypocrisy of a kind here - but only because it is specifically at the level of the general commitment to morality. The militiaman's critique of the mayor is not based on any genuine commitment to living by moral principle. He would not otherwise have put the mayor in such a tragic dilemma.

\section{Commissive discourse}

Possibly contributory as to why there has been a failure to theorise the 'silencing' dimension of moral discourse is a tendency to think that such discourse is only purely locutionary, merely descriptive of what is the case from the moral point of view. Sometimes, of course, it is: two moral philosophers might argue over what morality says about a situation which is quite abstracted from their own experiences without having to care about doing the right thing in the situation themselves. But the 'silencing' we are examining occurs in a particular type of interpersonal moral discourse, where the discursants are directly passing judgments on each other's moral beliefs and behaviour. So the diagnosis of 'silencing' must say that the agent-independence of the moral point of view does not mean that those who give voice to it in interpersonal discourse can legitimately do so as insincere purveyors of its judgments and still be regarded as engaged in genuinely moral discourse. Engagement in such, to be genuine, successful and authoritative, must be expressive of a sincere commitment to morality's precepts on one's own behalf: one has not adopted the moral point of view, or given true voice to morality, if one merely parrots what morality says about a particular situation, not really taking it seriously for oneself.

Thus, interpersonal moral judgment is best conceptualised as a form of commissive discourse. It is not quite the same as the standard form of commissive speech act, which is specific in its commitment: for example, when one says 'I promise to do X tomorrow', one is thereby - by the mere utterance - undertaking specifically to do $\mathrm{X}$ tomorrow. What we have here is more generalised in content - if you engage in moral blame and praise, you are not thereby undertaking to do any act in particular, but you are committing yourself to live by morality's precepts in general - but its form is essentially the same. Hypocrisy and other forms of disinterest in, or disregard for, the commitment to morality actually robs the judgment of its moral character and that is what makes it so inappropriate for the person to mouth the words of that judgment. People who are liable to tu quoque and/or co-responsibility ripostes manifest this essential indifference to morality and are therefore not in a position to be entitled to make moral criticisms. And although not necessarily undermined altogether, morality 
may be tarnished when its articulators are not themselves sincerely supportive of it, much as it might be thought, in a partly parallel way, that the law's authority is besmirched when, say, lawmakers and judges fail to respect it.

\section{Discourse friendship}

If we adopt this account, we commit ourselves to the ideas that: (a) a moral discursant has, or should have, a particular kind of relationship to morality which requires its project to be her project; (b) we should treat our moral interchange with our fellow discursant as expressive of a joint commitment to live morally which therefore frames a particular relationship between us.

But we should now confront a somewhat different way of reading the militiaman story, utilising some elements from Stanley Cavell's theory of morality which partly issues from a critique of C. L. Stevenson's emotivism. For Cavell, Stevenson is committed to saying that, in support of a moral claim, any kind of statement a speaker makes with an eye to altering the sentiments of the hearer must count as morally relevant. But Cavell thinks this completely misdescribes what kind of support is actually relevant for a moral claim: moral discourse is of a very particular kind, governed by certain specific rules which are far less permissive than those implied by emotivism. Indeed, the emotivist fails to understand morality by thinking that it is about the manipulation of attitudes.

A disillusionment about morality as conceptualised by emotivism arises from being told that one may treat me morally and yet act only in terms of his attitudes, without necessarily considering me or mine. If this is so, then the concept of morality is unrelated to the concept of justice. For however justice is to be understood - whether in terms of rendering to each his due, or in terms of equality, or of impartiality or of fairness - what must be understood is a concept concerning the treatment of persons; and that is a concept, in turn, of a creature with commitments and cares. But for these commitments and cares, and the ways in which they conflict with one another and with those of other persons, there would be no problem, and no concept of justice (Cavell 1979: 283).

Whereas the 'silencing' account presented thus far proposes that it is a failure to care about morality in general that 'silences' a moral critic, this passage suggests that we focus instead more directly on the particular relationship between the critic and the criticised. Proper interpersonal moral judgment could then be framed not by a shared commitment to morality in general but by a very particular focus on each other's cares and concerns. The relationship is not mediated by the commitment to (agent-independent) morality as it is in the other depiction of the scenario. An analogy: moral criticism according to the initial account is akin to my criticism, as lead violin, of your violin-playing being premised on our joint commitment - justifiably inferred from the fact that we both belong to it - that the orchestra plays well, through which arises my concern that you personally play well. The 'Cavell' account is akin to my criticism arising directly from my prime concern that you, qua individual violin player, want to play your instrument well. Defenders of this account might say that their position 
provides the more emphatic demonstration of how the agent-independence of the moral point of view does not translate into agent-indifference on the part of those who give voice to it in concrete situations. So, in response to the 'silenced' critic, they may want to say we should meaningfully replace 'you have no right to say that!' with 'what do you care?'.

The 'Cavell' account suggests that, ideally, a moral interchange would betoken a form of friendship between the discursants, even, or perhaps especially, when it is critique that is being exchanged. The friendship need not be as intense or as engaging as platonic love, in which friends selflessly care for each other and their projects more comprehensively. And, although it does not require us to give up on the agent-independent conception of morality, this account is clearly moving close to the more agent-dependent versions of the ethic of care. Its strikingly agent-engaged conception of moral judgment seems to share the latter's view of morality as immediately particularistic.

Supporters of this account may also argue that it could take agent-engagement more seriously in another way, too. Hitherto, the overall analysis has been rather one-sided in its concentration on the critics who are liable to tu quoque and coresponsibility ripostes. It is flaws in their declamations that matter in 'silencing'. But it is, after all, the criticised who utter the ripostes, who experience the 'silencing' and it might be thought only appropriate that they figure rather more proactively in the explanation of how criticism of them may be deflected. In looking at the relationship between the critic and the moral point of view, the first account - so it might be thought - unfortunately diverts our attention from the person who actually suffers the misplaced criticism.

\section{Respect}

In one of the rare pieces in analytic moral philosophy that discuss this topic, Gerald Dworkin claims that 'silencing' is induced by the loss of respect that the criticised has for a tu quoque/co-responsibility-liable critic:

The sanctions of morality ... operate effectively only when they resonate with the person being sanctioned. (The criticism) must come from a source whose criticism I care about. It is because the criticism causes me to lose status in the eyes of the person who makes the criticism that it moves me.... (But) (w)hen the person who calls attention to my character fault suffers from the very same fault, this puts him on a par with me - with respect to this fault at least. If I lose respect in his eyes because of the presence of this fault, he must lose respect in my eyes as well. But this means that I do not care as much whether he disapproves of my conduct. And this means that the criticism cannot be as effective as it normally would have been.

(Dworkin 2000: 187)

Moral criticisms might fail for numerous reasons, including a lack of care for the specific agent in question and the loss of respect that an agent may experience 
for their morally impugned critic. True to the spirit of agent-engaged concern, the nature of the specific relationship crucially matters when determining which 'failure' reason is the most significant in any one instance. But even if it is not always the most important of the reasons why a critic is 'silenced', I maintain that the care/personal respect type of account may not always focus clearly on a key 'silencing' factor.

For example, and against Dworkin's diagnosis: it is doubtless true that someone who has occasion to fire back a 'silencing' riposte to a moral critic may thereby also signal a loss of respect for the critic. But it is not clear that respect necessarily disappears in such instances, not least because the respect that one may have for one's moral critic may be founded on more than just our appreciation of their moral utterances. Such respect is often hard-won on a number of fronts and does not therefore always vanish on the basis of infelicitous criticism alone, as seems to be implied by Dworkin's account of it. That does not mean the critic should not be regarded as 'silenced' on this occasion. I can still respect you whilst thinking that you do not have the right to criticise me on this score.

More generally, we should recognise that 'silencing' has another kind of agent-independent characteristic which significantly downplays the importance of the agent-engaged notions of personal care and respect in explaining it. Sure, we want to say that an impugnable critic has no right to criticise even when the objects of their criticism do not, for whatever reason, recognise this for themselves. Third parties are, ceteris paribus, as conceptually enabled and as morally entitled to pass 'silencing' judgments and it is often morally and politically crucial that they do so on behalf of the quiescent criticised. To see the importance of this, think of the power that overdogs can exercise over underdogs in stifling their voices: the latter are sometimes rendered incapable of fully grasping the circumstances of their own oppression and may indeed continue to have respect, perhaps even love, for their oppressors. In no way does that render a moral criticism by the overdogs of something done by the underdogs any less problematic, even if it requires others to say so on the latter's behalf - duped as they are by misguided sentiments and beliefs about their oppressors. A focus on personal attitudes and relationships in the propriety of moral discourse cannot properly account for this kind of situation.

\section{Concern for morality}

It is anyway evident that not all moral discourse requires discursants to care about each other in some quasi-platonic manner. The moral condemnation of a genocidal maniac hardly seems to presume any particularly strong idea that one cares directly, immediately about that person: all that matters is that we care that they should have done what morality requires of them, as it does of anyone else. (Indeed, in this kind of case, it is, apart from anything else, probably futile to care for the maniac in the sense that you want them hereafter to change their ways, a concern or hope that probably lies at the heart of a lot of 'care.') So the lack of such care should not be thought central to the general diagnosis of 'silencing'. 
Another drawback with the 'personal care' account is that it bears its main superficial appeal only with respect to co-responsibility. It has far more obvious problems with tu quoque, for the critic in this instance can quite easily have very deep personal concern for the cares and commitments of the criticised, without that having any bearing on his (lack of) right so to criticise. What she feels for the criticised person is essentially irrelevant to the moral fault that neuters the criticism. We should not be misled by phrases such as 'interpersonal moral judgment' into thinking that we should have what we would conventionally understand as 'personal relationships' with all those with whom we enter into moral dialogue. For example, 'silencing' has significant bearing on the propriety of moral discourse in the political realm, in which politicians probably often lack the right, on 'silencing' grounds, to say the things they say in criticism of others. It is surely wrong to think that such politicians would only have that right on the basis of a personal care for the commitments of whoever they criticise beyond the commitment that they, and everyone, should act morally, which I am arguing they have to embrace if their moral judgments are to be authoritative.

Now, what is being proposed here may not be quite the austerely impersonal mode of moral engagement, as, say, critics of Kantian moral judgment often accuse it of favouring. There is some conception of agent-engagement (or, perhaps more appropriately modestly agent-sensitivity): the unimpugnable moral critic effectively treats the criticised person as being with her, together, in the project of trying to live morally. And, to reiterate, some morally discursive relationships will rightly place higher premiums on 'care' and 'respect' in the granting or refutation of moral authority, where such feelings are already in place as the basis of personal relationships. But the concern for morality in general, as identified by the first account, is the relevant common denominator among these instances and is the sole factor in many other types of moral discourse - so it is the factor that I propose we should use to diagnose 'silencing' in general.

\section{Co-responsibility}

I now consider who can be said to have what degree of relevant co-responsibility when working out the appropriateness of the co-responsibility riposte. The issue subdivides into these two questions: (A) what degree of co-responsibility is required to cancel the authority of a critic's moral voice? (B) How do we conceptualise 'responsible agency' to identify who might fall into the co-responsible category?

(A): It is obviously not difficult to think of ways in which a critic can have co-responsibility for the actions of the agent he is criticising. But surely not every degree - even the vanishingly small - can count as sufficient for 'silencing'. If we consider again the catalogue of possible variants of the coresponsibility riposte, we can readily judge that some of them implicate the critic far more seriously than others: 'you ordered me to do it' is more damning than 'you asked me to do it'; likewise 'you left me with no reasonable alternative' could be more serious than 'you gave me the means to do it'. 
We must not overlook the question of the victim's moral responsibility altogether when assessing her critic's own responsibility for her behaviour. The appropriateness of the critic's admonition may well vary according to the degree to which the victim was constrained into doing what she did by the critic. Suppose Jones, who I know to be notoriously work-shy, borrows $£ 500$ from me having accepted my greedily exorbitant interest rates. To meet my demand for repayment, he mugs someone. In response to his 'you-gave-me-no-choice' response, I point out, accurately, that there are plenty of jobs he can take to help him earn enough money to pay off the debt, he can cut down on his beerdrinking to save money, and so forth. I am aware of Jones' deep-seated reluctance to pursue these alternative debt-settlement strategies but is that necessarily sufficient to make me meaningfully co-responsible for his having mugged someone? Surely there must come a point in certain situations where the coresponsibility riposte simply fails to shift a sufficient degree of responsibility back to the critic for the failure to pursue a morally decent alternative to the immoral action which was actually performed.

The riposte succeeds in general only when there is a sufficient degree of coresponsibility to excuse whatever it is that the co-responsible critic is criticising. Someone may be excused for doing something when there are mitigating circumstances for that something which in fact they shouldn't have done. Their responsibility is in some way considered diminished, although it has not evaporated altogether. One can still make the judgment that they should not have done what they did, but our criticism of them is lessened because of the circumstances in which their decision to act arose. So, perhaps in some circumstances it is because somebody else has a degree of responsibility for making someone do what they did that an excuse is available, and its presence is what makes 'silencing' work with respect to that other person. But some people do things that are so awful that they cannot be excused, even when there is some degree of coresponsibility present. 'Excusability' can cover only a certain degree of $\sin$.

These remarks hardly provide us with a clear metric for (A) (how to work out 'sufficiency', for example?). But I venture that it is more determinate, at the current juncture in our understanding of 'silencing', than what we may obtain for (B). What it means to be 'responsible', both for one's own character and behaviour and for how that behaviour may affect the thoughts and actions of others, appears to be inherently liable to profound dispute; so, too, then, are the definitions of 'responsible' - and therefore 'co-responsible' agency. Some venerably perplexing debates in philosophy are packed in here: the possibility, nature and scope of free will, individualist versus collectivist methodologies in the explanation of social interaction, the moral weightings of actions and omissions in the ascription of responsibility, for example. Politics, again, probably exhibits the starkest of the practical controversies here: think of the myriad disputes over the extent to which individuals are held somehow liable for the actions of collectives to which they belong but in which they themselves played no part, and whose decision-making bodies they may have opposed. (Think, for example, of the argument that citizens sometimes share responsibility for what 
their state does simply by virtue of the fact that it is their state, regardless of their individual attitudes and actions, or inactions, with respect to the matter at issue.) It is difficult to think that we would always be able to agree on the relevant criteria in these regards, and this might seem to pose a major problem for giving 'silencing' any extensive practical application in operationalising the idea of 'genuine moral discourse'.

\section{A modified proposal}

Does the inconclusiveness of our attempts to 'measure' tu quoque and coresponsibility indicate deep problems with this whole theory of moral discourse? It is too soon (because of the brevity of the above) to leap to this judgment. But let us now pause to consider how literally we should take the idea of being 'silenced'. It is not for nothing that 'silencing' has hitherto been wrapped in inverted commas: it is, in a profound sense, intended metaphorically. For, as some of the above examples already suggest, tu quoque and co-responsibility do not always mean that one should have literally desisted from making the moral criticism. Consider more carefully the biblical story of casting the first stone, mentioned above. The crowd who wish to stone the adulteress believe themselves to be sincerely enacting Moses's law. But Jesus tells them that is not enough to justify them in so acting, for they too are not without sin. And they learn from this, 'convicted by their own conscience' (John 8: 3-12).

If we are indeed to learn about ourselves and where we stand when we engage in moral discourse, and especially if such discourse is potentially transformative of our standpoint, then it may actually be better for discursants liable to valid $t u$ quoque and co-responsibility ripostes to air their criticisms for their infelicity to be exposed. To be 'silenced' in this regard would, then, still mean loss of authority in judgment of others - but without there necessarily being any implication that 'lack of authority' mandates nothing but literal muteness.

Here, we must distinguish between a critic who is simply manifesting incompetence in moral argument, and who has failed to appreciate what it means to be committed to morality, and one who, like the militiaman, is cynically using moral discourse when he quite consciously has no essential interest in it. We might propose, as a rule of thumb at least, that the latter's actions are rendered no less appalling by him daring to speak the language of morality in the course of his crime. But for the former it is less clear that 'silence' should in general be taken at face value. Sometimes, of course, someone in such a situation might nevertheless cause such offence when they open their mouths in criticism, with no sufficient good resulting, that they should have remained silent, all things considered. But, far from saying that 'silenced' discourse should never be uttered, sometimes perhaps often - it should be so, for important reasons connected to a crucial point about the whole business of interpersonal moral discourse.

This is where we may take up another proposal modified from Cavell. If one is aspiring to give voice to morality, and thereby expressing one's own commitment to it, one may be effectively saying something about oneself when that voice is 
actually given. Participation in moral discourse is partly a process of selfdisclosure, as the discursant seeks to establish where she herself stands as much as she is passing judgment on another in striving to articulate the moral point of view. And when someone challenges that judgment with a tu quoque or co-responsibility riposte, they may be forcing her to re-evaluate her position. Cavell places particular emphasis on this because - and he surely has a point here - the commitments of even the most sincere moral agents are sometimes opaque to them. Such ripostes could, then, be part of a collective effort, implied by the commitment to morality, to uncover and clarify, and perhaps revise, moral positions. The rightly criticised person clearly has something to learn, but so does the impugnable critic. Thus, in Cavell's conception of 'moral perfectionism' there is, centrally, a 'moment of encounter, or challenge' in moral reasoning (Cavell 2004: 42): that we are ourselves often confused (even when we think we are not), that we need to sort out such muddles in a moral encounter with others, and that for us to encounter another with her confusion or shortfall with respect to morality requires the justification of our own moral standing with respect to her:

[q]uestioning a claim to moral rightness ... takes the form of asking 'Why are you doing that?', 'How can you do that?', 'What are you doing?', 'Have you really considered what you're saying', 'Do you know what this means?'; and assessing the claim is, as we might now say, to determine what your position is, and to challenge the position itself, to question whether the position you take is adequate to the claim you have entered. The point ... is to determine what position you are taking, that is to say, what position you are taking responsibility for - and whether it is one I can respect. What is at stake ... is not the validity of morality as a whole, but the nature or quality of our relationships to one another.

(Cavell 1979: 268)

As a commissive discourse, moral judgment requires us not only to appreciate that we are committing ourselves to the project of leading moral lives when we make such judgments but that we are also therefore taking responsibility for the judgments we make in its name. For Cavell, moral arguments are 'ones whose direct point it is to determine the positions we are assuming or are able or willing to assume responsibility for' and the rationality of moral argument 'lies in following the methods which lead to a knowledge of our own position, of where we stand; in short, to a knowledge and definition of ourselves' (Cavell 1979, 312).

In fact, then, the criticised agent may not even want the last word when she says 'you have no right to say that!'. In line with this function of moral discourse, she might follow that up with explanations as to why that right is denied, which are intended to force the critic to reflect on his own standpoint and thus perhaps invite his continuation of the discourse. To be sure, he may have plenty to say in asserting his right to criticise - and he might, of course, succeed if what he says is genuinely concessive, or if we accept, as sufficiently authorityestablishing, the akratic statement: 'I know I'm weak-willed and do X, but X 
shouldn't be done and you shouldn't have done it'. (A bluntly petulant 'Do as I say, not as I do!', for example, probably has deservedly much less chance of succeeding in this regard.)

\section{Conclusion}

In sum, the tu quoque and co-responsibility ripostes could often be really continuations of, rather than abrupt halts to, the moral exchanges which begin the process of identifying the immorality of the position taken by the person to whom they are directed. Perhaps, in some circumstances, it is an unsilenced criticism that in effect brings the discourse to an end (proffered apologies notwithstanding), as the criticised has nothing to say in riposte. Central, though, is the idea that one learns about the propriety of moral discourse: learning when to be 'silent' is part of this process, and it cannot properly be legislated in advance of actual moral engagements.

And here is a reason why we may have to worry much less than might first be feared about the indeterminacies in abstractly working out the metric applications of 'silencing'. Bringing the discursive activity to the fore of our analysis yields an overtly embraced open-endedness in judgments about the appropriateness of specific ripostes that we cannot, and should not, expect any theory to close in abstraction from concrete situations and discursive encounters. To be sure, the moral philosopher can reflect on these and draw some generalised rules of thumb, as I attempted to do in a small way earlier (and I do not intend the foregoing remark to presume that no more constructive philosophical reflection on these matters is possible). But, although the moral philosopher can usefully assist us in this regard, as moral agents we acquire the competence in moral argument by our own experience of such encounters. These are the main sources, in this regard, of our moral knowledge - of our moral self-knowledge - and we hope to gain a modicum of expertise when we more fully appreciate what commitment to morality requires of us as authoritative moral critics. For those critics who do not see this point, or who are anyway uninterested in morality when they pretend to be, the 'silencing' ripostes alone are unlikely to shut them up. Even then, however, the ripostes will still, as justified rhetorical devices, help us to discredit them in our eyes and those of others such that, whatever other harm these critics do, the moral voice will not be drowned out by their cacophonous insincerity.

It might be objected that the foregoing has still, despite all of the arguments on 'moral sainthood' aired thus far, rendered the whole business of morality and moral discourse just too demanding. And here we can turn again to the political world, where it is I think obvious that my analysis has an especially powerful resonance. Consider what some might call the 'Machiavelli objection', which wants to teach us that politics too often requires its practitioners to do what is formally wrong in pursuit of politically justified goals (even if couched in the language of morality) and that, at best, politicians are faced with the need to identify the least of the evils which exhaust their range of possible actions. 
Furthermore, their effectiveness as politicians could be fatally compromised if they were openly concessive about their relationship to morality: the kind of moral dissimulation condemned in the present analysis is actually a crucial political tool. On this analysis then, political critique between politicians, and between politicians and citizens, will inevitably include people who would fall heavily foul of 'silencing'. The above account would thus seem necessarily to impugn much that will always, unavoidably, be the lifeblood of politics.

Yet there is a crucial difference between an ability to live up to morality's demands all the time and a wholehearted commitment to morality: the former may well be very difficult, but the latter is much less so. Do we really want to say that, in the absence of genuinely mitigating circumstances, moral commitment can quite acceptably be a half-hearted affair? Having invoked considerations bearing on the political realm in the present discussion, we might particularly press this question on politicians who, whether they are Machiavellians in the colloquial sense or not, will typically invoke the language of morality in self-justification. Particularly in light of whatever power over others they have at their disposal, it could be acutely important for citizens to hold them responsible according to the moral standards they profess: the levying of an ethic of responsibility, perhaps, in a quasi-Weberian sense ('quasi' only in the sense that this ethic ties the politicians, by dint of their employment of moral discourse to an ethic of ultimate ends more than Weber himself explicitly considers) (Weber 1991: 120-1).

What moral commitment requires of all of us, though, in some degree - and it is commitment, rather than ability, to do as much as we can for the project of morality that is being insisted upon here - is that we acknowledge, frankly, our moral failings and inabilities. We do not neglect them or, just as bad, adapt our conception of morality's demands to accommodate our failings so that they cease to be conceptualised as such. We reaffirm our commitment to morality in such critical self-reflection, whether we voice the latter in debate with others or, sometimes more readily, to ourselves in some still moment of solitude. And, insofar as we do so sincerely, we may earn ourselves the right to speak with an authoritative moral voice when we judge the beliefs and actions of others: it should not be considered an automatic entitlement. It does indeed matter much what manner of people we are who deign to be the voice of moral judgment, for even if the moral point of view is independent of our particular attitudes we are nevertheless the only ones through whom it ultimately speaks. No less than the integrity of morality itself could be at stake. ${ }^{1}$

\section{Note}

1 I am very grateful to the late Jerry Cohen for sending me, when I first worked on (a very early version of) this piece, what were then an unpublished lecture and related writings, and for the encouragement he gave me on reading what I initially produced. My sincere thanks go also to my colleagues on the ECPR project out of which this volume emerged and, especially, the supererogatory indulgence of the editors who should not have had to put up with the delays my efforts caused. 


\section{Bibliography}

Cavell, S. 1979. The Claims of Reason. Oxford: Oxford University Press.

Cavell, S. 2004. Cities of Words: Pedagogical Letters on a Register of the Moral Life. Cambridge MA: The Belknap Press of Harvard University Press.

Cohen, G. A. 2013. 'Casting the first stone: who can, and who can't, condemn the terrorists?' In G. A. Cohen, Finding Oneself in the Other. Princeton University Press, pp. 115-33.

Dworkin, G. 2000. 'Morally speaking' In E. Ullman-Margalit (ed.), Reasoning Practically. Oxford: Oxford University Press, pp. 181-8.

Shklar, J. 1984. Ordinary Vices. Cambridge MA: Belknap Press of Harvard University Press.

Weber, M. 1991. 'Politics as a vocation'. In H. H. Gerth and C. Wright Mills (eds), From Max Weber: Essays in Sociology. London: Routledge, pp. 77-128. 


\title{
4 What can we learn about political corruption from Kant's conceptions of honesty, publicity and truthfulness?
}

\author{
Doron Navot
}

\section{Introduction}

The aim of this chapter is to examine the conceptualization of political corruption on the basis of a critical reading of Kant's conceptions of honesty, publicity and truthfulness. The hope here is to contribute to the ongoing attempt to make the concept of political corruption more suitable for the study of democracies by critical engagement with Kant's political theory and these specific conceptions. A secondary aim is to shed some light on aspects of Kant's political theory that seem to be neglected in the literature about political corruption and in the more "realistic" texts that criticize Kant.

My original intentions were different. As a scholar whose main interest is political corruption, I wanted to examine if there was anything worthy to be learned about political corruption from Kant's claim that there is a legal duty not to lie. My first intuition was probably similar to that of the scholar who is interested in Kant but not an expert of him; I thought that we can hardly take seriously an argument that we do not have a right to lie, even to a would-bemurderer who is seeking his victim, but I also considered that there must be something profound in such an incongruous idea. Nevertheless, the deeper I dug the more I realized that a better approach might be to consider also his understanding of honesty and publicity in Perpetual Peace (Kant 1991[1795]). More specifically, I found it interesting that in Perpetual Peace Kant expressed a realistic approach to politics, while in his notorious essay "On the Supposed Right to Lie out of Philanthropy" (Kant 1996[1797]) he expressed a rigorist approach that does not seem to be realistic at all.

Moreover, it seems that, especially in Kant, like in Cicero before him, but in contrast to contemporary writers, realism and moralism are not mutually exclusive. That is, while Kant's program in Perpetual Peace is considered to be suitable even for a nation of devils and not only for "reasonable people," he requires that politics bend the knee to morality, and his writings defend the moral politician. If I am correct, then, Kant's conceptions of publicity and truthfulness may have even more value for thinking about political corruption than one could think. Accordingly, it may be worthwhile to ask the following questions: what are the relations between the idea that agents have a duty not to lie and the duty 
to make their principles public? What can they tell us about Kant's political theory? What can they tell us about the subject of sincerity in politics? Shall we, in the end, adopt Kant's conceptions when we think about political corruption in contemporary democracies?

The chapter suggests two major claims. The first claim is interpretive. I argue that both propositions about truthfulness and publicity are related to Kant's deep suspicion about human motivations and about our ability to know what motivates others and what motivates us, as well as to his belief that "the problem of setting up a state can be solved even by a nation of devils" (Kant 1991[1795]: 112). Put differently, Kant's conceptualization of honesty, publicity and truthfulness is influenced not only by his uncompromised commitment to the creation of a rightful condition, but also it is shaped by his suspicion towards human motivations, on the one hand, and his optimism about institutions and their capacity to direct human behavior with external incentives, on the other. My second claim is normative. Assuming that my first argument is correct, I argue that this is not a good approach for conceptualization of political corruption in contemporary democracies. As an alternative I suggest a neo-Kantian conception of political corruption, that shares his commitment to the ideal of equal worth of persons, but not his optimism about institutions.

The chapter proceeds as follows. In the second section I shall present Kant's conceptions of truthfulness and publicity and put these in historical and philosophical context. I suggest that Kant's conceptions and conceptualization are part of a more general idea that there are principles with no exceptions in politics. Kant requires not only truthfulness but also strict application of principles and duties. Such a position is more plausible if we consider it as part of a larger attempt to promote republics at the expense of monarchies, in an age of optimism about enlightenment, progress and institutional design. In the third section, I present recent conceptualizations of political corruption. While they are importantly different, all have reservations about Kant and all share his most important political ideas. In the fourth section, I suggest an alternative for recent conceptualizations of political corruption. My conceptualization is not based on democratic principles such as publicity, as Thompson suggested, or on the idea that corruption necessarily involves deception, as Warren suggested; rather, my conceptualization is based on the idea that political agents, whether politicians and public agents or not, should be motivated not only by their private interests but also by the desire to respect other people's right to be their own masters. This is a Kantian moral idea, and the reason why Kant did not adopt it will be further clarified in the concluding section.

\section{Kant on honesty, publicity and truthfulness}

In the last decade of the eighteenth century, under the influence of the French Revolution, questions about principled and radical politics had immediate impact on the future of Europe. It was also then that philosophers were discussing the meaning of progress and humanity, and the role of reason and freedom in human affairs. 
In Perpetual Peace Kant argued in favor of honesty and publicity: "Honesty is better than any policy" (Kant 1991[1795]: 116). Soon afterwards he emphasizes the importance of publicity: "all actions affecting the rights of other human beings are wrong if their maxim is not compatible with their being made public" (Kant 1991[1795]: 126). That is, publicity is important as a device against the abuse of public power. For example, attempts to promote one's private gain at the expense of other citizens, he argues, cannot be made public. The public would refuse to accept them. And if they can be made public, then this is an indication they are legitimate. This proposition is akin to the idea of "reasons that all can accept," although it is more specific and it emphasizes the external, public element of action.

One year later, Benjamin Constant published a pamphlet, in which he argued that, if everyone adhered strictly to the principle of telling the truth, all society would become impossible. Constant wrote and published his pamphlet in conditions of growing distrust in France, as a result of the terror and violence, during what are known as the "post-revolutionary years." For Constant, under such conditions, a moral person had to learn how to do things that under normal circumstances would be regarded as immoral, such as lying (Holmes 1984: 108). Politically speaking, Constant took a stand against the more democratic principles of the revolution and in favor of the political claims of the Directorate (Benton 1982: 139). Therefore he also argued that there was no duty to tell the truth to someone who has no right to hear it: "Where there are no rights, there are no duties. To tell the truth is a duty, but only to those who have a right to the truth. But no one has a right to a truth which injures others" (in Kant 1996[1797]: 611).

Constant also blamed "the German philosopher" (referring to Kant. according to the editor of Constant's pamphlet [Paton 1953]) for arguing that we have no right to lie even to murderers. Indeed, Kant was in favor of the French revolution, and as we saw he was taking a firm stand in favor of honesty and publicity. But he had never argued such an extreme assertion before the publication of Constant's pamphlet. Nevertheless, Kant was willing to advocate this radical position of not telling lies whatsoever. In the notorious essay, Kant maintains that the moral law against telling lies can admit of no exceptions whatsoever: "[T]he duty of truthfulness [...] makes no distinction between persons towards whom one has this duty and persons towards whom one has not this duty. Truthfulness is a duty unconditionally - a duty which holds in all circumstances" (Kant 1996[1797]: 614).

The duty not to lie holds even when the outcome of telling the truth would be, almost with absolute certainty, the death of innocent people. This is such a depressing and cruel idea that some Kantians suggested that it shows that Kant would not have tried to defend such a position, had he not been advanced in age. It was the confusion that came with age that led him to believe that Constant was blaming him for something that he had written, although he had not, and it was only pride (which also comes with age and perhaps professional habits), which made him defend something that he did not have to, and actually could not, 
defend (Paton 1953: 202-3). But it is also possible that Kant's "confusion" reflects something else, namely, that he could have agreed with the idea that Constant ascribed to him (Benton 1982: 138). I shall suppose, then, that this is the major reason that Kant wrote the article. This is also the best way to interpret it, if we want to consider Kant's conceptions of honesty, publicity and truthfulness. More accurately, what is of interest for us is whether certain interpretations of these notions are of use for discussions of political corruption.

There are differences among honesty, publicity and "not lying whatsoever". Honesty is a subjective disposition, or an attitude, that reflects not only the true values of sentences as the agent conceives of them, but also his authentic willingness to share his understanding. Most importantly, honesty has an intersubjective quality. To ask for honesty is also to be given the space and autonomy not to say anything. Sometimes not talking is a sort of honesty. Honesty is not necessary telling the truth.

Publicity is also distinct from the virtue of not telling lies. As Dennis F. Thompson (1999) suggested, the publicity principle is consistent with secrecy, and even with lying. As long as the political agent hides his actions or lies for the public (as in cases of foreign affairs), the secrecy is temporary and his actions are under a certain kind of surveillance and procedures, the principle of publicity, or the core of the ideal of publicity, is observed.

Telling the truth or not lying, on the other hand, is something more technical. One can avoid lying without being honest. Indeed, this is what sometimes the misleader does. Under certain conditions, the requirement of honesty is more demanding compared with the requirement of truth telling. More accurately, sometimes one simply cannot require honesty. A murderer, for example, can require hearing the truth. There is nothing unreasonable if he requires hearing the truth and no lies. He may also use brute force to extract the truth, or to enforce on the agent the requirement of avoiding lies. But he cannot use brute force to achieve honesty. It would be unreasonable to expect honesty when torturing someone, for example. The upshot of all this is that the requirements of publicity and honesty that appear in Perpetual Peace are different: they are weaker and more reasonable than the requirement not to tell lies no matter what. This is clearer if we consider that the duty not to lie is not correlated to the allegedly right of the would-be-murderer for the truth, for, according to Kant, he has no such right.

But why is being truthful so important? What makes telling lies wrong, if no specific person is wronged? Kant's answer is that telling lies wrongs humanity in general. It does so by (i) corrupting the language (which is source of right or the united will), (ii) transgressing the duties of truthfulness and of publicity that comprise the form of the united will, and (iii) violating an unconditional duty of truthfulness that is the juridical condition for the unification of wills, especially by contracts (Weinrib 2008, 156). It is not only the violation of dignity - we are not dealing here with ethics or virtue - but of the basis for any rightful condition. The pre-condition of the rightful condition is what is at stake in the imperative of not lying. 
Nevertheless, such a position is still not entirely reasonable. First, can it be argued that the would-be murderer makes the rightful condition impossible; that his murder makes honesty and truthfulness a chimera? Second, Kant presupposes that we already live in a rightful condition, and what's more interesting, that France or at least most of the countries in Europe in the 1790s live in a rightful condition; one can wonder how accurate such a description is even today for the countries in which we live. Third, we shall not accept the idea that language could be so easily corrupt, an idea presupposed by Kant's argument; such a position towards the effect of lying on language, or towards speaking and words, seems to be more mystical than rational, like a relic of religious beliefs (Williams 2002). Language is not something so corruptible. Furthermore, the possibility of lying exists whether or not someone told a lie to a would-be murder, and this possibility is what makes the pre-condition of the rightful condition fragile.

To see this, we can compare telling a lie to a would-be murderer with another situation that Kant mentioned in Feyerabend Lectures: giving a counterfeit bill to someone who sells a blind horse (and the seller tries to hide this fact). Indeed, when one gives counterfeit money to a person to whom one is not indebted, one does no wrong to him. The problem is not between these two persons but rather with the fact that by passing counterfeit money, one endangers the possibility to live in a rightful condition. As Weinrib explained,

The counterfeiter does wrong by using money, the public means of exchange, in a manner that is inconsistent with its publicity. Similarly, the liar does wrong by using language, the means through which wills are united and rights proceed, in a manner that is inconsistent with its publicity.

(Weinrib 2008: 152)

Nevertheless, the analogy between counterfeiting a bill and telling a lie is not appropriate. Lies do not have the material existence and the persistence of counterfeit bills. A lie to a murder is not necessarily circulated in the way in which bills usually are.

Therefore, I suggest three intertwined and complementary ideas that make, I believe, Kant's approach more sensible, although not necessarily more acceptable. Both are related to the impact of the Scottish enlightenment on his political theory, but also to Kant's religious beliefs. The first idea is that people as such are not trustworthy. They are inclined to advancing their own well-being. They are egoistic and self-centered. From Kant's point of view, if you let them decide about making an exception, such as lying to a murderer, they will probably abuse this allowance and think on other occasions as well that they can make an exception to the principle of not lying and justify in this way the violation of a principle. The problem of slippery slope is so acute in human affairs that nothing but strict compliance is enough.

The second idea is that humanity has reached a point where institutions can provide incentives for a rightful behavior (although not necessarily a moral 
behavior). Kant sometimes called it the cunning of nature or providential order. ${ }^{1}$ That is, we do not need to presuppose that people are good to organize society in a rightful condition. We only need to assume that people are rational. The virtuous agent is not needed nor the public official who is inclined or motivated by the public good. It is enough that society would have the right institutions. Part of this institutional turn are the formal principles of honesty, publicity and truthfulness. Relatedly, philanthropy is not important.

Lastly, Kant was very suspicious not only about human motivations but also about the ability to know what motivates us, not to mention what motivates others. Probably for these reasons he did not forbid misleading but forbade lying, even though the liar and the one who misleads are motivated by a similar or maybe identical motivation, and the effect of their behavior is basically the same (or worse in the case of the misleader, who actually and by definition succeeds in his attempt, while the liar does not necessarily succeed). This is another reason to think about right and wrong in politics as violations of formal principles, and not as things someone does out of selfish motivation.

Now let us think about political corruption via Kant's conceptions and conceptualization. Assuming that the core of political corruption is the misuse of public power for private gain, our mission is to develop a Kantian conception of this notion. We can actually develop two conceptions of political corruption. First, we can conceive political corruption as a wrong done to humanity in general or to a public right, but not to specific individuals. That is, political corruption consists of behavior and practices that deviate from certain principles. The wrong that characterizes political corruption is not to any specific person but rather to the principles themselves. Thus, this conception does not recognize or does not have an interest in the harm of specific persons.

Another conception would conceive political corruption as a form of deception or secrecy. In addition, this Kantian conception of political corruption dismisses the subjective element of political corruption, and the material harm to specific individuals. In other words, what makes something corrupt is not the motivation to promote private interest but rather that the attempt to promote private interest is done in a manner that violates the imperative of honesty and publicity. Against this background, I want to turn now to contemporary writers who suggested revised conceptions of political corruption.

The upshot of all this is that Kantian conception of political corruption tends to be abstract and tends to be focused on official duties and institutions. It does not acknowledge the importance of motivations. Its starting point is not who endangers democracy, but what kind of behavior contradicts democratic principles. In addition, the conception does not have a place for class politics. The identity of the agent and the identity of the victim are not important. As we shall see in the next section, Kant's conceptualization is very similar to recent conceptual works on political corruption, although some of them intend to develop a different approach to the subject, and some of them reject Kant's ideas. We can take it as an example of misreading Kant, but that is not my point and I am not sure that this is the case. For the purpose of this chapter the more important 
question is what the similarity to Kant tells us about the advantages and disadvantages of these recent developments.

\section{Contemporary conceptualizations of political corruption}

Several works over the last two decades have criticized past conceptualizations of political corruption and have attempted to reinvigorate the concept of political corruption by making it less moralistic. In brief, these works tell us to try to achieve a more nuanced view of political affairs (Philp 1997; Thompson 1993). That requires adopting procedural, rather than substantive principles, accepting and endorsing the pursuit of self-interest, and accepting a view of politics as competition between groups.

The starting point of recent conceptual work on political corruption is the existence of fundamental disagreements about moral and political issues in contemporary democracies, and the realization that moral principles cannot determine what is corrupt or what we shall do to avoid corruption. Instead of connecting the notion of political corruption to some ethical idea, political corruption should be defined in relation to the notion of politics (Philp 1997; Warren 2004: 332; Andersson and Heywood 2009: 750). For Thompson (1995: 28-9), the locus of politics is given by political processes, and thus political corruption is the pollution of the democratic political processes by private interests. Warren (2004) is focused on the democratic norm, which he conceives as inclusion. He thus suggests conceiving political corruption as a specific violation of the norm of inclusion. Corruption in democracies is a form of duplicitous exclusion. Philp (1997), to take another example, believes that ruling, authority and political order are the core of politics. Accordingly, he asserts that "corrupt behaviour directly subverts the principles and procedures (either formal rules or implicit norms) which demarcate the public domain and govern the representation and pursuit of individual or group interests" (Philp 2002, 54-5).

Although they adopt different theories of the political order, recent theorists accept the importance of struggles, conflicts and competition to political life (Philp 2007; Thompson 2005: 1042-3). Johnston (2010: 11) asserts that what is needed is a conceptualization of political corruption that encourages more competition, "driven not by visions of civic good but rather by plain old selfinterest."

The acknowledgment that conflicts are part of the political is also one of the reasons that we should take more seriously disagreements about the meaning of the political and about the applicability of the concept to concrete cases (Johnston 2010: 15; Philp 2006: 50-1; Thompson 2002: 108). Thus, the scholar better take into account the public opinion or local norms when he applies the concept to concrete cases. But he should not take public opinion as a final authority, because the public may be corrupt, too moralistic, not sophisticated enough or simply not interested in politics. To conclude this point, some ambiguity remains with regard to the role of the public in the conceptualization of political corruption. 
A similar ambiguity can be found with regard to the role of motivations. Despite the differences, all versions share the view that we don't need to focus on motivations. Indeed, the political approach acknowledges that political corruption involves the promotion of private gain at the expense of the public, but processes, procedures and outcomes, they emphasize, are more important for an appropriate understanding of corruption (Philp 1997: 448, 2007: 80-1, 2010: 470). Moreover, attention to motives may lead to cynicism, for one can always doubt what motivates a politician to act the way he does, and question the sincerity of the claim that he is motivated by his interpretation of the common good. As cynicism prevents compromises between rivals, such a conceptualization would actually serve the status quo, and hamper any possibility of improving social and political conditions (Gutmann and Thompson 2012). Furthermore, a politician who is driven by hope to be elected may nonetheless serve the public more effectively than a politician who thinks only of the public good. Thus the agent who acts from a sense of duty to promote the public interest may be acting from the wrong sort of motivation (Thompson 1993: 372-5). Nevertheless, recent scholars include intentional wrongdoing (Philp 2002: 54) or duplicity (Warren 2004) in the definition of corrupt political behavior. Furthermore, they are still focused on individuals - whether these are political leaders (Philp 2007) or public officials (Thompson 1995: 7). And while they are interested in systemic problems, they define political corruption in behavioral terms ("the abuse of public roles or resources for private benefit") (Johnston 2005: 12).

The focus on individuals, against the intent to focus on institutions and systemic problems, is out of respect for the political order and its constituent institutions. But the political approach has reservations about conceptualization associated with Kantian moralism and focusing on individuals and motivations echo exactly this kind of moralism. As a result, the role of motivations remains unclear. The point is that the aspiration to combine acknowledgment in the importance of motivations and realism in the concept of political corruption in a way that avoids entirely liberal moralism is indefensible. Because such an attempt is impossible, it leads to ambiguity. Similar problems appear with the role of public opinion, and for similar reasons. On the one hand, the approach is based on respect to pluralism and to local interpretations. On the other hand, it criticizes the public for being too moralistic. Because it is impossible to respect local interpretations and disagreements and to dismiss them as moralistic, this strategy leads to ambiguity. Worst of all, it leads to a conception that is not critical enough of politicians, wealthy citizens and institutions.

First, as scholars lack a clear commitment to substantive normative values, in favor of a commitment to politics, their analysis tends to prefer competition at the expense of values, such as equality. For example, Thompson rejects contribution-blind schemes, which aim to reduce the power of wealthy people and increase equality, because they "would throw out the baby of political competition with the bathwater of political corruption" (Thompson 2005: 1042). He justified his position in favor of a connection between donors and politicians by saying: "Stated at this level of generality, the connection is not only acceptable 
but desirable: it expresses part of the essence of democratic accountability...." (Thompson 2005: 1043).

A related problem is that scholars, who are fond of competition, as these scholars seem to be, tend to ignore important facts in their political analysis. They are especially insensitive to class politics and to the disproportional influence of rich individuals on decision-making. For example, supporters of the political approach forcefully deny that "money is the root of all evil" (Johnston 2010; Thompson 2002, 2005), as though money, and not agents with a lot of money, is the issue when it comes to political corruption. Indeed, they want to open our eyes to the possibility that, with a different attitude to money in politics, we may find better solutions to corruption. But their pragmatism encourages the continuity of the current problematic system. The attempt to educate the public not to be too moralistic also has a chilling effect. Moreover, condemning the use of public power for private gain is a fundamental element of any viable political activity (Saxonhouse 2004: 46). To deny this is to deny politics.

The upshot of all this is that the pro-competitive approach and the attempt to conceptualize political corruption in a way that transcends contemporary public criticism and decrease scandals is flawed. As a matter of fact, while it attempts to be more political by comparison with other conceptions, it is almost identical to Kant's ideas and method. Because it cannot be sustained, recent conceptualizations lead to inconsistent attitudes towards motivations and public opinion and leave the role of the theorist undetermined. Furthermore, the current form of the politicizing of the concept of political corruption has difficulty criticizing institutions and citizens that do not fulfill official duty. To conclude, while we can ascribe Kant's rigorist approach to his optimistic perspective on history, we cannot justify today an approach that shows such optimism about institutions and the cunning of nature or politics. This suggests that the political approach should also be revised.

\section{An outline of the motivational conception of political corruption}

The conception of political corruption suggested here aims to mitigate the problems of the Kantian conceptualization and the current writings by emphasizing the importance of motivations for good political order and good political behavior.

In general, to promise that the conception will not be too narrow, the first question is what we should think about political behavior and practices, and not what we should do about them (Cohen 2008). To encourage strategic and institutional thinking is to give up from the start engagement in a critical dialogue with the public. This also may reduce the capacity to maintain the critical distance needed for examining practices and institutions. While our starting point should be the common meaning of political corruption, our task is to provide a modified conception based on the ideal of equal worth of persons. In addition, we should explain the limitations of a properly understood concept of political corruption. 
For example, to explain why under certain circumstances disagreements about the applicability of the concept to concrete cases are inevitable, and why sometimes we better accept the corruption of others, although they have no justification to act in the way in which they do. Another task is to provide empirical arguments regarding what has the potential to corrupt the society under investigation, that is, which agents and what kind of arrangements impose the greatest danger for freedom (for elaboration, see Ron 2010).

Although the motivational conception is based on substantive principles and on a critical approach to the institutionalization of power, it acknowledges that there are close relations between our public duties, our sense of public duty and political institutions. Thus, we need to distinguish between corrupt political behavior on the one hand, and corruption in institutions, or structural corruption, on the other. The first part of this section focuses on corrupt political behavior. The second part deals with institutions that encourage selfish behavior, that is, with structural corruption.

According to my proposed definition, corrupt political behavior is the use of public power that (1) is motivated by the desire to promote a goal that is personally connected to the power holder and because of this connection; (2) is done intentionally, that is, with the intention to pursue a personal goal; (3) is without sufficient attention to the basic right of people to respect and freedom; (4) the agent knows, or should have known, that it violates another's freedom. Together, these elements create the phenomenon of corrupt political behavior.

Before continuing, let me clarify what I mean by motivations and the relations between this notion and intentions. Motivations are emotions and desires that are at least part of the cause of an action (the other parts are beliefs and capacities). Intentions, on the other hand, are related to the agent's goals and how he can pursue them, but they are reducible to neither emotions nor desires. A given intention could be the result of several motives, and it is perfectly reasonable to ask what was the motivation behind an intention to do something (Sverdlik 1996: 339).

The agent who acts corruptly is motivated only, or mostly, by care for his personal good, including the good of people who are close to him or people whom he believes will take care of him or her. There are objectives that are clearly personal - like fulfilling one's physical needs (i.e., sleeping, eating) while others are dependent on historical circumstances (i.e., being considered brave). Finally, as long as the attempt to gain power is motivated by care for oneself, it can fulfill this condition.

A political behavior can be considered corrupt if the agent harms the public intentionally, in the sense that he thinks that his private gain is worth the harm to the public. But more often than not he does not intend to harm the public. That is, it is not a requirement that the agent intend to harm the public for a political behavior to be considered corrupt. Note also that not in all corrupt political behavior and actions are agents fully aware of the wrongness of their behavior. But the agent knows, or should be cognizant, that his attempt to pursue a personal goal may have negative consequences for the public or the rights of others. 
Moreover, he knows or should have known that what he does lacks justification. If we cannot tell that an agent should have known that he harms the public, it means that we cannot tell that he had the duty to care about others. In that case we better not talk about corrupt political behavior.

When it comes to the struggle for power, both motives and intentions are important. An agent may act with the intention of achieving a political gain for himself, and may attempt to do so by breaking legal rules, but may nonetheless be motivated by the desire to promote the public interest. Depending on other circumstances, such as his justification to break rules (independent of his motivation to serve the public), an act might not be considered corrupt but merely a case of "dirty hands" (Walzer 1973). Outside of the struggle to achieve or maintain power, even a worthy motivation does not excuse behavior that exploits power for personal gain: for instance, accepting a bribe so as to give the money to a friend with a serious illness. The reason for the difference is that struggling to achieve power is something with a public merit, especially if the motivation is to serve the public. But to help a friend is not. However, the noble motivation does tell us something about the character of the agent. A politician who accepts a bribe to help his ill friend is probably a better person than a politician who accepts a bribe to enrich himself.

Motivations are less crucial when the agent's intentions are good (which is not the case of "dirty hands", where only the motivations are good). The intention to serve the public, whatever the motivation behind it, excludes behavior from the category of political corruption. Furthermore, as long as the agent is obliged to respects others' right to freedom, in the sense that his concern for the others' rights constrains his behavior, we need not talk about political corruption, even if what motivated the agent was his private gain, that is, even if without the personal incentive he would not have intended serving the public. Such a kind of political behavior may lack moral worth from a Kantian point of view (Herman 1981), and it may tell us something about the agent, but it cannot be considered as corrupt.

The separation between private gain and public gain is based on a substantive notion of the common good. The use of public justification as the major criterion for distinguishing between them (Warren 2006; Thompson 1995) is insufficient. In political systems that are based on ideologies that encourage self-interested behavior, many practices and behaviors can be publically justified (Bohman and Richardson 2009; Sunstein 1984: 1698). It is not that self-interested behavior is necessarily unjustified, but rather that when it is unjustified, in systems that encourage self-interested behavior, it can quite easily gain public justification. Moreover, the acceptance of competition in politics means that one can easily justify behavior that aims to promote private interest whatever its consequences. That is, even in cases where agents cannot convince others that their actions are good, they can justify themselves by saying that disagreements are natural, self-interested behavior is welcomed and what is important is that they are playing by the rules.

In cases when there are normative disagreements about this good (and often there are no normative disagreements but rather factual ones), we can demonstrate 
that the motivations of certain agents are selfish by referring to the ways that subordinated citizens, or those who suffer from the abusive behavior and the questionable practices, understand the behavior under investigation. The crucial point is that the applicability of the concept to concrete cases requires practical judgment, sensitivity to power relations and familiarity with the system under investigation. To be more specific, one of our missions is to identify what kind of configurations of power tend to create temptations and abuses of power and by whom, and which practices tend to violate the right to freedom and other negative results.

As for the methodological challenge of acquiring definitive empirical information about the interests of the agents and their motivations and intentions, at times selfishness is self-evident, and there is no difficulty identifying the corruption. In other cases, we adopt the "tendency standard", that is, assume that agents who use their power in a conflict of interests are using it to promote personal gain (Thompson 1993). Yet in other cases we usually need to depend on courts or other trustworthy investigative bodies. These types of bodies are in a better position to interpret the motives of the agents for the simple fact that they investigate them, and because they have access to the details of the case. Indeed, when there are complicated cases that were not investigated, or when the investigative bodies are not reliable, it would be very difficult to tell whether or not we have a case of corrupt political behavior. I shall emphasize, however, that we are not dependent on these bodies' normative judgment, but only on their empirical findings.

\section{Conclusion}

The analytical account put forward in this chapter offers a response to Kantian conceptualization and to the politicization of the concept of political corruption as it has evolved in the last two decades. Indeed, the motivational conception may inspire mistrust in the government, and may result in a greater problem. But when large corporations and wealthy individuals wield enormous power, as they do today, and especially when their preferences deviate from those of the majority of the people (Page et al. 2013), the resulting attitude toward democratic politics is mistrust. What about scandals? If there be scandals, their nature should be a bit different, for we shall hear more talk about the structural problems of electoral systems. Anyhow, turbulence "prevents the degeneracy of government," and - to rephrase what Jefferson said about rebellion - corruption scandals "now and then may be a good thing" (Sunstein 1985: 40).

Several lessons are suggested by this chapter. First, as citizens, we better require from politicians and powerful citizens not only commitment to procedures and legal rules but also to the common good. Second, to engage in political theory we need not attempt to think about politics in purely political or formal terms. Moreover, we should be aware of the danger of being analytical at the expense of being political. Being analytical is inherently good, and also has the merit of helping to distinguish between degrees of wrongness. But more often 
than not to be analytical one must avoid substantive argumentation, and he or she loses the ability to criticize entire systems. We may want, instead, to pay in clarity to be political. We better combine substantive notions in our conceptualization, and realize that the application of the concept would require sophisticated analysis and it may not lead to conclusive judgments.

\section{Note}

1 For a discussion on Kant's philosophy of history, see Apel 1997.

\section{Bibliography}

Andersson, S. and Heywood, P. M. 2009. "The Politics of Perception: Use and Abuse of Transparency International's Approach to Measuring Corruption." Political Studies 57: 4, 746-67.

Apel, K.-O. 1997. “Kant's 'Toward Perpetual Peace' as historical prognosis from the point of view of moral duty." In J. Bohman and M. Lutz-Bachmann (eds), Perpetual Peace - Essays on Kant's Cosmopolitan Ideal. Cambridge, MA and London: The MIT Press, pp. 79-112.

Benton, R. J. 1982. "Political expediency and lying: Kant vs Benjamin Constant.” Journal of the History of Ideas 43: 1, 135-44.

Bohman, J. and Richardson, H. S. 2009. "Liberalism, deliberative democracy, and 'reasons that all can accept'." The Journal of Political Philosophy 17: 3, 253-74.

Cohen, G. A. 2008. Rescuing Justice and Equality. Cambridge, MA: Harvard University Press.

Gutmann, A. and Thompson, D. F. 2012. The Spirit of Compromise. Princeton and Oxford: Princeton University Press.

Herman, B. 1981. "On the Value of Acting from the Motive of Duty." Philosophical Review 90: 3, 359-82.

Holmes, S. 1984. Benjamin Constant and the Making of Modern Liberalism. New Haven and London: Yale University Press.

Johnston, M. 2005. Syndromes of Corruption. Cambridge: Cambridge University Press.

Johnston, M. 2010. "Democracy without politics?" In M. A. Genovese and V. A. FarrarMyers (eds), Corruption and American Politics. New York: Cambria Press, pp. 9-36.

Kant, I. 1991[1795]. “The perpetual peace.” In Reiss H. S. (ed.), Kant-Political Writing. Cambridge: Cambridge University Press, pp. 93-130.

Kant, I. 1996[1797]. "On a supposed right not to lye from philanthropy.” In M. J. Gregor and A. Wood (eds, and trans.), Immanuel Kant - Practical Philosophy. Cambridge: Cambridge University Press, pp. 605-16.

Page, B. I, Barteles L. M. and Seawright J. 2013. "Democracy and the policy preferences of wealthy Americans". Perspectives on Politics 11: 1, 51-74.

Paton, H. 1953. "An alleged right to lie, a problem in Kantian ethics." Kantian Studies 45, 190-203.

Philp, M. 1997. "Defining political corruption.” Political Studies 45: 3, 436-62.

Philp, M. 2002. "Conceptualizing political corruption.” In A. J. Heidenheimer and M. Johnston (eds), Political Corruption - Concepts and Contexts, 3rd edn. New Brunswick and London: Transaction Publishers, pp. 41-58. 
Philp, M. 2006. "Corruption definition and measurement." In S. Charles, A. Shacklock, C. Connors and F. Galtung (eds), Measuring Corruption. Hampshire, UK and Burlington: Ashgate, pp. 45-56.

Philp, M. 2007. Political Conduct. Cambridge, MA and London: Harvard University Press. Philp, M. 2008. "Peacebuilding and corruption." International Peacekeeping 15: 3, 310-27.

Philp, M. 2010. "What is to be done? Political theory and political realism." European Journal of Political Theory 9: 4, 466-84.

Rawls, J. 2005. Political Liberalism (Expanded Edition). New York: Columbia University Press.

Ripstein, A. 1994. "Universal and general wills - Hegel and Rousseau." Political Theory 22: 3, 444-67.

Ripstein, A. 2009. Force and Freedom. Cambridge, MA and London: Harvard University Press.

Ron, A. 2010. "The hermeneutics of the casual powers of meaningful objects." Journal of Critical Realism 9: 2, 155-71.

Ronzoni, M. and Valentini, L. 2008. "On the meta-ethical status of constructivism: reflections on G.A Cohen's 'Facts and Principles'." Politics, Philosophy and Economics 7: $4,403-22$.

Saxonhouse, A. W. 2004. "Corruption and justice: the view from Ancient Athens." In W. C. Heffernan and J. Kleining (eds), Private and Public Corruption. Lanham: Rowman and Littlefield, pp. 25-52.

Sunstein, C. R. 1984. "Naked preferences and the constitution." Columbia Law Review 84: 7, 1689-732.

Sunstein, C. R. 1985. "Interest groups in American public law." Stanford Law Review 38 : $1,29-87$.

Sverdlik, S. 1996. "Motive and rightness." Ethics 106: 2, 327-49.

Thompson, D. F. 1993. "Mediated corruption: the case of the Keating Five." American Political Science Review 87: 2, 369-81.

Thompson, D. F. 1995. Ethics in Congress. Washington, DC: The Brookings Institution.

Thompson, D. F. 1999. "Democratic secrecy: the dilemma of accountability." Political Science Quarterly 114, 181-93.

Thompson, D. F. 2002. Just Elections. Chicago and London: The University of Chicago Press.

Thompson, D. F. 2005. "Two concepts of corruption: making campaigns safe for democracy." George Washington Law Review 73, 1036-83.

Weinrib, J. 2008. "The juridical significance of Kant's 'supposed right to lie'." Kantian Studies 13: 1, 141-70.

Walzer, M. 1973. "Political action: the problem of dirty hands." Philosophy and Public Affairs 2: 2, 160-80.

Warren, M. E. 2004. "What does corruption mean in a democracy?" American Journal of Political Science 48: 2, 328-43.

Warren, M. E. 2006. "Political corruption as duplicitous exclusion." PS: Political Science and Politics 37: 4, 803-7.

Warren, M. E. 2010. "Low trust in democratic institutions." In M. A. Genovese and V. A. Farrar-Myers (eds), Corruption and American Politics. Amherst: Cambria Press, pp. 37-64.

Williams, B. 2002. Truth and Truthfulness: An Essay in Genealogy. Princeton, NJ: Princeton University Press. 



\section{Part II}

\section{Rhetoric}





\title{
5 The political rhetoric of administrative ethics
}

\author{
Obama vs. the cynics
}

\author{
Anders Berg-Sørensen
}

\section{Introduction}

In his first inaugural address as the 44th President of the United States, Barack Obama (2009a: 8) declared that he would 'restore the vital trust between a people and their government'. This aim was given meaning by distancing his administration from the former, labelled 'the cynics', associated with the brute sovereign use of power and war making, despair and disillusion in the citizenry (Obama 2009a). In other words, cynicism was presented as the negation of Obama's political and administrative ethics. Cynicism is the failure of sincerity in terms of the distrust and disillusion it creates. Scrutinizing Obama's political rhetoric, cynicism is found to be coined as the opposite of all the values he stands for. Cynicism is put into play as the negation of all that Obama is fighting for by creating political visions and moral imaginations for the citizenry. Thus, Obama's political rhetoric operates as a performative power, creating moral imaginations wherein cynicism becomes the constitutive condition of his administrative ethics. The focus in this chapter is this negative relationship between ethics and cynicism rather than the positive conceptions of transparency and open government, public interest and public trust formulated in Obama's 'Executive Order on Ethics Commitments by Executive Branch Personnel', which was made public the day after the inaugural address.

More particularly, the question is whether cynicism is a moral psychological and political departure that one has to - and can - repudiate as Obama does or whether it is an inevitable feature of political-administrative life. On the one hand, there is the intuitive sense that cynicism is a vice that one instinctively repudiates: it is normally used in a pejorative sense and attached to one's political opponents with the aim to delegitimize them. On the other hand, there is a tacit acceptance that cynicism is an inevitable feature of politics and administration. If that is the case, the crucial question becomes which kind of cynicism we can live with and which kind we cannot accept rather than repudiating cynicism entirely. In the words of David Runciman (2008: 3): 'The difficulty, though, is knowing how to get this mixture right'. Reflecting upon this question, this chapter includes the political thought of Judith Shklar (1984), analysing whether cynicism can be considered 'an ordinary vice'. 
Obama's political rhetoric illustrates the meaning cynicism is ascribed in a modern political and moral vocabulary. In everyday political and moral vocabulary, cynicism is associated with egoism, opportunism, manipulation, the use and abuse of power, despair, disillusion, fatalism, distrust in conventional norms and values, distrust in language and the sincerity of others' speech, distrust in democratic institutions and procedures, distrust in collective action and problem-solving, and, thus, distrust in the possibility of political agency and social transformation. In other words, the cynic is a morally compromised person without principles, conscience and hope, and he considers human nature and especially the nature of politicians to be characterized by self-interest and desire for power. And the cynic might express these points of view using sarcasm and satire. This contemporary everyday meaning of cynicism, however, stands in contrast to the etymological meaning of cynicism and the ethics of the ancient cynics.

Etymologically, cynicism refers to the ancient Greek word kyon, literally meaning 'dog'. According to the myths, it associates how the ancient cynics lived their lives like dogs. The ethics of the ancient cynics include work on personal character, integrity, independence, self-discipline and self-sufficiency. These ideals of personal ethics and practices of self-governance were supposed to give the cynics an independent point of view for criticizing the use of power, corruption, conventions, customs, traditional values and commonly held opinions. The cynics therefore rated an extended freedom of speech very highly to tell the power of the truth (Desmond 2006). On the one hand, then, ancient cynicism implies personal ethics and social criticism, self-sufficiency and truthful speech; on the other, their way of life was considered shameless, scandalous, disgusting and disrespectful in a manner that dissolves the common norms of a society. This ambiguity has played a role in the historical receptions of and reactions to ancient cynicism; it is adopted in the modern meaning of cynicism and it is implicit in this chapter's actual reflections on the plural meanings of cynicism in political life (cf. Laursen 2009; Mazella 2007; Shea 2010).

To address the question raised in Obama's political rhetoric as to which kind of cynicism we can live with and which kind we cannot accept, the first section will reconstruct Obama's administrative ethics and public morality by focusing on the performative power of his political rhetoric and the implied binary oppositions that constitute the conditions of possibility of his political and moral vocabulary (cf. Alexander 2010). These include his identification of 'the cynics' as his opponents and of cynicism as the negation of his administrative ethics and moral imaginations of the citizenry. His approach to political and administrative ethics could be called ethics via negativa. The following section will reflect further on the meaning of cynicism in political-administrative life. It will include the political thought of Judith Shklar and, in her language, analyse and discuss whether cynicism can be considered 'an ordinary vice'; and if so, how to handle cynicism as an inevitable feature of everyday political life. As for the ancient cynics, such an understanding of cynicism as an ordinary vice points out the crucial role of personal ethics - vices not only as flawing our character but also as potentials of ethical cultivation; the cultivation of a vigilance towards ordinary 
vices and courage to act on this knowledge. For that purpose, the chapter brings in Shklar's reflections on negative moral-psychological characteristics, her ranking of vices and her emphasis on story-telling in exploring ordinary vices. On the basis of this sketch of the meaning of cynicism, the chapter will return to the question of which kind of cynicism we can live with and which we cannot accept, where Shklar's priority of cruelty as a negative moral standard constitutes the limit.

\section{Obama vs. the cynics}

In the prologue to The Audacity of Hope: Thoughts on Reclaiming the American Dream, Barack Obama writes about his decision to run for political office and the reactions it triggered in the neighbourhood in which he worked as a community organizer: 'You seem like a nice enough guy. Why do you want to go into something dirty and nasty like politics?'.

I was familiar with the question [...]. It signaled a cynicism not simply with politics but with the very notion of public life, a cynicism that [...] had been nourished by a generation of broken promises. In response, I would usually smile and nod and say that I understood the scepticism, but that there was and always has been - another tradition of politics, a tradition that stretched from the days of the country's founding to the glory of the civil rights movement, a tradition based on the simple idea that we have a stake in one another, and that what binds us together is greater than what drives us apart, and that if enough people believe in the truth of that proposition and act on it, then we might not solve every problem, but we can get something meaningful done.

(Obama 2008a: 3-4; emphasis added)

The same line of thought is presented in Obama's first inaugural address delivered January 20, 2009, which adds emphasis on what is characterizing the past and present administrations:

Now, there are some who question the scale of our ambitions, who suggest that our system cannot tolerate too many big plans. Their memories are short. For they have forgotten what this country has already done; what free men and women can achieve when imagination is joined to common purpose, and necessity to courage.

What the cynics fail to understand is that the ground has shifted beneath them, that the stale political arguments that have consumed us for so long no longer apply. The question we ask today is not whether our government is too big or too small, but whether it works [...]. And those of us who manage the public's dollars will be held to account - to spend wisely, reform bad habits, and do our business in the light of day - because only then can we restore the vital trust between a people and their government.

(Obama 2009a: 7-8; emphasis added) 
These quotes reflect a commitment to general values, such as openness, transparency, accountability, impartiality and neutrality, which are crucial for government and administration in a democratic political regime to serve the public interest. In Obama's words, the aim of invoking these values is 'to restore the vital trust between a people and their government'. Such values of government are codified in Obama's executive order on 'Ethics Commitments By Executive Branch Personnel' from 21 January 2009, which states that 'he will strive to lead the most open, transparent, and accountable government in history' (Obama 2009b). The order consists of an ethics pledge that all appointees in executive agencies must sign to keep the public trust. The ethics pledge is binding and enforceable under law on the appointees in the executive agencies. It focuses primarily on the economic and political independence of the appointees in relation to lobbyists and to former and future employers or clients potentially giving gifts and other kinds of private gain. In that sense, it emphasizes the priority of public interest and the illegitimacy of private interests in government; or, as written in the 'Ethics Commitments', 'the integrity of the Government's programs and operations' (Obama 2009b).

These administrative values of accountability and transparency are parts of a broader picture that Obama creates with his political rhetoric - a vision for a new American political life - in his presidential race, labelled 'Change we can believe in'. In this vision, the temporal dimension plays a crucial role. To achieve resonance among ordinary citizens, Obama not only invokes the general ethics of a democratic government, he also brings to the fore the whole American political tradition and its embedded values of liberty and equality as they have been lived and experienced by the citizenry. In other words, his narrow administrative ethics is embedded in a broader vision for a new American political life, which, he claims, is embedded in the existing American public morality with a potential to be revitalized.

Furthermore, Obama's vision is articulated so as to be in opposition to the cynics and cynicism, implying that it is given meaning not only by the positive invocation of the political principles and values embedded in the American democratic political regime and political tradition but also by the negative relationship to the cynics, naming the former administration, the Bush administration, and a general mood of despair among ordinary American citizens. To the point, then, cynicism is represented as the negation of Obama's administrative ethics and vision for a public morality.

To dig deeper into that project, we have to reconstruct what is meant by the cynics and cynicism in Obama's political rhetoric. In general terms, one can distinguish between, on the one hand, the cynicism characterizing the individual moral psychology and the societal public morality and, on the other hand, the cynicism of the political and administrative use of power. The first is the kind of cynicism that expresses a mood of despair in politics, the belief that it is not possible to make a difference and that one cannot make a difference oneself, that it is useless to do the effort, and that it is not worth trying to improve the conditions of living for the citizenry and societal welfare by political means and 
engagement. Another connotation of the first kind of cynicism is egoism. In the words of Obama: 'After all, a cynical electorate is a self-centered electorate' (Obama 2008a: 49).

The second kind of cynicism involves a political and administrative use of power, where political principles and ideals are 'deployed in the service of cynical aims' (Obama 2008a: 12; emphasis added). This kind of cynicism is associated with what Obama conceives as an increasing absolutism in political life and government. It is especially related to the Bush administration, but also - to some degree - to former Democrat governments. In Obama's sketch of the absolutism in political life and government, absolutism has three characteristics that have come to work together: 'the absolutism of the free market', 'the religious absolutism of the Christian right' and the absolutism of 'those who claim the power in the name of the majority' (Obama 2008a: 46).

Economic absolutism claims the priority of the free market economy and reduces government to the protection of private property and the provision of national security. Religious absolutism claims Christianity to be the dominant religion in the USA and defends a particular fundamentalist interpretation of the Bible and the implications of such an evangelical Christian morality for public policy. This Christian absolutism does not give room for alternative interpretations and understandings of the Christian faith and tradition, nor for religions other than Christianity. The absolutism of 'those who claim the power in the name of the majority' represents a kind of political absolutism that disrespects and suspends democratic rules of decision-making and mechanisms of public control while at the same time hollowing out civil and human rights. This is most significant in questions of national security and the 'war on terror'; more generally, however, it also characterizes the political processes in the Congress and Senate according to Obama. Political absolutism halts any democratic conversation and contestation by claiming both truth and power and, thus, by disrespecting rights, the rule of law and the rule of the democratic game with the consequence that the American polity and society is divided and that citizens and politicians in opposition to government are disempowered and despaired. In that sense, it brings us back to the first kind of cynicism, which hollows out both personal and public morality.

Obama's vision for a new American political life is articulated in opposition to cynicism in these various senses. Cynicism works as the constitutive condition of Obama's understanding of administrative ethics and public morality in terms of a negative relationship. At the same time, however, he invokes the American political tradition and history, political principles and values as a lived and experienced common heritage and reservoir of meaning to be revitalized to assemble all Americans irrespective of belonging and, thus, to lay the ground for political reforms and cultural changes. In that sense, he also invites ordinary American citizens to join the renewal of American political life. As he writes in The Audacity of Hope, reflecting on his encounters with ordinary citizens:

Not only did my encounters with voters confirm the fundamental decency of the American people, they also reminded me that at the core of the American 
experience are a set of ideals that continue to stir our collective conscience; a common set of ideals that bind us together despite our differences; a running thread of hope that makes our improvable experiment in democracy work. These values and ideals find expression not just in the marble slabs of monuments or in the recitation of history books. They remain alive in the hearts and minds of those Americans - and can inspire us to pride, duty, and sacrifice.

(Obama 2008a: 11)

The crucial question is how a government can represent the people and, thus, create public trust and common hope. Obama's answer includes both the invocation of what he conceives the living American political tradition and the invitation to ordinary American citizens to take active part in forming this living tradition with its common ideals, common experiences and common hopes. The latter reflects Obama's conception of democracy as an open-ended and incomplete experiment embedded in a long-living political tradition. In identifying some more specific characteristics of the public morality underlying his vision for a new American political life, Obama refers to character virtues such as honesty, decency, fair play, tolerance, responsibility, responsiveness, curiosity, courage, loyalty, patriotism, hard work, sacrifice, duty and pride. Together with values such as liberty and equality, impartiality and neutrality, transparency and accountability, these character virtues form the imaginations of a public morality that Obama wishes could give ordinary citizens hope and inspire them to cultivate their personal character so that they could play an active role in the renewal of America in accordance with the long-living political tradition. This is a common endeavour made possible by working on the moral imaginations of the citizenry. In several of his speeches, Obama has referred to 'the continued expansion of our moral imagination; an insistence that there's something irreducible that we all share' (Obama 2009d). In his speech at the memorial service for the victims of the shooting in Tucson in January 2011, Obama repeats this idea of expanding our moral imaginations:

As we discuss these issues, let each of us do so with a good dose of humility. Rather than pointing fingers or assigning blame, let's use this occasion to expand our moral imaginations, to listen to each other more carefully, to sharpen our instincts for empathy and remind ourselves of all the ways that our hopes and dreams are bound together.

(Obama 2011a, emphasis added)

Obama's call for expanding the moral imaginations of the American citizenry includes 'something irreducible that we all share', and the ability to have a sense of the shared 'something irreducible' implies the cultivation of personal character. In that sense, the expansion of the moral imaginations includes both an invocation of the living American political tradition and an invitation to ordinary American citizens to give them hope that dreams can become true. Obama 
situates this hope in one of the victims of the shooting, nine-year-old Christina Taylor Green, born on 9/11 - the date symbolizing the collective trauma of the American people - and invigorates her faith in democracy as a rejection of cynicism:

And I believe that for all our imperfections, we are full of decency and goodness, and that the forces that divide us are not as strong as those that unite us./That's what I believe, in part because that's what a child like Christina Taylor Green believed./Imagine - imagine for a moment, here was a young girl who was just becoming aware of our democracy; just beginning to understand the obligations of citizenship; just starting to glimpse the fact that some day she, too, might play a part in shaping her nation's future. She had been elected to her student council. She saw public service as something exciting and hopeful. She was off to meet her congresswoman, someone she was sure was good and important and might be a role model. She saw this through the eyes of a child, undimmed by the cynicism or vitriol that we adults all too often just take for granted.

(Obama 2011a, emphasis added)

The Christina Taylor Green example is a story about a faith that one can make a difference and that it matters to be engaged in democratic politics. Her story symbolizes the hope Obama would like to invigorate in all ordinary Americans citizens as a common endeavour. As Obama writes elsewhere in The Audacity of Hope:

They are out there [...], those ordinary citizens who have grown up in the midst of all the political and cultural battles, but who have found a way [...] to make peace with their neighbors, and themselves. [...] I imagine they are waiting for a politics with the maturity to balance idealism and realism, to distinguish between what can and cannot be compromised, to admit the possibility that the other side might sometimes have a point. They don't always understand the arguments between right and left, conservative and liberal, but they recognize the difference between dogma and common sense, responsibility and irresponsibility, between those things that last and those that are fleeting.

(Obama 2008a: 51-2)

This is where Obama's pragmatism enters the stage. To solve the present political problems, one must balance between idealism and realism. This is not a cynical resignation on reality (i.e. that the idea of making a difference has to be given up because of how things are); nor is Obama's vision for a new American political life based on public morality an expression of unrealistic idealism; rather, it is a consideration of the possibilities within the American political heritage and the experiences of ordinary citizens for making an effort to change. This is a problem-solving approach that bridges political ideals and reality, that 
comprises present reflections on past experiences guided by visions for the future. It has been emphasized that Obama is a pragmatist not only in the ordinary language sense of the word - the readiness to leave one's democratic principles for the sake of political compromise - but also in the philosophical sense deeply embedded in the American political culture (cf. Aboulafia 2010; Elridge 2011; Kloppenberg 2011: 151-247; Koopman 2011; Schultz 2009, 2011). Here, the focus is on Obama's understanding of democracy as an openended and always-ongoing conversation related both to the experimentalism of democratic trial and error on the basis of common experiences and faith in democracy and to fallibilism, which entails the acknowledgment that one can be in error even in one's deepest convictions. As Obama says:

Adhering to this law of love has always been the core struggle of human nature. For we are fallible. We make mistakes, and fall victim to the temptations of pride, and power, and sometimes evil. Even those of us with the best of intentions will at times fail to right the wrong before us./But we do not have to think that human nature is perfect for us to still believe that the human condition can be perfected. We do not have to live in an idealized world to still reach for those ideals that will make it a better place. [...] For if we lose faith - if we dismiss it as silly and naïve; if we divorce it from the decisions that we make on issues of war and peace - then we lose what's best about humanity. We lose our sense of possibility. We lose our moral compass. [...] We can acknowledge that oppression will always be with us, and still strive for justice. We can admit the intractability of depravation, and still strive for dignity.

(Obama 2009d, emphasis added)

The embracement of fallibilism is where pragmatism opposes absolutism and criticizes absolutist points of view claiming an absolute truth superior to conversation and contestation (cf. also Bernstein 2005, 2010). In the case of Obama, fallibilism is associated with humility and imperfection, but also with faith and the continuous striving for a better acknowledgment of injustices within society. Obama frames this as his modest consideration of what can be done and how, which is based on common sense, in opposition to the absolutist attitude, which is based on dogma characterizing cynicism. In that sense, fallibilism implies the point of view that democratic principles are subject to criticism and continuous revision. The reference to experimentalism reflects Obama's conception of democracy as an experiment involving ordinary citizens based on their shared experiences in concrete communities and shared traditions where people are willing to listen to each other and take the perspective of others in the process of establishing a common ground. This is supposed to be made possible by the expansion of the moral imaginations of the citizenry.

On the one hand, Obama's political rhetoric has been praised for revitalizing the American political tradition to energize the citizenry in democratic politics 
on the basis of common experiences and experiments (cf. Kloppenberg 2011; Sandel 2010). On the other hand, it has been criticized as an elitist articulation of common moral imaginations in the disguise of a grassroot democracy, which fails to create any democratic movement among the citizenry (cf. Stout 2010; Walzer 2010).

This tension has to be seen in relation to the political context of the first period of Obama's presidency. First of all, he was elected in the beginning of the financial crisis, which shaped the frame of what was possible politically and what ordinary citizens experienced in their everyday life (e.g. in terms of increasing unemployment, inability to pay mortgage and various forms of scarcity). These experiences must be considered in light of the expectations Obama had created with his political program and rhetoric. Second, his remedies, such as public investments, social security and a strengthened public healthcare system, were met by a fierce ideological reaction in the Republican camp, where the Tea Party movement was founded and received increasing support in the American public sphere. This opposition was manifest in the November 2010 mid-term elections, where the Democrats lost their majority in the Congress. Thus, the aim of assembling the American people across the division between Democrats and Republicans under a shared moral imagination reiterating the crucial elements of American political history on the basis of a common heritage and political tradition was challenged. Although the Tea Party movement had lost momentum, Obama's second presidential race against Mitt Romney highlighted the divisions and challenges.

\section{Cynicism: an ordinary vice?}

The question then becomes, (1) what characterizes the reality that one has to consider according to Obama's pragmatism? And (2) is cynicism not a characteristic of this political reality and hence a characteristic that one has to accept to some degree? And if cynicism in its negative sense is an inevitable feature of modern politics, then we must also reflect on which kind we can live with and which we cannot accept. To take a step further, it might be helpful to include Judith Shklar's idea of ordinary vices and consider whether cynicism can be understood as an 'ordinary vice', in her language. Shklar describes an ordinary vice as follows:

Ordinary vices are the sort of conduct we all expect, nothing spectacular or unusual.... It is only if we step outside the divinely ruled moral universe that we can really put our minds to the common ills we inflict upon one another every day.... These vices may involve our whole character, and our responses to them are therefore far deeper, both emotionally and speculatively.... Misanthropy is itself a vice that liberals need to think about, especially if they do not wish to succumb to its more threatening and cynical forms. 
Shklar's conception of ordinary vices as part of our everyday experiences and practices, part of our whole character formed continuously over time, might contribute to the discussion of cynicism. When focusing on ordinary vices, one takes a step away from moral idealism and faces the human reality of everyday life. In so doing, Shklar emphasizes the crucial role played by human character and the cultivation of character. From that point of view, it is a question of cultivating a sensibility and awareness of both the existence of ordinary vices and the negative consequences they can have. One of these consequences is cynicism in terms of despair. In her overall understanding of ordinary vices, Shklar (1984: 242) ranks cruelty as the first and worst ordinary vice, as fear of cruelty is the most fundamental moral-psychological characteristic of human beings and, in her words, 'deformity of our character'. In other words, to prevent that deformity, Shklar's liberalism of fear is grounded in cruelty as a negative moral standard, and putting cruelty first is conceived as a powerful part of a liberal consciousness. In liberal democratic regimes, fear of cruelty is met by the balance of power by constitutional law and the rights of protection aiming at the most extended freedom as possible. A liberal democracy, however, is also a political community of plural moralities wherein virtues and vices are contested and contestable. This requires even more of the ethical cultivation of personal characters.

In other words, Shklar's understanding of the ethical cultivation of personal characters is embedded in a more general conception of liberal democracy:

Liberal democracy is more than a set of political procedures. It is a culture of subcultures, a tradition of traditions, and an ethos of determined multiplicity. It puts enormous burdens of choice upon all of us, and it ought to be seen as very demanding. But it has never been easy to choose the dispositions required for a good character. No one has ever promised us an effortless moral life... Given that as liberals we have abandoned certainty and agreement as goals worthy of free people, we have no need for simple lists of vices and virtues. On the contrary, it seems to me that liberalism imposes extraordinary ethical difficulties on us: to live with contradictions, unresolvable conflicts, and a balancing between public and private imperatives which are neither opposed to nor at one with each other. The ordinary vices, at the very least, reveal what we have to contend with if we want to be fully aware of what we think we already know.

(Shklar 1984: 248-9)

According to these thoughts on liberal democracy and democratic political culture, it seems a more fruitful strategy to be aware of the existence of cynicism in politics and not least its various different elements and, then, be suspicious of these elements at play in every decision made in political and administrative life, rather than repudiating cynicism all the way as Obama does. The latter veils crucial characteristics of everyday political reality that people should be able to reveal to criticize the use of power and hold government accountable and 
responsible to the citizenry. That is the danger of a pompous political rhetoric of administrative ethics and public morality. At the same time, however, the storytelling in Obama's political rhetoric can create visions for a common political life and energize the citizenry in its call for the ethical cultivation of personal character. This reflects Shklar's method of doing political theory by including story-telling with the aim of building up personal character and vigilance towards vices. To balance between idealism and realism and to get things working - the aim of Obama's pragmatism - one must acknowledge the characteristics of political reality in its ordinary sense. And cynicism might be one of those characteristics.

Returning to the case of Obama, one could ask whether his position as president and his political rhetoric and moral vocabulary do not include a degree of cynicism. In what is referred to as Obama's speech to the Muslim world, his speech 'A New Beginning' held at Cairo University June 4, 2009, he said the following:

In Ankara, I made clear that America is not - and will never be - at war with Islam. We will, however, relentlessly confront violent extremists who pose a grave threat to our security [...]. And it is my first duty as President to protect the American people./The situation in Afghanistan demonstrates America's goals, and our need to work together. Over seven years ago, the United States pursued al Qaeda and the Taliban with broad international support. We did not go by choice; we went because of necessity. I'm aware there's still some who would question or even justify the event of 9/11. But let us be clear: Al Qaeda killed nearly 3000 people on that day. The victims were innocent men, women, and children from America and many other nations who had done nothing to harm anybody. And yet al Qaeda chose to ruthlessly murder these people, claimed credit for the attack, and even now states their determination to kill on a massive scale. [...] These are not opinions to be debated; these are facts to be dealt with.

(Obama 2009c, emphasis added)

It can be asked whether the argument Obama makes in this passage is not an expression of cynicism. According to the argument, security trumps all other reasons, by necessity and not by choice, and this mode of reasoning is inscribed in the moral vocabulary of the executive office; the duty of a president to protect his people. As head of state, in other words, Obama cannot think otherwise. He represents a 'raison d'état', giving priority to security issues and the sovereign use of power to protect his people and defend his nation. In the terms of Michael Freeden, such an argument is an example of 'decontestation'; that is, it decontests the American military engagement in Afghanistan and, thus, removes the contestation of the decision to enter Afghanistan and increase the number of troops there (cf. Freeden, 2005). Applying Obama's own terms of cynicism to the statement, such a decision is cynical in the sense that it involves an absolutist use of sovereign power in combating Taliban and al Qaeda; absolutist, because 
the decision is not to be questioned; it was not a choice, it was taken by necessity. In his Nobel Peace Prize acceptance speech in Oslo half a year later, however, Obama denies this to be an expression of cynicism:

For make no mistake: Evil does exist in the world. A non-violent movement could not have halted Hitler's armies. Negotiations cannot convince al Qaeda's leaders to lay down their arms. To say that force may sometimes be necessary is not a call to cynicism - it is a recognition of history; the imperfections of man and the limits of reason.

(Obama 2009d)

This denial emphasizes Obama's reflections on the reality of political life, the evils of the world, the imperfections of man and the limits of reason, while at the same time keeping up the aim of a moral imagination without falling back in despair. This emphasizes Obama's debt to Reinhold Niebuhr and his Christian realism. He repudiates cynicism but recalls a realistic hope acknowledging the evil in the world and the practical necessities to combat evil (de Vries 2012). Whereas Niebuhr would describe himself as a 'tamed cynic', however, Obama would not. In the argument, he does not open up for criticism and the contestation of the claim that security trumps all other reasons and points of view. In the words of Richard Rorty (1999), his argument therefore works as a 'conversationstopper'. If it is not justified; it can create the despair Obama seeks to avoid. In that sense, an argument like Obama's creates cynicism in terms of disillusionment and distrust among the people. It delegitimizes other points of view and reasons and, thus, indicates that nothing could be imagined differently.

One could ask, however, whether Obama is not doing what Judith Shklar requires, namely putting cruelty first. He is fulfilling the duty of his public office as president and he has a moral sense of the evils of the world that he has to eliminate. He has cultivated a practical wisdom that, in some situations, 'the use of force' is 'not only necessary, but morally justified' (Obama 2009d). In that sense, he indicates that some decisions are necessary, but can also be justified morally. This might rather be a tragic necessity where one must make a decision; and by making the decision, place some moral imperatives aside while following others. While this might dirty the hands, Obama insists that this is justifiable (cf. Bellamy 2010; Coady 2008; Walzer 2007). This situation can be illustrated by the killing of Osama bin Laden on May 1, 2011. On that occasion, Obama said:

Americans understand the costs of war. Yet as a country, we will never tolerate our security being threatened, nor stand idly by when people have been killed. We will be relentless in defense of our citizens and our friends and allies. We will be true to the values that make us who we are. And on nights like this one, we can say to those families who have lost loved ones to al Qaeda's terror: Justice has been done. [...]/The cause of securing our country is not complete. But tonight, we are once again reminded that 
America can do whatever we set our mind to. [...]/Let us remember that we can do these things not just because of wealth of power, but because of who we are: one nation, under God, indivisible, with liberty and justice for all.

(Obama 2011b)

The remarks on the killing of Osama bin Laden have three elements of argumentation worth noting: first, the security argument is repeated; second, the killing is morally justified with reference to a notion of justice ('Justice has been done'); and third, the search for justice is presented as a common endeavour that has united the American people, and now, when this search for justice has been fulfilled, it represents the energy this unity has in healing the collective wounds by action in concert on the basis of the crucial values embedded in the American political tradition. In that sense, Obama's justification of his dirty hands reflects the moral imaginations that he would like to create among the American citizenry. This is what Richard Bellamy (2010) refers to as 'dirty hands' with 'clean gloves'. Obama admits that he himself can feel 'doubtful or cynical', but 'what gives' him 'the most hope is the next generation - the young people whose attitudes and beliefs and openness to change have already made history' (Obama 2008b). In that sense, he acknowledges the possibility of cynicism in terms of despair and disillusion, but he defends himself against cynicism understood as the absolutist use of sovereign power. That is how Obama distinguishes between which kind of cynicism he can live with and which kind he cannot accept.

One could ask, however, whether he reflects sufficiently on the kind of cynicism he cannot accept and whether he takes the awareness of the ordinary vices implicit in everyday political life seriously enough and, like the ancient cynics, considers the natural human fallibility and imperfections a reason for ethical self-cultivation, critical attitude and truthful speech sufficiently to give voice to the people and the political community of plural moralities. Although related to the character virtues of humility, fallibility and sense of imperfection, the ordinary vices remain veiled by his vocabulary of moral imaginations intended to give hope and energize the citizens of America - and the world - in common endeavours. According to Peter Sloterdijk (1987), Obama would be a cynic despite repudiating cynicism all the way. He is cynical, because he knows he has the power to do what he does and he is still using this executive power; although, in his own terms, it was an example of cynicism when his opponents did the same. He claims that he has justified his own use of power morally - but how? Has he been enlightened by the democratic conversation that he praises? What seems to be missing - in Sloterdijk's terms - is a more self-critical and -reflective attitude and approach to the exercise of power. From this point of view, one could wish that he brings his relationship with philosophical pragmatism to the fore and shows a stronger sense of the plural meanings of cynicism in politicaladministrative life. One way of doing this would be to take Shklar's priority of cruelty as a negative moral standard seriously and integrate this knowledge in one's reflections regarding the limits of cynicism. 


\section{Bibliography}

Aboulafia, M. 2010. 'Afterword' to Transcendence: On Self-Determination and Cosmopolitanism. Stanford: Stanford University Press. http://sup.org/books/pages/17999/ Afterword.pdf.

Alexander, J. C. 2010. The Performance of Politics: Obama's Victory and the Democratic Struggle for Power. Oxford: Oxford University Press.

Bellamy, R. 2010. 'Dirty hands and clean gloves: liberal ideals and real politics'. European Journal of Political Theory 9: 4, 412-30.

Bernstein, R. J. 2005. The Abuse of Evil: The Corruption of Politics and Religion since 9/11. Cambridge: Polity Press.

Bernstein, R. J. 2010. The Pragmatic Turn. Cambridge: Polity Press.

Coady, C. A. J. 2008. Messy Morality: The Challenge of Politics. Oxford: Oxford University Press.

Desmond, W. D. 2006. The Greek Praise of Poverty: Origins of Ancient Cynicism. Notre Dame: Notre Dame University Press.

Elridge, M. 2011. 'Linking Obama's pragmatism to philosophical pragmatism: Obama as a pragmatic democrat (and why it matters)'. Contemporary Pragmatism 8: 2, 113-21.

Freeden, M. 2005. 'What should the "political" in political theory explore?' Journal of Political Philosophy 13, 113-34.

Kloppenberg, J. T. 2011. Reading Obama: Dreams, Hope, and the American Political Tradition. Princeton: Princeton University Press.

Koopman, C. 2011. 'Pragmatist interpretations of Obama: on two ways of being a pragmatist'. Contemporary Pragmatism 8: 2, 99-112.

Laursen, J. C. 2009. 'Cynicism then and now'. Iris: European Journal of Philosophy and Public Debate 1: 2, 46982.

Mazella, D. 2007. The Making of Modern Cynicism. Charlottesville: University of Virginia Press.

Obama, B. 2008a [2006]. The Audacity of Hope: Thoughts on Reclaiming the American Dream. New York: Vintage Books.

Obama, B. 2008b. 'A More Perfect Union'. Philadelphia, 18 March 2008 http://my. barackobama.com/page/content/hisownwords (visited 1 February 2011).

Obama, B. 2009a. The Inaugural Address 2009. New York: Penguin Books.

Obama, B. 2009b. 'Executive Order on Ethics Commitments By Executive Branch Personnel'. 21 January 2009 www.whitehouse.gov/goodgovernment/actions/firstprinciples\#ethics-menu (visited 1 February 2011).

Obama, B. 2009c. 'A New Beginning'. Cairo University, Cairo, Egypt, 4 June 2009 www.whitehouse.gov/the-press-office/remarks-president-cairo-university-6-04-09 (visited 1 February 2011).

Obama, B. 2009d. 'Acceptance of the Nobel Peace Prize'. Oslo City Hall, Oslo, Norway, 10 December 2009 www.whitehouse.gov/the-press-office/remarks-president-acceptancenobel-peace-prize (visited 1 February 2011).

Obama, B. 2011a. 'Remarks at a Memorial Service for the Victims of the Shooting in Tucson, Arizona'. University of Arizona, Tucson, Arizona, 12 January 2011 www. whitehouse.gov/the-press-office/2011/01/12/remarks-president-barack-obamamemorial-service-victims-shooting-tucson (visited 1 February 2011).

Obama, B. 2011b. 'On Osama bin Laden'. 2 May 2011 www.whitehouse.gov/the-pressoffice/2011/05/02/remarks-president-osama-bin-laden (visited 9 May 2011).

Rorty, R. 1999. 'Religion as conversation-stopper'. In R. Rorty, Philosophy and Social Hope. New York: Penguin Press, pp. 168-74. 
Runciman, D. 2008. Political Hypocrisy: The Mask of Power, from Hobbes to Orwell and Beyond. Princeton: Princeton University Press.

Sandel, M. 2010. 'Obama and civic idealism'. Democracy: A Journal of Ideas 16, 9-14.

Schultz, B. 2009 'Obama's political philosophy: pragmatism, politics, and the University of Chicago'. Philosophy of the Social Sciences 39: 2, 127-73.

Schultz, B. 2011. 'Pragmatist in chief: further reflections on the pragmatism of Barack Obama'. Contemporary Pragmatism 8: 2, 7-15.

Shea, L. 2010. The Cynic Enlightenment: Diogenes in the Salon. Baltimore: Johns Hopkins University Press.

Shklar, J. N. 1984. Ordinary Vices. Cambridge, MA: The Belknap Press of Harvard University Press.

Sloterdijk, P. 1987. Critique of Cynical Reason, tr. Michael Eldred. Minneapolis: University of Minnesota Press.

Stout, J. 2010 Blessed Are the Organized: Grassroots Democracy in America. Princeton: Princeton University Press.

Vries, H. de. 2012 “"Simple ideas, small miracles": the Obama phenomenon'. In P. S. Gorski et al. (eds). The Post-Secular in Question: Religion in Contemporary Society. New York: New York University Press, pp. 105-34.

Walzer, M. 2007 [1973]. 'Political action: the problem of dirty hands'. In D. Miller (ed.), Thinking Politically: Essays in Political Theory. New Haven: Yale University Press, pp. 278-95.

Walzer, M. 2010. 'Missing the movement'. Democracy: A Journal of Ideas 16, 14-17. 


\title{
6 A Kantian rhetoric of sincerity Politics, truth and truthfulness
}

\author{
Pamela Sue Anderson
}

\section{On rhetoric: politics and ethics}

Immanuel Kant might be the last person to whom philosophers would turn to study a rhetoric of sincerity. Nevertheless, I will seek to articulate "Kantian" rhetoric as my interpretation of Kant's art of philosophical persuasion. I will also consider the inherent problem, which Western philosophers have had to face, in linking rhetoric and its properties to sincerity as truthfulness. ${ }^{1}$ To begin, I turn briefly to Aristotle who is better known for articulating a positive and lasting sense of philosophical rhetoric. Aristotle will, then, inform what is said about both rhetoric and politics in "A Kantian Rhetoric of Sincerity."

Aristotle develops the art of rhetoric into a high ethical science of speech and writing. ${ }^{2}$ As a science, rhetoric would, in turn, be legislated by the most authoritative science of all: politics. ${ }^{3}$ Aristotelian rhetoric rested on the ability of the philosopher to see what is persuasive in every situation for which he (sic) publically argued a case; but this did not mean that the rhetorician would always be able to convince the public in every situation. Moreover, Aristotle readily accepts that rhetoric can be misused. Nevertheless, he contends that "its abuse is no argument against its proper use on the side of truth and justice." 4 The proper use of rhetoric, in involving listeners or readers, equally supports, what I will argue is, "Kantian sincerity" in writing or speaking truthfully. Truthfulness means sincerity in politics. Thus, those speakers trying to establish - in Aristotle's sense of ethics as politics ${ }^{5}$ - what is true and just will need rhetoric, to persuade a public audience, especially an audience unable to follow, or to be convinced by, strictly formal logical argumentation.

Aristotle's three "modes" for persuasion are: (i) the personal character of the speaker; (ii) a certain frame of mind of the audience; and (iii) the words of the speech itself. ${ }^{6}$ Aristotle's "means of effecting persuasion" are also three: (i) to reason logically; (ii) to understand forms of human goodness; and (iii) to understand emotions, their causes and ways. ${ }^{7}$ Although Kant never explicitly discusses modes and means of philosophical persuasion, I seek to demonstrate that he employs rhetoric, even if unwittingly, as political; and the means of Kantian rhetoric include - similar to Aristotelian rhetoric - logic, ethics and emotions. 
Aristotle's definition of politics is the most authoritative "science of the good for man"; the science of rhetoric is one of its offshoots. ${ }^{8}$ Aristotle's Nicomachean Ethics studies the good for human beings as the end (telos) of political science. Although politics is the science of the good for "man" and the good for a single individual is worthwhile, Aristotle asserts, "it is finer and more godlike to attain [the good] for a nation or city-state." "We will find that Kant assumes a similar sense for ethics - as the good for humans individually and universally - which Aristotle claims for politics.

Let us bear in mind that an Aristotelian sense of politics is employed, at times, as synonymous with both ethics and rhetoric. As both a philosophical art of persuasion and a high ethical science of speech and writing, Aristotle's rhetoric brings us close to what a Kantian philosopher requires for a rhetoric of sincerity. Despite any negative sense of rhetoric, with its dangers for philosophical argumentation and for ethics, my aim is to elucidate a Kantian rhetoric of sincerity, especially its positively persuasive roles for politics, truth and truthfulness. I will assess, in particular, the ethical salience of Kant's rhetorical distinction between - on the one hand - telling the whole truth as candour (Offenherzigkeit), and - on the other hand - truthfulness (Wahrhaftigkeit), sincerity (Redlichkeit) and uprightness (Aufrichtigkeit); the latter German word is, at times, also translated as sincerity. ${ }^{10}$

\section{On sincerity: truth and truthfulness in Kant's writings}

Kant's ethical and religious writings contain passages where sincerity is articulated philosophically in comparison with a range of human dispositions from candour to uprightness and sincerity. With the help of "the philosophical imaginary," Kant persuades his readers that the sincerity of human subjects is truthfulness. ${ }^{11}$ While truthfulness will be seen as the opposite of lying, candour - in telling the whole truth - will be distinguished from sincerity. Kant's rhetorical strategies concerning sincerity will involve us in the philosophical art of persuasively employing subtle ethical distinctions aimed at truthfulness in politics. Here politics will be understood in the Kantian sense of the public use of reason, where public means universal.

However, when employed to convey the ethical or political significance of sincerity, Kant's rhetoric raises both a practical and a logical question of consistency with his well-known, early conception of the perfect duty to others not to lie. ${ }^{12}$ To avoid contradiction, I suggest that he distinguishes two kinds of perfect duties not to lie: (1) a narrow duty to others not to lie; and (2) a wide duty to oneself not to lie to oneself or to others. At various points, I will refer to these two.

A practical illustration of the distinctions between candour and sincerity, and between truthfulness and lying, is found in Kant's response to a letter which he received in 1791 from Maria von Herbert. At that time, Kant was 70 years old and living in Konigsberg; Maria was 20 years old and living in Austria where she had read Kant's ethics. (Apparently, her brother had introduced Maria to 
reading Kant.) Maria's letter to Kant raises philosophical questions about truth and right action, especially intriguing is the question of candour.

Kant employs salient ethical distinctions to persuade Maria about the nature of sincerity (Redlichkeit), the moral significance of uprightness (Aufrichtigkeit), but also about the differences of these two terms to candour (Offenherzigkeit). The exact meanings of these (German) terms are contentious matters in interpreting the eighteenth-century, international exchange between the elderly philosopher, Immanuel Kant, and the young woman, Maria von Herbert. ${ }^{13}$ A critical point of contention is whether or not Kant would demand complete candour of any human agent. I contend that this point recalls Kant's "An Answer to the Question, 'What is Enlightenment?", (1784), where his rhetoric concerning the scholar, the teacher and the clergy(man) persuasively defends an Enlightenment sense of sincerity. ${ }^{14}$ This Enlightenment sense renders a Kantian rhetoric of sincerity useful today for politics as the good for human beings in the public, but also in the private, use of reason.

Moreover, in his Religion within the Boundaries of Mere Reason (1793) Kant employs rhetoric to involve his readers in thinking about sincerity as truthfulness. ${ }^{15}$ This rhetoric distinguishes sincerity from candour; the former is a good moral disposition, from which Kant distinguishes candour and questions its ethical role. But this means questioning whether "telling the whole truth" is ethically necessary. If not, is Kant persuading us that telling the truth is not a perfect duty for human subjects? ${ }^{16}$ At a minimum, Kant's rhetorical distinction places truthfulness on the side of human sincerity and as the opposite of lying. As we will see, according to this rhetoric of truth and truthfulness, the latter as sincerity is to be cultivated as a virtue.

One objection might be that not truthfulness, but telling the whole truth is the opposite of lying. We know when we have told a lie; we have a perfect duty not to lie; and we lie when we have not told the whole truth which we know; so, the opposite of lying is telling the whole (known) truth. In response to this objection, I will argue that the Kantian agent has limited knowledge of the truth concerning her or his own motives for action, in this case, for lying. So, to fulfill Kant's moral law, and "act for the sake of duty alone," it is necessary and sufficient when it comes to not lying, "that everything said be said with truthfulness." 17 Once we have cultivated truthfulness, we intend to act for the sake of the duty alone, not intending to lie.

As I will demonstrate, for Kant, truthfulness is judged by an inner consciousness of what we honestly intend as the maxim of our actions (even if we don't know all of the truth about [our] actions and intentions). When it comes to sincerity, the intention is to speak truthfully. My interpretation of Kant's philosophy is that, as human, we can never know all the things, which might be known about what is said; we could be wrong both ethically and epistemologically; and yet, sincerity as truthfulness is achievable. We must avoid the danger of candour, which would produce "inward hypocrites."18

If we take an example from Nazi Germany, we begin to see the problem with assuming that our only choice is either lying or telling the whole truth. I might 
have lied about hiding a Jewish woman in my house when a Nazi officer came to my door looking for her. Consistent with Kant's “On A Supposed Right To Lie from Philanthropy" (1797), I would not know when asked, if in fact the Jewish woman was not in the house because without my noticing she had fled out the bathroom window. ${ }^{19}$ Ironically, in this case, when I think that I have told the truth, in saying that the Jewish woman is in my house, I have not told the truth: no Jewish woman is hiding in my house. The point is we might lack knowledge of the whole truth of the matter. Nevertheless, we can act with sincerity: that is, act for the sake of the duty alone, and let everything said be said with truthfulness! This is consistent with Kant's conclusion: "To be truthful (honest) in all declarations is therefore a sacred command of reason prescribing unconditionally, one not to be restricted by any conveniences. ${ }^{20}$

Similar to Kant's reply to Maria, the rhetoric in Religion seeks to persuade us that a perfect duty not to lie does not require candour. In the fourth section of this chapter, we will learn that a direct consequence of Maria's open-heartedenss concerning an earlier lie is the loss of her fiancé. Of course, any negative consequence of this candour does not constitute a Kantian objection to Maria having told the whole truth without restraint. However, Kant (seeks to) persuades us that it is not necessary to tell all we know, or think we know, to fulfill the duty not to lie. So, again, Kantian rhetoric supports truthfulness as both necessary and sufficient for the perfect duty not to lie. "Being truthful" as a perfect duty would ensure that we know when we lie, that is, when we are not (inwardly) truthful. Thus, we should and can be sincere.

Nevertheless, critical questions are raised about Kant's rhetoric in response to the honest, young woman, Maria: that it is not (always) necessary to tell the whole truth! Won't this be lying by Kant's own ethical standards? Kant tries to persuade his reader that the perfect duty of an honest woman is (only) to hold fast to truthfulness; and so, to a human predisposition of sincerity. ${ }^{21}$ I propose that this persuasion is consistent with Kant's account of the morally weak nature of a man (or, a woman) and epistemologically limited nature of a woman (or, a man). ${ }^{22}$ Given the finitude of both the one who is told the truth and the truth teller, Kant's predisposition to sincerity requires appropriate restraint on telling the whole truth; such restraint is arguably a result of the "inner religion," which Kant will associate with conscience. ${ }^{23}$ This rhetorical move from truth to truthfulness is political, allowing a certain leeway for the honest agent to recognize his or her duty in the public use of reason. Reticence is ethically necessary, when it comes to telling whatever amount of truth a man or a woman knows, while treating one another as ends in ourselves.

Thus Kantian rhetoric, in communicating fine distinctions, makes up a philosophical art of negotiating highly nuanced ethical matters: the key issue is whether we are persuaded that we can be truthful, but not tell everything we know, and still fulfill our perfect duties. Kantian rhetoric implies that truthfulness will not undermine our perfect duties (not to lie); but then, a further issue is whether or not misleading is wrong. The critical question remains whether a Kantian rhetoric of sincerity can convey the appropriate distinction between 
sincerity and candour, while also remaining consistent with Kant's earlier writings on moral obligation: that is, consistent with the absolute necessity not to lie to others. ${ }^{24}$ If not, this Kantian rhetoric would fail to uphold Kant's perfect duty to others not to lie.

So, we arrive at the heart of the challenge for this chapter: we need to discover whether we can speak with sincerity - without lying - in negotiating between truthfulness and the truth. The rhetoric in Religion helps Kant to argue that the dispositions of sincerity and candour are not opposites, giving us a distinction between saying everything with truthfulness and telling the whole truth. By employing an appropriate rhetoric of sincerity with ethically persuasive claims of truthfulness, the good Kantian agent - following Kant's initial reply to Maria - is to maintain her or his perfect duties not to lie. I call this rhetoric of sincerity "Kantian," insofar as it persuasively links politics, truth and truthfulness.

\section{Kant's rhetorical strategies}

The previous section introduced key writings for a Kantian rhetoric of sincerity. A crucial premise is that Kantian rhetoric introduces the practical distinctions necessary for sincerity. The most fundamental distinction is that between truthfulness and lying: sincerity as truthfulness is the opposite of lying. ${ }^{25}$ Now, interpretative questions about Kant's rhetorical strategies take us into the heart of politics. Why does Kant describes it a "private" use of reason when the clergy(man) is sincere, in withholding candour, when doing his "official" duties? The additional distinctions of private and public reason, and of official and unofficial duties, give a slightly odd sense to the clergy's strictly "private," not public or universal, use of reason in not telling the whole truth. Are these distinctions right? Distinguishing different practical identities such as those of clergy and scholar, Kant seeks to persuade us when we have a duty to (if ever), and how we, tell the whole known truth.

In "An Answer to the Question: 'What is Enlightenment?'," Kant persuades us that the rational agent, whose practical identity is that of a clergy(man), takes up official (private) duties for the church. However, if the clergy(man) finds "he" cannot fulfill these official duties in good conscience because of disagreeing with what he is expected to say or do, then he will have to give up his official clerical position, at least temporarily. In so doing, this "man" no longer has the practical identity of the clergy in the private use of reason. He is, then, free to take the identity of scholar in the autonomous, public use of reason; he can make a truthful declaration of his view. ${ }^{26}$

This Kantian rhetoric of truthfulness and truth concerning the clergy and the scholar can be translated into the contemporary terms of barrister. ${ }^{27} \mathrm{~A}$ barrister fulfills her or his official duties rhetorically with truthfulness. When the barrister acts on behalf of a criminal, making a persuasive defence, that barrister is not defending her or his own views of the crime or the criminal. Nor does the barrister speak all of the truth, which she or he knows. But a barrister gives up her 
official role to take on a practical identity of autonomous agent, to speak her own mind in public. Like the scholar, this rational agent is no longer constrained by duties of the bar. Thus, she is free to speak truthfully her own view.

Kant's rhetorical strategy of employing practical identities to make a point conveys subtle nuances in how human subjects fulfill their duty not to lie. This rhetoric does not change substantially Kant's position on the perfect duty not to lie. Instead it clarifies private and public relationships. Admittedly, Kant's private and public distinction raises contentious matters for politics; and there is not space to tease out the full ramifications of this debatable political distinction. ${ }^{28}$ Nevertheless, understanding Kant's rhetorical use of private and public is also necessary for challenging the roles which Kant gives to women and men; my concern is whether Kant shows appropriate awareness of individual differences across gender distinctions for politics, truth and truthfulness.

Other Kantian and non-Kantian ethicists might object to Kant's rhetorical strategies. Are truth and truthfulness merely rhetorical terms that, in the end, fail to guide ethical action? A Kantian distinction between truth and truthfulness is undeniably important for politics after Kant. ${ }^{29}$ And yet destabilizing questions about truth and truthfulness can also be threatening to both ethics and politics.

I defend the rhetorical and political uses of these distinctions to persuade ethicists that sincerity is necessary for the complexity of politics and for what we hold to be true. Kant's rhetorical distinction between truth and truthfulness is ethically salient to enable confident application of Kantian sincerity to religious matters. In the next section, we will see how to adopt Kant's distinctions, to make both true and truthful assertions with good dispositions. I will need to demonstrate that a Kantian rhetoric of sincerity requires a human subject neither to know the truth of everything said nor to disclose everything she knows.

\section{Maria's letter and Kant's reply}

In 1791, after publishing "An Answer to the Question: 'What is the Enlightenment?'” (1784), but before publishing Religion (1793), Kant receives Maria's rhetorical request for divine guidance, persuading him to reply in the same spirit. Kant takes on the gendered authority of the ideally good man-god who answers Maria in the rhetorical form of a sermon. Maria's pleading for divine help begins,

Great Kant! As a believer calls to his God, I call to you for help, for solace, or for counsel to prepare me for death. The reasons you gave in your books were sufficient to convince me of a future existence - that is why I have recourse to you - only I found nothing, nothing at all for this life, nothing that could replace the good I have lost. For I loved [someone] that seemed to me to encompass everything (...) so that I lived only for him. (...) Well, I have offended this person, because of a protracted lie, which I have now disclosed to him though there was nothing unfavourable to my character in it - I had no viciousness in my life that needed hiding. The lie was enough, 
though, and his love vanished. (...) Oh, my heart splits into a thousand pieces! If I hadn't read so much of your work I would certainly have put an end to my life. But the conclusion I had to draw from your theory stops me - it is wrong for me to die because my life is tormented (...) I've read the metaphysic of morals, and the categorical imperative, and it doesn't help a bit. My reason abandons me just when I need it. Answer me, I implore you - or you won't be acting in accordance with your own imperative. ${ }^{30}$

Maria's assumptions about Kant's perfect duties in her rhetorical pleading reveals her knowledge of his wide duty; she has sought to fulfill the perfect duty to herself not to lie to herself or to others. Six years later Kant mentions this sense of duty in "On a Supposed Right to Lie from Philanthropy." 31 But in 1792, his rhetorical role as the highest male and/or divine authority is to exhort Maria to be honest on the grounds of "the dignity of humanity in our own person." 32

Your deeply felt letter comes from a heart that must have been created for the sake of virtue and honesty, since it is so receptive to instruction in those qualities.

(...) The sages of old complained of [a] secret distrust - "My dear friends, there is no such thing as a friend!" (...) We can't expect frankness [candour] of people, since everyone fears that to reveal himself completely would be to make himself despised by others. But this lack of frankness [candour], this reticence, is still very different from dishonesty. What the honest but reticent man says is true, but not the whole truth. What the dishonest man says is something he knows to be false. Such an assertion is called, in the theory of virtue, a lie. It may be harmless, but it is not on that account innocent. It is a serious violation of a duty to oneself; it subverts the dignity of humanity in our own person, and attacks the roots of our thinking. As you see, you have sought counsel from a physician who is no flatterer. (...) if your reproach is grounded in a moral judgment of your behaviour, it would be a poor moral physician who would advise you to cast it from your mind. When your change in attitude has been revealed to your beloved, only time will be needed to quench, little by little, the traces of his justified indignation, and to transform his coldness into a more firmly grounded love. If this doesn't happen, then the earlier warmth of his affection was more physical than moral, and would have disappeared anyway - a misfortune which we often encounter in life, and when we do, must meet with composure. For the value of life, insofar as it consists of the enjoyment we get from people, is vastly overrated. Here then, my dear friend, you find the customary divisions of a sermon: instruction, penalty and comfort. Devote yourself to the first two; when they have had their effect, comfort will be found by itself. ${ }^{33}$

Kant's reply could be analyzed in more detail than I will do here. (I could assess the role of emotion; Kant's claim about how to find comfort; the sense of heartlessness that nevertheless pervades his "instruction" and "penalty." Thinking of 
the serious distress which Maria expresses, Kant offers inadequate emotional encouragement to the young woman, merely dismissing "the enjoyment we get from people" as "vastly overrated.").

My focus remains on a Kantian rhetoric of sincerity as evident in the (above) rhetorical terms of honesty, dishonesty, duty, reticence and truthfulness. Each of these terms in the sermon format helps to make a persuasive case for Kant's good guidance. Dishonesty is distinguished from true assertions; reticence from expressing the whole truth. This reticence means ethical restraint; but it might also imply what Kant elsewhere describes as inner consciousness and a predisposition to sincerity. ${ }^{34}$

A year prior to his reply to Maria, Kant had published, "On the Miscarriage of All Philosophical Trials in Theodicy" (1791). Again Kant presents the two different kinds of distinctions: truthfulness is the opposite of lying; and truthfulness is closer to uprightness than to candour. But he makes two additional assertions about truthfulness and truth. First,

[o]ne cannot always stand by the truth of what one says to oneself or to another (for one can be mistaken); however, one can and must stand by the truthfulness of one's declaration or confession, because one has immediate consciousness of this. ${ }^{35}$

\section{Second,}

if someone says to himself ... that he believes, without perhaps casting even a single glimpse into himself - whether he is in fact conscious of thus holding a truth or at least of holding it to some degree - then such a person lies. ${ }^{36}$

So, we have "truthfulness of one's declaration" distinguished from "the truth of what one says"; and we have an inner consciousness of "holding a truth" as a necessary condition to ensure a person is not lying. Kant's conclusion concerning sincerity as "a predisposition" is missing from this 1791 essay.

Later the two assertions (above) come together in Religion (1793). Truthfulness and an inner consciousness of holding something as true meet in the predisposition to sincerity:

I can admit, though it is much to be deplored, that straightforwardness ${ }^{37}$ (saying the whole known truth) is not to be found in human nature. But we must be able to demand sincerity (that everything said be said with truthfulness) of every human being, and if in our nature there were no predisposition to it, whose cultivation is only being neglected, the human race would have to be in its own eyes an object of deepest contempt. ${ }^{38}$

This passage, from a footnote in Religion, explains sincerity in terms similar to those in contemporary philosophy of a "sincerity condition" 39 - to which I will return. 


\section{Kant's ethical and religious philosophy}

Let us consider more closely what Maria's letter reveals about her knowledge of Kant's ethics and what Kant's reply reveals about right and good. Maria knew from Groundwork to the Metaphysics of Morals that Kant's moral law as the ground of obligation carries with it "an absolute necessity"; and that his first example of the moral law is "thou shalt not lie." 40 The nature and amount of her knowledge of Kant's view of lying appear similar to popular knowledge of Kantian duty today. However, Kant's reply to Maria's letter challenges the simplicity of this common view of duty. Doesn't the perfect duty not to lie require a simple, straightforward application! I offer further background.

In Maria's letter, as we have seen, she explains having followed Kant's categorical imperative, addressing her duty to refrain from lying, by seeking to tell the whole truth to her fiancé about an earlier lie which she had concealed from him. But the outcome of this candour will end in loss of his love. ${ }^{41}$ So, it might seem to the non-Kantian ethicist that Maria would have been better off not being completely honest with her fiancé.

In Kant's reply, given his conception of a perfect duty to others, it is surprising to find the suggestion that Maria need not have told her fiancé the whole truth. Kant's ethical view appears to be that only truthfulness is necessary. Perhaps this makes Maria's relationship to her fiancé more like the clergy(man)'s relationship to his parishioners! Remember that the clergy(man)'s official duties are private rather than public. Nevertheless, Maria - and we - might have expected to hear Kant maintaining that the ethically right action is always to tell the whole truth. If truthfulness is sufficient for Kantian sincerity, we might think that this rhetoric undermines the application of Kant's categorical imperative when it comes to the perfect duty to others to refrain from lying. ${ }^{42}$

In response to this issue, let us return to Kant's Religion and consider another dimension of Maria's case. To the rhetoric distinguishing truthfulness from telling the whole truth, Religion adds the distinction between divine and human beings. Here Kant maintains that perfect goodness and full rationality describe the moral judgment of a divine being: only a divine being knows the whole and perfect truth. Adding this dimension of divine being(s) to Kant's politics, we discover another reason for a Kantian rhetoric of sincerity: the rhetorical distinction of human, not divine is equally implicit in Kant's conception of duty. Good is what human moral agents ought to be, but only a divine being is perfectly good. The human subject is not divine, so is never wholly true to herself or himself, or to others. Instead, as human, we have at most a perfect duty to self to be truthful to oneself and to others. We strive to cultivate ethically good dispositions with the hope of perfect virtue, knowing that as human we can never know fully (our) moral perfection in this life. In the rhetoric of Religion, the "morally well-disposed human being" continues to struggle with evil; moral striving continues, even when free to "live for righteousness": 
The battle that every morally well-disposed human being must withstand in this life, under the leadership of the good principle, against the attacks of the evil principle, can procure him, however hard he tries, no greater advantage than freedom from the dominion of evil. That he be free (...) this is the highest prize that he can win. He still remains not any the less exposed to the assaults of the evil principle; and to assert freedom, which is constantly under attack, he must henceforth remain forever armed for battle. ${ }^{43}$

This rhetorical imagery concerning a battle between the principles of good and evil evokes an only too human moral struggle.

In the chapter, following Religion's discussion of the good and evil principles, we find the crucial footnote, from which I quoted earlier. Here Kant is clear: with his rhetorical distinction between sincerity and candour, only the former functions as a moral virtue. ${ }^{44}$ Kant's rhetorical strategy is to portray sincerity in a narrative aside, referring to an ancient myth about the goddess of uprightness (sincerity), who must flee Earth for Heaven to preserve her openheartedness. This narrative deifies truth and sincerity; yet human beings (ought to) seek to be truthful with no assurance of their impact on others. So, Kant personifies sincerity, as a young virgin, the goddess Astraea who flees Earth for Heaven; humans do not know how to get Astraea to return.

More prominent than Kant's rhetoric about divine and human beings is his title, declaring rational boundaries for human religion. The difference between divine and human reason is implicit in placing "religion within the boundaries of mere reason., ${ }^{\prime 45}$ It follows that Kant's divine ideal of perfect goodness - that is, "the ideal of moral perfection ... the prototype of moral disposition in its entirety purity" 46 - is regulative for human reason. The boundaries marking the difference of the human from the divine persuade us that perfect goodness and absolute truth in politics - as in moral religion - are unachievable for human beings.

The difference which being human, rather than divine, makes to truth is significant for Kant's distinction between truthfulness and lying. Now we understand that this distinction is required for finite rational agents who live under non-ideal conditions. As human, our knowledge of truth is limited; and our good dispositions are weak, threatened by evil. So, as long as we are human and not divine, Kant must hold that we can never know if, or when, we achieve the ideal of perfect goodness. In Maria's case, she could know both that and what she had lied. And, in retrospect, she could tell the truth of her lie. But once she had undone her lie, Maria merely accepts Kant's penalty for having to undo her lie. At the same time, Kant's instruction to Maria implies that we should - and, indeed, can - not demand of any human agent perfect candour or sincerity without appropriate reticence. We must turn to inner consciousness before we speak openheartedly. Kant continues to maintain that we should not lie; the opposite of lying is truthfulness. We have the ability to communicate what is truthful, without disclosing everything, which is (said to be) known to be true.

In returning to Groundwork with a Kantian rhetoric of sincerity, we can maintain the distinctions between truthfulness and candour, and between truthfulness 
and lying. Maria brought to our attention that telling the whole truth to her fiancé might not be the right action. Unlike the perfect duty to others not to lie to others in the Groundwork, Maria refers to a perfect duty to self not to lie to oneself or to others. Kant cautions her, claiming that reticence may be ethically necessary when telling the truth. So, is Kant referring to a nuanced duty to self in his letter to Maria? Kant advocates reticence, apparently because it allows us to take into account the imperfection of men and women. And then, the duty to self to refrain from lying must also protect one's own integrity with regard to what we tell others.

Sincerity in practical reasoning may be incompatible with popular uses of the categorical imperative. How far we can push the differences between Kant's categorical imperative, requiring the perfect duty to others not to lie, and Maria's duty to herself not to lie to herself, allowing ethical reticence? A gendered reading of personal relations between women and men might consider assessing Kant's awareness of a young woman who is vulnerable in her relations to a man whom she loves; and so, she must not treat herself as a mere means to her fiancé's happiness. Is it so astounding that he had a highly specific reading of gender? Evidence of Kant's awareness - to some degree of gender - makes sense when we include moral virtues, accompanying a wide, perfect duty to self. ${ }^{47}$

No human can achieve perfection knowingly. Yet fulfilling our duty to humanity in itself is possible and necessary; this includes the perfect duty to self for women and men. When reticence is motivated by a duty of humanity in her person it acquires moral worth. In contrast, a merely prudential reason for (this) reticence would be non-moral. In a social world like Kant's - and ours - where manipulation of one another is part of life, and so is using a lover as "a mere means," a Kantian rhetoric of sincerity tells us something about his awareness of human ethical, religious and personal life; this life includes intimate relations, marriage and its failures. Thus, we see how crucial rhetoric is in addressing the highly nuanced dimensions of (gender) politics.

In defending the ethical salience of Kant's rhetorical distinctions, I have in mind Maria's emotional state; after having told the whole truth, she suffers for the candour shown to her beloved. Of course, Kant is not going to advocate that in the future "she think of the consequences before she acts"! Instead he urges her to consider fine distinctions internal to the duty of truthfulness as a duty to self not to lie to one's self or to others. Moreover, Kant's Religion confirms what I take to be Kant's advice. A moral reason exists for maintaining ethical reticence: the good is always an "ought" for human beings. This means Maria's beloved may not respond as he ought; she did not always tell the truth. Only a divine being is perfectly good; only a divine always knows and tells the whole truth.

\section{Kant's rhetoric and the philosophical imaginary}

It is important to explore the role that the philosophical imaginary plays in a Kantian rhetoric of sincerity, as it shapes Kant's philosophical writing. This imaginary accompanies philosophical arguments in what we have seen to be the 
gendered imagery, narrative asides, mythical figures, human and divine beings in Kant's texts. ${ }^{48}$ These elements connect Kant's texts with other texts in the history of philosophy, by illustrating sincerity's affinity to truthfulness with ethically nuanced distinctions and connections between various terms.

In my central ethically salient example, Kant portrays sincerity with a narrative about a mythical figure, Astraea, the goddess of Aufrichtigkeit (sincerity). Taking up imagery from myths known by Western philosophers, Kant shows how perfect moral truth flees Earth to Heaven where sincerity reigns supreme. Astraea is the daughter of Themis; the mother represents justice, while the daughter represents sincerity. Exploiting this philosophical imaginary - of Greek mythology - a Kantian rhetoric of sincerity takes Astraea to be the divine being who left Earth where human beings can cultivate truthfulness, but not perfect righteousness. The narrative concerning the flight of Astraea from Earth enables Kant to represent the distance of human beings from the perfect uprightness of a divine being in Heaven. In contrast, a human being as morally imperfect can be upright only with appropriate reticence applied to truth telling. The rhetorical distinctions, dividing Earth and Heaven, human and divine, have enabled Western philosophers to imagine an original, unconditioned condition of moral innocence: what I have referred to as Kant's assumption of a human predisposition to sincerity. While Astraea was on Earth she portrayed an original predisposition of innocence; and the imagery of Heaven and Earth portrays a moral (possibly, ontological) distance between divine and human beings.

Finally, I turn to the full extent of the crucial footnote in Religion. This reflects the philosophical imaginary at work in Kant:

Oh sincerity! You Astraea, who have fled from the earth to heaven, how are you (the foundation of conscience, and hence of all inner religion) to be drawn down from there to us again? I can admit, though it is much to be deplored, that straightforwardness (saying the whole known truth) is not to be found in human nature. But we must be able to demand sincerity (that everything said be said with truthfulness) of every human being, and if in our nature there were no predisposition to it, whose cultivation is only being neglected, the human race would have to be in its own eyes an object of deepest contempt. This required quality of mind is one, however, exposed to many temptations, and costs many a sacrifice, and hence also calls for moral strength, i.e., virtue (which must be earned), yet must be guarded and cultivated earlier than any other, for the opposite propensity is the hardest to extirpate if it is just allowed to take root. - Now contrast with it our manner of upbringing, especially in matters of religion or, better, doctrines of faith, where fidelity of memory in answering questions concerning them, without regard for fidelity of profession (which is never put to the test), is accepted as already sufficient to make a believer of him who does not understand even what he professes as holy, and one will no longer wonder at the lack of sincerity that produces nothing but inward hypocrites. ${ }^{49}$ 
This passage explains sincerity as "everything said be said with truthfulness." Kant is talking about a "moral strength," or virtue, which must be "earned" and "cultivated" with understanding. Truthfulness is not merely a narrow, perfect duty to others to refrain from lying. ${ }^{50}$ But it is, I submit, the perfect duty for the self to cultivate the predisposition of sincerity. Even though the truth cannot be known fully, sincerity in its association with an original innocence can be imagined as that which has fled Earth for Heaven. Thus, we find that understanding on matters of religion is rare; and Kant's knowledge of perfect truth, just like the divine ideal of the pure perfect moral disposition, is strictly speaking out of complete reach. And yet, we can make a faithful "profession" in being truthful.

The philosophical imaginary as part of our social and historical assumptions in philosophy is implicit in Kant's rhetorical use of a mythical narrative about a divine being who transcends human spatial-temporal limitations to a mythical place beyond the Earth: from Earth where human beings look to Heaven. As ancient mythology tells us, after leaving Earth Astraea is placed among the stars, where she becomes the constellation of Virgo as a star-virgin. So, Astraea is the innocent virgin, while Themis is the just mother portrayed holding a pair of scales, in which she weighs the claims of opposing parties in a human dispute (perhaps, at the entrance to Heaven).

By this point it should be clear that sincerity has a greater role to play in Kant's philosophy than expressing a perfect duty not to lie. This greater, critical role is not only supported by Kant's Religion, but also by "An Answer to the Question: 'What is Enlightenment?'." As mentioned already, the latter establishes the necessary conditions for any truthful assertion on religious matters: such an assertion requires both religious maturity and moral autonomy. Sincerity is required to unite "inner" religion and "outer" identity.

We have yet another distinction here - inner and outer - which requires negotiation for a Kantian rhetoric of sincerity. This distinction forces us to confront a tension, if not a contradiction, between the inner and outer roles of sincerity. For instance, one could be, as quoted earlier, "an inward hypocrite" with an outer (false) appearance of dutiful truth telling. The official identity of, say, the clergy is meant to be sincere. But he might need to change his practical identity from clergy to scholar, if he does not honestly hold to the church's official duties, to speak truthfully with the autonomous use of reason. Alternatively, the sincerity of one's inner religion might not be what appears outwardly to be sincere: can sincerity be seen? Inner religion demands sincerity; but the outer disposition does not necessarily express inner sincere. Admittedly, there is always the possibility of being sincere, where the inner and outer could both be truthful. Kant's rhetoric concerning the public use of reason 'should' mean the autonomous use of reason; and this enables sincerity.

\section{Conclusion}

A Kantian rhetoric of sincerity is neither a sketch of an ethical ideal nor a doctrine against social hypocrisy. Instead sincerity in Kant's ethical and religious 
philosophy requires the use of rhetorical strategies to enable our grasp of difficult and highly nuanced ethical features of human life and personal relationships. I have tried to anticipate those objections of Kantian ethicists who simply dismiss the idea that Kant has anything at all constructive to say to a woman who suffers a loss of love because of her attempt at openheartedness. Yet Maria's attempt at telling the whole truth to her beloved was informed by Kant's own ethics; she mentions studying his categorical imperative, the duty to others not to lie, and his metaphysics of morals, the perfect duties to self; but the ultimate result of her struggles with these duties was tragic for Maria (some years later Maria takes her own life). Kant takes seriously Maria's plight: a situation in which an honest and sensitive woman is abandoned precisely because she thought that the ethically right action was to tell the complete truth as she knew it to be. But we have learnt that things are not that simple in telling the truth and truthfulness. We would not say that Maria's action was wrong because of the consequences: she is abandoned by her fiancé, by love and any personal comfort. The real issue is that Maria's failure to grasp the highly complex nuances of Kant's ethics is a failure we recognize in ourselves.

So, if this chapter has contributed new insight into Kant's ethics, then I am pleased. But the new feature of his philosophy which I have defended is the role of rhetoric for Kantian politics, truth and truthfulness. I have directed readers to philosophical texts which exhibit a Kantian rhetoric of sincerity. Kant's surprising assessments of candour and of the enduring predisposition to sincerity as truthfulness are worth studying in more depth. The Kantian message for politics is to tread carefully, with sincerity tempered by ethical reticence, aware that human beings cannot have complete truth about the reality of their moral lives.

\section{Notes}

1 For the problem in linking rhetoric and its properties to sincerity (as truthfulness) in both making sense of our philosophical history and involving listeners or readers emotionally in how the past is understood, see Williams 2002: 242-50; also, for Williams' discussion of Kant on sincerity, lying and misleading, see ibid.: 101-10.

2 For the "art" of rhetoric, its role as persuasion and as an offshoot of politics, see Aristotle 2010: 7-8 (Book 1, Chapter 2, lines 25-9).

3 For rhetoric as a "science" legislated by politics, see Aristotle 1980: 2 (Book I, 1094a).

4 Aristotle 2010: viii.

5 Aristotle equates politics with "the science of the good for man" and "ethics" is another name for this science, 1980: 1-2 and 18 (1094a19-b12 and 1099b10-32).

6 Aristotle 2010: 7.

7 Aristotle 2010: 7-8.

8 Aristotle 1980: 2 (Book I, 1094a19-).

9 Aristotle 1980: 2 (Book I, 1094a).

10 English translations of Aufrichtigheit and Redlichkeit have been either "sincerity" for both terms or "uprightness" for the former and "sincerity" for the latter. For Aufrichtigheit as sincerity, see Kant 2009a: 211n347; 1996a: 206n+; cf. Kant 1793: 190n347; also see $120,171,180-2$ and 282. 
11 The role of "the philosophical imaginary" will be explored in discussing Kant's use of the Greek myth and imagery related to Astraea, to divine and human relations, and to the narrative asides, all of which connect Kant's philosophical argumentation with other texts in the history of Western philosophy; for further discussion concerning the philosophical imaginary in Kant's texts, see Anderson 2012: 169-77, 189-95.

12 Kant 1997: 2-3 (1785, 4: 389); also see 1997: 15 (1785, 4: 402-3). For his later articulation of the perfect duty to self not to lie to oneself or to others, see Kant 1996c: 611-15 (1797a). This perfect duty to self is most important in my discussion of Maria von Herbert's letter to Kant and his response to her.

13 For contentions concerning all of Maria von Herbert's letters to Kant and his responses, see Langton 1992: 481-505; and Walla 2013: 307-23.

14 I have put brackets around "man" in clergyman to signal that in Kant's day the clergy would have been men; but with his rhetorical strategies concerning practical identities it is not clear whether the category of "clergy" must include only men as Enlightenment continues today. I propose that this category include, for Kantian thinkers today, women if they are given the official duties of the clergy; see Kant 2009b: 1-11.

15 For sincerity as the translation of Aufrichtigheit and of Redlichkeit, see Kant 2009a: 60, 130, 133, 189, 211n347, 216n382 (Kant 1793: 52, 117, 120, 171, 180-182, 190n347, 195n382). Also, see Kant 1996a: 206n+.

16 For additional discussion concerning human and divine subjects, see Anderson 2013: 5-16.

17 Kant 1996a: 206n ${ }^{+}$(1793: 190n347).

18 Kant 1996a: 206n ${ }^{+}(1793: 190 n 347)$.

19 Kant 1996c: 612-613 (1797a, 8: 427).

20 Kant 1996c: 613 (1797a, 8: 427).

21 Kant 1996a: 206n+ (1793: 190n347).

22 The rhetorical properties of Kant's narrative concerning the origin of radical evil in human nature involve attributing moral weakness to the man (Adam) who is seduced by the whole truth. I propose that the whole truth, as told to Adam in the Genesis myth by the woman (Eve), includes not just the divine command but the truth concerning the tree of knowledge of good and evil; see Kant 1996a: $79-97$ (1793, 6: 32-6: 53).

23 Kant 1996a: 202-7 (1793, 6: 185-91).

24 Kant 1997: 2-3 (1785, 4: 389).

25 Kant 1996a: 206n ${ }^{+}(1793,6:$ 190n347).

26 Kant portrays the duties of the teacher and those of the clergy(man) as official and, in doing so, both the teacher and the clergy represent the private use of reason, see Kant 2009 b (1991): 5-6. For the damage done by priestcraft to the sincerity of the clergy, see Kant 1996a: 194-202 (1793: 176-85).

27 I owe my use of a barrister to an informal conversation with A. W. Moore; also, see Moore 2003: 89.

28 Feminist philosophers and political theorists have challenged more generally the Enlightenment distinction between private and public spheres of life: the decisive issue has been placing "private" life outside of political scrutiny and ethical judgment.

29 Williams 2002: 84-205.

30 Kant 1999: 379-80.

31 Kant 1996c: 611-15 (1797a, 8:425-8: 430).

32 For a less sympathetic reading of Kant's response to Maria, see Langton 1992: 481-505.

33 Kant 1967; cf. Kant 1999: 411-13.

34 See footnote 38 .

35 Kant 1996a: 34 (1791, 8: 267).

36 Kant 1996a: 34 (1791, 8: 268). 
37 Instead of "straightforwardness," other English translations use "candour" and "saying [or speaking] the whole truth that [or which] one knows," see Kant 2009a: $211 n 347$. Also, see Kant 1960: 178n.

38 Kant 1996a: 206n+. Kant's other discussions of "sincerity", in the "Doctrine of Virtue," have explained "sincerity" (Redlichkeit) in terms of "rectitude" (Aufrichtigkeit) which is closer to uprightness: see Kant 1996d: 182-4 (1797, 6: 429-31). For a passage supporting the necessity of sincerity as a predisposition, described as a "foundational principle," without which other properties of human character would have no "true inner value," see Kant 1996b: 36 (1791, 8: 270).

39 Kant's condition for sincerity as "everything said be said with truthfulness" is similar to what J. L. Austin identifies as "the sincerity condition" of any illocutionary act; this is the deceptively simple requirement that one actually be doing what one purports to be doing in speech, see Austin 1962, especially Lectures 2 and 4, 12-24 and 39-52. The limitation of this sincerity condition has led to disagreements between Humean and Kantian moral philosophers on the question of trust and sincerity; for example, Baier 2010: 189-215, especially 210n23. Cf. Piper 2013, vol. I, 545-65, especially $557-7 \mathrm{n} 19$.

40 Kant 1997: 2-3 (1785, 4: 389). Also, see footnote above.

41 Concerning this loss and her later letters which confirm this, see Langton 1992: 481-505; and Walla 2013: 307-23.

42 See Kant 1997: 2-3 and 14-15 (1785, 4: 389 and 4: 402).

43 Kant 1996a: 129 (1793, 6: 93).

44 Kant 1996a: 206 (1793, 6: 190n347).

45 An alternative translation of Kant's title, Religion within the Bounds of Bare Reason, indicates rational boundaries in terms of the "bounds" of "bare" reason, in "Introduction," Kant 2009a: XVn1.

46 Kant 1996a: 104 (1793, 6: 61).

47 Kant 1996d: 32, 173-5 (1797b, 6: 417-20).

48 For more background on the role of the philosophical imaginary - especially, the role of metaphor - in Kant's writings, see Anderson 2012: 169-96.

49 Kant 1996a: 206n+.

50 Kant 1997: 14-15, 31-2 and 37-9 (1785, 4: 402; 4: 421-2 and 4: 429-30).

\section{Bibliography}

Anderson, P. S. 2012. "Metaphors of spatial location: understanding post-Kantian space." In R. Baiasu, G. Bird and A. W. Moore (eds), Contemporary Kantian Metaphysics. New York: Palgrave Macmillan, pp. 169-96.

Anderson, P. S. 2013. "Immanuel Kant." In C. Meister and J. Beilby (eds), The Routledge Companion to Modern Christian Theology. London: Routledge, pp. 5-16.

Aristotle. 1980. Nicomachean Ethics. Translated with an Introduction by W. D. Ross. Oxford World Classics. Oxford University Press.

Aristotle. 2010. Rhetoric. Translated by W. Rhys Roberts and edited by W. D. Ross. Oxford University Press, Cosmic Classics edition.

Austin, J. L. 1962. How to Do Things With Words, William James Lectures. Oxford University Press.

Baier, A. 2010. "Sympathy and self-trust." Reflections on How We Live. Oxford University Press, pp. 189-215.

Kant, I. 1967. “To Maria von Herbert, Spring 1792.” Philosophical Correspondence, 1759-9. Translated by Arnulf Zweig. The University of Chicago Press; (1999) reprinted in Correspondence, pp. 411-13. 
Kant, I. 1996a. Religion within the Boundaries of Mere Reason [1793]. Translated by George di Giovanni, in Religion and Rational Theology. Edited by Allen Wood and George di Giovanni. Cambridge University Press, pp. 39-215; (1960) Religion within the Limits of Reason Alone. Translated by Theodore M. Greene and Hoyt H. Hudson. New York: Harper Torchbooks, Harper \& Row Publishers.

Kant, I. 1996b. "On the Miscarriage of all Philosophical Trials in Theology" [1791]. In Religion and Rational Theology, pp. 19-38.

Kant, I. 1996c. "On the Supposed Right to Lie from Philanthropy" [1797a]. In Practical Philosophy. Translated and edited by Mary J. Gregor and Allen W. Wood. Cambridge University Press, pp. 611-15.

Kant, I. 1996d. The Metaphysics of Morals [1797b]. Translated and edited by Mary J. Gregor. Cambridge University Press.

Kant, I. 1997. Groundwork of the Metaphysics of Morals [1785]. Translated and edited by Mary Gregor. Introduction by Christine M. Korsgaard. Cambridge University Press.

Kant, I. 1999. "Maria von Herbert to Kant," Correspondence. Translated by Arnulf Zweig. Cambridge University Press, pp. 379-80.

Kant, I. 2009a. Religion within the Bounds of Bare Reason. Translated by Werner S. Pluhar, with an Introduction by Stephen R. Palmquist. Indianapolis, IN: Hackett Publishing Company; (1793) Die Religion innerhalb der Grenzen der bloBen Vernunft. Konigsberg: Nicolovius.

Kant, I. 2009b. An Answer to the Question: 'What is Enlightenment?' [1784]. Translated by H. B. Nisbet. Cambridge University Press (1991); reprinted in Great Ideas series, Penguin books. London: Penguin Books Ltd.

Langton, R. 1992. "Duty and desolation." Philosophy 67: 262, 481-505.

Moore, A. W. 2003. Noble in Reason, Infinite in Faculty: Themes and Variations on Kant's Moral and Religious philosophy. London: Routledge.

Piper, A. 2013. Rationality and the Structure of the Self. Berlin, Germany: APRA Foundation, 2nd edn, www.adrianpiper.com/rss/docs/PiperRSSVol.1.KC.pdf.

Walla, A. P. 2013. "Virtue and prudence in a footnote of the Metaphysics of Morals (MS VI: 433n)." In B. S. Bird, J. Hruscha and J. C. Joerden (eds), Annual Review of Law and Ethics, Band 21. Berlin: Duncker \& Humblot, pp. 307-23.

Williams, B. 2002. Truth and Truthfulness: An Essay in Genealogy. Princeton University Press. 


\title{
7 Making sense \\ The possibility of truthfulness in politics
}

\author{
Esther Abin
}

\section{Introduction}

In Truth and Truthfulness, Williams (2002: 3) asks whether the notions of "truth and truthfulness can be intellectually stabilised in such a way that what we understand about truth and our chances of arriving at it can be made to fit with our need for truthfulness'. Williams takes the view that the ideas of truth and truthfulness matter in that they are 'significant in our lives' (2002: 5). The word 'significant' is here central to Williams' philosophical approach and to the scope of this chapter.

As Sissela Bok (1999: 8) argues, truth and truthfulness are now clearly conceivable as two distinct concepts:

Any number of appearances and words can mislead us; but only a fraction of them are intended to do so. A mirage may deceive us, through no one's fault. Our eyes deceive us all the time. We are beset by self-delusion and bias of every kind. Yet we often know what we mean to be honest or dishonest. Whatever the essence of truth and falsity, and whatever the sources of error on our lives, one such source is surely the human agent, receiving and giving out information intentionally deflecting, withholding, even distorting it at times. Human beings, after all, provide for each other the most ingenious obstacles to what partial knowledge and minimal rationality they can hope to command. We must single out, therefore, from the countless ways in which we blunder misinformed through life, that which is done with the intention to mislead, and from the countless partial stabs at truth, those which are intended to be truthful.

Instead of focusing on the idea of 'truth' per se, I wish to concentrate on the process of seeking truth, a process that Williams identifies with an attachment to 'truthfulness'. More specifically, seeking truth in politics proceeds through a kind of rational and moral thinking, which takes into account the contingency and temporality of surrounding circumstances: it corresponds to an attitude which attempts to make sense of a given situation with integrity. The latter is yet encumbered by the necessity to make compromises. 
One of the main reasons why politicians cannot afford being sincere lies in the risk they would take in behaving otherwise: personal or professional risks, risks regarding their commitments to a project or obligation, risks likely to undermine the final outcome of the objectives pursued. Being truthful does not exclude making mistakes either; it can even entail a lack of sincerity. It means that the quest for truth can entail a provisional lack of sincerity meant to accommodate the contingent and practical limits of a given situation that one needs to 'fill in' (through appealing to narratives for instance) - but it does not mean that a provisional lack of sincerity is necessarily and always intended to deceive. Without denying the value of sincerity in politics, it is desirable to give a less ideal account of it. The chapter first evaluates the extent to which a sincere claim is necessarily consistent with a true claim and looks at the ambivalent account of sincerity in politics. It then tries to balance the act of being sincere with that of making sense in an attempt to disentangle the concept of sincerity in politics from that of truthfulness: while a sincere claim can turn out to be untrue, a truthful claim seeks truth in a way that can distance itself from an account of sincerity.

\section{Sincerity and truthfulness in politics: tensions and ambiguities}

Narratives can be seen as instruments which help to make sense of situations in which there is no clear understanding or indication of where one is supposed to stand. It is generally assumed that, in politics, one is less concerned about being sincere than intelligent and lucid. In other words, sincerity is rarely a matter of conscience for politicians. The lack of political sincerity becomes an issue when it is explicitly and publically exposed as an act of intended deception. Besides, sincerity can be seen as an unencumbered way of conveying a thought, whether the latter is true or not. Sincerity is thus not necessarily bound to truth; it is bound to the idea that there is no calculation, no underlying strategy to hide what one thinks behind what one expresses or discloses. Sincerity belongs to an ideal of purity and nakedness within a responsive world in which there is no danger in 'exposing' oneself; it is rooted in the ideal of a correspondence between the truthful self and the world.

Drawing on Jean Starobinsky (1976) and his interpretation of Rousseau's attachment to sincerity, Bernard Williams (2002) explores further the way in which sincerity is actually withdrawn from politics, for nobody can afford remaining sincere when being surrounded by society. Williams argues that Rousseau's fictional account of the state of nature aims to restore sincerity in its original form. When transposing the state of nature to the political state, Rousseau attributes the protection of sincerity and transparency to the setting of Republican and egalitarian laws. The virtues of sincerity and transparency are thus enabled artificially through the morality of the Republican State - a virtue that, if taken to extremes, will inevitably turn into forms of personal inquisition. Ideals of sincerity and transparency are thus here indissolubly bound to an account of political policing and control. 
If we get back to a more moderate and ordinary account of political decency (not to say morality), sincerity is almost naturally incompatible with politics whereby power requires having certain talents of secrecy, dissimulation and diplomacy. Mutual adhesion between contending parties, although it lacks genuine sincerity, is a matter of convention - and is often de facto essential to the possibility of reaching agreements and achieving a process of 'peace keeping'. In other words, the circumstantial lack of sincerity in political relations is a tacit norm meant to avoid overt conflicts; it is deemed acceptable because it helps to avoid war. Machiavelli (1992) and Constant (2009) provide bountiful arguments and examples to elaborate this view. Insincerity in politics is clearly not an issue when it serves a higher cause than that of sincerity; for example, when the liberation of hostages is at stake, deceiving public opinion through lying for the sake of covering up a plan of liberation is something accepted in principle because the purpose of political lying is considered as consequentially superior to the value of sincerity. Some situations in politics do require lack of sincerity from politicians.

Sincerity can also obscure truthfulness when it arises from kinds of beliefs, which obliterate concerns for truth. Political indoctrination stems from such a travesty: in such a case, the sincerity with which a person holds a claim has more value than its veracity, for she has annihilated her critical judgement and surrendered herself to beliefs, regardless of whether they are true or not. If withdrawn from any attachment to truth, sincerity can provide a deceitful representation of reality. It is different from lying, for the liar is, in that case, aware of the discrepancy between truth and falsity. The sincere 'bullshitter' (Frankfurt 2005) has no regard for the veracity or the falsity of his claim: his belief shadows entirely his concern about truth.

Any tyrannical regime, which stands through the tyranny of fear, destroys the possibility of grounding anything in truth - tyrants consider themselves beyond any objective or foundational standard of truth, for they associate truth with the power to decide what is true. The tyrant's will is deemed sufficient to shape any account of truth because his will is powerful enough or at least perceived as such. In that case, the difference between truth and lie nullifies - the tyrant will hold a lie or a true claim indifferently, for his accounts of truth and lie are grounded in his own will, which serves ultimately and opportunistically his own tyrannical power.

As we will elaborate further with Williams' Critical Theory Test (2002; 2005), there is an important relationship between truthfulness and power, for the latter can contribute to making certain claims or situations acceptable (if not perceived as 'truthful') and thus legitimate. The limit to power's intervention in the way that truthfulness is accounted lies in what people deem just or unjust to them. There is a real tension in the way in which Williams articulates both notions of sincerity and truthfulness - arising from his view, it seems reasonable to infer that one can moderate and adjust the ideal of sincerity while maintaining truthfulness as a central component of a legitimate polity. However, Williams points out an important and yet slightly taboo feature of political stability in the 
context of liberalism: people do not have a full overview of 'what is going on' at the level of political representatives and institutions and this fact contributes to maintaining political and social stability.

As Williams puts it:

It is not foolish to believe that any social and political order means something which effectively uses power, and which sustains a culture that means something to the people who live in it, must involve opacity, mystification, and large scale deception. Reasonable people can believe, contrary to the ideals of liberalism, that human beings cannot live together effectively, at least on any culturally ambitious scale, if they understand fully what they are doing.

(Williams 2002: 232)

To what extent can the ethics of truthfulness be made consistent with the conduct of political life, a conduct bound to a certain level of indeterminacy, risk and provisional lack of sincerity? Political stability is not bound to public deception - this is where Williams draws the line. He does not renounce the ethics of truthfulness in politics, but the latter is a quest bound to imperfection and certainly not a moral imperative, for 'ought' does not always imply 'can'. His attachment to truthfulness differs substantially from Kantian and utilitarian legacies and stems from several features of his moral and political philosophy. Those can be pinned down in his account of practical reasoning, which is sensitive to temporal and subjective parameters, and his acquaintances with the genealogy of Nietzsche, which will here be interpreted through the scope of Spinoza's immanent causality instead.

\section{Truthfulness, integrity and uncertainty}

Williams situates his reflection on ethics and truthfulness at the level of the individual's immanent consciousness. Truth does not inevitably prevail, and he is indeed critical of such a claim. What prevails lies instead in the fact that an event or an idea makes sense to oneself at a certain time in a certain place. Williams is thus open to consider that narratives can be part of a category of truthfulness to the extent that one remains truthful to a certain type of rational and ethical framework: that of integrity and responsibility. This framework can be associated with what Williams call the 'Basic Legitimation Demand' (BLD) (2005). BLD is fundamentally rooted in the idea that illegitimacy lies in oppressive or abusive forms of power, as for instance that of intended deception. The oppressive and therefore illegitimate nature of power lies in that the latter cannot be justified because it must be 'a legitimation offered which goes beyond the assertion of power' (2005: 11). In Williams' words, this legitimation is reached through a form of intelligibility that he associates with the cognitive activity of 'making sense': 'a category of historical understanding' or 'hermeneutic category' (2005: 11), which is immanent to people's moral and rational thinking here and now. 
The difference between Kant's and Williams' accounts of practical rationality lies in that the former appeals to a form of intuitive guidance that is 'atemporal' (Boyer 2001), whereas the latter stems from one's capacity to react critically against unjustified practices of power. In both cases the role of rational and critical thinking is at stake, but not in the same way. The kind of rationality on which Williams bases his political theory implies a form of responsiveness to temporal factors which include historical and cultural contexts as well as a certain degree of contingency. This form of rationality thus escapes from a pregiven framework of intuitive and transcendental moral norms; it arises from what Williams calls the 'Critical Theory Test' (2005). It is this theory of practical rationality that I wish to examine further in considering whether it can help in defining a paradigm of truthfulness consistent with the temporal and contingent nature of politics.

Williams' work on ethics is explicitly concerned with the relationship between contingency, rational and moral thinking. In his early work on 'morality' (1972), he emphasises that being moral entails seeking from deep within oneself what one truthfully thinks; one's 'deepest impulse.' Being moral is not viewed by Williams as a matter of 'happiness' but of 'well-being'; it starts from oneself and develops into reflections, which involve practical considerations, trust, uncertainty and hope. But all this is in relation to what oneself needs and wants:

[I]f someone said - obscurely enough - that men need a world in which there is a risk, uncertainty, and the possibility of despair, then a morality which emphasised this, as opposed to moralities which want as much as possible tidied up, might still be said to be concerned with men's well-being.

In later works, Williams established a formal distinction between 'morality' and 'ethics' (1993). He translates this aspect of personal morality into an account of 'integrity'(1972), from which he develops further reflections about the nature of practical rationality and ethics. Moral thinking is not viewed as devoid of substance; it arises from an intention expressed in particular circumstances and directed towards an action. Morality thus resides in an 'attitude', rather than relying on a prescriptive system of a priori obligations. Moral thoughts cannot reach absolute certainty but 'require trust' within the margins of what one finds 'acceptable':

How can an $I$ that has taken on the perspective of impartiality be left with enough identity to live a life that respects its own interests? If morality is possible at all, does it leave anyone in particular for me to be? These are important questions about morality and life: about morality, because, as a particular view of the ethical, it raises that question in a particularly acute form, and about life because there are, on any view of ethical questions, real issues about the relations between impartiality and personal satisfactions and aims - or, indeed, personal commitments that are not necessarily 


\section{E. Abin}

egoistic but are narrower than those imposed by a universal concern or respect for rights.

Williams links reflections on morality and rationality to the way in which one 'feels', 'experiments', 'needs' and 'wants': a state of being 'here and now'. He insists that moral assessment depends on how things turn out, which means partly on luck. Morality is therefore not under the full control of what one thinks as a moral choice; it carries with it a part of indeterminacy inherent to the outcome of any life experience:

It will be clear that when I say of something that it is a matter of luck, this is not meant to carry any implication that it is uncaused. My procedure in general will be to invite reflection about how to think and feel about some rather less usual situations, in the light of an appeal to how we - many people - tend to think and feel about other more usual situations, not in terms of substantive moral opinions or 'intuitions' but in terms of the experience of those kinds of situation.

(1981: 22)

Rationalisation in this context is associated with 'practical deliberation' defined as the 'rational assessment of probabilities, and the optimal ordering of actions in time' (1981: 31). It does not consist in calculating possible outcomes arising from particular decisions, which cannot be clearly established: 'practical deliberation' is to be determined by the actualisation of one's decision or judgement (1981: 30). Williams argues that one cannot seek to yield a justificatory account for one's action or decision in a systematic way, for the circumstances in which this decision or action is initially undertaken are not fully determined. In his very important essay 'Internal and external reasons' in Moral Luck (1981: 110), he argues that practical reasoning does not provide access to free will, for one is always determinated by one's contingent and subjective condition:

It is unclear and I regard it as a basically desirable feature of a theory of practical reasoning that it should preserve and account for that unclarity. There is an essential indeterminacy in what can be counted a rational deliberative process. Practical reasoning is a heuristic process, and an imaginative one, and there are no fixed boundaries on the continuum from rational thought to inspiration and conversion.

\section{Another paradigm of truthfulness: from being sincere to making sense}

In political theory, acknowledging contingency in the conduct of one's actions and the formulation of one's thoughts immediately leads to questions of ethics and responsibility. It means considering that decisions can be judged or adjudicated in 
acknowledging the lapse of time between what one thinks acceptable and what proves in fact acceptable. The rigid application of a code of morals does not recognise or overcome this problem. In deliberating and adjudicating, one cannot reach any ideal of truthfulness and impartiality regardless of contexts and circumstances. Williams' theory of legitimacy explores the repercussions of this problem in the political theory of liberalism. In the chapter 'Realism and Moralism' (2005), he examines the essential features of legitimacy and the evolution of the concept towards contemporary accounts of 'liberal legitimacy'. Williams characterises the BLD as the minimum requirement for a state to be legitimate. The BLD consists in providing the minimum 'acceptable' conditions of security and order 'to save people from terror' (2002). The BLD constitutes de facto what 'distinguishes a LEG [legitimate] from an ILLEG [illegitimate] state'. Williams does not provide any straightforward answer to the question of what this minimalist form of legitimacy is about, for he denies that it is a moral principle that can be 'prior to politics'. Instead, he argues that the BLD implies a form of morality that derives its normative dimension from what is 'inherent in there being such a thing as politics'.

The idea behind the BLD (2005: 5) is that the coercion constitutive of politics should contain the reasons of oppression and wars. Politics requires that it has to be something in the mode of justifying explanation or legitimation: hence the BLD'. By appealing to a 'mode of justification and explanation', which he also defines as the 'Critical Theory Test', Williams draws on his account of practical deliberation and practical ethics: one cannot be ethical in his conduct if he is not concerned with the meaningfulness of what he does, says or thinks. What Williams describes as a 'mode of justifying explanation or legitimation' refers to his account of practical rationality mentioned earlier. If Williams thinks that the liberal state often meets the BLD while 'non-liberal states often do not' (p. 4), he certainly doesn't think that only liberal states meet the BLD. Liberal legitimacy arises from forms of practical rationality that correspond to the historical formation of the liberal state. It depends ultimately on the historical contexts in which the state and its constituent cultures have developed.

Historical and cultural contexts contribute significantly to determining what citizens will deem 'acceptable'. The BLD does not arise from a superior cognitive norm; it constitutes the most accepted form of coercion, for it is grounded in a context recognized by most citizens. As Williams puts it (2005: 9):

Moralistic liberalism cannot plausibly explain, adequately to its moral pretensions, why, when, and by whom it has been accepted and rejected. The explanations of the various historical steps that have led to the liberal state do not show very persuasively why and how they involved an increase in moral knowledge; but from here, with our conception of the person, the recognition of liberal rights indeed looks like a recognition.

In other words, the political acceptance of liberal legitimacy does not derive from forms of authoritative and normative prescriptions of moral knowledge 


\section{E. Abin}

about liberal life; we do have a moral conception of the person (in relation to which ascription to the person of rights looks like) but it is recognised not invented: we cannot actually tell a convincing historical story whose culmination consists in arriving at non-historical moral knowledge. The 'cognitive status of history' (p. 9) thus contributes to nurturing reflections on the effects of a particular lineage of ideas or ideals on certain political norms and practices.

The way in which Williams associates the BLD with a 'demand for justification' that is 'implicit in the very idea of the legitimate state' and therefore 'inherent to any politics' (2005: 8) is consistent with his underlying critique of moral systems (1993: 174-96). He explains it as follows:

We reject PM (Political Moralism), which claims the priority of the moral over the political [...]. It [BLD] does not deny that there can be local applications of moral ideas in politics, and these may take, on a limited scale, an enactment or a structural form.

(2005: 8)

But when moral attitudes interfere with politics, this should not be at the expense of political agency. Williams draws a boundary between the 'political' and the 'non-political', in that the latter fails to justify coercive forms of power. (pp. 5-6) He recognises that ultimately coercion is necessary to any form of political organisation, and therefore to any form of legitimacy and with this in mind he offers a theory of justifiability: that is the roughly equal acceptability of coercion to each person subject to it - 'a constraint of roughly equal acceptability' (p. 7) between the state and every subject.

It is clear that aside from this critique of moral systems, Williams' account of 'politics' and the notion of 'Basic Legitimation Demand' incorporate the major concerns of his philosophy, namely, practical rationality, morality, truthfulness and the role of history and temporal contingency. Conversely he criticises political moralism for ignoring the practical and contextual evolution of moral ideas throughout the shifts of history. The retrospective recognition of the legitimacy of liberalism operates 'individually' and 'collectively' through practical experience and the enjoyment of 'liberal' rights (p. 9). In Williams' alternative account of moral attitudes, one is being true to oneself in the recognition of one's own motivations and projects.

Williams' account of practical rationality respects the perceived context that surrounds the interpretative acceptance of an idea - what he calls 'making sense' (MS) (2005: 11): 'MS is a category of historical understanding - which we can call, if we like, a "hermeneutical category"'. By establishing a difference between 'making sense' and 'being normative', Williams draws on his account of moral attitudes - formed through a process of 'practical deliberation' through which one attempts to be consistent to what and who one is, that is to possess integrity (a process aided by an awareness of formative historical conditions).

'Making sense' is a way of internalising for oneself why something is legitimate or not; it thus differs from Kant's transcendental dialectic of rationality 
(1997). 'Making sense' is an original account of how rationality integrates and associates subjective and contingent factors in the selection and acceptance of values and norms. Further, MS proceeds through a subjective/affective kind of intellect which impacts on the way in which one justifies a moral attitude - the term 'disposition' is here paramount in Williams' terminology (1993: 199):

Even if an ethical thought has a foundation in determinate conceptions of well-being, the consequences of that could lie only in justifying a disposition to accept certain ethical statements, rather than showing, directly, the truth of those statements $[\ldots]$.

The difference between 'making sense' and 'being normative' is that the former arises from here, while the latter refers to something external - as Williams puts it (2005: 11):

What it [Making Sense] is not, is normative: we do not think, typically, that these considerations should guide our behaviour, and there is no point in saying that they ought to have guided the other people's behaviour, except in exceptional cases where there was a clash of legitimations, of which, in the light of the circumstances, one more MS (as it seems to us) than the other.

The internalisation of an idea is a reflective and deliberative process of interpretation underpinned by a sense of responsibility with regard to the implications of this idea in a particular context. It is only after this process of 'internalisation' that a political idea 'makes sense', and only then can it become legitimately 'normative':

In any case, there is no problem about the relation between the 'external' and non-normative 'MS' that we apply to others, and the 'MS' we use about our own practices, which is normative: this is because of the hermeneutical principle, which is roughly that what they do MS if it would MS to us if we were them.

The process of making legitimacy normative operates through a specific process of internalisation and acceptance of political norms; a process bound to historical and cultural patterns and underpinned by what Williams calls, drawing on Weber, 'the ethic of responsibility' (2005: 12). In Williams' view, it is from a certain sense of responsibility that there follows an acceptable degree of coercion. Political stability is at the cost of an acceptable, because responsibly consented to, level of coercion, which corresponds to that of the BLD. Williams' 'critical theory principle' (2005: 6) is necessary, in this context, to guarantee that the acceptance of political authority, which can in certain cases be coercive, is not at the cost of one's responsible consent: 
What may be called the critical theory principle, that the acceptance of a justification does not count if the acceptance itself is produced by the coercive power which is supposedly being justified, is a sound principle: the difficulty with it, of making good on claims of false consciousness and the like, lies in deciding what counts as 'having been produced by' coercive power in the relevant sense.

There is therefore in Williams' accounts of the BLD and Critical Theory Principle a strong emphasis on the conditional possibility to consent to political authority so long as one is responsible for one's decision - responsible in the sense of understanding and accepting this authority. In hard cases, that is when authority is perceived as coercive, one has to be willing to accept this authority, for it obeys the BLD (in giving a 'legitimation to every subject' [2005: 6]). Behind this argument resides Williams' critique of forms of authority based on $a$ priori theories of what is right or legitimate. His insistence on the idea of acceptance, consent and responsibility accompanies his criticism of unduly metaphysical justifications of authority, which eschew the 'critical theory principle'. The latter requires a sort of genealogical inquiry into how one has come to believe in, accept and assert certain ideas:

We need a schema by which we start with the people's current beliefs and imagine their going through a process of criticism, a process in which the test plays a significant part. We can think of the disadvantaged as asking a series of reflective questions about their situation. Our picture of this will of course be an artificial rationalization, but something like it does actually happen on a social scale. It is not surprising that often it is started by an influence from outside a society which up to that point had been relatively closed.

(2002: 227)

\section{Truthfulness at the crossroad of liberty and determinism}

Despite his overt commitment to liberalism, Williams can leave us with doubts and scepticism about the way in which he connects ethics to politics - he is, for that reason, often identified as a 'liberal realist', for he does not promote the universal endorsement of liberal values (Sleat 2010). Anti-idealist critics of Williams associate his approach to ethics with an enterprise of deconstruction. Raymond Geuss (2012) roots Williams' account of ethics in Nietzschean premises. Yet, he finds Williams left with 'three marks of optimism' respectively about 'truth', 'truthfulness' and the 'meaning of individual life' (2012: 155), which conveys quite clearly the idea that his philosophy cannot be reduced to a Nietzschean legacy, to which Williams remains nevertheless partly indebted.

This ambiguity, which Richard Rorty perceived extremely well in his review of Truth and Truthfulness (2002), arises from his attachment to truth conceived of as an account of authenticity, a manner of being truthful to oneself. 
Truthfulness is thus immanent to a way of being here and now, that is, at a particular time and place - it cannot extend to a general and transcendental principle. Admittedly, one could infer that Williams has a relativist account of truthfulness. However, it is also legitimate to postulate that being true to oneself is an attitude, which although immanent, remains valuable per se, regardless of how, when, and where this attitude is adopted. More specifically, both value of truthfulness and its corollary attachment to the postulate of truth constitute the ethics of Williams: an internal ethos rather than an external code of conduct.

His internalism is not without recalling the Ethics of Spinoza (1994), and this association contributes to grasping what distinguishes his ethics from that of Kant (1997). In fact, Williams is much concerned with freedom but he seems similarly less convinced about the possibility of free will. The difference between both concepts is central to the way in which he articulates his account of truthfulness in the context of liberalism. A Spinozist reading of Williams' ethics brings light to his emphasis on 'making sense' and his sensitivity to temporality and affects. His ethics is like in motion, it evolves along intellectual forms of feeling, needing and wanting. It remains entangled with the fluctuation of affects, by which one is necessarily determined and therefore withdrawn from free will. Relativists account for this determination as something, which encloses one's ethical commitment within one's temporal and contextual self - in other words, relativists do not postulate the possibility of free will, neither that of freedom.

Like Spinoza (2009), Williams finds freedom in the way of accepting a form of determinism through understanding it. That is the very reason why he places so much emphasis on 'making sense' of one's response to the complexity of life. Understanding, for Spinoza and for Williams, proceeds through rendering intelligible the causes of one's affects, for they determine the way in which one thinks rationally and morally of a given situation. This philosophical perspective explains his account of legitimacy (BLD) as being central to liberal regimes. Liberalism does not provide the conditions of free will - liberal regimes remain determined, to a certain extent, by the conditions of their times. The value of liberalism lies in that it provides the possibility to reflect internally on the necessary conditions of freedom 'for the time being'.

The liberal value of a polity arises from the capacity it provides to its members to reflect critically about the necessary and minimal conditions of freedom. In that respect, Williams' account of the Critical Theory Test in the context of liberalism is not without recalling Spinoza's political defence of freedom of philosophising within a political state (2007) - neither philosophy nor liberalism can withdraw human beings from their natural and determinate conditions, but they can help in accommodating them in giving a sense of freedom. For Spinoza and seemingly for Williams, freedom lies essentially in the acceptance of one's natural determinism. This acceptance proceeds through a mode of explaining the causes (hence Williams' taste for 'genealogies' [2002]) of one's rational and moral being 'here and now'. In A Political Treatise (2005, I §4), Spinoza mentions the 'freedom of spirit' for which he aspires through the rational and natural experience of politics: 
Therefore, on applying my mind to politics, I have resolved to demonstrate by a certain and undoubted course of argument, or to deduce from the very condition of human nature, not what is new and unheard of, but only such things as agree best with practice. And that I might investigate the subjectmatter of this science with the same freedom of spirit as we generally use in mathematics, I have laboured carefully, not to mock, lament, or execrate, but to understand human actions; and to this end I have looked upon passions, such as love, hatred, anger, envy, ambition, pity, and the other perturbations of the mind, not in the light of vices of human nature, but as properties, just as pertinent to it, as are heat, cold, storm, thunder, and the like to the nature of the atmosphere, which phenomena, though inconvenient, are yet necessary, and have fixed causes, by means of which we endeavour to understand their nature, and the mind has just as much pleasure in viewing them aright, as in knowing such things as flatter the senses.

There is also something from Spinoza's Ethics (1994) in the way in which Williams accounts for truthfulness as having an intrinsic value and having to be pursued for its own sake. Comparable with the way that Spinoza used the language of geometry and mathematics in his demonstration (1994), Williams' inclination for analytical philosophy, as presumably free from metaphysics and epistemology, serves his rational inquiry almost like an instrument of logical and deductive explanation. This is where Williams can be sometimes misunderstood as using analytical and affective/subjective intellectual approaches to practical reasoning. It could very modestly be suggested here that, because Williams is too much aware of human beings' natural tendency to wield power with domination, including when they think for themselves what they should do, he appeals to the signs of mathematics like a way of drawing a line in the sand.

\section{Conclusion}

In Williams' approach to ethics, the necessity of being truthful in the conduct of one's life is paramount. Aside from criticising universalist accounts of morality, Williams reconsiders moral thinking from the perspective of one's life in all its complexity and temporality - including its provisional choices and values, its vicissitudes and imperfections, and its likely mistakes and regrets. He refers to politics as an area of actions and practical constraints which impact on the way in which one deals with ethical concerns and attitudes. Among these attitudes lie those about sincerity and truthfulness. Again, the matter is not about ruling out the ethical value of sincerity - but sincerity cannot suffice to define an ethical attitude towards truth: it does not provide an exhaustive account of concern about truth, as exemplified earlier with the description of the 'bullshitter'. Arising from this, truthfulness is closer than sincerity to an account of ethics in relation to truth, for a truthful attitude is primarily guided by a sense of faithfulness towards truth. 
Yet, the quest for truth is like a tortuous path; it can be sloppy, confusing, obscure. It is on this path that Williams wants to take us when considering what it means to be truthful in politics. The quest for truth appeals to a form of rationality that Williams describes as 'practical deliberation' or 'practical thinking'. It involves a special kind of receptiveness to what one feels, needs and wants; it implies taking into account the temporality of one's decision, for the latter can evolve without having to be inconsistent or disloyal. It is in the capacity to make sense of the world that people get the chance to escape abusive forms of power. For Williams, oppression lies less in the uncertain and contingent aspects of the world than in the incapacity to make sense of it; in its arbitrary domination.

\section{Bibliography}

Bok, S. 1999. Lying, Moral Choice in Public and Private Life. New York: Vintage Books. Boyer, A. 2001. Hors du Temps, Un essai sur Kant. Paris: Librairie Philosophique J. Vrin. Constant, B. 2009. Cours de Politique Constitutionnelle: Ou, Collection Des Ouvrages Publiées sur le Gouvernement Representative. Paris: Bibliobazaard.

Frankfurt, H. G. 2005. On Bullshit. Princeton: Princeton University Press.

Geuss, R. 2012. 'Did Williams do ethics?' Arion 09.3 (winter), 141-62.

Kant, I. 1997. Critique of Practical Reason. Cambridge: Cambridge University Press.

Machiavelli, N. 1992. The Prince, ed. R. M. Adams. London: W. W. Norton \& Company. Rorty, R. 2002. 'To the sunlit uplands'. London Review of Books 24: 21.

Sleat, M. 2010. 'Bernard Williams and the possibility of a realist political theory'. European Journal of Political Theory 9: 4, 485-503.

Spinoza, B. 1994. Ethics. Princeton: Princeton University Press.

Spinoza, B. 2005. A Political Treatise. Hackett Publishing Co.

Spinoza, B. 2007. Theological-Political Treatise. Cambridge: Cambridge University Press.

Spinoza, B. 2009. On the Improvement of Understanding. Forgotten Books.

Starobinsky, J. 1976. Jean-Jacques Rousseau: la Transparence et l'Obstacle. Paris: Tel Gallimard.

Williams, B. 1972. Morality, an Introduction to Ethics. Cambridge: Cambridge University Press.

Williams, B. 1981. Moral Luck. Cambridge: Cambridge University Press.

Williams, B. 1993. Ethics and the Limits of Philosophy. London: HarperCollins Publishers.

Williams, B. 2002. Truth and Truthfulness, an Essay in Genealogy. Princeton: Princeton University.

Williams, B. 2005. In the Beginning Was the Deed. Princeton: Princeton University Press. 


\title{
8 On doubt and otherness \\ Deconstructing power and dissent
}

\author{
Simone Cheli
}

"And therefore one was breaking the law

by having previously belonged to it"

(Orwell 1938: 160)

Sincerity and ethics are two elusive and multifaceted constructs. As people and contexts change, ethical questions look similar, whereas answers do not. From my point of view, talking about ethics means asking oneself why lying or conflicting, for example, could be the preferable choices for someone. It means bringing both one's own and other people's assumptions into question, and to recognise that doubt is perhaps the path toward otherness. The goal of the present chapter is to explore the role of epistemological doubt in dealing with different people and political dissent.

\section{Political truths and ethical doubts}

One of the key figures of politics in the twentieth century, Henry Kissinger (1994), describes the diplomatic relations between Europe and USA as a pattern of cultural misunderstanding. From World War I to the New World Order the most part of the political tensions seem to result from an antithesis (Kissinger 1994: 221, 399, 426, 597, 767, 809): the American Idealism, that subsumes an underlying harmony in the world, versus the European Realpolitik, that subsumes many conflicting geopolitical interests. Kissinger is often reputed as a cynical politician, but in his most famous work (1994) he examines the history of international relations as an encounter between different persons and so between different assumptions. Aside from any critique on Kissinger's life and work, that is on his personal choices, he has shown a significant ability in understanding the assumptions of others. Many politicians have shown this same ability throughout history, in spite of their deceptions, wars, cynicism. The meaning itself of politics seems to be the art of deeply understanding all the features of a situation and then of acting accordingly (Hobbes, Leviathan, $\mathrm{Ch}$. XVIII, Par. 6-15). ${ }^{1}$ Any ethical question seems to be an obstacle, a delusion that prevents politics from being implemented: "One prince has to ignore the infamy 
of being called cruel, in order to hold his subjects together"2 (Machiavelli, De principatibus, Ch. XVII, Par. 8$){ }^{3}$

In each and every nation we face and walk such a path of politics. We see different assumptions and choices, and the politician seems to be the one who is not influenced by any ethical duty. Kissinger describes the American Idealism and the European Realpolitik as meaningful viewpoints that don't prevent errors, defeats and victories. Maybe he wants to highlight his ability in changing perspective as the foundation of diplomacy? In this respect, I believe that a few questions arise: Does this ability negate a difference between good and bad? Does this ability mean putting oneself outside any ethical range? Is it possible to understand and draw up different viewpoints?

But answers to these questions prove to be elusive precisely because they probably subsume all the assumptions we make about the human mind and thinking. Therefore I would like to explicitly start from the constructivist assumption that all that is known is known by an observer, a new reading of Protagoras' famous aphorism: "Man is the measure of all the things, of things which are, that they are, and of things which are not, that they are not" (Plato, Thaetetus, 152a). ${ }^{4}$ Constructivism does not reject the existence of reality, it highlights that an organism has to construct a representation of the data that its neurological networks are processing (Foerster 2003; Glasersfeld 1995; Piaget 1937). “At a certain level of physiological analysis there is no reality but the firing of single neurons" (Hebb 1958: 461) and so "the thing to remember in this context is that observations are made by an experiencing subject and therefore depend on that subject's way of perceiving and conceiving" (Glasersfeld 2007: 22). Knowledge turns out to be an agent's active construction, which we can understand through its adaptation in experiencing the environment.

Unfortunately when we talk about mind and knowledge we often deal with an epistemological antithesis that is as irreconcilable as the political antithesis Kissinger describes. On one side we face an absolute idea of a knowledge in which there is only one truth, an unquestionable belief about good and bad, right and wrong. And so we have to assume that "if the very nature of knowledge changes, at the time when the change occurs there will be no knowledge, and, according to this view, there will be no one to know and nothing to be known" (Plato, Cratylus, 440). ${ }^{3}$ On the other side we face a solipsist idea of knowledge in which it is impossible to reach a shared certainty. One might even say that "everything goes" (Feyerabend 1975: 26) and that no scientist has a shareable criterion for making up theories. Giambattista Vico (De antiquissima, Ch. II, Par. 2-3) ${ }^{5}$ dealt with this epistemological antithesis and realized that if we reach a truth it is the one of the observer (Cheli and Velicogna 2011). "To be true is the one and the same as to be made" (Vico, De antiquissima, Ch. I). ${ }^{4}$ We create the so-called reality by narrating our vision of the world and by connecting this narrative with the people around us. "What saves this epistemological model from absolute solipsism is the constructivist concept of adaptation" (Glasersfeld 2007: 85), as the evolutionary viability of the observer's constructs when dealing with the others and the whole environment. Darwin's theory of 
evolution can be described in terms of constraints rather than of causation (Bateson 1972: 399-400): "The environment does not cause certain organisms to have certain characteristics...[it]...merely eliminates those organisms that knock against its constraints"(Glasersfeld 1981: 89). The uncertainty we face is just due to "the realization that no knowledge can claim uniqueness" (Glasersfeld 2007: 97). If we assume a continuous and changeable interaction with the world we have to call the permanence of our constructs into question. Maybe this doubt is not the way towards the solipsism or towards the impossibility of a certain knowledge. Doubt has been the path of the Western philosophy since its early beginning. I believe the meaning at the core of such a doubt is the idea of an always-reciprocal relation between any selfhood and any otherness (Cheli 2011). It describes a quest for an epistemological coupling between an observer and, at least, one referent, both "capable of developing with others a linguistic consensual domain" (Maturana and Varela 1980: 121). I guess this is Socrates' lesson: to know ourselves means to know the co-construction between us and our families, friends, communities (Patocka 2003). The Socratic construct of the good is strictly linked with the Delphi's precept know thyself: "The knowledge about good, that is for the man a specific knowledge, is, in the true epistemological form, to know that you do not know" (Patocka 2003: 377).). If I realize the continuity of any personal and social system, I have to totally know that I know nothing. All the epistemological constraints, and therefore possibilities, vary depending on the varying of considered times and contexts. Whenever I recognize my boundaries I am ready to meet the other.

The path of epistemology is perhaps the path of ethics. The "world is not something that is given to us but something we engage in by moving" (Varela 1999: 8), by acting and embodying our choices. And any choice is our personal attempt to make life meaningful and worth living (Kelly 1955: 64-8). Therefore what is common to the way we know and the way we meet others is the personal identity that arises whenever I am in a here-and-now relationship. Any understanding is a kind of reciprocity, a rediscovery of the I in the Thou (Levinas 1961). Ethics talks about a relationship of reciprocal identity validation (Giliberto 2010). It is not a know-what, a set of contents of a specific culture or nation, it is a know-how, a common identity-making process of humankind (Varela 1999). Whenever we recognize the other as a person, as a meaningful interlocut, we recognize him as part of our identity-making process. An "ethical encounter is so a reflexive linking between identity and experience" (Cheli and Giliberto 2012: 465). Whenever the others are not part of our identity deception or violence is viable, "we can do things to them but we cannot relate to them" (Bannister and Fransella 1971: 28). We might extend these assumptions about ethical processes both to individuals and to states: a political role is just a mask we wear. Any choice is the choice of one or several persons, a government does not make choices. "There will never be a really free and enlightened State until the State comes to recognize the individual as a higher and independent power, from which all its own power and authority are derived, and treats him accordingly" (Thoreau 1849: 211). 


\section{Identity traps inside power relations}

The issue of identity within political discourse raises many problems and traps (Du Preez 1980: 30-1). Politics usually tends to crystallize identity within a fixed and tight range of possibilities. People and personal choices seem to be forgotten whether you impose your own viewpoint or try to integrate different viewpoints. Even if we refuse the essentialist approach of only one truth, things are not so clear. Others seem to restrict our freedom in spite of any politically correct statement. In any case we have to deal with a "double bind" (Bateson 1972: 206-7) of conflicting injunctions and assumptions. We can personally construe our identities, but we cannot disown certain identities. We can develop personal beliefs, but we cannot reject certain truths.

To make a step further we have to understand how a political system socializes and preserves its own truths, sets the epistemological constraints and possibilities of any identity and choice.

Each society has its regime of truth, its general politics of truth: I mean by that the types of discourse it adopts and makes work as true; the mechanisms and the demands that allow to discern the true and false statements; the way to sanction the one or the other; the techniques and the procedures that are valued to pursue the truth; the statute of the ones who are in charge of designating what works as true.

(Foucault 2001: 158)

Foucault exhorts us to discover the rules that few or many people are perpetuating to maintain the current constraints and possibilities, in other words the current system of power. We may assume a similitude, or rather similar processes in construing experience (Kelly 1955: 90), inside the cultural and economic elite that maintains such a system and its own definition of truth. We may also assume our meanings are not private inventions but rather a bridge toward significant others we have met or not (Bannister 2003: 189). The basic question is:

which are the rules of law the relations of power implement to produce discourses of truth? Or even: Which kind of power is the one that is susceptible of producing discourses of truth, that have, in a society like ours, so powerful effects?

(Foucault 2001: 175)

To answer these questions we have to consider power as "a productive network that passes through the whole social body rather than a negative plea with a repressive function" (Foucault 2001: 149). It seems to penetrate into and be better understood inside the minimal daily contexts in which a discourse of truth emerges as the most viable choice, the one that allows persons "to make sense of experience in order better to avoid clashing with the world's constraints" 
(Glasersfeld 2007: 11). To maintain a fixed definition of norms and values seems to indeed facilitate a person's course of action: A nothing-but belief type simplifies our experience, narrowing the possible choices and minimizing the apparent incompatibilities. At the same time the more unvarying and fixed our beliefs, the more anxious any possible alternative. "Psychologically we cannot choose between a something and a nothing; we have to choose between two somethings" (Kelly 1955: 895), otherwise we do not have a real alternative. I would like to illustrate the viability of maintaining a truth and the anxiety of looking for an alternative with a few examples from the Italian daily context. The focus is always politics or better politics of truth. I choose to highlight how different opinion-makers (scholars, journalists, bloggers, etc.) support discourses of truth rather than simply criticizing politicians' speeches. I believe that when an opinion-maker uncritically identifies himself with the rulers, he runs the risk of losing the necessary sense of responsibility (Orwell 1968). He may obstruct rather than facilitate the opinion-making, by assuming that what is defined as true is really true.

In the minimal context of education a teacher, for example, may spread and validate the regime of truth he or she shares with a cultural and political elite. As can be seen in IRC Verona's presentation Secondo Incontro con i Dirigenti Scolastici $^{6}$ (2012), if one assumes a binding theological "regime of truth" (Foucault 2001: 158), a psychological support to adolescents could not be based on job descriptions, professional rules, codes of conduct or categorical imperatives. It ought to be specifically based on the religious morality, so a priori excluding any alternative foundation or intervention. Inside these epistemological constraints a traditional psychological approach founded on client's introspection and professional guidelines is not enough. It lacks a clear-cut definition of true and false, right and wrong that can guide the teacher and the students through a normative target of mental sanity and morality. Whenever we assume mental disease as a deviation from a norm we have to strictly define such a norm. However "mental illness, of course, is not literally a thing - or physical object and hence it can exist only in the same sort of way in which other theoretical concepts exist" (Szasz 1960: 113). By assuming the role of an expert in a normative set we force our interlocutor to become aware of an inadequacy in his epistemological system and to "seek to remedy the fault by invoking another system" (Kelly 1955: 578). Sometimes it may be a proper solution to exhort the other person, but he or she will inevitably "attempt movement within the framework of the present construct system" (Kelly 1955: 584). On one side the other person will at any rate see the exhortation through their personal glasses, on the other side, once they will be under treatment, they will experience a continuous anxiety ${ }^{7}$ by having to paradoxically choose between a something and a nothing.

The narrative of the expert is a very common device inside the discourses of truth. It allows the positioning of oneself in terms of a dichotomized adherence or deviation from a fixed and incontrovertible axis. It also facilitates the propagation and the maintenance of a regime of truth by a hierarchical and cloning transmission. I can develop if, and only if, I recognize a present elite and 
assimilate its truths. I cannot conceive an outside power and its foundations, and any kind of opposition seems to lead to a sanctionable deviation and preventive anxiety.

At this point a few questions seem to arise. Is there an alternative, an outside? Is it a viable choice? Is it possible to reject a discourse of truth without "succumbing to essentialist temptations" (Newman 2001: 137)? How and what can we choose between "to attempt an exit and a deconstruction without changing terrain, so repeating what is implicit in the founding concepts" or "to decide to change terrain, in a discontinuous and irruptive manner, so brutally placing oneself outside and affirming the absolute rupture and difference" (Derrida 1972: 162)? In any case it seems we deal with a threatening ${ }^{8}$ crossroad in which any possible choice evokes a personal and relational dissatisfaction. In the first case we cannot really change and so experiencing a frustration in desiring something we are not going to realise. In the second case what we crave endangers all the beliefs and the relations we live in. Whatever our starting position and preferable choice may be, we formulate and verify our hypotheses within the social sea of discursive networks we are immersed in. Assumptions, truths, doubts and ruptures are constituted by and within a web of co-construed meanings we necessarily use as components and media of our choices. If we want to preserve a social system, we have to move through its nodes and relations. If we desire a new system, we have at any rate to construct and share it with the old nodes and relations.

In short, nowhere does it appear more clearly that man's desire finds its meaning in the desire of the other, not so much because the other holds the key to the object desired, as because the first object of desire is to be recognized by the other.

(Lacan 1977: 58)

Such a craving for recognition is as ineluctable as the consequent dissatisfaction just because "the being of language is the non-being of the object" (Lacan 1977: 263). We assume to share a stereotyped and incontrovertible signified rather than a consensual and socialized signifier.

Desire is that which is manifested in the interval that demand hollows within itself, in as much as the subject, in articulating the signifying chain, brings to light the want-to-be, together with the appeal to receive the complement from the Other, if the Other, the locus of the speech, is also the locus of this want, or lack.

(Lacan 1977: 263)

Language is the dominion of ambiguity, of the lack between abstractly presumed truths and relationally experienced doubts. Whenever we face Derrida's (1972: 162) dilemma of "to change" or "not to change" terrain, we usually, and in any case, forget or minimize such a lack and so elaborate an alternative by looking, 
again, for an ultimate truth. We omit that the locus of any choice is in the hereand-now relationships we experience. We attempt to make a step forward by seemingly moving backward.

The terrain we are probably talking about is the one of a cultural hegemony we are trying to de-construe or re-construe. "The concept of hegemony is really a very simple one. It means political leadership based on the consent of the led, a consent which is secured by the diffusion and popularization of the world view of the ruling class" (Bates 1975: 352). It subsumes the idea that a discourse of truth becomes a "regime of truth" (Foucault 2001: 158) through the creation and the maintenance of a cultural cohesion. The architects of this cohesion are the elites of society-specific opinion-makers. They seem to be characterized by three factors: (I) they show similar epistemological processes; ${ }^{9}$ (II) they refer to a specific social group; ${ }^{10}$ (III) they support a given system of power. ${ }^{11}$ The more an opinion-maker is integrated in a system of power and in its discourses of truth, the more he or she "is in a strategic position to assume a leadership relationship to the group" (Kelly 1955: 96). As an expert of "the mechanisms and the demands that allow one to discern the true and false statements" (Foucault 2001: 158), he or she may understand a system of relations and the possible choices of any member at a higher level of generality. Therefore an opinion-maker might be tempted to, by any means, maintain an existing or newly born hegemony.

During the last Italian political campaign, the international press observed a very populist debate in which it was difficult to predict the next government agenda and the election returns (Foot 2013). This uncertainty was fostered both by the politicians and by the columnists (i.e., the opinion-makers). As we can see in the episode Dopo Monti Tocca a Me (2012) of the nationaltelevision talk-show Porta a Porta, without a cross-examined debate ${ }^{12}$ the listeners have only two options: to agree with a revealed truth, or to just be stuck in an unsolvable doubt. In this talk-show the former Prime Minister Silvio Berlusconi was able to take the liberty of describing himself as the only one alternative and the other parties as the only cause of past and future crises. Similarly when Pier Luigi Bersani, the premier candidate of the main left party, declared (Collini 2013) that the Italian problems were a result of ten years of Berlusconi's hegemony, the interviewer did not remind him about the two governments his party sustained. ${ }^{13}$

Cultural hegemony is in many cases the most viable choice, it is an attempt to give meaning to the world we live in and to a course of actions we fear is scarcely predictable and navigable. No matter how obvious it may be that a person would be better off if he supports the maintenance of a discourse of truth, it simplifies their own choices and clearly describes the possible consequences. "A paradox in ecology is that the most flexible species are the dullest" (Keeney 1983: 126), as they are the most controlled by and integrated in their ecosystem. And even if we aim to change terrain and develop an alternative paradigm, we are constantly tempted to look for the same unvarying predictability. Such an alternative is frequently defined in opposition to a perceived political crisis and 
as a salvation against consequent "forms of relativism" (Gramsci 1975: Q3, §34) that alarm ruler and ruled, prominent and aspiring opinion-makers. This kind of threat $^{7}$ may channel our choices and lead us to disown the very assumptions from which we start.

The third option other than the two traditional Italian parties, ${ }^{14}$ in the 2013 elections, was the independent Five Stars Movement, set up in clear-cut opposition to the existing cultural hegemony. The founder and undisputed opinionleader is Giuseppe Piero Grillo, an Italian comedian and activist, never elected in the parliament. During the campaign in which he repeatedly criticized the uniformity of Italian politics, he strongly attacked internal dissent:

Those who are inside the Movement and do not share these principles and raise many questions and address problems about the democracy of the Movement, have to get out. Get out of the Movement! No one forces them. And they are going out.

(Grillo 2013)

What happens if, looking for a radical alternative, we are still bound by the assumptions of cultural hegemony? What happens if protesting means the pursuit of a new discourse of truth, despite being defined as a rupture? Psychologically we are describing no more than a shifting from one side of a meaning dimension to the other side, a kind of superficial movement that "is too likely to end up in seesaw behavior" (Kelly 1955: 938). Whenever I am not re-construing or reorganizing my personal system, I am not experimenting with something new. To do that I have to raise "to a higher level of abstraction" (Kelly 1955: 976) and not focus exclusively on the critical situations I perceive. Otherwise I run a risk of being locked inside the same constraints and possibilities.

In an enlightening essay Derrida (1990) wonders what the foundations of law and of its enforcement may be. As usual he prefers not to give clear-cut answers and certainties. However, he highlights that each legal statement is founded on essentialist claims about human life. The same ultimate claims we have found in dissenters and supporters of a cultural hegemony, the ones that make us forget the here-and-now relationships we live in and the ones through which we formulate and verify our beliefs. At first we assume an absolutely free man and a rule valid for all times and contexts. "We would not say of a being without freedom, or at least of one without freedom in a given act, that its decision is just or unjust" (Derrida 1990: 961). Second, law always leads to a clear-cut and dichotomized decision, assigning each of its elements to a category on an all-ornothing basis. It aims to avoid the undecidable as

the experience of that which, though heterogeneous, foreign to the order of the calculable and the rule, is still obliged - it is of obligation that we must speak - to give itself up to the impossible decision, while taking account of law and rules. 
Finally justice, we may say any cultural hegemony we know, is pushed up by "the urgency that obstructs the horizon of knowledge" (Derrida 1990: 967) and so rends dialectics and imagination. Man turns out to be so threatened by the undecidable he chooses not to question his horizons.

\section{Dissent from an epistemological point of view}

We may be lured to offhandedly change direction toward a vague horizon-break and a non-substantiated openness. We may orient present discussion toward the concept of dissent as a healthy habit inside power relations and affirming further explanations would mean going back on our premises. At the same time we may ask if horizon-break and dissent are just new discourses of truth and if they really work in each and every situation. We would probably be blocked in another closed dilemma. As a new Prometheus we would find ourselves bound inside a forever painful dichotomy: to renege our choices, and thus, identities or to suffer an eternal agony, by remaining unchained. "It is precisely this unquestioned illusion that one has to make choice between $a$ and not- $a$, that there is no other way out of the dilemma, which perpetuates the dilemma and blinds us to the solution" (Watzlawick et al. 1974: 88). Looking for an answer inside the same framework is definitively not a way out.

"Only those questions that are in principle undecidable, we can decide" (Foerster 2003: 293). Indeed, what is decidable has fixed constraints and possibilities. What is undecidable urges us to re-frame a referent system and to let a novel solution emerge that "is a second-order change which consists in leaving the field and which cannot be contained within itself, in the language of Principia Mathematica, ${ }^{15}$ it involves all of a collection and cannot, therefore, be part of it" (Watzlawick et al. 1974: 25-6). The way-out from a dilemma requires a consideration and a re-construction of the superordinate "process leading to it" (Varela 1979: 99), that is the recursive pattern of high-level self-organizing complexes. This kind of re-framing may be defined as "a corrective change in the system of sets of alternatives from which choice is made" (Bateson 1972: 293), a new epistemology, new ways of understanding our ways of understanding. ${ }^{16}$ From such a second-order cybernetic point of view "change in the direction of learning, adaptation, and evolution arises from the control of control, rather than unchecked change per se" (Keeney 1983: 71).

Cybernetics assumes "cognitive processes as never-ending recursive processes of computation" (Foerster 2003: 217). A living organism's nervous system "organizes the world organizing itself" (Piaget 1937: 311) inside an epistemological closure resulting from this self-regulation process. We aim to maintain a constancy of ours through recursive changes and so we change just to maintain this constancy we are used to calling life (Bateson 1972: 17). There is a balance of stability and change that recurs in any state and at any level of reframing. On the one hand any epistemological possibility emerges just because a biological constraint encloses it (Varela 1979). On the other hand people are dissipative systems ${ }^{17}$ which repeatedly alternate between near-to-equilibrium states 
and, especially, far-from-equilibrium states (Prigogine 1977: 14). These fluctuations result from a continuous exchange with the environment and lead to consecutive bifurcations through which the undertaken alternative is, in the most cases, irreversible (Prigogine 1982: 49-51). You disassemble and resolve a puzzle but the childhood of a person or of a nation you do not.

The world as a whole seems to belong to these complex systems, intrinsically random, for which irreversibility is meaningful, and it is to this category of systems with broken time symmetries that all phenomena of life belong and, as a consequence, all human existence.

(Prigogine 1982: 54)

If we want to re-frame dissent from an epistemological point of view we have to consider the very two sides of the same systemic coin: the epistemological and biological closure of any complex system and the continuous and irreversible fluctuation of states throughout inside-outside relations. We may understand this apparent antithesis through the superordinate ethical process "as a shift from causal unidirectional to mutualistic systemic thinking, from a preoccupation with the properties of the observed to the study of the properties of the observer" (Howe and Foerster 1975: 1-2). Politicians, opinion-makers and also political scientists are nevertheless enclosed in the epistemological systems they are trying to orient towards. Therefore a step further is perhaps needed in their practice to be aware of the epistemological "closure constitutive of a particular configuration of speaking/listening positions in relation to each other, the characteristics of which define the culture we are working in" (Boxer and Kenny 1990: 217). Such a configuration never reaches a conclusive equilibrium. It oscillates based on the varying of speaking/listening positions and on a here-andnow knowledge as "conceptual structures that epistemic agents, given the range of present experience within their tradition of thought and language, consider viable" (Glasersfeld 1992: 381). The "Other, the locus of the speech" (Lacan 1977: 263) seems to be before us, seems to be beyond any margin between an inside and an outside. We may suppose for now that dissent is the awareness of a (Lacanian) lack between a system's closure and the system's continuity.

To overcome the distinction of "what pertains to the system as constitutive of its phenomenology from what pertains to the need of our domain of description" (Varela 1979: 6), we have to "consider reality as the co-mergence of many interdependent systems, that is, in a naïve way, of many interdependent observers" (Cheli, 2011: 3). The focus of present discussion pertains to some processes that are neither-between-nor-within two or more systems. "The entities we categorize as things in the ordinary sense are better understood as instantiations of certain sorts of processes or process-complexes" (Brenner 2005: 167). Hence the individual realm may be re-framed not as an irreducible principle but rather as an emergent (or co-mergent) quality of a wider process of individuation, in which we replace the social realm as a logical argument with the social relations system as something we experience only through itself (Simondon 2005). Politically 


\section{S. Cheli}

speaking it is the same conclusion two very different thinkers came to. Friedrich Hayek (1944), a liberal economist, and Christopher Caudwell (1938), a Marxist writer, realized politics should not pursue a concept of freedom as an absence of constraints. The only one possible freedom consists in the presence of possibilities, that are co-merging inside the system of relations we live in.

In conclusion, dissent from an epistemological point of view may be considered a recursive process that shifts a political system from a near-toequilibrium state to a far-from-equilibrium state. The more we de-construe it, and therefore re-frame the whole political system, the more we anticipate and govern the inevitable shift in the equilibrium, and understand why lie, deception and conflict could become preferable options. Dissent is something we ought to promote to recursively call our assumptions into question and to promptly look for new viable choices. As I have tried to demonstrate, a tertium datur ${ }^{18}$ exists between accepting or rejecting a cultural hegemony. Such alternative leads one to re-frame personal epistemologies of dissenters and supporters in a new superordinate epistemology to be continuously tested out on the co-mergent qualities of a referent system. To do that we have to scientifically assess the viability of present choices and the anxiety-inducing dilemmas that obstruct the horizon of knowledge (Cheli 2013). ${ }^{19}$ The dissent we may find between or within political groups is a useful tool in assessing and resolving a possible conflict. To govern a party or a nation means to deal with the continuous equilibrium-shifting that dissent seems to highlight. It is an equilibrium we never reach, neither as politician nor as citizen.

The will to govern must not be confused with the will to power. The will to govern is the will to govern the others; the will to power is the will to govern oneself.

(Coomaraswamy 1918: 139)

\section{Notes}

1 See the Clarendon edition (Malcolm 2012).

2 I have personally translated this and all other excerpts from non-English original sources.

3 See the Istituto Storico Italiano per il Medio Evo edition (Inglese 1994).

4 See the Clarendon edition of the works of Plato (Duke et al. 1995).

5 See the Edizioni di Storia e Letteratura edition (Sanna 2005).

6 The Secondo Incontro con i Dirigenti Scolastici (Second Meeting with School Heads) was a training seminar on the support of teenage students with severe psychological complaints. Alessandro Meluzzi, psychiatrist, Catholic deacon and former Italian Senator (elected within Silvio Berlusconi's party) delivered a lecture about what he called Christ-therapy, in opposition to standardized psychotherapy.

7 According to constructivist psychology anxiety is defined as "the recognition that events with which one is confronted lie outside the range of convenience of one's construct system" (Kelly 1955: 495).

8 According to constructivist psychology threat is "the awareness of imminent comprehensive change in one's core structures" (Kelly 1955: 489). 
9 Constructivist psychology describes such similitude as follows: "To the extent that one person employs a construction of experience which is similar to that employed by another, his psychological processes are similar to those of the other person" (Kelly 1955: 90).

10 "An independent class of intellectuals does not exist, but rather each social group has a class of intellectuals or tends to create it" (Gramsci 1975: Q19, §69).

11 "The intellectuals succeed in creating hegemony to the extent that they extend the world view of the rulers to the ruled" (Bates 1975: 353).

12 When Bruno Vespa, the interviewer, asked for a clarification on incongruences in Berlusconi's speech, the former Prime Minister exhorted him to literally sit down and without any further questions went on describing his own truths.

13 The two governments were led by Prodi (2006-8) and Monti (2011-13). Moreover, the current government (2013), led by Letta, is a grand coalition that includes Bersani's and Berlusconi's parties.

14 The 2013 Italian elections identified three main parties: the left-wing coalition led by Bersani's Democratic Party (17,044,684 votes); the independent Five Stars Movement $(15,975,308$ votes), led by Giuseppe Piero Grillo; the right-wing coalition led by Berlusconi's People of Freedom (14,225,559 votes). The reported figures are the collected sums of the votes at the Chamber of Deputies and the Senate of the Republic (Italy, Ministry of Interior, 2013).

15 Authors refer to Whitehead's and Russell's (1962) essay.

16 Psychologically many types of learning (Bateson 1972: 287-308) and change exist (Kelly 1955: 938-41). The re-framing I am describing is considered the highest level type.

17 A dissipative system is a thermodynamically open system which is working out of and far from thermodynamic equilibrium in an environment with which it exchanges matter and energy (Kondepudi and Prigogine 1998: 427).

18 "An included or additional third state $\mathrm{T}$ emerges from the point of maximum contradiction at which A and non-A are equally actualized and potentialized, but at a higher level of reality, at which the contradiction is resolved" (Brenner 2005: 176).

19 In a pilot study I have tested an assessment procedure using repertory grid technique (Fransella et al. 2004) and content analysis of structured interviews (Krippendorff 2004). The procedure was specifically designed to promote a tailored intervention in conflict resolution between political groups.

\section{Bibliography}

Bannister, D. 2003. "Personal construct theory and politics and the politics of personal construct theory." In Fransella F. (ed.), International Handbook of Personal Construct Psychology. Chichester: John Wiley \& Sons.

Bannister, D. and Fransella, F. 1971. Inquiring Man. Harmondsworth: Penguin.

Bates, T. R. 1975. "Gramsci and the theory of hegemony." Journal of the History of Ideas 36: 2, 351-66.

Bateson, G. 1972. Steps to an Ecology of Mind. San Francisco: Chandler Publishing Company.

Boxer, P. and Kenny, V. 1990. "The economy of discourses: a third order cybernetics?" Human Systems Management 9: 4, 205-24.

Brenner, J. 2005. "Process in reality: a logical offering." Logic and Logical Philosophy 4, 165-202.

Caudwell, C. 1938. Studies in a Dying Culture. London: John Lane The Bodley Head.

Cheli, S. 2011. "Neither between, nor within. Selfhood and otherness in epistemology." In 14th International Congress of Logic, Methodology and Philosophy of Science 


\section{S. Cheli}

(CLMPS). Nancy, Tuesday 19th to Tuesday 26th July, 2011. www.univ-nancy2.fr/ poincare/documents/CLMPS2011ABSTRACTS/14thCLMPS2011_B1_Cheli.pdf (accessed June 21 2013).

Cheli, S. 2013. Variazioni sul Tema del Potere. Da un'Epistemologia della Politica a una Politica dell'Epistemologia. A thesis submitted in partial fulfillment of the requirements of Institute of Constructivist Psychology for the School in Psychotherapy. Padua: Institute of Constructivist Psychology.

Cheli, S. and Giliberto, M. 2012. "What part could PCP play in dialogue with approaches where there is no alternative?" In M. Giliberto, C. Dell'Aversano and F. Velicogna (eds). PCP and Constructivism: Ways of Working, Learning and Living. Florence: Libri Liberi.

Cheli, S. and Velicogna, F. 2011. "An Italian precursor of Kelly and friends? The quasiconstructivism of Giambattista Vico." In D. Stojnov et al. (eds). Personal Construct Psychology in an Accelerating World. Beograd: EPCA Publications.

Collini, S. 2013. Con Noi si Cambia. Stop a Chi Ha Fallito. L'Unità. 3rd February. www. unita.it/italia/bersani-con-noi-si-cambia-br-basta-promesse-da-chi-ha-falliito-1.481797 (accessed June 21 2013).

Coomaraswamy, A. 1918. The Dance of Siva. Fourteen Indian Essays. New York: The Sunwise Turn.

Derrida, J. 1972. Marges de la Philosophie. Paris: Les Éditions de Minuit.

Derrida, J. 1990. "Force de loi: le fondement mystique de l'autorite." Cardozo Law Review 11, 919-1045.

Duke, E. A. et al. (eds) 1995. Platonis Opera. Oxford: Clarendon Press.

Du Preez, P. 1980. The Politics of Identity. Oxford: Blackwell.

Feyerabend, P. 1975. Against Method: Outline of an Anarchistic Theory of Knowledge. London: New Left Books.

Foerster, H. Von. 2003. Understanding Understanding. Essays on Cybernetics and Cognition. New York: Springer.

Foot, J. 2013. "Berlusconi has tainted Italian politics for years to come." Guardian. 21 February. www.guardian.co.uk/commentisfree/2013/feb/21/berlusconi-tainted-italianpolitics (accessed June 21 2013).

Foucault, M. 2001. Dits et Ecrits. Édition Quarto. Paris: Gallimard.

Fransella, F., Bell, R. and Bannister, D. 2004. A Manual for Repertory Grid Technique. New York: John Wiley \& Sons.

Giliberto, M. 2010. "An Invitation to Elaborate Ethics through PCP.” In D. Bourn and M. Fromm (eds). Construing PCP: New Contexts and Perspectives. Norderstedt: Books on Demand.

Glasersfeld, E. Vonn. 1981. "The concepts of adaptation and viability in a radical constructivist theory of knowledge.” In I. E. Sigel, D. M. Brodzinsky and R. M. Golinkoff (eds), Piagetian Theory and Research. Hillsdale: Erlbaum.

Glasersfeld, E. Von. 1992. "Constructivism reconstructed." Science \& Education 1, 379-84.

Glasersfeld, E. Von. 1995. Radical Constructivism: A Way of Knowing and Learning. London: Falmer Press.

Glasersfeld, E. Von. 2007. Key Works in Radical Constructivism. Rotterdam: Sense Publishers.

Gramsci, A. 1975. Quaderni dal Carcere. Turin: Einaudi.

Grillo, G. P. 2013. Obiettivo: Elezioni 2013. [Online] December 11 2003. www.beppegrillo. it/2012/12/obbiettivo_elez/index.html (accessed June 21 2013). 
Hayek, F. A. 1944. The Road to Serfdom. Chicago: Chicago University Press.

Hebb, D. O. 1958. "Alice in Wonderland or psychology among the biological sciences." In H. F. Harlow and C. N. Woolsey (eds). Biological and Biochemical Bases of Behavior. Madison: University of Wisconsin Press.

Howe, R. and Foerster, H. Von. 1975. "Introductory comments to Francisco Varela's calculus for self-reference”. International Journal of General Systems 2, 1-3.

Inglese, G. (ed.). 1994. De Principatibus. Rome: Istituto Storico Italiano per il Medio Evo.

IRC Verona. 2012. Secondo Incontro con i Dirigenti Scolastici. [Online video]. April 17. www.youtube.com/watch?v=6uXMgStQCMw (accessed June 21 2013).

Italy. Ministry of Interior. 2013. Elezioni 2013. http://elezioni.interno.it/ (accessed June $212013)$.

Keeney, B. P. 1983. Aesthetics of Change. New York: The Guildford Press.

Kelly, G. A. 1955. The Personal Construct Psychology. New York: Norton.

Kissinger, H. 1994. Diplomacy. New York: Simon \& Shuster.

Kondepudi, D. and Prigogine, I. 1998. Modern Thermodynamics: From Heat Engine to Dissipative Structures. New York: John Wiley \& Sons.

Krippendorff, K. 2004. Content Analysis. An Introduction to Its Methodology. Thousand Oaks: SAGE.

Lacan, J. 1977. Écrits. A Selection. Translated from French by A. Sheridan. New York: Norton.

Levinas, E. 1961. Totalité et Infini. Le Hague: Nijhoff.

Malcolm, N. (ed.). 2012. Leviathan. Oxford: Oxford University Press.

Maturana, H. and Varela, F. 1980. Autopoiesis and Cognition. The Realization of the Living. New York: Kluwer.

Newman, S. 2001. From Bakunin to Lacan. Anti-Authoritarianism and the Dislocation of Power. London: Lexington Books.

Orwell, G. 1938. Homage to Catalonia. London: Secker and Warburg.

Orwell, G. 1968. "Rudyard Kipling." In G. Orwell, Collected Essays, Journalism, and Letters of George Orwell, Vol. II. London: Secker \& Warburg.

Patocka, J. 2003. Socrate. Translated in Italian from Czech by M. Cajthaml. Turin: Bompiani.

Piaget, J. 1937. La Construction du Réel chez l'Enfant. Paris: Delachaux et Niestlé.

Porta a Porta. 2012. Dopo Monti Tocca a Me. [Online video]. December 18. www.rai.tv/ d1/RaiTV/programmi/media/ContentItem-672baf11-d611-4889-baf0-e6369e0558c1. html (accessed June 21 2013).

Prigogine, I. 1977. Self-Organization in Nonequlibrium Systems. New York: John Wiley $\&$ Sons.

Prigogine, I. 1982. Only an Illusion [Lecture] The Tanner Lectures of Human Values. Jawaharlal Nehru University, December 18 1982. http://tannerlectures.utah.edu/_ documents/a-to-z/p/Prigogine84.pdf (accessed June 21 2013).

Sanna, M. (ed.). 2005. De Antiquissima Italorum Sapientia. Rome: Edizioni di Storia e Letteratura.

Simondon, G. 2005. L'Individuation à la Lumière des Notions de Forme et d'Information. Grenoble: Jérôme Millon.

Szasz, T. 1960. "The myth of mental illness." American Psychologist 15, 113-18.

Thoreau, H. D. 1849. Aesthetic Papers. New York: Putnam.

Varela, F. 1979. Principles of Biological Autonomy. New York: Elsevier North Holland. 


\section{S. Cheli}

Varela, F. 1999. Ethical Know-How: Action, Wisdom, and Cognition. Stanford: Stanford University Press.

Watzlawick, P., Weakland, J. H. and Fisch, R. 1974. Change. Principles of Problem Formulation and Problem Resolution. New York: Norton.

Whitehead, A. N. and Russell, B. 1962. Principia Mathematica to *56. Cambridge: Cambridge University Press. 


\section{Part III}

\section{Institutions}





\title{
9 Political dissimulation à la Kant Two limits of the sincerity requirement
}

\author{
Sorin Baiasu
}

\section{Introduction}

According to a standard objection, ${ }^{1}$ Kant holds an unacceptably strict view on lying and deception, and an unreasonably demanding requirement of sincerity. Especially in his late essay 'On a supposed Right to Lie from Philanthropy', Kant seems to endorse an unconditional prohibition against lying, even lying to a murderer who asked us whether a friend of ours whom he is pursuing has taken refuge in our house. ${ }^{3}$ Yet, there are two limitations of this 'unconditional' prohibition which Kant asserts and which should make his view more palatable. First, the sincerity requirement is limited by the condition that the agent be forced to communicate. When the agent can refrain from communicating, there is no obligation to tell the truth. Second, the sincerity requirement is limited by the condition that the basic political structure of a state be not undermined. For agents who play a role in the political institutions of a state, not only can it be the case that there is no obligation to tell the truth, but there can be an obligation on their part to dissimulate, even when dissimulation implies intentional deceit.

My aim here is not to defend Kant's position overall or even to provide a thorough defence of these two limitations to the principle of sincerity. Given the limited scope of this chapter, I will try to identify Kant's justification for these limitations without attempting to evaluate this justification; if a justification can be found, then we will end up with a Kantian view of sincerity in politics which is less strict than the standard interpretation usually credits Kant with. We will also have an illustration of the types of justification Kant allows for what seem to be exceptions from unconditional moral principles. Whether this Kantian view of sincerity is sufficiently flexible and whether the justification provided by Kant is compatible with his moral theory and, more generally, philosophically convincing, will remain open questions for a different occasion.

\section{Truth and truthfulness}

In his famous essay 'On a supposed right to lie from philanthropy', Kant makes the following comments in relation to Benjamin Constant's claim that 'To tell the truth is a duty, but only to one who has a right to the truth' (SRL 8: 425): 
... the expression 'to have a right to the truth' is meaningless. One must instead say one has a right to his own truthfulness (veracitas), that is, to the subjective truth in his person. For to have a right to a truth objectively would be tantamount to saying that, as in the case with what is yours and mine generally, it is a matter of one's will whether a given proposition is to be true or false; and this would give rise to an extraordinary logic.

(SRL 8: 426)

What does Kant mean when he says that 'to have a right to a truth objectively would be tantamount to saying that [...] it is a matter of one's will whether a given proposition is to be true or false'? And why does he think this will lead to an 'extraordinary logic' (SRL 8: 426)?

To make his argument against Constant's supposed 'right to the truth', Kant uses an analogy with 'what is yours and mine generally'. In the Metaphysics of Morals, what is yours and mine generally refers to what Kant calls intelligible possession or property, and he distinguishes between empirical and intelligible possession. Empirical possession is given by the control I can exercise over an object that I physically possess - say, holding a mobile phone in my hand and trying to protect it from someone who is trying to snatch it from me. By contrast, intelligible possession or property is possession 'merely by my will; hence, merely rightfully' ( $M M$ 6: 248). For instance, my (rightful) possession of the mobile phone after it was snatched from me and taken away enables me to will rightfully that the mobile not be used and be returned to me promptly. To be sure, merely rightful possession does not allow the same control over my property as physical possession, but it is what counts when we consider the fate of my property under conditions of justice.

In the case of physical possession, if someone snatches an object from me, then I am not wronged in virtue of the fact that something has been done with the object of my possession without my consent; for, after all, once I no longer hold it, I am no longer in its (empirical) possession. So, instead of wronging me in my possession of the object (say, the mobile phone mentioned above, in the possession of which I am merely empirically), in having it snatched from me, I am wronged 'with regard to what is internally mine (freedom)' (MM 6: 248). In other words, when I possess something merely physically, having it taken from me does not wrong me in my possession of the object, but in my freedom not to have my body (which is both physically - assuming we can talk about this in relation to the body - and intelligibly mine) moved against my will.

For my consent to be relevant, I would need to be able to 'assert that I am in possession of the object even without holding it' (MM 6: 248). In this case, I possess the object intelligibly and, when I have the object snatched from me or when the object, of which I am no longer in physical possession, is used in a way which is against my will, I can still claim to be its rightful owner (and to possess it intelligibly) and, hence, intelligibly or from the perspective of what is right, my decision about the fate of the object is what is important. Hence, empirically, the fact that I hold an object only gives me (some) control over it as 
long as I hold it, but this control is transferred to another person who is now holding the object, once it has been snatched from me. Intelligibly, I possess an object when I can decide what happens with it (in the sense that my decision is the rightful one) even though, as a matter of fact, empirically, I may have no physical control over it.

By analogy, to talk meaningfully about my having a right to the truth, we would have to assume that the person having the duty to tell me the truth would be able to do so, if she wanted. Yet, whether a statement is true or false does not depend on a person's will. In other words, she would have to be in possession of the truth not simply empirically, by happening to formulate a true statement, but intelligibly, by being a matter of her will whether the statement were true or false. Kant rejects a view of truth as dependent on a person's will. ${ }^{4}$ Whether something is true or false is an objective, not a subjective, consideration, so it cannot depend on my decision.

What a person can deliver and, hence, assuming that I have a right to that, what I, as a person, can have a right to, is not truth, but truthfulness. ${ }^{5}$ I have a right to a person's truthfulness, to her being truthful in her declaration; her declaration may be false even when the person, to the best of her knowledge, thinks it is true, hence the truth or falsity of a statement does not depend on the person's will. As all a person can achieve is that the statements she utters be truthful, I cannot be expected to be provided with the truth and, hence, to have a right to being provided with the truth. In short, I cannot have a right to the truth. I can, nevertheless, have a right to the other person's truthfulness.

Kant's objection to Constant is terminological; I doubt Constant would deny Kant's criticism, as, by denying Kant's criticism, we end up indeed with what Kant calls 'an extraordinary logic'; having a right to the truth would imply that the truth of a claim would depend on the person's willingness to utter what is true, whereas our ordinary, everyday life teaches us that some of our claims turn out to be false despite our best intentions. Having clarified the sense in which Kant talks about a duty to truthfulness, let us move on to the main topic of this chapter, namely, the extent of this duty. In the next section, we will look at the justification, and some of the limits, of this duty.

\section{Duty to truthfulness}

In the previous section, we saw that Kant's focus in the essay on a 'Supposed Right to Lie' is on a person's truthfulness, rather than the truth of her claims. In the same essay, Kant makes also his famous claim concerning the normative significance of a duty to truthfulness:

Truthfulness in statements that one cannot avoid is a human being's duty to everyone, however great the disadvantage to him or to another that may result from it; and although I indeed do no wrong to him who unjustly compels me to make the statement if I falsify it, I nevertheless do wrong in the most essential part of duty in general by such falsification, which can 
therefore be called a lie (though not in a jurist's sense); that is, I bring it about, as far as I can, that statements (declarations) in general are not believed, and so too all rights which are based on contracts come to nothing and lose their force; and this is a wrong inflicted upon humanity generally.

(SRL 8: 426)

First, Kant asserts here a duty to truthfulness that any person owes to everyone else. This duty outweighs any potential disadvantages to the person herself or to any other person. Hence, if there is a limitation on the duty to truthfulness, this is not given by the consequences of being truthful. No matter how negative such consequences will be, Kant thinks there is still a duty to be truthful. Thus, as he puts it, to be 'truthful (honest) in all declarations is therefore a sacred command of reason prescribing unconditionally, one not to be restricted by any conveniences' (SRL 8: 427).

Kant has justified this duty in the ethical sense elsewhere. ${ }^{6}$ Here he mentions one of the logical implications of a lie in the particular situation discussed: were a person to lie, when she could not avoid answering a question (for instance, as a result of being compelled by another person to answer), she would not wrong the individual who raised the question (as this individual unjustly compels her to answer), but she would wrong humanity generally, as she would bring it about that statements in general, including rights based on contracts, would lose their force. According to this argument, a lie undermines the force of statements, including statements constituting contracts and formulating rights. Being willing to lie in this way presupposes also being willing to undermine the capacity of persons to unite under a rightful condition (by undermining contracts and rights), and this is a fundamental duty for Kant.

Both in the first and in the second quotation above, Kant makes it clear that the unconditionality of the duty to truthfulness is defined by reference to advantages and disadvantages, conveniences and inconveniences - being unconditional means being beyond dis/advantages and in/conveniences. We can, however, notice one limitation Kant sets on this duty to truthfulness, a limitation which is not incompatible with its unconditionality relative to disadvantages and inconveniences; according to him, the duty to truthfulness applies to situations where I cannot avoid an answer. I have therefore the following three moral facts: first, there is an obligation to be truthful, when I cannot avoid communicating; second, when I can avoid communicating, there is an obligation not to be untruthful, because being untruthful is a maxim which Kant deems impermissible in general; finally, if I can avoid communicating, there is no obligation to be truthful, as otherwise the unconditional duty to truthfulness would not be limited to situations where I cannot avoid communicating. From the second and third facts, it follows that, when I can avoid communication, I am allowed to be either truthful or non-truthful; if I am not truthful, given that I cannot be untruthful, the only option left is that I am allowed to keep silent. ${ }^{7}$

This means that the duty to truthfulness is limited by the possibility of keeping silent; this duty is not unconditional - its validity depends on whether I 
can avoid communication. If I can avoid communication, one permissible option is to keep silent. ${ }^{8}$ Kant can be interpreted as defending this negative duty as the result of his putative method of justification: the Categorical Imperative requires us to act on maxims which can be universalised; hence, when the attempt to universalise a maxim leads to a contradiction, it cannot be universalised, and acting on that maxim is forbidden. In our case, the attempt to universalise a maxim of untruthfulness leads to contradictions. ${ }^{9}$ Hence, we can conclude on this basis that it is not truthfulness, which should be promoted, but non-truthfulness or untruthfulness, which ought to be omitted. ${ }^{10}$ When communication cannot be avoided, to avoid untruthfulness one must be truthful. ${ }^{11}$

Kant seems to be able to justify an unconditional duty to avoid untruthfulness and a conditional duty to truthfulness, in cases where communication cannot be avoided. The limitation applicable for the duty to truthfulness is generated by the permissibility of a maxim to keep silent, when not communicating by keeping silent is allowed. As we have seen, on Kant's account, when we are unjustly forced to answer a question, falsifying the answer does not wrong the person who constrains me to answer, but wrongs humanity in general. Because such a falsification wrongs other persons, Kant calls it a lie, but he is quick to point out that it should not be taken in the jurist's sense. In the next section, I will examine this sense of a lie, as well as two other notions of a lie, which can be found in Kant's texts.

\section{Lies}

Kant's notion of a lie is relatively complex and when considering also its relation to other impermissible maxims, such as that of deception, the story becomes quite complicated. His claim above about the distinction between a lie and a lie in the jurist's sense suggests a distinction between two types of lie, but, in fact, the short essay 'On a Supposed Right to Lie' makes reference to yet another, third sense of a lie. This threefold distinction has been operative throughout his work. I will shortly focus mainly on an intention to deceive, but given that lying presupposes an intention to deceive, it is useful to discuss the threefold Kantian distinction between types of lie.

According to James Mahon (2009), all lies make an untruthful statement with the intention that the statement be believed to be true. To have a lie, therefore, the person lying must make a statement, ${ }^{12}$ she must be aware that she makes this statement untruthfully (that is, think the statement is false), ${ }^{13}$ and intend to make the statement to a person for this person to believe it. ${ }^{14}$ According to Mahon, a lie in the ethical sense is an acknowledged untruthful statement uttered with the intention to be believed - it is very broad in scope and includes lies to oneself (2009: 208-9). Because a lie to oneself is harmless to others, a lie in the ethical sense may be intentionally harmless to others. Although ethical lies are ethically wrong and impermissible, they may not be punishable by law, as they may be lies to oneself. ${ }^{15}$

By contrast, a lie in the juristic or juridical sense is much narrower in scope than in the ethical sense (Mahon 2009: 209). It is an intentional untruth formulated to a particular other person with the intention that the person believe the 
statement and be harmed by believing it. Harming a person is understood as violating the person's rights. Hence, a lie in the juristic sense is an intentional untruth formulated to a particular other person with the intention that the person believe the statement and be deprived of what is rightfully hers. When Kant says that the lie he talks about in the essay on the supposed right to lie is not a lie in the juridical sense, he denies that this lie harms the person to which it is made. In the same essay, Kant also specifies that he is not interested in the notion of a lie in the ethical sense. Hence, he can only have in mind the third type of lie: a lie in the sense of right, to which I now turn.

A lie in the sense of right is the making of an untruthful statement to others with the intention that others believe that statement to be true and with the intention that humanity generally be harmed in this way. As we have seen, the intention to harm humanity generally is visible in the intention to violate a right of mankind, namely, the right to enter into, and maintain, a society. As Kant mentions in the passage quoted above, through an intended untruthful statement, I 'do wrong in the most essential part of duty in general [...], I bring it about [...] that all rights which are based on contracts come to nothing and lose their force' (SRL 8: 426). On Mahon's account, a lie in the sense of right is broader in scope than a lie in the juristic sense, but narrower than an ethical lie (2009: 211).

On Mahon's account, all these suggest the following links between the three types of lie. First, because an ethical lie is simply an intentional untruth, every lie in the juridical sense and in the sense of right is also an ethical lie. Moreover, because intentional untruths, which are intended to harm a particular person (lies in the juridical sense), also harm humanity in general, they are also lies in the sense of right. Finally and by contrast, not every lie in the sense of right is juridical or ethical (Mahon 2009: 209-14).

Now, if we take a lie in the ethical sense to be simply an intentional untruth (and this includes the intention to utter it for it to be believed), then all lies are ethical and the label 'ethical' does not really play any role, apart perhaps from pointing to the fact that any lie is ethically impermissible (but this would need a separate argument anyway); what can be said by talking about 'ethical lies' is also said by talking simply in terms of 'lies'. When a person utters a lie, she either utters it to herself or to another person. Hence, an ethical lie uttered to oneself is a specifically ethical lie, as it cannot harm others and therefore cannot be either a lie in the sense of right or in the juridical sense. A lie uttered to another person, by contrast, may be a lie specifically in the sense of right, when it does not harm particular individuals, but humanity as a whole. Such a lie is not specifically ethical, as specifically ethical lies are lies to oneself. It is not a lie in the juridical sense either, as it is not a lie to particular individuals. Finally, a lie to others may be specifically juridical, when it harms particular individuals. Such a lie would not be specifically ethical, as specifically ethical lies are lies to oneself, and it would not be specifically in the sense of right either, as the latter are not lies to particular individuals.

So, on this new nomenclature, an actual lie will be either specifically ethical or specifically in the sense of right or specifically juridical. The intentional 
untruth uttered with the intention of being believed will become the definition of a lie in general, but specific, existing lies will be in one of the three categories I have just mentioned. ${ }^{16}$ In addition to distinguishing between lies in the specific senses mentioned above, we can adopt a different strategy and distinguish between lies which are impermissible from an ethical perspective, lies which are impermissible from the perspective of right, and from the juridical perspective. ${ }^{17}$ In this way we can say that all lies are ethically impermissible, ${ }^{18}$ a narrower group (those which harm humanity as a whole) are also impermissible in the sense of right, and an even narrower group (those which harm particular individuals) are additionally impermissible juridically (or juristically).

Recall Kant's claim that falsifying a statement to the person who unjustly compels me to answer his question does not wrong that person, but wrongs duty in general, and this makes it a lie (though not in a jurist's sense). Here Kant talks about a lie which is impermissible from the perspective of right, but not from a juridical perspective. Our distinction between specific senses of lies makes it possible to explain what Kant means when he says:

I here prefer not to sharpen this principle ['Truthfulness in statements that one cannot avoid is a human being's duty to everyone'] to the point of saying: 'Untruthfulness is a violation of duty to oneself'. For this belongs to ethics, but what is under discussion here is a duty of right.

(SRL 8: 426n)

Because all lies are impermissible from an ethical perspective, it is unclear in what sense Kant claims that the principle of a duty to truthfulness does not belong to ethics. In fact, it is clear now that Kant simply asserts the distinction between a specifically ethical lie (a lie to oneself) and the lie specifically in the sense of right with which he is concerned.

To conclude this section and in preparation for the remainder of the chapter, I will briefly present the implications of Kant's view of lies for the relation between lies and deception. According to the general definition of lies, as an intentional untruth (that is, an untruthful statement uttered with the intention that it be believed), a lie involves an intention to deceive: the liar intends that the lie be believed by the person lied. Yet, if the liar is not successful, then no deception actually occurs. There are of course cases where a lie is successful, and then it also deceives, but there are also cases where a person is deceived and no lie is uttered. When verbal communication takes place, then there are situations where truthful statements may be used to deceive another person. ${ }^{19}$

When verbal communication does not take place (for instance, when a person is keeping silent, as she is not forced to answer or say anything, and prefers to be quiet, rather than untruthful), Kant still thinks ${ }^{20}$ we are dealing with a case of deceit: he distinguishes between concealment or reservation by dissimulation ('negatively, when we do not disclose, or allow it to be seen, what we are thinking' - V-MS/Vigil 27: 699) and by simulation ('when by fabricating the opposite we try to occasion an error on the other's part' $-V$-MS/Vigil 27: 699-700 ${ }^{21}$ ); 
then he claims that the 'former deceives (fallit)', whereas the other tries to make the person the author of the other's error (V-MS/Vigil 27: 700). ${ }^{22}$

It follows therefore that lying and deceiving are in a sense independent phenomena: one may lie without deceiving and one may deceive without lying. As we have seen, one way to avoid the strict obligation formulated by Kant against lying, an obligation which can be interpreted as one to truthfulness, is by keeping quiet; however, one may deceive another person without lying - for instance, one may be truthful, but deceiving, one may keep quiet in a deceiving way or communicate without believing the content of what is being communicated.

What makes lying wrong is not deception, as we may have a lie where no deception occurs, and lying is still wrong. A lie is wrong because an intention to deceive is wrong. Hence, although lying and deceiving are independent wrongs, there is a strong link between lying and intentional deceit: a lie presupposes an intention to deceive. As we will see in the next section, Kant suggests there are situations in which a particular type of an intention to deceive may be not only permissible, but also required. ${ }^{23}$ It is this kind of situation which seems to represent a second limitation on a duty to be truthful.

\section{Political dissimulation}

As we saw in the previous section, if we focus on an obligation not to be untruthful, we seem to have an unconditional requirement of omission. The same obligation would also obtain in the case of a maxim of an intention to deceive. Yet, about 12 years before his essay on lying, in 'An answer to the question: What Is Enlightenment?', Kant seems to acknowledge another limitation on the duty of omission of an intention to be deceitful through one's actions. This limitation seems applicable to cases where a person is 'institutionally engaged', that is, she performs a particular role in one of a society's institutions.

Thus, on Kant's account, in such cases, it seems the person should act in accordance with the expectations associated with the role, even when she thinks that acting in that way is not the way in which she should act. In other words, although she believes $\mathrm{Y}$, which can be expressed by doing X, Kant thinks she should not do $\mathrm{X}$, but should act in accordance with the expectations associated with her role:

it would be ruinous if an officer, receiving an order from his superiors, wanted while on duty to engage openly in subtle reasoning about its appropriateness or utility; he must obey. But he cannot fairly be prevented, as a scholar, from making remarks about errors in the military service and from putting these before his public for appraisal. A citizen cannot refuse to pay the taxes imposed upon him; an impertinent censure of such levies when he is to pay them may even be punished as a scandal (which could occasion general insubordination). But the same citizen does not act against the duty of a citizen when, as a scholar, he publicly expresses his thoughts about the inappropriateness or even injustice of such decrees. So too, a clergyman is 
bound to deliver his discourse to the pupils in his catechism class and to his congregation in accordance with the creed of the church he serves, for he was employed by it on that condition. But as a scholar he has complete freedom and is even called upon to communicate to the public all his carefully examined and well-intentioned thoughts about what is erroneous in that creed and his suggestions for a better arrangement of the religious and ecclesiastical body.

(AQE 8: 37-8)

Kant draws here a distinction between two ways in which a person may act in the same context: as a scholar, a person is expected to communicate to the others her considered views on what the appropriate response in that context is; by contrast, as a citizen, officer or priest (or what one may call, as holder of a public position), she is expected to communicate or act in the ways her role prescribes, even when she would in this way express a different view than Y. Different reasons are provided: it would be 'ruinous', if the officer did not obey the orders of his superiors; it could cause a 'scandal' and perhaps 'general insubordination', if the citizen refused to pay taxes; finally, for the clergyman, to talk with his congregation about what seems to him erroneous in the respective creed, is to go against a condition for his appointment on that role, the condition of delivering his discourse 'in accordance with the creed of the church he serves'.

In these situations, Kant advises a person engaged in an institutional role to make declarations or act in ways which are different from the ways the holders of those roles think they should be talking and acting. It would seem clear therefore that these public officials will have as a minimum to dissimulate their views on the matters, even if this simply means to keep silent. Talking about the obligation the clergyman has to carry on teaching the congregation as if he had no reservations and objections to the creed and arrangements of the church he serves, Kant notes:

And there is nothing in this that could be laid as a burden on his conscience. For what he teaches in consequence of his office as carrying out the business of the church, he represents as something with respect to which he does not have free power to teach as he thinks best, but which he is appointed to deliver as prescribed and in the name of another. He will say: Our church teaches this or that; here are the arguments it uses. He then extracts all practical uses for his congregation from precepts to which he would not himself subscribe with full conviction but which he can nevertheless undertake to deliver because it is still not altogether impossible that truth may lie concealed in them ...

(AQE 8: 38)

When Kant says that the clergyman should feel no burden on his conscience, he must mean one of the following two alternatives: the prohibition of an intention to deceive is unconditional, but what the clergyman does cannot be understood 
as an instance of an intention to deceive; or what the clergyman does is an instance of an intention to deceive, but the obligation not to intend to deceive is not unconditional.

The easiest would be to show that what the clergyman does is not an instance of an intention to deceive. For, then, the question is answered; whereas, if it turns out the clergyman is intentionally deceitful, we have the additional task of understanding what could justify such a limitation of the requirement of nondeceitfulness. So let us try with the first alternative.

To begin with, the clergyman is not appointed to deliver his views, but to teach as prescribed. The congregation should be aware of this condition, and should not be under the illusion that what the clergyman says is what he is fully convinced of. ${ }^{24}$ Second, the clergyman can reinforce the importance of this condition by making explicit reference to the church, as the authority prescribing the teaching ('Our church teaches this or that; here are the arguments it uses'). This also has the advantage that it avoids untruthful claims; the clergyman would claim what the church says, rather than suggest that the claims made are his own views. ${ }^{25}$ Finally, in deriving practical conclusions from the church's precepts, the clergyman makes claims, the truth of which he cannot subscribe to, but he cannot reject either; this minimal condition of not being able to show that the views presented to the congregation are impossible is needed if the clergyman is not to be accused of teaching views he himself knows to be false. ${ }^{26}$

This, however, seems to go against a certain claim Kant makes in the Doctrine of Virtue. In the 'Casuistical Questions' subsection of the section 'On Lying', Kant discusses the case of a servant who is instructed by his master to say 'Not at home', when a certain visitor asks for him. On Kant's account, the servant lies (and hence manifests an intention to deceive) and is responsible in part for the consequences of this lie. ${ }^{27}$ The servant is supposed to deliver a prescribed sentence, irrespective of whether it will be uttered truthfully or not. Any person in the role of the servant would be expected to say the same sentence. If we were to follow the reasoning above, no visitor should be deceived by the servant's claim, as the subtext is: 'Not at home, as the master explicitly or only implicitly commanded me to say'. ${ }^{28}$ There are, however, several other problems.

First, as we have seen, it is unclear the clergyman, the citizen who refuses to pay taxes and the officer do not know that what they do or say is false: the officer will eventually argue that there are 'errors in the military service'; the citizen will talk 'about the inappropriateness or even injustice' of the arrangements; the clergyman will claim that the church's creed is (at least partly) 'erroneous' ( $A Q E$ $8: 37-8$ ). It is likely they all think they are right and, hence, the views expressed by acting as expected are wrong. Second, as we have seen, while Kant regards reservation in the form of dissimulation as permissible, he still thinks it would be better if we could adopt a candid and openhearted attitude. Given the kind of beings we are, as already mentioned, he regards our reservation as 'a neat quality which then does not fail to progress gradually from dissimulation to intentional deception and finally to lying' (A 7:332). This is why lack of candour is wrong and dissimulation includes an intention to deceive. Finally, the case of the 
clergyman in particular seems to fall under the category of situations where truthful statements are used to deceive. ${ }^{29}$

This suggests that the first alternative (the duty not to be intentionally deceitful is unconditional, but the clergyman's behaviour is not an instance of an intention to deceive) is not palatable. Hence, the second alternative (the clergyman's actions are exceptions to the unconditional principle of avoiding deception) seems more likely. The difficult task, then, concerns the justification of this exception. To this I turn in the next section.

\section{Justifying the unjustifiable}

Let us consider the reasons invoked by Kant for not allowing the officer, the citizen and the clergyman to act (in a general sense, including speech) in accordance with their own views. What is common in all three cases is the existence of contractual relations which may also presuppose a hierarchy. This is clear in the example of the officer, who is not allowed to question the orders of the superior, but must obey and only after that submit his views publicly for consideration. In the example of the citizen who refuses to pay taxes, Kant talks about 'insubordination', which is again a clear indication of an existing hierarchy of superiors and subordinates. Finally, in relation to the example of the clergyman, Kant invokes a contract, which the clergyman must respect, as he agreed to this when he was employed. All these cases reflect the fact that, by entering a civil condition, persons subject themselves to a public lawful condition, which limits their 'wild, lawless freedom', to allow them to find it 'undiminished, in a dependence upon laws, that it, in a rightful condition' (MM 6: 315).

In this way, persons and groups exit the state of nature, where each party (whether individual or state) 'has its own right to do what seems right and good to it and not to be dependent upon another's opinion about this' (MM 6: 312). In the state of nature, each party 'follows its own judgement'; by contrast, in the rightful condition, each party unites itself with all others and subjects itself to a public, external rightful condition. We can now draw some conclusions concerning the requirement of dissimulation for those performing roles in public institutions.

Recall the distinction between the three types of lie presented. Given that lies in general include the intention to deceive, we can distinguish also between three types of intentions to deceive. There are, first, the specifically ethical ones, which are intentions to deceive oneself. Second, there are the specifically juridical ones, which include an intention to deceive and in this way also to harm particular persons. Finally, the intention to deceive specifically in the sense of right will harm humanity as a whole, in virtue of the intention to deceive, although this intention is not directed to particular persons.

It seems clear that the clergyman, the citizen and the officer who are expected to obey and dissimulate their views do not try to deceive themselves. After all, they are also expected to voice publicly their own views with regard to the arrangements they consider problematic. Their dissimulations will either include 
an intention to deceive in the specifically juristic sense or in the sense of right. In both cases, however, a rightful condition is presupposed, as these types of deception include by definition an intention to harm and harm is defined by Kant as a violation of a person's rights. Therefore, insofar as the requirement of dissimulation is meant to prevent a return to the state of nature, it is more fundamental than an obligation not to form an intention to deceive and to harm others, as it makes possible such an obligation.

However, although the requirement of dissimulation may outweigh normatively the obligation not to form intentions to deceive others, it would still go against an ethical (in the general, not specific sense) requirement of nondeception. Moreover, on Kant's account, any legal obligation can become an ethical one if observed for the sake of its rightness. This means that the ethical duty derived from the requirement of dissimulation would clash with the ethical obligation not to form intentions to deceive. A solution to this problem is suggested by the previous case. As we have seen, in the case of an intentional deception specifically juristic or in the sense of right, we could establish a relation of priority by reference to the rightful condition in general: the requirement of dissimulation is needed for the preservation of a rightful condition, which makes possible the specifically juristic (or in the sense of right) prohibition of intentional deception. Perhaps a similar argument can be constructed at the ethical level. The starting point for this, I would like to argue, is given by the distinction between truth and truthfulness discussed previously. The difference discussed there was between the control we have over the truthfulness of our claims, and the lack of control we have over their truth. One implication of this lack of control is that we can fail to formulate true claims about what we should do in cases like those of the officer, the clergyman and the citizen.

This lack of control may of course result from our limited knowledge, but it may also result from what I would call 'residual' bias, bias which remains even after we have made a conscientious effort to the best of our abilities to judge the situation under discussion objectively. The partiality which threatens the judgement of individuals in situations of conflict justifies the introduction of a rightful condition where decisions are sought with the hope of overcoming partiality and aiming for omnilaterality. The requirement of dissimulation is precisely the requirement to overcome partiality in the attempt to achieve an omnilateral decision. It is, therefore, an epistemic principle, which must precede any substantive ethical principle, such as the prohibition of intentional deceit.

The obligation to act in accordance with the institutional expectations, rather than with one's own view of what is good or right, is an obligation to aim for a decision which is fair and right. To be sure, to aim for a decision which is right does not guarantee that the decision which is reached is actually right. What the rightful condition does guarantee is that the circumstances in which a right decision can be achieved are improved in comparison with a state of nature. In a state of nature, in a situation of conflict, parties involved in the conflict will decide how to act, while at the same time being involved in the conflict; by 
contrast, in the rightful condition, at least in theory, the legitimate authority will make a decision independently from the parties.

Given that the right decision is not guaranteed in the rightful condition, the additional provisos Kant mentions are apposite. Thus, according to Kant, the obligation to obey holds when the institutional expectation does not rely on assumptions which are obviously false. Moreover, it holds only when the obligation to follow the institutional expectations does not go against moral principles. If they do contradict moral principles, then Kant advises that the person resign from her role. ${ }^{30}$ This avoids situations like those of Milgram's experiments, where the expectation is that innocent individuals be harmed. Furthermore, what makes the obligation to obey even less dangerous is that the person would formulate and voice her concerns publicly. This can be a test for her judgements concerning the appropriateness of being obedient.

Hence, what seems to be an exception to the ethical principle prohibiting intentional deception turns out to be a more fundamental epistemic requirement for the possibility of ascertaining the right decision in situations involving interpersonal relations. Moreover, given the provisos mentioned by Kant, it is a requirement with a reasonable degree of plausibility. ${ }^{31}$

\section{Conclusion}

In this chapter, I examined two limitations Kant imposes on an 'unconditional' obligation to be truthful. An obligation to be truthful holds only when an agent has to communicate; if communication is not required, then it is permissible not to be truthful. We have seen that this is an implication of the way in which Kant's Categorical Imperative functions: we can justify as unconditional an obligation not to be untruthful, which is compatible with lack of communication. But we have seen that the obligation not to be untruthful and also not to intend to deceive holds only up to the point where being truthful can undermine the rightful condition. When this becomes a risk, not being truthful is not only permissible, but is required. As we have seen, political dissimulation can be justified on the basis of a fundamental epistemic principle in conditions of coexistence in limited space. According to this principle, when the interests of several parties are at stake, the best way to avoid any residual bias in making a decision is by giving authority to adjudicate to an agent whose interests are not at stake. Dissimulation is obligatory when the view of a person with an institutional role goes against the decision of the authority.

We have in this way what looks like a Kantian view of political dissimulation, which goes beyond a permission not to be candid, and asserts the obligation, for those engaged in institutional roles, to dissimulate (even when this produces intentional deceit) and to obey the decisions of the authorities. To be sure, the requirement to obey is in its turn limited and the obligation to dissimulate is tamed by the public expression of disagreement. These convey further plausibility to the Kantian view, but whether this plausibility is sufficient remains an open question for another occasion. 


\section{Notes}

1 This is reflected also in several essays in this volume - see the texts by Glen Newey, Doron Navot, Esther Abin and Marguerite La Caze.

2 In citing Kant's works the following abbreviations are used:

SRL: On a Supposed Right to Lie from Philanthropy (1797), in Kant (1996);

MM: The Metaphysics of Morals (1797), in Kant (1996);

GMM: Groundwork of The Metaphysics of Morals (1785), in Kant (1996);

C: Philosophical Correspondence (1759-1797), in Kant (1967);

V-MS/Vigil: Lectures on the Metaphysics of Morals (Vigilantius) (1793), in Kant (1997);

V-MS/Collins: Lectures on Universal Practical Philosophy (Collins) (1784-5), in Kant (1997);

AQE: An Answer to the Question: What Is Enlightenment? (1784), in Kant (1996);

A: Anthropology from a Pragmatic Point of View (1796/1798), in Kant (2006).

Pagination references in the text and footnotes are to the volume and page number in the German edition of Kant's works (1900-). I am using the translations listed in the Bibliography.

3 This famous case is formulated by Benjamin Constant and Kant replies to Constant in $S R L$. I am not going to discuss this case here; there is good and growing literature on this topic (e.g. Varden 2010; Cholbi 2009; Mertens 2016). For the purpose of this chapter, however, it is not necessary to engage in the debates related to this topic.

4 According to Bernard Williams, this may simply be the result of a concern with truthfulness:

Truthfulness implies a respect for the truth. This relates to both of the virtues that $[\ldots]$ are the two basic virtues of truth, [...] Accuracy and Sincerity: you do the best you can to acquire true beliefs, and what you say reveals what you believe.

(2002: 11)

I think at this junction in Kant the concern is mainly with the second virtue, that of sincerity. For Kant's understanding of 'truthfulness' and 'sincerity', see the next footnote.

5 Truthfulness is the attitude of expressing accurately one's beliefs. Kant treats 'truthfulness' and 'honesty' as synonyms and regards 'sincerity' as having a more restricted sense, whereas 'rectitude', a more general one: 'Truthfulness in one's declarations is also called honesty and, if the declarations are promises, sincerity; but, more generally, truthfulness is called rectitude' (MM 6: 429). I think 'rectitude' refers to an honest attitude beyond one's declarations, for instance, when communication is not verbal.

6 For instance, in the Groundwork, he argues against making lying promises (GMM 4: 422). In the 'Doctrine of Virtue', he argues against lying more generally (MM 6: 429).

7 I assume here that we are talking about being truthful in declarations or that 'silence' refers to communication more generally and not simply to verbal communication. One of these assumptions is necessary, as I may be verbally silent and still untruthful, when the message I communicate is not in accordance with what I take to be the case. I talk a bit more about these situations later in this chapter.

8 See C 11: 332. Kant talks about reticence also in the Metaphysics of Morals, in the 'Doctrine of Virtue' (6:471). There is a debate on the extent to which Kant was right to affirm a duty to truthfulness and the permission to be reticent. See, for instance, Langton (1992), Mahon (2006) and Chapter 6 in this volume by Pamela Sue Anderson.

9 See, for instance, $T L$ 6: 429. 
10 As already mentioned, one way in which one can avoid being untruthful is, where possible, by keeping silent. Nevertheless, keeping silent may be deceitful; it does avoid lying, as no statement or declaration has been formulated, but it can be a deceiving silence. Hence, one can deceive while withholding one's thoughts without lying for instance, when one's silence can be interpreted in a particular way and one continues to be silent although one knows this will be interpreted in a deceiving way.

11 On a standard account of the justification of Kant's ethical principles, we obtain an obligation, when the universalization of the maxim (say, 'To do A, if B') under discussion does not generate any contradictions, whereas the universalization of the contrary of the maxim ('To omit A, if B') yields a contradiction; if the universalization of the maxim does yield a contradiction, whereas the universalization of the contrary of the maxim does not, then acting on the maxim is forbidden; finally if the universalizations of the maxim and its contrary are both either free of contradictions or yielding contradictions, then the maxim is permissible (O'Neill 2013: esp. ch. 5). For the maxim of omitting untruthfulness to be an obligation, we would need that the contrary maxim ('To be untruthful') lead to a contradiction when universalized, which is certainly Kant's view; at the same time, the universalization of the maxim itself should be free from contradictions - again, not a controversial claim in Kant, although, as I have mentioned and as we will see shortly, this should be understood as a maxim of avoiding untruthfulness, rather than as one of promoting truthfulness.

12 Mahon provides a detailed discussion in his 2009 text (esp. 203-5).

13 For more details on this second condition, see Mahon (2009: 205-6).

14 Further details can be found in Mahon (2009: 206-7).

15 This follows from nature of juridical laws for Kant - they must be enforceable, which presupposes that they can be monitored reliably - lying to oneself cannot be monitored in this way. For a discussion of the necessary conditions of juridical laws and for the relation between ethics and law in Kant, see respectively Baiasu (2013: 24-7 and 2016).

16 In fact, in the Vigilantius ethics lectures, Kant distinguishes between an untruth and a lie: 'both, indeed, contain a falsiloquium, i.e. a declaration whereby the other is deceived, but the latter is uttered with an associated intention to injure the other by the untruth' (V-MS/Vigil 27: 700).

17 This seems to be John Atwell's strategy:

$\mathrm{He}$ [Kant] condemns lying on three grounds: (1) as lying promise, it violates a perfect duty to others, and thus infringes someone else's rights (2) as a lie in general, it violates a strict duty to oneself; and [...] (3) a lie violates the rights of mankind.

(1986: 193-4)

Hence, there are various perspectives for the normative evaluation of lies (depending on the duty and rights considered), and some lies violate some duties and rights, others, other such duties and rights.

18 Kant claims this repeatedly in various texts - for instance, V-MS/Vigil 27: 701.

19

... a Mennonite swore an oath that he had handed over the money he owed to his creditor, and in a literal sense he could swear this, for he had hidden that very sum in a walking-stick and asked his adversary to hold it.

(V-MS/Vigil 27: 702)

20 It is worth pointing out that I will refer here to his lecture notes, but I do not think this would be a problematic distinction.

21 As Kant explains, '[s]imulation can only be impermissible, though, when a person gives signs indicative of thoughts that he does not have, and thus becomes auctor erroris [the error's author] in the other' (V-MS/Vigil 27: 700). 


\section{S. Baiasu}

22 When verbal communication does not take place, there can still be other forms of communication which can be used to deceive. A person may suggest non-verbally that something is the case, although she does not believe it is in fact the case:

I can make a pretence, and give expression to something, from which the other may deduce what I want him to; but he has no right to infer from my utterance a declaration of intent, and in that case I have told him no lie, for I never declared that I was opening my mind to him; if I pack my bags, for example, people will think I am off on a journey, and that is what I want them to believe.

( $V-M O / C o l l i n s ~ 27: 446-7)$

23 Kant's interest in 'On a supposed right to lie from philanthropy' is twofold: whether being untruthful intentionally is permissible or obligatory in a situation in which lying can save the life of a person. On Kant's view, it 'would be a crime to lie to a murderer who asked us whether a friend of ours whom he is pursuing has taken refuge in our house' (SRL 8: 425). I raise the same questions about deceitful attitudes.

24 'Can an untruth from mere politeness (e.g., the 'your obedient servant' at the end of a letter) be considered a lie? No one is deceived by it' (MM 6: 431). Similarly, the clergyman's teaching represents what the church teaches, not what the clergyman himself happens to believe.

25 '...concealment, reservation, is a precaution that is approved of in ethics...' ( $V$-MS/ Vigil 27: 699).

26 The condition of not being able to show that something is impossible, when we cannot show that it is the case is required by Kant for that thing to be the object of a doctrinal belief (MM 6: 354; A824/B852). An additional condition, which I omitted for the sake of brevity, is that the view the clergyman must teach be not contrary to 'inner religion' (SRL 8: 38). This indicates that the clergyman does not consider the content of his teaching morally impermissible.

27 Thus, according to Kant (in the chapter 'On Lying', section 'Casuistical questions'), '... a householder has ordered his servant to say 'not at home' if a certain human being asks for him. The servant does this and, as a result, the master slips away and commits a serious crime, which would otherwise have been prevented by the guard sent to arrest him. Who (in accordance with ethical principles) is guilty in this case? Surely the servant, too, who violated a duty to himself by his lie, the results of which his own conscience imputes to him' (MM 6: 431).

28 An important difference between the case of the servant and that of the clergyman (as well as citizen and officer) may be that the former knows that his claim is false, whereas, as Kant puts it, in the case of the latter, 'it is not altogether impossible that truth may lie concealed in [the claim]' ( $A Q E$ 8: 38). And, yet, there is no reason we cannot imagine the example of the servant as allowing this kind of uncertainty - the servant might think that unbeknownst to him, the master has left and is no longer at home. As we will see shortly, the difference between these cases can also be reduced from the opposite direction, that is, by showing that the clergyman, officer and citizen also know that performing their roles will express false beliefs.

Hence, concealment, reservation, is a precaution that is approved of in ethics, though admittedly it is expressed (a) dissimulando, i.e., negatively, when we do not disclose, or allow it to be seen, what we are thinking; (b) simulando, when by fabricating the opposite we try to occasion an error on the other's part. The former deceives (fallit), but the latter endeavours to become the auctor erroris in alio.

( $V$-MS/Vigil 27: 700)

'This reticence, however, this want of candour [...] is only a wrong that hinders the expression of all the possible good that is in us' (C 11: 332). 
30 This is how I read Kant's condition that the clergyman's dissimulation do not contradict his 'inner religion' - see note 26 above; for if it did, 'he could not in conscience hold his office; he would have to resign from it' ( $A Q E$ 8: 38).

31 Acknowledgements: An early version of this paper was presented to the ECPR Joint Sessions of Workshops at the University of St Gallen in 2011 as part of a workshop on sincerity. I am grateful to the participants of the workshop, and in particular to Rainer Forst, David Owen and Peter Niesen, for a very useful discussion. Work on this paper was also carried out while I was visiting at the University of Vienna as part of the ERC project 'Distortions of Normativity' and during a 'sabbatical'; I am grateful to the project's PI and to Keele University for making those periods of research possible.

\section{Bibliography}

Atwell, J. E. 1986. Ends and Principles in Kant's Moral Thought. Dordrecht: Springer.

Baiasu, S. 2016. 'Right's complex relation to ethics in Kant: the limits of independentism'. Kant-Studien 107: 1, 2-33.

Baiasu, S. 2013. 'Kant's highest political good'. In V. Muresan and Kajima Shunzo (eds), Applied Ethics. Sapporo: Hokkaido University Press, pp. 15-35.

Cholbi, M. 2009. 'The murderer at the door: what Kant should have said'. Philosophy and Phenomenological Research 79: 1, 17-46.

Kant, I. 1900. Gesammelte Schriften. Vols 1-22 Preussische Akademie der Wissenschaften; vol. 23 Deutsche Akademie der Wissenschaften zu Berlin; vol. 24 Akademie der Wisseschaften zu Göttingen.

Kant, I. 1997. Lectures on Ethics. Tr. Peter Heath. J. B. Schneewind and P. Heath (eds). Cambridge: Cambridge University Press.

Kant, I. 1999. Practical Philosophy. Tr. and ed. Mary Gregor. Cambridge: Cambridge University Press.

Kant, I. 2006. Anthropology from a Pragmatic Point of View. Tr. and ed. Robert Louden. Cambridge: Cambridge University Press.

Langton, R. 1992. 'Duty and desolation'. Philosophy 67: 262, 481-505.

Mahon, J. E. 2009. 'The truth about Kant on lies'. In C. W. Martin (ed.), The Philosophy of Deception. Oxford: Oxford University Press.

Mertens, T. 2016. 'On Kant's duty to speak the truth'. Kantian Review 21: 1, 27-51.

O’Neill, O. 2013. Acting on Principle. An Essay on Kantian Ethics. 2nd edn. Cambridge: Cambridge University Press.

Varden, H. 2010. 'Kant and lying to the murderer at the door.... One more time: Kant's legal philosophy and lies to murderers and Nazis'. Journal of Social Philosophy 41: 4, 403-21.

Williams, B. 2002. Truth and Truthfulness: An Essay in Genealogy. Princeton, NJ: Princeton University Press. 


\section{Pretending peace \\ Provisional political trust and sincerity in Kant and Améry ${ }^{1}$}

Marguerite La Caze

My subject is trust within a state and between individual citizens and how it can be established and maintained, rather than trust in intimate relationships. Political trust is relevant to rebuilding society after civil war, genocide or another calamity has occurred. Philosophers discussing trust take trust to be an implicit confidence that others have good will or lack ill will towards us. ${ }^{2}$ This confidence can be made explicit if we reflect on it. Trust can be distinguished from reliability, as that is based on a conscious prediction of the behaviour of others (Thomas 1990: 238; Baier 1995: 98-9). I will argue that trust involves respect in the sense of limiting deception of others and care for others, or at least the conditions that will make truthfulness and care more likely. When we trust we are vulnerable to being harmed by others; however, we tend not to deliberate on such vulnerability.

To begin, I consider Kant's contribution to understanding trust. Kant is the first focus here as trust is central to his account of establishing and maintaining peace, and his condemnation of lying. The importance of trust in his moral philosophy has not been properly recognised. ${ }^{3}$ Kant links trust with proper respect for right/law, as we have to respect right to institute political community where people trust each other (1996a, 8: 380). Trust between members of a community can also enable a rightful condition or civil union by making society one of respect for right, not deception and violence (1996a, 6: 307). My interest is in the question of how we can enter what Kant calls a rightful state, where basic rights are respected and so trust is prevalent or how we can enter such a state after it was destroyed. Within states, these basic foundational rights are freedom, equality and independence. ${ }^{4}$ Kant discusses the rightful condition as passing into a state where people can enjoy rights because right action is defined both formally as right conduct and materially, what is covered by law, and a court decides how to apply law. A rightful condition is one we ought to enter into, so the rights of all will be respected and enforced (1996a, 6: 306).

Second, I consider the possibility of help as also necessary to trust, through the work of Jean Améry. Améry's idea of 'trust in the world' is explored to give a fuller picture of what is needed for basic trust between human beings. My argument is that both Kant's and Améry's accounts of trust are needed together to provide a full account of trust. Finally, I consider the difficulty of rebuilding 
lost trust after a calamity and its relation to sincerity in post-genocide Rwanda. I contend that sometimes sincerity is not the most important consideration. Instead, truthfulness and the willingness to act as if we believed in the goodness of others, and thought others and the world worthy of our trust can be. Sincerity involves meaning what we say and believing in the way we act, and can be distinct from truthfulness, as I will explain below.

\section{Kant, trust and sincerity}

Kant's discussion of trust between and within states in 'The Doctrine of Right' and 'Toward Perpetual Peace' needs to be extrapolated. His vision is cosmopolitan, and so when he writes about moving from a provisional state or state of nature to a rightful state, he argues that rights will be provisional until we share a rightful condition with the whole human race, in accordance with the idea of an original contract as a standard of justice (1996a, 6: 266). Thus, in that sense, we do not fully live in a rightful condition now, as there is no world of rightful states and no rightful condition between states. We are still in a provisional phase and may always be so. ${ }^{5}$ Arguably, Kant had a sense of the unlikelihood of a non-provisional politics evidenced in his work through his stress on the need for principles even in such situations. ${ }^{6}$ In 'Toward Perpetual Peace', he allows that some of the articles for perpetual peace concerning the cessation of disposing of states as if they were a piece of goods, the abolition of standing armies and national debts used as war chests may not be implemented immediately. In that case, Kant states that lawmakers can take 'into consideration the circumstances in which they are to be applied' and 'postpone putting these into effect, without however losing sight of the end' (1996a, 8: 347). This latitude of postponement is very different from the strict principles that must be observed for it to be possible to leave the state of nature. His account provides the minimal conditions for leaving the path open to trust after conflict, so we can move from a provisional time to rightful one. We have to follow principles 'that always leave open the possibility of leaving the state of nature among states ... and entering a rightful condition' (1996a, 6: 347) even in circumstances of conflict.

Let me consider the question of truth, lying and sincerity. In 'The Doctrine of Right', Kant says people have the innate right to communicate their thoughts to others even if what they say is untrue or insincere, as we are free to 'do to others anything that does not in itself diminish what is theirs' and people may take the statements how they like (1996a, 6: 238). Sincerity here is different from telling the truth, in that sincerity concerns meaning what we say, even though we may be mistaken. In 'On the Miscarriage of All Philosophical Trials in Theodicy' [1791], Kant distinguishes truth and truthfulness - stating something that is true - from sincerity this way $(1996 \mathrm{~b}, 8: 268)$. Of course, often they are indistinguishable because when we state the truth we usually mean what we say. Furthermore, we may mean what we say or be quite sincere, but because of self-deception or negligence, we may not be telling the full truth about what we believe. ${ }^{7}$ Kant was aware of these possibilities, declaring that 'in the judgment 
whether I in fact believe to be right (or merely pretend it) I absolutely cannot be mistaken, for this judgment - or rather this proposition - merely says that I judge the object in such-and-such a way' (1996b, 8: 268). ${ }^{8}$ He notes that someone may declare they believe something without reflecting at all, and such carelessness is not really telling the truth as they see it. So, I will take Kantian sincerity to involve our saying what we think to be true, in contrast with what really is true, and reflecting on what we believe. In considering moral duties to ourselves, he argues that inner insincerity, what we would call self-deception, should be condemned, as it is likely to lead to lying to others. ' 'Internal lying' damages our own self-respect, and even innocent examples, such as blinding ourselves to our beloved's flaws, can spread lying into all our relationships, according to Kant (1996a, 6: 429-31). ${ }^{10}$

Yet in 'The Doctrine of Right', Kant says the only lies that violate right are those where we make false claims that we have a contract with someone or when we defame someone by suggesting they are a liar (1996a, 6: 239). ${ }^{11}$ In expressing ourselves, we are not wronging a particular other. We are all free to make choices and free from the constraints of others as long as our freedom is compatible with their freedom in accordance with a universal law (1996a, 6: 237). ${ }^{12}$ Yet this idea is difficult to square with Kant's argument that deceptive practices in conflict situations should be restricted and with his essay 'On a Supposed Right to Lie from Philanthropy'.

In this notorious essay, Kant claims that any lie brings it about that statements are not believed and thus undermines rights based on contract (1996a, 8: 426). He uses the example where a murderer is looking for my friend to kill him and asks me where he is. He maintains that we may not lie to the murderer, a conclusion often found repugnant and absurd. Kant reasons that we must be truthful or honest in the sense of revealing the information we have in this case, where we do not have the option of not responding, because lying harms humanity in general or is a formal wrong. ${ }^{13}$ A lie is 'an intentionally untrue declaration to another' (1996a, 8: 426). There may not be any material or concrete wrong in each case I actually lie, as the murderer, for example, has no right to know where my friend is and I do not harm the murderer by lying. ${ }^{14}$ Kant also says that a formal wrong is worse than a particular injustice, as

though by a certain lie I in fact wrong no one, I nevertheless violate the principle of right with respect to all unavoidable necessary statements in general (I do wrong formally, though not materially); and this is much worse than committing an injustice to someone or other, since such a deed does not always presuppose in the subject a principle of doing so.

(1996a, 8: 429)

On my interpretation, the way to make sense of this passage and Kant's distinction between a formal and material wrong is that formal wrongs involve a principle of action whereas material wrongs do not. Thus, not forming a principle to lie is needed to develop trust, because a particular lie told thoughtlessly or 
negligently or a lie told according to some other maxim or principle may not break down trust but a principle of lying is far more likely to. This formal wrong is adopting a principle to do wrong, such as to tell lies when it is convenient. In contrast, a material wrong is an actual violation of the imperative of truthfulness, such as a particular lie. So lying is a formal wrong only when I make it my maxim or principle to lie, for instance if I tell myself I have a right and possibly even a duty to lie. ${ }^{15}$ I could also form the maxim to lie but not lie - so I am formally but not materially wrong.

To show that Kant is consistent in his view of lying between The Metaphysics of Morals and 'On a Supposed Right to Lie from Philanthropy', Helga Varden argues we do not always have to be honest to others in the sense of revealing all that we know or believe because they do not have a right to our information (2010: 408). She also notes that the murderer wrongs you by unjustly coercing you to tell him something (1996a, 8: 426). In contrast, Allen Wood argues that the murderer is not unjustly coercing anyone as he is simply asking a question, and if he was, Kant could allow for 'a necessary lie'. In his lectures on ethics, Kant stipulates a lie can be necessary 'where the declaration is wrung from me, and I am also convinced that the other means to make a wrongful use of it' (1997, 27: 448). While Wood finds the murderer at the door example unconvincing, as he thinks it unlikely to have to make a reply to a murderer that is not unjustly forced, Kant's own example of force in the lectures sounds very similar or at least equally forced. He refers to 'somebody, who knows that I have money, asks me: Do you have money at home?' (1997, 27: 448). The two cases appear similar enough that his different conclusions need explaining. ${ }^{16}$ In both cases, a question is being asked and silence would provide an affirmative answer. In any case, in general, Kant allows that we might be able to withhold information from people, keep secrets and even deceive them in certain ways, for example, in polite compliments, ambiguous wording, and through exaggerated stories (e.g. 1996a, 6: 466; 6: 472; 6: 431; 6: 433; 1997, 27: 61).

Nevertheless, there are serious problems arising from forming a maxim or principle of lying, and these are related to trust. Lying to others, or deliberately and directly telling an untruth to others based on a principle to lie, harms humanity in that a principle of lying may lead to a total breakdown in trust and truthtelling. Thus, the approach Kant takes is one that sheds light on both the development and the maintenance of a rightful condition and the restoration of one after breakdown. In a useful discussion of the nature of trust, J. M. Bernstein links trust and what he calls 'normative rules', arguing

We are normatively invested in practices carried out in trusting conditions because lying beneath them is the presumption that following the rules of the practice $i s$ respecting me as one of its participants; and hence breaking the rules of the practice may signal that I no longer count as a person for you. 
While Bernstein does not reference Kant, we can see the connection with the humanity formulation of the categorical imperative (treat others as ends in themselves and not as a mere means) and trust (1996a, 4: 429). The distinction between formal and material wrongs also helps make sense of Kant's thinking about limits on action even in provisional times, or times where a fully rightful situation does not exist, a situation that may never exist. We should not act upon maxims that harm humanity even in a circumstance of provisional justice.

More specifically, Kant sets out conditions for a basic level of trust in times of conflict. His view is that if everyone is, say, feuding, they do not do each other wrong in engaging in such behavior, but they do wrong 'in the highest degree' by subverting right and law (1996a, 6: 308). He outlines the conditions needed to re-enter a rightful condition in 'Toward Perpetual Peace', which contains rightful constraints on politics between states in preliminary and definitive articles. The preliminary articles require the abolition of standing armies and prohibit the acquisition of existing states, the contracting of national debts with regard to external affairs, interference with the governments of other states, and the use of duplicitous means in war, such as assassins, breaching surrender or incitement to treason. ${ }^{17}$ The definitive articles recommend republicanism for all states, a federalism of free states and the cosmopolitan right of hospitality.

The first preliminary article states 'No treaty of peace shall be held to be such if it is made with a secret reservation of material for a future war' (1996a, 8: 343). Here a secret plan for further conflict is undermining of peace and trust. More importantly, the 6th preliminary article states that:

No nation at war with another shall permit such acts of war as shall make mutual trust impossible during some future time of peace: Such acts include the use of Assassins (percussores) Poisoners (venefici) breach of surrender, instigation of treason (perduellio) in the opposing nation, etc.

Hannah Arendt notes that this is 'the most important and also the most original' of the preliminary articles because it best expresses the ideal of communication between human beings and the greatest enlargement of our mentality and unites the actor who acts and the spectator of history who judges (1982: 75). Kant also mentions the use of snipers and the spreading of false reports, further practices that corrupt trust (1996a, 6: 348). He is against such 'dishonorable stratagems' because 'Some level of trust in the enemy's way of thinking [Denkungsart] must be preserved, even in the midst of war, for otherwise no peace can ever be concluded and the hostilities would become a war of extermination (bellum internecinum)' (1996a, 8: 347). A war of extermination could be a world war, civil war or genocide. ${ }^{18}$ Such a war must be completely forbidden, as it would lead to the death of humanity. Kant's argument is that we need a level of trust in the enemy so we can limit war and achieve peace. Elisabeth Ellis argues that using people as assassins 'constitutes unacceptable contradictions to the idea of the rule of law itself' in that misusing human actors undermines the moral integrity 
of the state (2005: 80). ${ }^{19}$ She links Kant's view to the idea of the 'rule of law', and illuminates the connection with trust, as there must be a degree of order even amid chaos, for trust not to break down completely. Maintaining a measure of trust is essential to restricting the scope and horrors of war and making peace possible, to leaving that provisional state.

Kant further argues that such means lead to total war because

Once they come into use, these intrinsically despicable, infernal acts cannot long be confined to war alone. This applies to the use of spies (uti exploratoribus), where only the dishonorableness of others (which can never be entirely eliminated) is exploited; but such activities will also carry over to peacetime and will thus undermine it.

(1996a, 8: 347)

This article is strict - Kant argues it should be implemented immediately. He shows how we must beware of the moral degeneracy of certain practices in war and their destruction of the minimal conditions for restoring peace after war. Another more specific example concerning breach of surrender is

An enemy who, instead of honorably carrying out his surrender agreement with the garrison of a besieged fortress, mistreats them as they march out or otherwise breaks the agreement, cannot complain of being wronged if his opponent plays the same trick on him when he can.

(1996a, 6: 308)

Kant's argument is that these are formal wrongs 'because they take away any validity from the concept of right itself and hand everything over to savage violence, as if by law, and so subvert the right of human beings as such' (1996a, 6: 308). They do not harm the other in a material or concrete sense but Kant believes they undermine the principle of the right of human beings.

In a way relevant to trust within states, Kant explains the importance of publicity and honesty to trust in political leaders. In a second appendix to 'Toward Perpetual Peace', he maintains that maxims must be able to be made public. His transcendental formula of public right is 'All actions relating to the rights of others are wrong if their maxim is incompatible with publicity' (1996a, 8: 381). The key idea is that actions that affect the rights of others are unacceptable if they need to be kept secret. Kant argues for this principle of public right as follows:

For a maxim that I cannot divulge without thereby defeating my own purpose, one that absolutely must be kept secret if it is to succeed and that I cannot publicly acknowledge without unavoidably arousing everyone's opposition to my project, can derive this necessary and universal, hence a priori foreseeable, resistance of everyone to me only from the injustice with which it threatens everyone.

$(1996 \mathrm{a}, 8: 381)^{20}$ 
This principle is not only ethical (part of the doctrine of virtue); it is also juridical (related to right), Kant contends, and shows its relevance to civil, international and cosmopolitan right (1996a, 8: 381). What he means is that it is not only a principle that we should follow insofar as we are virtuous, but that it is enforceable as well. International right is the right of nations. Cosmopolitan right is the right to hospitality or the right to visit all the countries in the world..$^{21}$ I will concentrate on civil right.

Civil right concerns right within a state. Kant upholds the right of human beings to respect by the state, saying 'The right of human beings must be held sacred, however great a sacrifice this may cost the ruling power' (1996a, 8: 380). Nevertheless, with regard to the rights of people against the state, he argues rebellion is shown to be wrong by the fact that publicly revealing a maxim of rebellion would make it impossible, whereas a head of state can publicly declare his willingness to punish rebels. ${ }^{22}$ He says that 'the maxim of rebellion, if one publicly acknowledged it as one's maxim, would make one's own purpose impossible. One would therefore have to keep it secret' (1996a, 8: 382 ). A state cannot be run on secret principles, like a cabal, and any state keeping secrets in this way cannot be trusted. While Kant does not state explicitly that states or citizens that have to keep their maxims secret to avoid everyone's opposition is untrustworthy, his discussion implies this idea. Keeping secrets of this kind entails widespread and deliberately formulated deception, and thus undermining of open communication. This kind of secrecy is different from the possibility of, for example, friends keeping information secret from each other to avoid overwhelming them with intimacies (1996a, 6: 470). Arendt suggests Kant has confused revolution with a coup d'état, as the latter needs to be kept secret, while plans for a revolution can be and are open and public (1982: 60). In any case, the reverse is not held to be true - actions that are consistent with publicity are not necessarily right, or deserving of trust, as Kant observes, as a powerful state can be open about its maxims even when they are immoral (1996a, 8: 385). The power of such a state means it does not have to be concerned about opposition to its maxims, and a powerful leader might not be threatened by the opposition of their people. Thus, Kant needs another principle to solve this problem.

The second transcendental principle of public right is: 'All maxims which need publicity (in order not to fail in their end) harmonize with right and politics combined' (1996a, 8: 386). Kant contends that if maxims can only be successful through being made public, they need to agree with what he calls the 'universal public end' or happiness, which politics as a whole has to achieve. In addition,

But if this end is to be attainable only through publicity, that is, by the removal of all distrust toward the maxims of politics, such maxims must also be in accord with the right of the public, since only in this is the union of all ends possible.

$(1996 a, 8: 386)^{23}$ 
He means that these maxims would be decided on by reasonable citizens. A state that adopts such principles can be trusted.

What is needed for more complete trust is peace and a federation of states, so individual states would be better able to engender stability and trust as other states are also set in that direction. As long as states are at war or not willing to pursue peace, trust does not prevail and cannot be developed, and that will affect other countries. Kant allows that practical conditions can make it difficult to institute trust immediately and so it may be gradually developed. For example, individual states may have to wait to introduce reforms until that can be done peacefully (1996a, 8: 373). Thus, it is prudent to wait until the state is secure from invasion before rectifying injustice if that injustice protects the state. A federation of nations, he argues, is needed to protect rightful states from others and to encourage other states to become rightful (1996a, 6: 344). This would be a way to engender trust and to shift from a provisional to a rightful state.

Kant appears to believe we should go on doing what is right regardless of what others do. However, sometimes we may need to resist, say, when we are threatened with coercion in transitional situations (1996a, 6: 307), and that resistance is related to trust in that when all trust and rightfulness is destroyed, resistance is necessary. Sometimes we can only bring about trust through defiance, rather than simply by ruling out deceptive actions. This is the case in particular emergencies, such as in totalitarian regimes that Kant unsurprisingly did not foresee. A philosophy professor, a member of 'The White Rose', a group that resisted the Nazis late in the war, Kurt Huber, reflected using Kant's categorical imperative and found that the resistant maxims could be universalized as they would bring about order, the rule of law and trust (Scholl, 1970: 64-5). In this case, only by defying the present 'legal' order can trust be restored.

However, Kant condemns revolutions. This condemnation appears counterintuitive as building trust seems to necessitate the overthrow of leaders that prevent the development of trust. Yet his statement on obedience to the extant powers may permit exceptions, because it has a final caveat. Kant says 'there is a categorical imperative, Obey the authority who has power over you (in whatever does not conflict with inner morality)' (1996a, 6: 371). This possibility is supported by a comment in his notes on the 'Doctrine of Right'. There he states

Force, which does not presuppose a judgment having the validity of law is against the law; consequently the people cannot rebel except in the cases which cannot at all come forward in a civil union, e.g., the enforcement of a religion, compulsion to unnatural crimes, assassination, etc.

(Kant, AK, XIX, Reflections 8043, 8044, 594-5, quoted in Dostal, 1984: 732)

The relevance is that in these situations Kant's usual strictures do not apply. If murderers at the door were the rule, as under Nazism or the reign of terror, rather than the exception, perhaps he could accept non-obedience. As Varden notes, 
Nazism tried to destroy rightful relations per se: 'It was an attempt to institutionalize a coercive system in which there is no innate right to freedom at all on the land, which is barbarism at its worst' (2010: 416). Trust cannot be developed in these kind of circumstances. Given that tyranny and totalitarian regimes that would compel perverse actions may not be considered 'civil unions' for Kant, revolution or at least resistance could be appropriate for it is needed to restore the conditions for trust. ${ }^{24} \mathrm{We}$ must not always do what we can to maintain trust or rather trust can only be brought into being through resistance instead of cooperation. The need to resist in extreme situations to bring about the basic conditions for trust is an essential addition to the restrictions on underhand behavior even in conflict situations outlined. Nevertheless, Kant's account needs to be linked to other concerns about trust.

\section{Améry and trust in the world}

Although I find Kant's view of trust a significant starting point for understanding political trust, it is also incomplete. His idea of trust is based on justice and respect; we must have certain limited conditions for trust, which in turn support right. We should develop principles that cannot harm humanity. Otherwise we cannot build a just world based on a certain level of honesty and sincerity. But what is also needed is a caring trust, that takes things further, that means we trust that others will love and care for us. This is what Améry's idea of 'trust in the world' brings and I turn to Améry to help develop a fuller account of conditions for trust.

Améry makes an important point about the nature of trust in his book At the Mind's Limits (1980) that takes the question of trust further than and in a different direction from Kant. He analyses the experience of torture and demonstrates a specific and extreme experience of the collapse of trust. Améry was a Jewish Austrian working for the resistance in Belgium when he was arrested and tortured by the Gestapo in 1943 and subsequently sent to Auschwitz and other camps. (1980: 107) He survived to write a series of searching books and essays before finally committing suicide in 1978. His account of torture brings out another vital element of trust.

At the moment of what he calls 'the first blow', the first time he is hit by his torturers, Améry realized he had lost what he calls his 'trust in the world'. This trust may involve fundamental acceptance of a natural world that runs smoothly. However, more importantly for him, such trust concerns our faith in our relations with other human beings. He prefers to see the wrong of torture as the destruction of trust than as the loss of human dignity, a term he finds too abstract. While many authors focus on trust between individuals and entrusting something to someone, (for example, Baier 1995) or on maintaining trust by not lying to others, as Kant does, Améry centres on a trust in the world that is more general and I believe combines elements of both respect and love. ${ }^{25}$

According to Améry, on the one hand, torture takes away our trust that our bodily integrity will be respected: 
more important as an element of trust in the world, and in our context what is solely relevant, is the certainty that by reason of written or unwritten social contracts the other person will spare me - more precisely stated, that he will respect my physical, and with it also my metaphysical, being. The boundaries of my body are also the boundaries of myself. My skin surface shields me against the external world. If I am to have trust, I must feel on it only what I want to feel.

$(1980: 28)^{26}$

Améry suggests that there are contexts in which retaliation may be a way of restoring trust in our own existence going on, but that is not possible under torture.

In addition, we lose the minimal care we trust others will give us. In a safe world we have a basic, taken for granted, assumption that if we are in trouble, if we have an accident, someone will come to help us: 'The expectation of help, the certainty of help, is indeed one of the fundamental experiences of human beings' (1980: 28). This is part of the implicit trust I mentioned at the beginning of the chapter. At the first blow, Améry felt that trust, the secure feeling that others will come to help us, instantly disintegrated. He knew he was alone with his torturer and no one would come to help him. ${ }^{27}$ The power of the torturer is distinguished by Améry from the sovereignty of a king, who could be both cruel and kind, in that it is simply 'the power to inflict suffering and to destroy' (1980: 39). He argues that the lost trust in the world cannot be regained, as the tortured person remains forever tortured. He concludes that 'Trust in the world, which already collapsed in part at the first blow, but in the end, under torture, fully, will not be regained' (1980: 40). ${ }^{28}$ It is almost impossible to recover trust.

The tortured person is left with fear and resentments that preclude forgiveness or the regaining of trust unless there is some sort of dramatic moral change in the relation to the Nazi past of the nations responsible for the regimes of torture. A change of heart, maintains Améry, is not possible until there is a full recognition of the wrongness of the holocaust and the Nazi regime as a whole. For him, because there was not a proper reckoning after the war, he feels that 'Every day anew I lose my trust in the world' (1980: 94). And this is not an existential mistrust or distrust; it is society that fails him: 'For it and only it caused the disturbance in my existential balance, which I am trying to oppose with an upright gait. It and only it robbed me of my trust in the world' (1980: 100). Améry declares that until society admits its faults and restores to him that confidence that he will be cared for, he cannot have trust. ${ }^{29}$ His account demonstrates how a more comprehensive picture of trust than Kant presents is needed. The idea of confidence in help and care is essential to life in a stable and decent political community. Nonetheless, Améry's account is limited in its own way, as trust can be lost without one being subjected to torture and rape. Deception is sufficient for the betrayal of trust, as Kant argues. What we need is an account of trust that takes both 
these features seriously together, and I will look at these features in a situation of breakdown of trust. I also suggest that restoration of trust may not always require complete sincerity.

\section{Trust in post-genocide Rwanda}

As an example I discuss how Kant and Améry's models of trust help us to understand developments in post-genocide Rwanda. I consider this situation to show how both Kant and Améry are useful for considering the conditions of trust and how to restore it. We can see that there are political conditions of non-betrayal and the condition of help. In that genocide, 800,000 people were killed. The perpetrators were often neighbours, friends and even family. These actions were facilitated by a racist ideology that deceived people about their own history, especially the relations between Tutsi and Hutu. The process of rebuilding the country is many-faceted, and one central facet is the rebuilding of the trust in society and the world that Améry shows is lost in these situations and the rebuilding of a fundamental sense of trust as moving towards a rightful condition, of a provisional period that will lead us to a more rightful one. What is needed in these circumstances, Bernstein suggests, is to

find a world by establishing for a second time reassuring relations with others that enable [us] to build up reflective confidence that in ordinary patterns of encounter and engagement [we] will be acknowledged as a person someone with the standing of being a person - in a manner sufficient to not feel imminently threatened.

(2011: 399)

Kant's basic conditions for trust of 'a rightful condition' are satisfied to some extent. Courts and the government have tried to establish truth-speaking about the genocide through gacaca courts that encouraged both perpetrators and victims to come forward and discuss what had happened. International and national courts also established justice for past wrongs. ${ }^{30}$ In moves to ensure that agitation for genocide is no longer acceptable, racist ideology and racist political parties are banned.

Yet it is not clear that trust or even reliability has been widely established in post-genocide Rwanda. As one woman observes who lives close by released prisoners, she can live peacefully with them, 'Unless they kill again' (Carlin 2003). Trust has not become that fundamental sense of well-being that it should be. As I noted, one way of thinking about trust is that we feel trust if there is good will or at least no bad will. Yet state-building in Rwanda shows that trust and good will have to be developed together through a wide range of means.

The gacaca courts may have played some role in helping to re-establish trust in that issues were out in the open, but they could also make things worse, stirring up anger and the desire for revenge. Revenge in the form of open murder is 
mainly suppressed, although it is claimed that other means, such as secret poisoning and intimidation, are found by both perpetrators and survivors (Clark and Kaufman 2009: 176). These behind-the-scenes actions must be undermining of trust, as Kant noted in the case of war. There are many grenades left in Rwanda and they are sometimes used to settle scores (David 2011). These are individual actions rather than state actions, but they are of the kind Kant condemns.

The stability needed for trust is widely held to be precarious. Paul Kagame has been president of Rwanda since 2000, and many find reconciliation to be entirely dependent on Kagame, such that if he were no longer president, they feel genocide could easily erupt again. One survivor says that " "If he [Kagame] were not there, we would all be killed"' (Gourevitch 2009: 41). A survivor comments on having the perpetrators living in the village 'I look at them now when I pass on the street and usually they shy away from me because they know I am a victim' (Carlin 2003). It is difficult, to say the least, to have comfortable, trusting relations in these circumstances.

Many of the steps taken in the wake of the genocide are steps to promote safety in the event of attempts at mass killing, rather than simply trusting that will not happen or taking steps to promote trust that it will not happen. Rwandans have rebuilt villages close to the road so that it is easier to call for help and escape (Gourevitch 2009: 42). This move is not a sign of trust, but a way of creating reliability and safety. People also tend to stay in at night as they are scared of what might happen if they are outside in the dark - that is, both genocide survivors and perpetrators are scared in this way. This fear results from the existence of revenge killings for murders during the genocide as well as killings or threats against witnesses to cover up participation in the genocide. ${ }^{31}$ The latter is more of a problem (Gourevitch 2009: 39; Buckley-Zistel in Clark and Kaufman 2009: 135-7). Genocide survivors continued to be murdered by perpetrators to prevent people from witnessing against them in gacaca, the national court or the International Criminal Tribunal for Rwanda in Arusha, Tanzania (Kayigamba in Clark and Kaufman 2009: 40).

Some perpetrators are more afraid of the other killers they testified against than survivors, one saying:

Nobody ever threatens me.... But I don't stay out late. I come home by seven o'clock. I stay in with my wife and children. So if I am killed it will be at home, and if someone else is killed, and they blame the former prisoners, I am here, nobody can blame me.

(Gourevitch 2009: 40)

Thus, the perpetrators have to take precautions against others rather than trust or even rely on them. Gourevitch notes that people try to maintain the appearance of friendly relations to avoid aggravating more violence. Similarly, the victims often have to simply hope that they are safe.

Another factor significant to understanding relations in Rwanda is that people have to live together to survive and victims may even depend on the killers to 
get by. They must work out some means of peaceful coexistence for everyday survival. One woman says 'we live with a family who killed our relatives. We have to relax and remain confident, and pretend that there is peace' (BuckleyZistel, Clark and Kaufman, 2009, 137). ${ }^{32}$ Here we see not the restoration of trust but an attempt to cope in an extremely tense and challenging situation. What people have to do is coexist; they might not yet trust each other. But trust may be built over time.

Is there trust in the form of the help Améry lacked? For many survivors there is a level of protection and safety, not total. International aid and development help to provide for those in need. ${ }^{33}$ There are also limited attempts to provide reparation to the survivors: $10 \%$ of the annual budget is devoted to a National Compensation Fund for survivors (Buckley-Zistel, Clark and Kaufman 2009: 134). Perpetrators convicted of property crimes have to return stolen goods and restore damaged property, and to contribute to the Compensation Fund if they can (Clark and Kaufman 2009: 315). ${ }^{34}$ There are also programmes that build trust, such as survivors and perpetrators working together on reconstruction projects in their villages and regular cleaning efforts. The survivors do not have the full confidence that others will come to their aid that Améry argued is necessary for trust in the world. But they have a practical approach to living and working with people they do not really trust, perhaps trying to build trust through that process. ${ }^{35}$ They are still in a provisional period that may last for a long time. The most minimal conditions for trust in Kant's sense are not entirely in place, yet there is gradual improvement in trust as some of those conditions develop, there is help and care in Améry's sense, and as time passes since the genocide trust could grow.

Kant also allowed that there can be value in less than total sincerity. Despite his strictures against insincerity, he admitted that outward shows of respect and even affection for others can lead to their reality. In the Anthropology, he states it is good that we are actors, 'For when human beings play these roles, eventually the virtues, whose illusion they have merely affected for a considerable length of time, will gradually really be aroused and merge into the disposition' (2006, 7: 151). Perhaps something of this process will take place in Rwanda, as pretending peace acquires an actuality of its own.

Kant's thinking here of trust between states can provide a model for understanding trust within states and between individuals, in terms of the limits that need to be placed on what we do in situations of conflict. Those limits will restrict deceptive practices that prevent the possibility of regaining peace. There may be a way of moving from the provisional state, even if we never truly reach a rightful one. Political trust is an essential element in the process. However, Kant's model of limiting deception and promoting respect also needs a consideration of the importance of care to trust that Améry identifies. Furthermore, the example of post-genocide Rwanda suggests that the first conditions for trust do not involve sincerity as such, but actions that help to establish basic trust, with sincerity as a hoped-for goal. Our steps towards political trust may always be provisional. 


\section{Notes}

1 Thank you to Sylvie Loriaux for her helpful comments on this paper.

2 See Hegel (2000: §268), Baier (1995: 99) and Bernstein (2011: 400).

3 Indeed, Thomas argues that Kant's moral ideals leave no room for trust at all (1990: 236).

4 In 'On the Common Saying: That May be Correct in Theory, but it is of no Use in Practice', Kant defines the principles of a civil state as 1 . The freedom of every member of the society as a human being. 2. His equality with every other as a subject. 3. The independence of every member of a commonwealth as a citizen' (1996a, 8: 290). In Perpetual Peace, he says the principles of a Republican state are freedom, equality and the dependence 'of all upon a single common legislation (as subjects)' (1996a, 8: 350).

5 In a discussion of Derrida's political philosophy, Thomassen argues that we must accept this provisionality in a Derridean sense of the 'to come', where politics is always 'lacking and perfectible' (2010: 454).

6 See Ellis (2005).

7 Ransome shows how insincerity and self-deception are distinct (2009: 58-63).

8 Also compare this quote from 'Religion within the boundaries of mere reason': 'we must be able to demand sincerity (that everything said be said with truthfulness) of every human being'. Without that we will become 'inward hypocrites' (1996b, 6: 190).

9 Kant links sincerity to making promises to others here, and from an ethical point of view, we should be both honest in telling the full truth and sincere in meaning what we say (1996a, 6: 429). See also The Groundwork, where he argues that lying promises violate the categorical imperative (1996b, 4: 403; 4: 430). Lies are also a violation of a duty of virtue to myself, according to Kant (1996a, 6: 429). See Mahon (2003; Cholbi 2009: 18) on this issue.

10 In my view, Kant's discussion of internal lying concerns inner insincerity, although that idea is complicated by his linkage of sincerity (Redlichkeit) to promises, noted above.

11 Byrd and Hruschka see this point as Kant's defence of freedom of expression, except in cases where we would harm others (2010: 84). Similarly, in 'The Doctrine of Virtue' Kant notes that telling intentional untruths is a violation of rights only when they harm others (1996a, 6: 430).

12 We have to treat ourselves as an end. Hindering others' freedom can be punished - a hindering of a hindering of freedom (1996a, 6: 331).

13 See Weinrib (2008: 150) for a discussion of the meaning of the distinction between a formal and a material wrong and how it relates to the right of human beings. Weinrib explains a material wrong as a wrong against a particular person, rather than a wrong against the principle of right. Varden points out that for Kant in 'The Doctrine of Right', a lie wrongs 'another person from the point of view of justice', only in cases of defamation or in lying contracts, yet 'In a Supposed Right to Lie from Philanthropy' he condemns lying in general (2010: 409). My interpretation differs from theirs in stressing the idea that we can sometimes commit an injustice without that presupposing a principle to do so.

14 Siebers maintains that when we are compelled in this way 'wherever it is possible, it is best to resist the evil choices that evil regimes would force on us' (1991: 38). In other words, we should try not to let murderers make liars out of us. In contrast, for example, Cholbi, argues that we can derive a duty to lie in such cases (2009), MacIntyre constructs a principle that allows lying to aggressors (2006) and Korsgaard concludes that lying may be permissible in non-ideal conditions (1986).

15 This idea is the source of the disagreement between Kant and Constant. See Benton (1982) for a good account of the circumstances and Constant (1964: 68) for his claim 
that 'a German philosopher' would argue that lying to murderers pursuing your friend would be a crime. Vuillemin suggests that Constant may have been thinking of a different example in The Metaphysics of Morals (1996b, 6: 431) of a servant who obeys his master's order to say that he is not at home, and thus the master is able to commit a crime (1982: 413-14). However, given Constant's essay was published first, Wood proposes that Constant was relying on hearsay (2008: $325, \mathrm{n} .8)$.

16 Weinrib argues we should take the view in the essay more seriously than the lectures as we cannot be certain that the lecture material represents Kant's view accurately, and in any case the essay represents Kant's more mature juridical views (2008: 161).

17 Ellis notes that standing armies slow progress but are not against right as such (2005: 80).

18 Kant does not consider the issue of targeting non-combatants, an issue that vexes just war theorists such as Walzer (2000). Yet his open-ended list of impermissible acts might be extended in that way.

19 Thomassen argues there may be disagreement and uncertainty about which practices undermine the possibility of peace and which do not (2010: 458).

20 The principles of public right are transcendental because they concern only the form of universal lawfulness, not empirical conditions. This argument is based on a presumption of reasonableness of 'everyone'. If people's judgment was distorted, perhaps their resistance would not indicate injustice, but their lack of understanding of the maxims.

21 International right must be an enduring free association between states. Kant argues that a nation could not make public that it would release itself from the promise to aid another nation, lesser nations could not make public their intention to attack a greater power pre-emptively, and a large nation could not make known that it would absorb smaller nations if it thought that necessary to its preservation (1996a, 8: 383-4). Cosmopolitan right's maxims work by analogy to those of international right.

22 See also Kant (1996a, 6: 320-3; 8: 301).

23 My emphasis.

24 Analogously, Hay argues from a Kantian perspective that we have an obligation to resist oppression as it damages and restricts our rational capacities (2011).

25 Similarly, Zolkos contends that

The practice of torture is a parasitical reversal of the idea of living together in the world, and thus of the idea of politics as a shared responsibility for the governing of the world, and of practicing care and respect for human life in that world.

(2010: 70)

26 Améry compares his experience to rape, and Bernstein argues that torture and rape are equivalent in their destruction of trust (2011: 396).

27 Zolkos argues that in torture there is also the experience of helplessness in being unable to help oneself (2010: 55).

28 Gry Ardal argues that distrust is also lost in this situation as the traumatised victim can no longer distinguish between when to trust and when to distrust but is rather 'stranded in a disoriented lack of judgment' (Ardal, in Grøn and Welz (2010: 129).

29 Brudholm makes the interesting point that part of what it would be for the perpetrators and bystanders to accept responsibility for what they had done is to mistrust their own 'national mores, history, and traditions' (2008: 150).

30 The Rwandan national court tries more serious cases than gacaca and the International Criminal Tribunal for Rwanda (ICTR) in Arusha (Tanzania) is supposed to try the very worst cases.

31 Revenge by survivors may not have played as great a role in Rwanda as in other cases, such as France after the liberation, because the killers initially fled over the border and there are so few survivors. See Lottman (1986) for a balanced discussion of treatment of collaborators in post-war France. 
32 As Baier notes, everyone has a role to play in overcoming a climate of distrust (2004: 180).

33 The economic growth rate in Rwanda overall is high (although half its budget comes from foreign aid). But many people are still poor in rural areas. (Helen Hintjens, Clark and Kaufman 2009: 79).

34 There is also a trust fund associated with the ICTR (Clark and Kaufman 2009: 266).

35 This could be seen as like Walker's 'hopeful trust' where we are uncertain that a person will act well, but we hope that our trust will be answered by the other's conscience (2006: 82).

\section{Bibliography}

Améry, J. 1980. At the Mind's Limits: Contemplations by a Survivor on Auschwitz and Its Realities, Trans. S. Rosenfeld and S. P. Rosenfeld. Bloomington: Indiana University Press.

Arendt, H. 1982. Lectures on Kant's Political Philosophy, R. Beiner (ed.). Chicago: University of Chicago Press.

Baier, A. C. 2004. 'Demoralization, trust, and the virtues'. In C. Calhoun (ed.), Setting the Moral Compass: Essays by Women Philosophers. Oxford: Oxford University Press, pp. 176-88.

Baier, A. C. 1995. Moral Prejudices: Essays on Ethics. Cambridge: Harvard University Press.

Benton, R. J. 1982. 'Political expediency and lying: Kant vs. Benjamin Constant'. Journal of the History of Ideas 43: 1, 135-44.

Bernstein, J. M. 2011. 'Trust: on the real but almost always unnoticed, ever-changing foundation of ethical life'. Metaphilosophy 42: 4, 395-416.

Brudholm, T. 2008. Resentment's Virtue: Jean Améry and the Refusal to Forgive. Philadelphia: Temple University Press.

Byrd, S., and Hruschka, J. 2010. Kant's Doctrine of Right: A Commentary. New York: Cambridge University Press.

Carlin, J. 2003. 'New dawn in Rwanda as a nation forgives'. Observer, 24 August.

Cholbi, M. 2009. 'The murderer at the door: what Kant should have said'. Philosophy and Phenomenological Research 79: 1, 17-46.

Clark, P., and Kaufman, Z. D. (eds). 2009. After Genocide: Transitional Justice, Postconflict Reconstruction and Reconciliation in Rwanda and Beyond. New York: Columbia University Press.

Constant, B. 1964. 'Des réactions politiques' [1797]. Écrits et discours politiques, Tome I. ed. O. Pozzo di Borgo, Paris: Jean-Jacques Pauvert, pp. 21-85.

David, K.-M. 2011. 'Grenade attack wounds 21 in Rwanda'. Reuters, 13 July.

Dostal, R. J. 1984. 'Judging human action: Arendt's appropriation of Kant'. Review of Metaphysics 37, 725-55.

Ellis, E. 2005. Kant's Politics: Provisional Theory for an Uncertain World. New Haven: Yale University Press.

Gourevitch, P. 2009. 'The life after'. The New Yorker, 4 May, 36-49.

Grøn, A. and Welz, C. (eds). 2010. Trust, Sociality, Selfhood, Tübingen: Mohr Siebeck.

Hay, C. 2011. 'The obligation to resist oppression'. Journal of Social Philosophy, 42: 1, $21-45$.

Hegel, G. W. F. 2000. Elements of the Philosophy of Right, Trans. H. B. Nisbet. Cambridge: Cambridge University Press. 
Kant, I. 1996a. Practical Philosophy, Ed. M. Gregor, Cambridge: Cambridge University Press.

Kant, I. 1996b. Religion and Rational Theology. Trans. A. W. Wood and G. di Giovanni. Cambridge: Cambridge University Press.

Kant, I. 1997. Lectures on Ethics. Trans. P. Heath. Cambridge: Cambridge University Press.

Kant, I. 2006. Anthropology from a Pragmatic Point of View, Trans. R. B. Louden. Cambridge: Cambridge University Press.

Korsgaard, C. M. 1986. 'The right to lie: Kant on dealing with evil'. Philosophy and Public Affairs 15: 4, 325-49.

Lottman, H. R. 1986. The Purge. New York: William Morrow.

Macintyre, A. 2006. 'Truthfulness and lies: what can we learn from Kant?' Ethics and Politics: Selected Essays, Vol. 2, Cambridge: Cambridge University Press, pp. 122-42.

Mahon, J. E. 2003. 'Kant on lies, candour and reticence'. Kantian Review 7, 102-33.

Ransome, W. 2009. Moral Reflection. New York: Palgrave Macmillan.

Scholl, I. 1970. The White Rose: Munich 1942-43. Hanover: Wesleyan Press.

Siebers, T. 1991. 'Kant and the origins of totalitarianism'. Philosophy and Literature 15: $1,19-39$.

Thomas, L. 1990. 'Trust, affirmation and moral character: a critique of Kantian morality'. In O. Flanagan and A. O. Rorty (eds), Identity, Character, and Morality: Essays in Moral Psychology. Cambridge: MIT, pp. 235-57.

Thomassen, L. 2010. 'Political theory in a provisional mode'. Critical Review of International Social and Political Philosophy 13: 4, 453-73.

Varden, H. 2010. 'Kant and lying to the murderer at the door.... One more time: Kant's legal philosophy and lies to murderers and Nazis'. Journal of Social Philosophy 41: 4, 403-21.

Vuillemin, J. 1982. 'On lying: Kant and Benjamin Constant'. Kant-Studien 73: 4, 413-24.

Walker, M. U. 2006. Moral Repair: Reconstructing Moral Relations after Wrongdoing, Cambridge: Cambridge University Press.

Walzer, M. 2000. Just and Unjust Wars: A Moral Argument with Historical Illustrations, New York: Basic Books.

Weinrib, J. 2008. 'The juridical significance of Kant's "supposed right to lie"'. Kantian Review 13: 1, 141-70.

Wood, A. W. 2008. Kantian Ethics, Cambridge: Cambridge University Press.

Zolkos, M. 2010. Reconciling Community and Subjective Life: Trauma Testimony as Political Theorizing in the Work of Jean Améry and Imre Kertész. London: Continuum. 


\title{
11 Governing by trust
}

\section{Sincerity as a procedural fairness norm}

\author{
Zsolt Boda
}

This chapter interprets sincerity of communication as a procedural fairness norm, and argues that as such, it is a condition of building trust. At the same time, trust is a condition of governing capacities. While politicians often seem to believe that disclosing too much information, or unveiling their true intentions might make them weaker, sometimes the opposite may be the case. Valid and fair communication can create trust that increases the allegiance towards political decisions. Trust also increases the citizens' willingness to cooperate with authorities and that makes policy implementation easier.

In the following I will first overview the literature on trust and governing capacity. Empirical findings demonstrate that the roots of trust towards political institutions are policy performance and the procedural fairness of institutional operation. However, as performance is itself dependent on trust - as trust makes citizens more collaborative with institutions and policies - we must argue that procedural fairness is the most important factor shaping trusting attitudes. Therefore in the second section of this chapter, we will clarify the notion on procedural fairness. The third section deals with the role of political leadership in creating trust - a topic which is unfortunately only sparsely treated in the political science literature. Finally, a Hungarian case of political lies, falling trust and decreasing governing capacities is presented illustrating the arguments advanced in the chapter.

\section{Trust and governing}

Why do people obey the law? Why would they accept policy changes? How do we make them cooperate with state institutions to render policy implementation and governing smoother? These, and similar questions, are of paramount importance if we want to increase policy effectiveness, or governing capacities. The problem is to solve the many collective action problems that are present in society, and which put heavy constraints on governing capacities. A strong paradigm in social sciences, the rational choice theory, suggests that institutions and rules should be designed in such a way that makes individual self-interested motivation work. A well-designed system of sanctions and rewards as well as market mechanisms, can ensure that free-riding behaviour becomes costly for individuals. 
However, rational choice theory has been challenged on both theoretical and empirical grounds. It has been proven analytically that it is not possible to design a perfect sanction and reward system to avoid all kinds of free-riding (Miller 1992). Moreover, human motivation is a sophisticated mechanism: more sanctions and more rewards in many situations have the paradoxical effect of actually lowering the quality of expected performance (Frey 1997).

A different approach is based on trust. Trust in the government and in politicians is part of the concept of legitimacy and political legitimacy is a prerequisite of governing capacity, as all kinds of governing depend on the allegiance, acceptance or support of the citizens (Beetham 1991). Tom Tyler argues that people do not obey the law because they fear the sanctions, but because they put trust in it. More specifically, if people believe that laws serve the common good, and that the judicial system is both effective and fair, then they are more willing to obey the law (Tyler 1990, 2003, 2012).

Institutional trust can be defined as the expected utility of institutions performing satisfactorily (Mishler and Rose 2001). In a similar vein, for Levi and Stokker (2000) institutional trust is the belief that the given institution produces positive outcomes for the given individual, and/or for society as a whole. Now, there are two possible problems with these definitions. First, they assume that people form evaluative opinions about individual institutions, rather than the political system as a whole - taken to the extreme, this approach implies that people evaluate institutions separately from each other and neglect general political, socio-economic, cultural or demographic variables that influence patterns of trust. Second, the above definitions very much reflect a consequentialist approach: they suggest that the performance of the institutions is the primary factor shaping people's confidence in them.

For the first problem, the answer is that indeed, people in well established democracies do form evaluative opinions about separate political institutions, that is individual properties of institutions, like their (perceived) effectiveness, do shape people's trust towards them (Schweer 1997). Data also prove that people, who in some ways are involved in a specific institution, are more strongly influenced by their perceptions on institutional performance (Hudson 2006). But the issue is far from obvious, especially in new democracies. Mishler and Rose (1997) formulate a provocative argument by claiming that people in Central and Eastern Europe are not actually capable of distinguishing between specific institutions as they do not make judgements about them on the basis of their individual performance or properties. Rather, people in these countries evaluate political institutions according to a general frame which is strongly determined by the economic situation. Mishler and Rose admit, however, that their data are from the beginning of the 1990s and that over the course of democratic development people may have become more aware of the differences between political institutions. In our recent analysis of European Social Survey data, we did not find sufficient evidence for CEE citizens being less capable of distinguishing between institutions along the dimension of trust than citizens of older democracies in Europe (Boda and Medve-Bálint 2010). Moreover, both 
Campbell (2004) and Mishler and Rose (2001) argue that income is a strong predictor of trust in political institutions both at individual and aggregate levels in the CEE-region. Again, in our study we indeed found that per capita GDP is strongly correlated with institutional trust, but not only in the CEE countries: this correlation holds for Western European countries as well (Boda and MedveBálint 2010). In sum, although exogenous factors (such as income, social status, education, etc.) may also influence patterns of institutional trust, data suggest that people are able and ready to evaluate individual institutions based on the institution's own properties and performance.

The second problem with the above definitions on institutional trust is that they follow a consequentialist logic: people will trust institutions if they produce positive outcomes to them. Indeed, there is a well-established tradition in political science which stresses the importance of 'output legitimacy': allegiance towards the political system and its institutions is shaped by the goods delivered to people. People "care about ends not means; they judge government by results and are ... indifferent about the methods by which the results were obtained' (Popkin 1991: 99).

Indeed, there is empirical evidence supporting the performance-based trust hypothesis: for instance, a general observation is that trust in government is more volatile than trust in constitutional courts. Presumably the performance of governments is seen as being less stable than that of the courts, moreover, people also attribute certain social, economic and political problems to the government which they are less likely to attribute to the constitutional court (Grosskopf 2003). Perceived institutional performance ${ }^{1}$ certainly has an effect on trust.

However, other findings prove that sometimes trust and performance show surprisingly weak relation to each other (see Smith et al. 2007: 288). Such findings lead della Porta to ask "why policy outputs ... play such a minor role in shaping confidence in democratic institutions' (2000: 202) and Pharr to conclude that 'policy performance ... explains little when it comes to public trust' (2000: 199).

Tyler also challenges the consequentialist approach. He argues that besides institutional performance, normative evaluations also play an important role in shaping people's trust or distrust in institutions. Those normative evaluations to a great extent concern the fairness of procedures used by the institutions, independent of the substance of the decision (Tyler 1990, 2003, 2012). That is, people trust an institution based on perceptions on how they are treated by it and whether it makes decisions in a fair way. This might be even more important than institutional outcomes: fair procedures provide a protective cushion for certain political institutions even in times of hard decisions (such as reforms or austerity measures). In a number of situations procedural fairness was indeed found to play a crucial role in shaping people's trust and their readiness for cooperation with institutions. Many studies argue that, for instance, trust in police is first and foremost affected by perceived fairness and that trust produces both a readiness to cooperate with the police and a positive attitude in evaluating its performance (see the review by Hawdon 2008). To put it differently, the 
effectiveness of the police improves, with increasing trust, and so does the degree of satisfaction with its performance. Murphy (2005) found that in Australia tax evasion was correlated with perceived unfairness of the tax authority. This explains why strict sanctions paradoxically did not have a positive effect on the willingness to pay tax. Instead, these measures triggered more tax evasion. Gangl (2003) argues that people's perceptions about the legitimacy of the American Congress are more influenced by considerations of procedural fairness than by the distributive effects of the decisions. Breitmeier, Young and Zürn (2006) analysed the effectiveness of international regimes and concluded that it is largely influenced by the perceptions of participants on the fairness of regime formation. The above examples provide evidence that (1) legitimacy of, or trust in, institutions is a function of the perceived fairness of the procedures the institutions use; and (2) fair procedures may enhance the effectiveness of the given institutions (police, tax authority, etc.).

\section{Procedural fairness, sincerity and leadership}

But how to define procedural fairness? Philosophers have devoted much less work to the concept of procedural fairness as such, although some of its elements have been extensively studied. For instance, a number of classical human rights, such as right to fair trial, right to non-discriminatory treatment, etc., clearly express norms of fair procedures, and are extensively treated in political philosophy. Participation in decision-making has become the topic of an increasing body of literature (see, e.g. Dryzek 2000).

Communicative ethics, by Karl-Otto Apel and Jürgen Habermas (Apel 1990; Habermas 1990), is an influential theory that developed the procedural norms for fair communication. Although the theory was initially elaborated to set the circumstances which may lead to development and acceptance of legitimate ethical norms, it can be applied to more practical situations as it provides the criteria of valid speech. That is, it provides ethical criteria to judge the validity, acceptability and legitimacy of a communication. The communicative situation must be free of coercion, and undistorted by power relations, and the communication must use rational arguments to convince the other parties. The validity of speech lies in its intelligibility (valid meaning), truthfulness (subjective authenticity), factual truth and correctness (normative justifiability). ${ }^{2}$ Now, sincerity can be interpreted in terms of both truth-telling, and truthfulness (subjective authenticity). Overtly lying is certainly against the norm of sincerity, and so it is to stand for something that one does not believe in. Actually, the frontiers between the lack of truth-telling and untruthfulness are not always easy to delineate, but they represent by any standards violations of the sincerity principle.

In general terms, Leventhal (1980) identified six criteria of procedural justice: representativeness (participation), suppression of bias (impartiality), consistency (equal treatment and consistency over time), accuracy (informed and highquality decision-making), correctability (of unfair or mistaken decisions) and ethicality (conformity to general moral standards). This last criterion should not 
be interpreted as meaning that on a final account procedural fairness encompasses all kinds of ethical values - it indicates only that norms other than listed in the first five criteria may also influence the perception of procedural fairness. It is clear that procedural fairness is a complex phenomenon. Using results of psychological research, Machura (1998) argues that throughout the socialization process we all internalize some kind of 'procedural justice heuristics', which is difficult to define in very precise terms, but which is used in evaluating social settings. We can add that procedural fairness certainly has different meanings for different political institutions, or, more precisely, different criteria of procedural justice are used in evaluating the fairness of different institutions.

But why procedural fairness - and why not, for instance, distributive justice? First, note that according to Leventhal's above definition, the concept of procedural fairness to some extent embodies ethicality, normative justification as such. If so, than a fair distributional decision includes some reference to legitimate distributive principles.

Second, as Smith et al. (2007: 288) put it, 'Much of the procedural justice literature offers no greater theoretical basis for the empirical results than the assertion that people simply desire procedural justice, and saying 'that is just the way people are' does not constitute a theory'. The importance of procedural fairness thus has been observed, but not explained. They intend to fill this lacune and propose an approach based on evolutionary theory. They argue that evolutionary theory offers a theoretical account of people's sensitivity to strictly procedural, and other 'nonoutcome' variables (which do not in any way reflect the substance of the decision outcome), such as the intention of the decision-maker.

They relate the sensitivity to 'nonoutcome' evaluative criteria to an evolutionary explanation of leadership.

Evolutionary pressures may have led to the predisposition of some human beings to be sensitive to nonoutcome factors because groups in which no one cares about group health are likely to find themselves at a disadvantage. In this sense, evolutionary theory helps to explain findings in the procedural justice literature as well as our findings on people's aversion to decisionmakers who desire power or who use power to benefit themselves at others' expense.

(Smith et al. 2007: 296)

That is, evolutionary pressures create a need for leadership in human groups to fulfil the role of organizing the community, but only 'good' leadership is valuable, that which seeks to promote the general interest. Ethical sensitivity is needed to detect the real intentions and character of potential leaders.

This also implies that a mixed strategy of trusting and distrusting is the most useful for human communities. Although the literature on trust has a tendency to idealize it, and argue that the lack or the decline of public confidence is the main problem to address, some arguments challenge this view. In fact, democracy can be interpreted as a political system which institutionalizes distrust by separating 
the branches of power and establishing a sophisticated system of checks and balances (Cleary and Stokes, 2006). In this respect, exaggerated trust in one element of the system, either in the government or in the ruling party, can be interpreted as a potentially dangerous development that might lead to the decline of democratic culture and the erosion of the rule of law.

\section{Trust and leadership}

The above argument advanced by Smith et al. (2007) traces back the importance of procedural justice to the evolutionary pressure to scrutinize the 'goodness' of potential leaders. That is, they suggest that the significance of procedural justice in relation to institutions is a phenomenon derived from the necessity of good leadership. Leadership in this context is defined as the main means to secure the collective good, or solve collective action problems. Procedural fairness acts as a proof that the collective good will indeed be promoted. The fairness expectations towards political institutions, per analogiam, also express the wish that the collective good be taken into account.

However, besides this theoretical approach, other, more practical, links also exist between trust and leadership. On the one hand, leadership certainly presupposes some trust from the followers, otherwise, it simply cannot work. In his classical study Burns defines leadership as a special relationship between the leader and the followers; it is a kind of power, but it differs from share coercion which is a failure of leadership (Burns 1978). 'Leadership over human beings is exercised when persons with certain motives and purposes mobilize, in competition or conflict with others, institutional, political, psychological, and other resources so as to arouse, engage, and satisfy the motives of followers' (Burns 1978: 18). Leadership is thus inseparable from the followers' needs and goals it can only work if followers believe in, or at least accept the leader.

Beyond the need for a minimum trust, it was demonstrated that a more trusted leader can expect more compliance, allegiance and cooperation from the members. For instance, experiments prove that high trust leads employees to believe the accuracy of information provided by the managers and accept the decisions of managers (Kramer 1999). Establishing trust may help reduce the likelihood of employee retaliation following bad news (Holtz and Harold 2008: 794).

On the other hand, a leader is not a passive receiver of trusting attitudes: she can actively contribute to the creation or destruction of confidence. In their empirical study, Holtz and Harold (2008) demonstrate that indeed, perceptions of fairness influence trust in leaders and also the readiness to accept their explanations. That is, the relationship among fairness, trust and cooperation/allegiance is proven one more time. Moreover, Holtz and Harold (2008) show that leadership style has a direct effect on trust. They hold, in conformity with other studies, that transformational leadership style is the one which is more likely to create trust among organizational members. Transformational and transactional leadership were defined by Burns (1978) and are still among the most dominant 
perspectives of leadership behaviour (Holtz and Harold 2008: 782). Transformational leaders increase subordinates' understanding of the importance of organizational outcomes and help transform followers' personal values to be congruent with the collective goals or mission of their organization. Transactional leadership, on the other hand, involves a negotiated exchange relationship between a leader and a subordinate. Some authors suggest that transactional leadership is based on economic exchange and transformational leadership is grounded in social exchange principles, and that only social exchange tends to engender feelings of personal obligation, gratitude and trust; purely economic exchange as such does not (Holtz and Harold 2008: 783).

The results of Holtz and Harold seem to support the thesis of Smith et al. (2007): a leader is more trusted if she is able to prove her commitment to the common good. For this, she should act in conformity with legitimate procedural fairness norms, under the scrutiny of sceptical subordinates.

Note that the above quoted studies on leadership focus on a business context. To my knowledge, no similar studies have been conducted in political science. More generally, the whole leadership problematique is more deeply embedded in the field of management and organizational studies than in political science. The conditions, prerequisites and roots of trust in political leaders have not been studied empirically. ${ }^{3}$ The reasons for this phenomenon might be numerous, but one is that political scientists tend to focus on institutions and the political system. Although in political marketing and communication studies the phenomenon of personalization has been extensively treated (see, e.g. Karvonen 2010), the approach is generally very instrumental: how to make campaigns more effective, how to use the tools of political communication in the service of personalization of party leaders. Neither the normative roots of political leadership, nor their relation to the political system are analysed, assuming that political choices are more deeply rooted in ideological partisanship, interests, etc. Although at the very practical level, in the election campaigns, the role of political leadership is acknowledged, the analysis of its relationship to creating or destroying allegiance towards the political system (that is, legitimacy) and of its embeddedness into political theory is lacking. One of the few exceptions is the empirical study of Levi et al. (2009), which states that the supposed or perceived motives of political leaders are influencing the legitimacy beliefs of citizens: people obviously trust less leaders who do not seem to stand for the general interests of the community and this distrust influences the general legitimacy of the political system.

Bowler and Karp (2004) also argue that '(v)ery few researchers have examined whether scandalous behavior on the part of politicians and government officials influences how citizens view government and institutions', and '(i)n part this oversight is due to the assumption that citizens evaluations of government and institutions are unrelated to their views of incumbent behavior and policy' (Bowler and Karp 2004: 272). In their study they contend and prove that citizens' attitudes toward political institutions may be influenced by the behaviour of politicians. Therefore the scandalous behaviour of politicians themselves may be partly to blame for the low levels of political support observed in recent years. 
Lacking extensive empirical results on the role of political leaders in creating or destroying trust in the political institutions, in the following I assume that both Levi et al. (2009) and Bowler and Karp (2004) are right, and such relationship does indeed exist. The last section of the chapter deals with a case that may illustrate how the lack of sincerity destroys trust and, therefore, governing capacity.

\section{'We were lying noon and night': a case of Hungarian politics}

I would argue that a lack of sincerity in political communication undermines the perception of fairness, which, in turn, has a negative impact on the leadership potential of a politician, and the governing capacity of the government. The argument needs refinement, because we cannot hold that violating the norm of sincerity always leads to the loss of governing capacity (see the Clinton case, Koven and Kunselman 2003), or that communication which does not live up to the highest norm of truthfulness cannot be useful in politics. But serious norm violations have a good chance to provoke disastrous consequences on political leadership.

Hungarian politics, unfortunately, provide a number of cases in which politicians were found to either undisclose important information about themselves, or to overtly lie to the public. From 2002 to 2010 the Socialist Party was in power, winning two elections consecutively, and unfortunately their reign was accompanied by ethical scandals. ${ }^{4}$ Already in 2002, just after the elections, Prime Minister Péter Medgyessy had to admit that he had served as a secret agent during communist times. In 2009 and 2010, just before the elections, several cases of corruption were discovered, leading to extremely embarrassing situations for the politicians involved and also the party leaders trying to communicate the situation. But the most dramatic case is undeniably that of Prime Minister Ferenc Gyurcsány (2004-8) who admitted in a secret speech to his fellow socialist politicians that in the Spring 2006 election campaign he had been lying about the economic prospects of the country, and reality was much bleaker. He said things like 'we were lying noon and night', 'I made tremendous efforts to look as if I was governing', 'we did hundreds of tricks with János Veress (Minister of Finance) towards the EU'. He was trying to convince his fellow politicians that now that they had won the elections, immediate austerity measures and reforms must be put in place.

Immediately after the disclosure of the speech a war of interpretations began. Gyurcsány himself, the Socialist Party and their political allies, the Liberals made desperate efforts in the media to convince the public that the speech had a moral message: it was a call to end self-deception and to restore sincerity in politics. According to the argument, the Hungarian society has unrealistic expectations concerning welfare and the political class, caught in a desperate competition for power, instead of telling the truth, is fuelling those expectations. The alleged message of the speech thus was: 'get real'. Politicians should stop lying and people should stop deceiving themselves. 
True, the speech contained elements of a self-critique and launched an awakening call to the Socialist Party to support economic and social reforms. Nevertheless, polls proved that the majority of the public accepted the alternative interpretation, provided by the political opposition, which stressed that the Prime Minister admitted he had been lying to the Hungarian citizens, as well as to the EU. The President of the Republic, László Sólyom said that Hungary was in a 'moral crisis' and that the Prime Minister should have resigned.

The disclosure of this speech was of a major importance both for the carrier of Gyurcsány, and for the development of Hungary in the upcoming years. Despite street demonstrations and protests beginning in autumn 2006, Gyurcsány did not resign until 2008 when his own, and his party's, popularity attained historically negative records. More importantly from my perspective, Gyurcsány was unable to carry on the needed reforms and his own political programme. All the important policy reforms he initiated, such as the privatization of the social security system, failed. The economic growth of Hungary has been the slowest in the Central and Eastern European region. The financial crisis hit Hungary hard, and only a rescue package from the IMF and the EU saved the economy from collapsing. As a consequence, Hungary's external debt grew from 52 per cent of GDP in 2002 to 85 per cent in 2010 . In the past 10 years Hungary, which was a leader of economic reforms in the 1990s, with relatively high economic growth, has lost its good position in the region. This is reflected in many dimensions. For instance, Slovakia's per capita GDP overtook the Hungarian per capita GDP, and unlike Hungary, Slovakia was able to join the Euro-zone.

It is far beyond the reach of the present study to analyse in detail the phenomena and possible causes of Hungary's economic problems. Also, it is impossible to assess how much they are the effects of the Gyurcsány-government's bad performance, and to what extent are they the product of long-lasting or external political, social and economic problems. ${ }^{5}$ Even if we assume that bad government performance had an effect, we cannot know how much the governing capacity of Gyurcsány was deteriorated by his scandal - we may think that he was a bad Prime Minister, anyway. But theoretically the case of Gyurcsány may illustrate the links between the violation of sincerity as a procedural norm and the loss of governing capacity. These links are established by declining trust in both politicians and political institutions.

The possible causal chain is as follows:

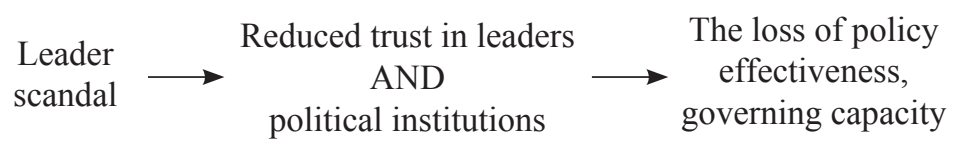

To prove the validity of the model, we must establish the causal chains between scandal and reduced trust on one hand, and between reduced trust and the loss of governing capacity. In the following I provide some evidence to the declining institutional trust in Hungary. Although the causal effect of Gyurcsány's scandal 
is not, by any means, proven, data show some interesting features which allow some inferences to be drawn.

In a previous study (Boda and Medve-Bálint 2010), we made an analysis of European Social Survey (ESS) data on institutional trust. ${ }^{6}$ In four consecutive ESS surveys (2002, 2004, 2006, 2008) the trust levels demonstrate remarkable stability as they tended to show little variation over time. However, the Central and Eastern European countries as a group are exceptions to this pattern as far as institutional trust is concerned: trust in national parliaments, politicians and political parties has declined in Central and Eastern Europe since 2002. ${ }^{7}$ Even within CEE, Hungary stands as a particularly negative example: all its institutional trust indicators have deteriorated over the period (Figure 11.1).

The mean value of the combined institutional trust indicator declined by 1.59 points between 2002 and 2008 in Hungary, and this fall is measured on a 10-point scale. In contrast, Figure 11.2 also illustrates how stable the interpersonal trust (that is, trust towards one's fellow citizens, the people in general) indicator remained in Hungary over the same period (the maximum variation stayed within a range of 0.26 points). We include data for Poland in the figure, which demonstrates a different 'trust trajectory': whereas Hungary has moved further away from the general European trend line between 2004 and 2008, Poland has drawn closer to it. Although Poland suffered a sharp fall in institutional trust between 2002 and 2004, since then the value of this indicator has been incrementally increasing and by 2008 almost reached the level of 2002 .

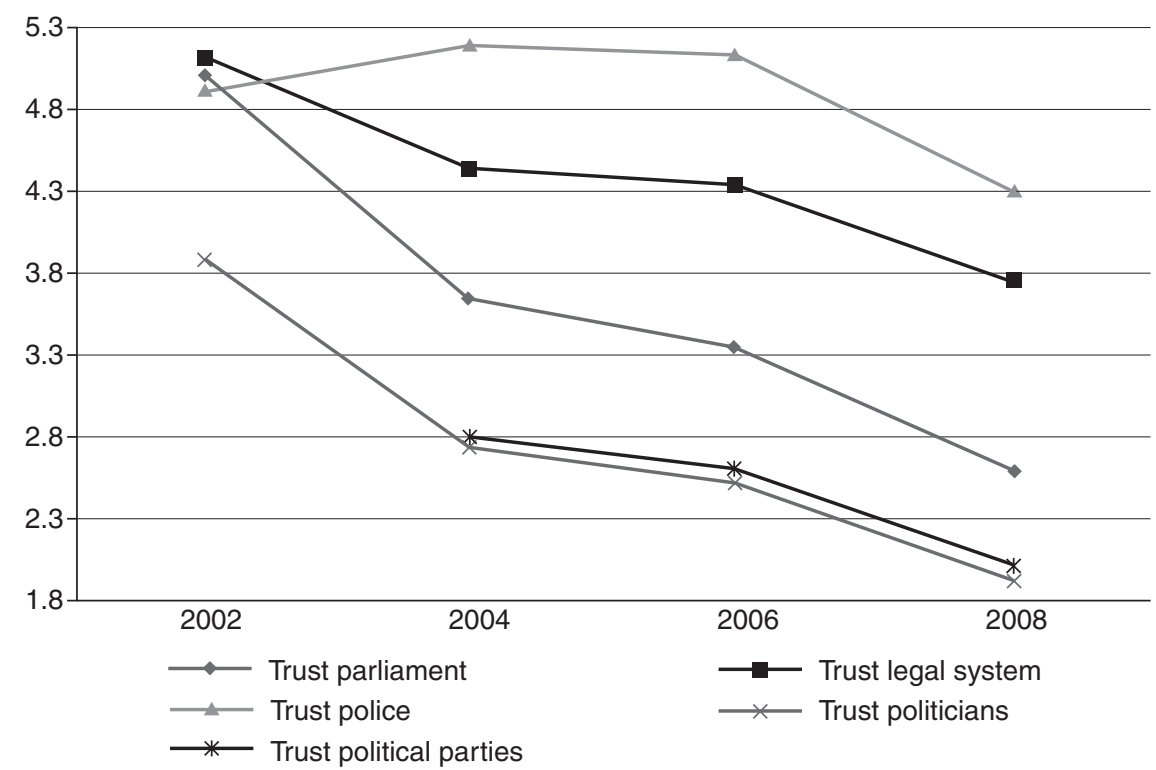

Figure 11.1 Institutional trust indicators in Hungary (2002-8).

Source: Boda and Medve-Bálint 2010: 191. 


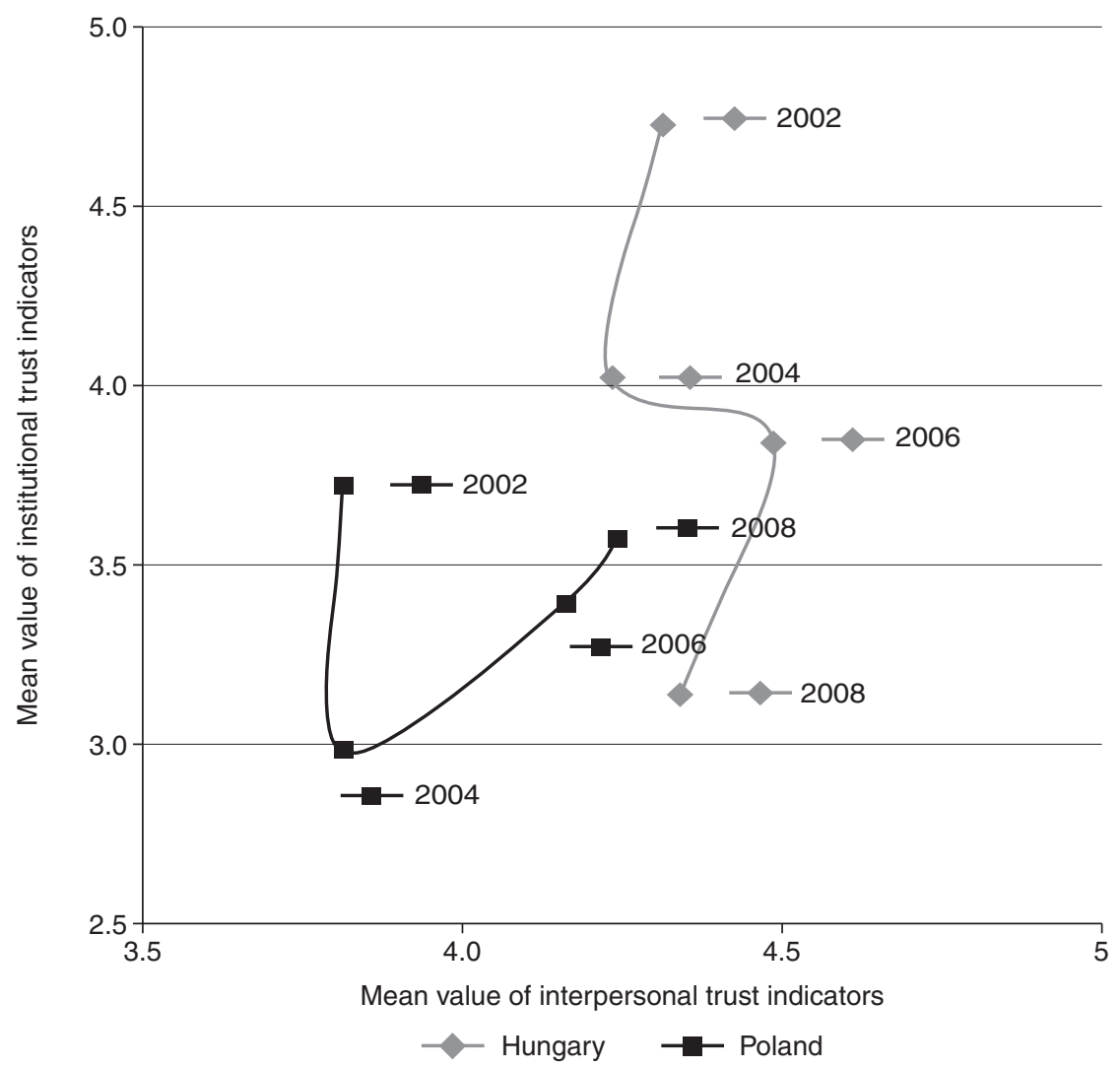

Figure 11.2 Trust indicators in Hungary and Poland (2002-8).

Source: Boda and Medve-Bálint 2010: 191.

Unlike in Hungary, change in institutional trust is not unidirectional in Poland but institutional trust still varies more (within the range of 0.74 points) in this period, while interpersonal trust remains relatively more stable (varying within the range of 0.44 points).

The higher volatility of the institutional trust indicator seems to support the view that endogenous factors, related to the institutions themselves, also play a role in shaping them. The Hungarian case is, in fact, very telling: while trust in political institutions has been falling since 2002, trust in the police remained stable till 2006 (see Figure 11.1). The 2008 survey, however, shows a significant decrease in confidence towards the police. Although we can only guess the causes of this decline, it is difficult to discard the assumption that the controversial and in many respects unlawful, violent reaction of the police to the street demonstrations in autumn 2006 had a significant effect on 
attitudes towards the police. The demonstrations and protests in September and October 2006 followed the disclosure of Prime Minister Ferenc Gyurcsány's secret speech to his fellow socialist politicians. A series of demonstrations began, sometimes turning into violent street fights, such as the assault against the seat of the national television. On the 50th anniversary of the 1956 revolution, on 23 October, extremists again threatened violent protests. However, the police reacted in an unusually brutal way, which had not been seen in Hungary since the change of regime in 1989. Several people - among them, clearly innocent bystanders - suffered grave injuries, were beaten up and humiliated by the police. A number of lawsuits were launched against policemen, of which very few concluded with imprisonment of the alleged offender.

If this is the case then we have an example where endogenous factors, that is, changing characteristics of the institution itself, influenced public trust. Moreover, this development also offers a case in which the institution was not judged on the outcomes of its performance (criminal activity did not increase in this period in Hungary), but on the legality and fairness of its actions. In short, we may have identified a case in which fairness and value judgements determined the change in the level of institutional trust.

As for our model above, we can conclude that:

- Although institutional trust also declined in several other CEE countries, the phenomenon was not an 'iron law' - see the example of Poland. Hungary may have had its particular reasons for declining trust.

- Trust in political institutions has been steadily declining in Hungary, but interpersonal trust remains stable. That is, declining institutional trust was not part of a general pattern of falling confidence. Presumably, it has its roots in the specificity of society - political system relations.

- Trust in other state institutions, such as the police, was not an integral part of the trend. That is, citizens lost confidence in politics, not the state in general. However, controversial police actions probably contributed to loss of confidence in the police.

The above arguments exclude some alternative explanations of falling institutional trust in Hungary. By no means do they prove the validity of the above model. However, if the literature on procedural fairness, leadership, trust and policy effectiveness is correct, then causal chains among scandal, declining institutional trust and loss of governing capacity are plausible. Further empirical research may find other justifications for application of the above model to the Hungarian case.

\section{Conclusion}

Researching institutional trust may have practical relevance because confidence in the political system is part of its legitimacy. Legitimacy is not necessary for 
its own sake but because it is a condition of effective governance. An extensive literature deals with the significance of procedural justice norms that institutions should use in their operations to establish trust.

An equally important group of studies prove that procedural justice is a condition of effective leadership. However, this research stream is well established only in management studies. The moral dimension of political leadership has been only sparsely studied. The effect of norm transgression as moral scandal by a political leader on institutional trust is intuitively plausible; however, empirical analyses do not abound on the issue. In the present chapter I intended to establish the links between the violation of sincerity as fairness norm, the declining trust in political institutions and reduced governing capacity using a Hungarian case. I do not claim to prove the causal links, but in an empirical analysis I tried to argue for the plausibility of the model. Further research may shed more light on this disturbing case and test the validity of the model.

\section{Notes}

1 Note that institutional performance is not always easy to evaluate: it is a construct, and an interesting question is how this construct is created by personal experience, public opinion, the media etc.?

2 Note that there is circular logic present in the theory: fair communication is needed for legitimate norms to be developed; however, the criteria of fair communication already include normative justifiability. But this is unavoidable: final foundation is possible only if we posit an axiom. Otherwise we are either caught in a circular argumentation, or in a regressio ad infinitum.

3 A relatively developed research field is that of collective identity and its importance in creating leadership and followership (see Tyler 1999; Haslam and Platow 2001; Simon and Klandermans 2001; Haslam et al. 2011). But it is more about the psychological roots of leadership than the political and moral conditions of it.

4 Note that I do not intend to suggest that the Socialist Party is more corrupt than other parties in Hungary. But they were involved in several scandals in the past ten years, and my empirical analysis relates to that specific period.

5 Some analysts, however, explain the bad economic performance of Hungary in terms of poor political leadership and a decline in trust towards economic policy-making. See Györffy $(2007,2009)$.

6 The advantage of ESS data is that they cover many - although not all - European countries, therefore they invite international comparison. However, there are some limitations of the datasets as well. First, data come from four surveys only (2002, 2004, 2006, 2008), which does not allow for performing a time-series analysis. Second, the panel of data providers is not stable in the surveys, which is an important concern regarding our purposes. For instance, the Czech Republic was not covered in the last two rounds, while Slovakia was missing in 2002. Third, questions concerning institutional trust are quite limited in their number. We used the questions about trust in the given country's parliament, in its legal system, in politicians, in political parties and in the police. We did not include in each analysis the questions regarding trust in the United Nations (UN) and in the European Union (EU), because we considered them to be potential distorters of the results. We used the questions on how much people can be trusted, how fair and how helpful they are as indicators of interpersonal (generalized) trust. At some point we also included in the analysis the questions about people's 
satisfaction with life as a whole, with the present state of the country's economy, with the national government, with the way democracy works in the given country, with the state of education, with the state of health services and with selected political and social institutions.

7 Note that here we refer to average values calculated for country groups. Therefore some countries within each group may deviate from the tendency that appears at the aggregate (country group) level. A further complication is caused as not all the same countries participated in all the survey rounds. Consequently, comparing data on the level of country groups across the different survey rounds becomes problematic.

\section{Bibliography}

Apel, K.-O. 1990. 'Is the ethics of the ideal communication community a utopia? On the relationship between ethics, utopia, and the critique of utopia'. In S. Benhabib and F. Dallmayr (eds), The Communicative Ethics Controversy. Cambridge, Mass.: The MIT Press, pp. 23-59.

Beetham, D. 1991. The Legitimation of Power. Palgrave Macmillan.

Boda, Z. and Medve-Bálint, G. 2010. 'Institutional trust in Hungary in a comparative perspective: an empirical analysis’. In L. Füstös László and I. Szalma (eds), European Social Register 2010. Budapest: MTA PTI - MTA SZKI, pp. 184-202.

Bowler, S. and Karp, J. A. 2004. 'Politicians, scandals and trust in government'. Political Behavior 26: 3, 271-88.

Breitmeier, H., Young, O. and Zürn, M. 2006. Analyzing International Environmental Regimes: From Case Study to Database. Cambridge, Mass.: The MIT Press.

Burns, J. M. 1978. Leadership. New York etc.: Harper and Row.

Campbell, W. R. 2004. 'The sources of institutional trust in east and west Germany: civic culture or economic performance?' German Politics 13: 3, 401-18.

Cleary, M. R. and Stokes S. C. 2006. Democracy and the Culture of Skepticism. New York: Russel Sage Foundation.

Della Porta, D. 2000. 'Social capital, beliefs in government, and political corruption'. In S. J. Pharr and R. D. Putnam (eds), Disaffected Democracies. Princeton: Princeton University Press, pp. 202-28.

Dryzek. J. S. 2000. Deliberative Democracy and Beyond: Liberals, Critics, Contestations. Oxford University Press.

Frey, B. S. 1997. Not Just for the Money. An Economic Theory of Personal Motivation. Cheltenham: Edward Elgar.

Gangl, A. 2003. 'Procedural justice theory and the evaluation of the lawmaking process'. Political Behavior 25: 2, 119-50.

Grosskopf, A. 2003. 'Explaining the democratic trust conundrum: the sources of institutional trust in the reunited Germany'. International Social Science Review 83: 1-2.

Györffy, D. 2007. 'Deficit bias and moral hazard on the road to the EMU: the politics of fiscal policy in Hungary'. Post-Communist Economies 19: 1, 1-16.

Győrffy, D. 2009. 'Structural change without trust. reform cycles in Hungary and Slovakia'. Acta Oeconomica 59: 2, 147-77.

Habermas, J. 1990. 'Discourse ethics: notes on a program of philosophical justification'. In S. Benhabib and F. Dallmayr (eds), The Communicative Ethics Controversy. Cambridge, Mass: The MIT Press, pp. 60-110.

Haslam, S. A., Reicher, S. and Platow, M. J. 2011. The New Psychology of Leadership. Identity, Influence and Power. New York, East Sussex: Psychology Press. 
Haslam, S. A. and Platow, M. J. 2001. 'The link between leadership and followership: how affirming social identity translates vision into action'. Personality and Social Psychology Bulletin 27: 11, 1469-79.

Hawdon, J. 2008. 'Legitimacy, trust, social capital, and policing styles: a theoretical statement'. Police Quarterly 11: 2, 182-201.

Holtz, B. C. and Harold, C. M. 2008. 'When your boss says no! The effects of leadership style and trust on employee reactions to managerial explanations'. Journal of Occupational and Organizational Psychology 81, 777-802.

Hudson, J. 2006. 'Institutional trust and subjective well-being across the EU'. KYKLOS 59: 1, 43-62.

Karvonen, L. (ed.). 2010. The Personalisation of Politics: A Study of Parliamentary Democracies. ECPR Press.

Koven, S. G. and Kunselman, J. C. 2003. 'Trust in government: lessons from the Clinton impeachment'. International Journal of Public Administration 26: 2, 197-212.

Kramer, R. M. 1999. 'Trust and distrust in organizations: Emerging perspectives, enduring questions'. Annual Review of Psychology 50, 569-98.

Leventhal, G. 1980. 'What should be one with equity theory? New approaches to the study of fairness in social relationships'. In K. J. Gergen, M. S. Greenberg and H. J. Willis (eds), Social Exchange: Advances in Theory and Research. New York: Plenum.

Levi, M. and Stokker, L. 2000. 'Political trust and trustworthiness'. Annual Review of Political Science, 3: 1.

Levi, M., Sacks, A. and Tyler, T. 2009. 'Conceptualizing legitimacy, measuring legitimating beliefs'. American Behavioral Scientist 53, 354-75.

Machura, S. 1998. 'Introduction: procedural justice, law and policy'. Law and Policy 20: 1 , January.

Miller, G. J. 1992. Managerial dilemmas: the political economy of hierarchy. New York: Cambridge University Press.

Mishler, W. and Rose, R. 1997. 'Trust, distrust, skepticism: popular evaluations of civil and political institutions in post-communist societies'. The Journal of Politics 9: 2, 418-51.

Mishler, W. and Rose, R. 2001. 'What are the origins of political trust?: Testing institutional and cultural theories in post-communist societies'. Comparative Political Studies 34: 1, February.

Murphy, K. 2005. 'Regulating more effectively: the relationship between procedural justice, legitimacy, and tax non-compliance'. Journal of Law and Society 32: 4, 562-89.

Pharr, S. J. 2000. 'Officials' misconduct and public distrust'. In S. J. Pharr and R. D. Putnam (eds), Disaffected Democracies. Princeton: Princeton University Press, pp. 173-201.

Popkin, S. L. 1991. The Reasoning Voter. Chicago: University of Chicago Press.

Schweer, M. K. W. 1997. 'Trust in central social institutions - results of an empirical study of young adults'. Gruppendynamik-Zeitschrift Fur Angewandte Sozialpsychologies 28, 201-10.

Simon, B. and Klandermans, B. 2001. 'Politicized collective identity. a social psychological analysis'. American Psychologist 56: 4, 319-31.

Smith, K. B., Larimer, C. W., Littvay, L. and Hibbing, J. R. 2007. 'Evolutionary theory and political leadership: why certain people do not trust decision makers'. The Journal of Politics 69: 2, 285-99.

Tyler, T. R. 1990. Why People Obey the Law. New Haven: Yale University Press. 


\section{Z. Boda}

Tyler, T. R. 1999. 'Why people co-operate with organizations: An identity-based perspective'. In B. M. Staw and R. Sutton (eds), Research in organizational behaviour. Greenwich, CT: JAI, vol. 21, pp. 201-46.

Tyler, T. R. 2003. 'Procedural justice, legitimacy, and the effective rule of law'. In M. Tonry (ed.), Crime and Justice: A Review of the Research. Chicago: University of Chicago Press, pp. 283-357.

Tyler, T. R. 2012. Why People Cooperate: the Role of Social Motivations. New Jersey: Princeton University Press. 


\title{
12 Truth-telling and right-speaking in European integration politics
}

\author{
From theory to practice and back
}

\author{
Catherine Guisan
}

\section{Introduction}

The specter of lying haunts Europeans at the turn of the twenty-first century. From Greece to Bulgaria, elected officials are going to prison for prevarication. In response to the egregious mendacity of its budget minister Jérôme Cahuzac, who denied having a Swiss bank account, the French government has required ministers and parliamentarians to make their assets public, and it is considering a program to teach "secular morality" in public schools (Zarka 2013; Tavoillot 2013). Yet philosophers and legal experts have long debated the wisdom of avoiding lies in politics (Machiavelli 1988; Arendt 1993; Varden 2010; Wood 2011). In the wake of the French Terror Immanuel Kant asserted against Benjamin Constant the unconditional duty to tell the truth even to a murderer looking for his victim at one's door (Kant 1949: 346-50), because lying voids "all rights based on contracts, and this is a wrong done to mankind generally"; it "vitiates the source of law itself" (Kant 1949: 347). Max Weber offered perhaps the most compelling challenge to Kant's injunction when he critiqued the ethics of conviction, which sticks to preestablished moral principles with no regard for consequences. He recommended the ethics of responsibility in politics, which weighs an action's impact before choosing to undertake it. Yet Weber wished for political actors who could hold both ethics: these "in unison constitute a genuine man - a man who can have the "calling for politics", (Gerth and Mills 1973: 127).

This chapter argues that the ethics of conviction need not give way to the ethics of responsibility in crisis times. This is the position of Jürgen Habermas, whose debt to Kant is well acknowledged (Mertens 1996: 328-9). Drawing from philosophy, linguistics and the social sciences to demonstrate that "language, reason and action are inherently intermeshed" (Fultner 2001: ix), Habermas stresses the political importance of speech acts' "normative validity": truth-like statements are indispensable to democratic politics' stability and legitimacy. Habermas has also commented extensively on European integration, although he does not explicitly link his empirical work with his theory (Habermas 2009, 2012a, 2012b on the EU). ${ }^{1}$

Meanwhile scholars of the EU democratic deficit have long critiqued the opaque nature of the European Union's (EU) institutions and policies: the only 
alternative to unaccountable technocratic governance is public discussion and persuasive justification by EU authorities of their actions. ${ }^{2}$ Yet the huge scholarly literature on the EU democratic deficit does not focus on the issue of truth in EU politics, with a few exceptions. ${ }^{3}$ This chapter has two purposes therefore. The main one is to draw from Habermas' theory of communicative action especially his discussion of truth-telling, truthfulness, right-speaking and intelligibility - to shed some light on the kind of discourse ethics and practices that moved the EU constitutional process forward. This argument challenges the well-accepted thesis that European founders were neo-functionalists, primarily motivated by technocratic concerns. To the contrary, these actors had a keen sense of the importance of intelligibility and truth-telling to legitimize the first European Community on Coal and Steel (ECSC). Such concerns were abandoned after the failure to establish a European Political Community (EPC) in 1954, and this chapter documents the corruption and a few attempts at regeneration of European discourse ethics since. A secondary purpose of this chapter is to draw from its empirical material to offer two rejoinders to Habermas' theory, as the case of the EU exemplifies both the relevance of this theory for EU politics, and the difficulties of implementation. One caveat at the outset: this chapter discusses only the quality of discursive practices among ECSC/EU decisionmakers during major debates over constitutional treaties. Indeed leadership rhetoric and practices are especially important during political founding (Gaffney 1999; Schmidt 2006), and the accession of new member states and the launching of ambitious new policies, such as the Economic and Monetary Union (EMU) have provoked a quasi-permanent EU constitutional process since the end of the Cold War. The discourse ethics of citizens matters just as much to politics, but because of space limitation this important topic is left aside here. ${ }^{4}$

The first part of the chapter outlines essential elements of Habermas' communicative action theory, in particular the redemption of validity claims to truth, rightness, truthfulness or sincerity, and intelligibility in communicative exchanges among people who seek legitimate political agreements. The second part discusses the European discursive practices of the early 1950s by evaluating them against the high standards of Habermas' discourse ethics. The next part analyzes recent EU constitutional debates and practices (2000-13). It interprets the Conventions on the European Charter of Fundamental Rights and on the Treaty for a European Constitution (TEC) as two experiments in right-speaking, which were jettisoned after the negative Dutch and French referenda on the TEC. With the 2009 Lisbon Treaty and the 2013 Treaty on Stability and Governance, EU decision-makers seem to have given in to what Habermas has called "decisionism", executive decisions taken for the sake of stability (Habermas 1975: 98-9) with little concern for rightness and intelligibility. As a result legitimacy and social trust are crumbling (Crum 2013). The conclusion discusses one current initiative in the European Parliament to bring back discursive ethics, two rejoinders to Habermas' theory of communicative action, and its continuing relevance to European integration's constitutional development. 


\section{Habermas on truth in politics}

\section{The communication community}

While sharing Kant's commitment to trustworthiness in intersubjective and political relationships, Habermas asserts that only discursive and rational communication among the many can define legitimate political norms and their application (Habermas 1975). Thus he translates "the Kantian conception of practical reason into communicative terms" (Allen 2012: 361). ${ }^{5}$ Discourse ethics indicates a procedural path to political legitimacy in highly diversified democracies, without defining the content of the good life, which is best left to the deliberation of specific individuals or communities (Habermas 1975: 107-8). This need not mean an end to history: the linguistic process of norm-setting is continuous, subject to revisions, thus non-essentialist (Camargo Brito 2010: 2, 4). In the 1970s Habermas had critiqued Western democracies' "legitimation crisis": governments bought their citizens' acquiescence through formal democratic procedures and the material rewards of the welfare state, but proved unable to create meaning and genuine assent. In a kind of thought experiment, he imagined instead a "communication community" situated in the life-world of voluntary associations - or civil society - which puts normative demands on the administrative and economic "subsystems". Habermas' communication community's participants are motivated by the "search for truth". And no force except the force of the better argument is exercised. Consensus of the participants through argumentation makes a norm "right" (Habermas 1975: 105, 108).

\section{How to assess the normative validity of speech acts?}

Communicative action theory has a strong normative content. Over time Habermas has deemphasized the capacity of civil society to act politically to privilege the mediating role of law between communicative rationality and state power (Allen 2012). It need not matter to this argument, however, whether the communication community consists of elected representatives or civil society or both. In all cases its participants elaborate norms of fairness legitimately by delivering speech acts, whose validity is assessed against "claims to truth, claims to rightness and claims to truthfulness" (Habermas 1990: 58). Claims to truth refer to something in the objective world of observable facts, for instance "the sky is blue"; truthfulness, or sincerity, on the part of the actor is demonstrated by consistent behavior (in other terms, a person can convince someone else that he means what he says only through his actions, not by giving reasons); claims to rightness refer to something in the shared social world (norms of fairness), such as "it is wrong to kill" (ibid.: 58-9). There is a certain ambiguity in Habermas' discussion of truth. Does truth stand for a rationally justified norm or an observable fact? Probably both. In the first version of his theory of communicative action Habermas had set a fourth validity claim, intelligibility - speech acts must carry an understandable meaning to the hearer - which he soon stopped 
mentioning (Camargo Brito 2008: 69). ${ }^{6}$ Yet intelligibility matters to this argument and will be retained here as a criterion; whereas an individual can redeem claims to intelligibility, rational truth and sincerity, claims to rightness are handled best in the communication community. In other terms, right-speaking is about the collective elaboration of rational political norms, or "truth-like" statements. Ideally, consensus-building requires unfettered communication. In practice, this is rare, but the very search for agreement implies this presupposition: a rule of action or choice is justified, and thus valid, only if all those affected by the rule or choice could accept it in a reasonable discourse (Habermas 1996: 107). As Amy Allen argues, the ideal of a communicatively structured life world, undistorted by relations of power, can at least serve as the point of view from which empirical reality can be assessed (Allen 2012: 359; Habermas 1996: 148). ${ }^{7}$

Communicative action does more than lay the ground for just norms, however; it constitutes also a process of self-understanding, a detector of identity. During the 1990 German reunification process Habermas called for a public process of truth-seeking and truth-telling about the Nazi and Stalinist regimes, in the mass media, schools and adult-education programs, and also in the scientific and literary public spheres, citizens fora, and official fact-finding commissions. Only at this price could the German people articulate an "honest collective selfunderstanding that simultaneously suffices as a norm for political justice and expresses the deeper aspiration of a political community shaped by its history" (Habermas 1997: 18-20). Therefore Habermas asked for a referendum on German reunification prepared by open debates (ibid.), and he has supported European-wide referenda on EU treaties, although German law does not allow them (Habermas 2006: 101).

\section{Early intra-European discursive practices}

\section{Communicative action and the ECSC founding}

The way a new political order is founded matters to its legitimacy. According to some scholars, the "traditional Monnet-method ... has, on the whole, historically shunned public opinion and democratic accountability" (Featherstone 1994: 150; see also Hug 2002: 1; Joly 2007: 111). For others, factual truth calls for a more nuanced assessment (Eriksen and Fossum 2012: 332; Guisan 2012: 111-13; Rittberger 2005: 1). In the spring of 1950 senior French public servant Jean Monnet wrote a proposal for a European Coal and Steel Community (ECSC) with a few collaborators. His concern for intelligibility was such that the proposal went through nine drafts before being forwarded to French Foreign Affairs minister Robert Schuman, who staked his reputation on it (Rieben, Nathusius, Nicod and Camperio-Tixier 2000: 113-52). The May 9, 1950 Schuman Declaration can be interpreted as a public and carefully thought through speech act, which defined in factual, rational and intelligible terms a problem (the bloody rivalries among France and Germany), political objectives (peace, prosperity and a federation) and the means proposed (the management of shared material interests, coal and 
steel, by a common European authority). No one doubted the sincerity of Schuman; and his Declaration, which remains an EU founding document (Fontaine 2000: 36-7), proved truthful in so far as consequent action followed. It opened up a political space for right-speaking among the representatives of six nations, which had fought each other recently (France still occupied part of the Federal Republic of Germany in 1950) and whose representatives negotiated the ECSC Treaty in Paris over an 18-month period (italics by the author). Monnet, who chaired the negotiations, discussed in his Memoirs the kind of discourse ethics needed to elaborate the new European norms of fairness:

To persuade people to talk together is the most one can do to serve the cause of peace. But for this a number of conditions must be fulfilled, all equally important. One is that the talks be conducted in a spirit of equality, and that no one should come to the table with the desire to score off somebody else.... The second condition is that everyone should talk about the same thing; the third, finally, is that everyone should seek the interest which is common to all. This method does not come naturally to people who meet to deal with problems that have arisen precisely because of the conflicting interests of nation-States. They have to be induced to understand the method and apply it.... For this purpose goodwill is not enough ... a certain moral power has to be imposed on everyone - the power of rules laid down by common institutions which are greater than individuals and are respected by States.

(Monnet 1978: 474-5)

European integration originated from a deliberative process embedded within the setting/institutions of already established democracies (Eriksen and Fossum 2012: 326, 337). In Paris the French and German delegations exhibited considerably more concern for democratic accountability, by insisting on a legislative body, than their Benelux counterparts who prioritized the defense of national economic objectives (Rittberger 2005). ${ }^{8}$ The Treaty of Paris ratification debates in the parliaments of the six future ECSC member states were public and highly contentious (Banchoff in Banchoff and Smith 1999: 186-90). Right-speaking proved to be conflictual.

Assessing how Monnet practiced discourse ethics (or his "method") in Habermasian terms, produces mixed results. Intelligibility, truth-telling and rightspeaking remained Monnet's concerns after he became the first president of the supranational High Authority (HA), the ECSC institution charged with the power of legislative initiative and the responsibility to rein in national interests in favor of the putative European common interest. Intelligible and persuasive communication meant for his collaborators the rewriting of countless drafts (Rabier 1999, interview). When the European Court of Justice (ECJ) ruled in 1954 against the HA for changing the steel pricing rules, he quipped: "Good. That shows the institutions are working” (Duchêne 1994: 241). But Monnet was critiqued for starting a tradition of elitism and technocracy as HA president 
(Featherstone 1994). By his own admission, he never sat down at the negotiation table without a carefully written draft, which was often accepted "in the absence of any competition," whether the argument seemed "the best" or not; and he relied on the pressure of "hard work" to create a "team spirit" (Monnet 1978: 323-5). French MEP Jean-Louis Bourlanges compares the HA and its successor institution, the Commission, to "Platonician" institutions, the fruit of Monnet's apolitical vision that wished for a "sacerdotal" committee of experts to deliver the "European truth." In March 1999 he rejoiced at the "desacralization" of the Santer Commission, which had just resigned under the threat of an EP motion of censure; at last, politics had emerged with its contradictory and legitimate options rather than "spontaneous agreement." Yet Bourlanges did not want to see the Commission lose its prerogative to initiate legislation, because it represents the only "source of coherence" in the EU system (Bourlanges 1999, interview).

For more evidence of the deeply held political commitment of the ECSC founders, one need only remember the 1952 French Pleven Plan for a European Defense Community (EDC), another Monnet idea, which came with a democratic and representative Political Community (EPC) at the request of Italian Prime Minister Alcide De Gasperi. The ECSC Assembly drafted the EPC statutes, but the French National Assembly's rejection of the EDC Treaty in 1954 put an end to constitution-making attempts for almost 50 years, and the Rome Treaty on the European Economic Community (EEC), which was negotiated two years later, marks the full onset of neo-functionalism. The original vision of European federalism gave way to the primarily economic concerns of the common market (Friedrich 2011: 87), and there was no Schuman-like Declaration to explain this re-founding clearly. ${ }^{9}$ From 1954 until the 1992 referendum over the Maastricht Treaty, which almost failed in France, EC/EU decision-makers paid little attention to issues of legitimacy beyond parliamentary ratification. Initially the European Communities enjoyed broad popular support (Hewstone 1986: 20). But political conflicts became adjudicated within the context of increasingly constraining norms closed to public scrutiny (Habermas 2009: 111), and existing treaties were amended rather than negotiated from scratch. Several negative referenda in the 1990s eventually convinced EU member states' governments to change method: a constitutional Convention would replace the secretive gatherings of bureaucrats and diplomats and draft under public scrutiny an intelligible constitutional treaty. This meant a return to the earlier practices of truth-telling and right-speaking to obtain popular legitimacy.

\section{Post-1992 EU discourse ethics}

\section{EU conventions and right-speaking}

At the turn of the twenty-first century European leaders began speaking and acting as if they had taken a Habermas 101 course on communicative action. They increasingly mixed their usual appeals to the enlightened self-interest of citizens with another kind of rhetoric, which promoted "norms," the equivalent 
of Habermas truth-like, or rationally debated and justified statements, around which a community organizes. The 1999 Convention on the Charter of European Fundamental Rights was the first elite level experiment in right-speaking about European norms, which was public. In December 2001 the European Council (the EU college of member states' government heads) appointed another Convention to draft the Treaty establishing a Constitution for Europe (TEC). With its 105 members plus alternates representing 28 nation-states' parliaments and governments (including Turkey), the European Parliament (EP) and the EU Commission, the Convention broke with the EC/EU model of the Intergovernmental Conference (IGC) meeting behind closed doors. The word truth was never mentioned, but the Convention was expected to hold open and inclusive debates in which the force of the better argument would prevail and produce a readable text defining EU norms, institutions and policies. Austrian member of the European Parliament (MEP) Reinhard Rack, a member of both Conventions, rejoiced that the "old European working method" with topics discussed solely at the intergovernmental level, without any transparency, had been left behind: "This is different: we make it clear when we do deal.... We pleaded for and obtained the same rights for the representatives of candidate countries. Now we have to prove that the Convention method will work" (Rack 2002, interview).

By 2003, the Convention's working groups had agreed to replace the eight treaties with one constitutional treaty; and the Convention process with its public plenary meetings, the presidium's proposals and the thousands of amendments immediately posted on the Internet, was deemed a success, even if the decisive role of the presidium of three in the decision-making process failed to meet the requirements of full equality for all participants - one central feature ensuring right-speaking in the Habermasian communication community. Part I of the TEC, which defined EU norms, goals and institutions and the sharing of competences between EU institutions and member states, was quite readable. And so was Part II's Charter of Fundamental Rights. But the TEC's Part III, which codified all the previously ratified treaties, was over 200 pages long, and unintelligible to unschooled readers. Its dispositions, having long been ratified and implemented, were not subject to a new decision. However, this was not made clear and Part III excited the strongest negative reactions among French and Dutch citizens, who rejected the TEC in two referenda in June 2005. This outcome was not what Jürgen Habermas might have wished for. Yet it "may have contributed to the emergence of a public space which he had hoped for" because of the many public debates it stimulated in France, and which were followed across Europe (Dehousse 2006: 159).

\section{Intelligibility and the Lisbon Treaty}

At the EP disappointment after the French and Dutch rejections of the TEC was keenly felt. The EP is the only body that can claim some likeness with Habermas' communication community. Its influence had steadily grown since its first direct election in 1979 thanks to the petits pas (small steps) of procedural 
revision, astute handling of its budgetary powers and the "large strides" of constitutional reforms (Judge and Earnshaw 2008: 38). Some individuals exerted decisive leadership, such as Italian MEP Altiero Spinelli who convinced his colleagues to submit to the European Council a Draft Treaty establishing the European Union (DTEU) in 1984, in effect a clearly written constitution; several DTEU proposals made it into the treaties of Maastricht and Amsterdam (Corbett 1998: 151). The two Conventions had been the first opportunities for MEPs to take part in the EU constitutional process directly.

MEPs tried to stay faithful to their ideals of transparency and democratic legitimacy, but in spite of several EP hearings in 2006, the talk of "deliberative assizes" and new conventions quickly vanished (Guisan 2011: 117). After a "period of reflection," the European Council imposed the return to the intergovernmental and opaque method of the IGC (Boylan 2008: 223). The term "constitution" was banned, and the new treaty (in fact two treaties, the Treaty of Lisbon and the Treaty on the Functioning of the Union) consisted once more of amendments to the previous treaties, that is clauses that only highly qualified lawyers could interpret. The Treaty of Lisbon starts with this unintelligible clause:

The Treaty on European Union shall be amended in accordance with the provisions of this Article. PREAMBLE 1) The preamble shall be amended as follows: (a) the following text shall be inserted as the second recital: "DRAWING INSPIRATION from the cultural, religious and humanist inheritance of Europe, from which have developed the universal values of the inviolable and inalienable rights of the human person, freedom, democracy, equality and the rule of law,"; (b) In the seventh, which shall become the eighth, recital, the words "of this Treaty" shall be replaced by "of this Treaty and of the Treaty on the Functioning of the European Union,"; (c) In the eleventh, which shall become the twelfth, recital, the words "of this Treaty" shall be replaced by "of this Treaty and of the Treaty on the Functioning of the European Union."

(European Council 2007)

MEPs were shut out from right-speaking: their representatives, Andrew Duff, Elmar Brok and Enrique Báron Crespo attended the Intergovernmental Conference (IGC) in a consultative role with no voting right. The EP rapporteurs acknowledged the different process and that an amending treaty is "inevitably less clear and readable than a codified treaty" (Corbett and Mendez de Vigo 2008: 10). Yet MEP Richard Corbett argued that this should not matter. Only academics, lawyers and journalists worry about intelligibility, but the "consolidated" versions of the Lisbon Treaty (rewritten in plain language and unofficial) should suffice to convince EU citizens (Corbett 2008, interview). His colleague Andrew Duff concurred (Duff 2008, interview). Others were not so sure. While acknowledging that the IGC method was the only one available after the negative referenda, German MEP Jo Leinen called the Lisbon Treaty a "camouflage of the EU project." He added, 
It looks like EU is coming from the back door, not the front door. We are losing the public discourse. Since 1999 the EU has been very dynamic with the enlargements, the EMU, the new treaties, Frontex and our security missions. Perhaps we will pay a bigger price later for the lack of public debate.

(Leinen 2008, interview)

Time will tell. The Treaty's new system of multiple presidencies (of the Commission, Council of ministers, European Council and EP) has come under critique for its lack of intelligibility and the cacophony stemming from the EU's "four or five different voices." Moreover the Lisbon Treaty does not set a clear distinction between EU and national competencies, making it impossible for citizens to "understand who does what" (Delors 2013: 175, 177). In spite of their long professed commitment to transparency, access and participation (Friedrich 2011: 81-123), EU elites could not deliver because the rejection of the TEC prevented them from reforming EU institutions in time for the 2004 and 2007 enlargements. More surprisingly, Habermas, the theorist unencumbered by the pressures weighing on the politician, endorsed the "slimmed-down" 2009 Treaty of Lisbon (511 pages in the 2012 English "consolidated" version), ${ }^{10}$ which "definitively sets the seal on the elitist character of a political process which is remote from the populations", with the future of Europe decided "behind closed doors" (Habermas 2009: 81). If discourse ethics matters to the formation of collective identity and legitimacy, then an unreadable text negotiated and written by an exclusive group of diplomats and civil servants away from public scrutiny is not a good foundation for the EU-28.

\section{The EMU's "post-truth democracy" and the 2013 "Fiscal Compact"}

The Lisbon Treaty was to provide lasting institutions and policies for the postCold War enlarged EU. The 2008 financial crisis and its impact on several Economic and Monetary Union (EMU) member states, which could no longer borrow on the open market at affordable rates, dashed this expectation. Habermas contrasts the communication community's deliberative and egalitarian processes of right-speaking with Carl Schmitt's decisionistic legal theory. In the latter case, "Positive law is valid by virtue of decision.... The formal rules of procedures require ... no further legitimation, for they fulfill their function - to absorb uncertainty" (Habermas 1975: 99). To bar "uncertainty," the European Council, a college of the EU heads of government, became the preeminent EU decision making-body under French and German leadership, although the Lisbon Treaty had not granted it legal authority. In December 2011 it announced the drafting of a new treaty, which would transform the EMU Stability and Growth Pact into a legally binding policy. The Pact had served as the admittance criterion to the EMU - low inflation rate, debt under 60 percent of the GDP and budget deficit under 3 percent - and its core norm to guide member state behavior, although it was interpreted rather loosely in the EMU's first decade (Crum 2013: 620; Strange 2012: 261). It has become now one of these truth-like 
statements that should have come out of right-speaking, except that an elite group of central bankers negotiated it, away from public scrutiny and according to somewhat arbitrary economic indicators (Jones 2002; McNamara 2011); Habermas dubs it a "fetish" (Habermas 2012b: 121). A confidential group of bureaucrats and diplomats drafted in only two months the Treaty on Stability, Coordination and Governance in the Economic and Monetary Union (TSCGEMU), also known as the "Fiscal Compact", which came into force on January 1, 2013 after being ratified by 25 of the 27 EU member states. The TSCGEMU gives up on the so-called "Community method" in the EMU by formally entrusting the main decision-making role to the European Council of heads of government in the EMU, and disempowering the EP, and its fledging communication community; nor is it part of the EU legal framework because of UK and Czech opposition. It is curious that Habermas called the TSGEMU a "step in the right direction" in his foreword to La constitution de l'Europe (Habermas 2012a: 10), while critiquing the EU turn toward "executive federalism" and "post truth democracy" (ibid.: 59; 2012b: 135). This may be symptomatic of the intellectual confusion created by hasty political decisions: "Typically, this centralization of power has been concealed by depoliticizing both the common standards adopted as well as the actual execution of policy surveillance [entrusted to the EU Commission]" (Crum 2013: 626-7).

\section{Conclusion: from theory to practice and back}

\section{EU discourse ethics after the fiscal compact}

Even under the new Fiscal Compact's regime deliberative politics are irrepressible. Gerard Strange argues that a process of "permanent renegotiations" over "different models of the EU," especially the French and German models, is going on, which the European Central Bank, the EU Council of finance ministers, the Eurogroup (EMU Council of finance ministers) and the European Council must arbitrate. The EP is left unmentioned unsurprisingly (Strange 2012: 270). But some MEPs resist being ousted from the "permanent renegotiations." The Spinelli Group, which formed in 2010, asked that a European Constitutional Convention be convened "as soon as possible" (at least by 2015), to draw up a new Treaty on economic governance especially. This third Convention could signify a return to the practice of right-speaking in EU constitutional politics. However there was little sense given, from the documents posted on Internet, whether this exercise would propose an intelligible treaty, or yet another set of unreadable amendments. Moreover the Spinelli Group's 110 members had their work cut out for themselves to convince their other 644 colleagues (Duff 2013: 148). Duff, who endorsed the Spinelli Group's proposal, welcomed more debates between nationalists and federalists at the EP and beyond, whose divide has been "perpetually disguised":

It would be useful, as well as fun, for the argument between "more" and "less" Europe to become more direct, better informed and more systematic.... 
Stronger direct engagement between the two sides might also reveal a surprising truth: that federalists and nationalists agree more than they expected on the diagnosis of Europe's problems and that they share a common enemy in the mainstream national parties which swap roles in national government and opposition while weakly dissembling and dealing in euphemism on matters European. At least Eurosceptics bring to European politics a gift of plain speaking which others would do well to emulate.

(Duff 2013: 151-2, italics by the author)

Issues of factual truth and truthfulness keep cropping up in EU politics, hence the continuing relevance of Habermas' theory of communicative action.

\section{Two rejoinders to Habermas}

A concrete case study raises new questions for theory, however. Empirical evidence confirms the importance of individual and small group agency in European integration politics (Eriksen and Fossum 2012: 332). But, as Habermas" "communicative rationality inheres in the practice of communication rather than in the individual subject" (Allen 2012: 361), his theory fails to address some important questions: Who sets up the communication community and initiates right-speaking? If debates get stuck, who helps return them to truthfulness and truth-telling? This chapter has mentioned Monnet, Schuman and Spinelli. Others could figure here such as German Foreign Affairs minister Joschka Fischer, whose speech to Berlin Humboldt University's students launched a transEuropean debate on the wisdom of a constitution for Europe, a taboo topic in the EU public sphere for 46 years (Fischer 2000; Dehousse 2004). Habermas' commitment to equality may bar him from overcoming the depersonalization inherent in his theory, and the lack of attention to political leadership. The Crisis of the European Union mentions the role of leaders committed to a normative project (i.e., Fischer) in contrast to those bent on winning reelection (i.e., Merkel and Sarkozy), but Habermas dedicates most of his comments to the factual reality of the EU demos whose individual subjects must reconcile their dual and sometimes contradictory interests as citizens of a member state and of the EU (Habermas 2012b: 28-44). This is a welcome return to his early interest in the communication community of citizens rather than of elected officials (Habermas 1975). Yet what might motivate a political leader to conceal or reveal political challenges clearly and truthfully? We need fresh theorizing of political leadership, akin to that which Habermas articulated about the collective capacity for right-speaking when he drew from Jean Piaget and Lawrence Kohlberg's theories of moral development (Habermas 1990: 116-94).

Habermas' discursive ethics could pay more attention also to the costs incurred by the communication community's actors. The three EU founding treaties (Paris, 1952, and Rome, 1958) required 18 months of arduous negotiations each (Melchionni and Ducci 2007). The theoretical fiction of an idealized communication community does not take sufficiently into account conflicts of 
interest and the difficulties of shared life. Nor does it acknowledge the necessary evocations and instrumental actions to convince or sometimes even frighten others into submission (Dietz 2002: 149-51). Citing Weber's apt metaphor for politics as "the strong and slow boring of hard boards," Mary G. Dietz articulates a concept of "methodical politics," that is "a sustained, purposeful activity that meets obstacle and undertakes acts of transformation in the world" (Dietz 2002: 162), which accounts better for the taxing aspect of truth-telling and rightspeaking in EU constitutional politics. Tantalizingly, Habermas introduces the question of time, which is "essential to justice" in his last essay on EU consitutionalism, but he does not develop this line of thought (Habermas 2012b: 70). What kind of discourse ethics would account for changes that cannot occur overnight? (ibid.: 69, Habermas' italics). It is to be hoped that Habermas will revisit the topic of temporality.

\section{Discourse ethics and political efficacy}

In the end what preoccupies his critics most is Habermas' insistence on truth in politics. They worry about "essentialism" while acknowledging the need for some standards to critique "ideology" (Camargo Brito 2010: 15-16). Against Kant, Hannah Arendt had critiqued truth in politics because its "coercive" aspects stifle the discussion of opinions whereas politics is about opinions, the justness of which can only be tried in dialogue among men in the plural. She added provocatively that the liar rather than the truth-teller is a political actor because he wants to make things different (Arendt 1993: 250-1). Yet it is no easier to get rid of truth in politics theoretically than it is in practice. In a surprising reversal, Arendt ended her famous essay "Truth and Politics" by claiming political relevance for truth: "Conceptually we may call truth what we cannot change; metaphorically, it is the ground on which we stand and the sky that stretches above us" (ibid.: 264). Too many lies or obfuscations, and the ground on which we stand is pulled from under our feet. Losing our bearing, our sense of reality we can no longer act. Arendt's equivocations are not unique and may explain the lasting hold of discussions on truth and lies (and Habermas' discourse ethics) in theoretical and political debates. For Allen W. Wood, Constant and Kant's disagreement about sincerity when hiding a potential victim of crime points to a very "troubling" dilemma. Yet, Wood agrees with "the decisive Kantian rejoinder ... that the policy of politicians to permit themselves lying declarations for supposedly worthy ends is precisely what does make possible much of what is utterly intolerable in our actual political life" (Wood 2011).

By discussing several validity claims Habermas brings helpful nuances to the discussion of sincerity in politics. What the EU case demonstrates empirically is that even on strategic grounds the redemption of linguistic validity claims matters. Former EU Commission President Jacques Delors recalls the two "methods" of decision-making in the EU's historical development: the community and intergovernmental methods. 
In practice the community method has been eroded, both by the treaties themselves, and by the behavior of the European Council. This has had the consequence of impeding the simplicity, and thus the transparency, of European debates. This in turn results in less efficiency, and in gaps in political and public communication.

(Delors 2013: 170-1)

The political legitimacy that justifies difficult decisions in times of crisis rests on trust, and trust rests on the perception that words describe verifiable facts, announce congruent deeds and develop rational arguments in intelligible terms. In other terms, truthfulness, right-speaking and efficacy should not be discussed as opposites but to the contrary as indispensable companions.

\section{Notes}

1 For critical commentaries on Habermas' discussions of European integration, see William E. Scheuerman 2008a, 2008b; and John P. McCormick 2007.

2 On the EU institutions' secretive nature see Anderson 2009. On the EU democratic deficit, see inter alia, Eriksen and Fossum 2000; Dehousse 2002; Nicolaïdis and Howse 2001.

3 For a discussion of truth in EU politics, see Boylan 2008; Schmidt 2006; and Guisan 2003.

4 The author has discussed this question elsewhere (Guisan 1999: 267-72; 2012: 120-3).

5 For Kant the articulation of universal norms comes out of the solitary exercise of one's reason.

6 On why Habermas dropped the validity claim of intelligibility, see Niemi 2005.

7 For an excellent discussion of Habermas' moral theory see Hunyadi 1990

8 Berthold Rittberger argues that on the basis of available evidence it is difficult to discriminate between communicative and strategic action in the discussions that led to the setting up of the Assembly. He concludes that, "in either cases, the outcome would have been the same" (Rittberger 2005: 103-5).

9 Monnet, who first opposed the idea of the common market, was not involved in the EEC negotiations (Melchionni and Ducci 2007: 67-80, 122-3; Anderson 2009: 25).

10 Treaty available at www.consilium.europa.eu/documents/treaty-of-lisbon?lang=en (downloaded, October 12, 2013).

\section{Bibliography}

Allen, A. 2012. "The unforced force of the better argument: reason and power in Habermas' political theory." Constellations 19: 3, 353-68.

Anderson, P. 2009. The New Old World. New York and London: Verso.

Arendt, H. 1993. Between Past and Future. New York: Penguin Books.

Banchoff, T. 1999. "National identity and EU legitimacy in France and Germany." In Banchoff, T. and Smith, M. P. (eds) Legitimacy and the European Union: The Contested Polity. London and New York: Routledge, pp. 180-98.

Boylan, T.S. 2008. "Did the Treaty of Lisbon need a European version of the Federalist Papers?" Hamburg Review of Social Sciences 3: 2, 213-46.

Camargo Brito, R. 2008. "The critique of ideology revisited: a Žižekian appraisal of Habermas's communicative rationality." Contemporary Political Theory 7, 53-71. 
Camargo Brito, R. 2010. 'Habermas avec Žižek', International Journal of Zizek Studies. www.zizekstudies.org/index.php/ijzs/article/viewFile/224/326.

Corbett, R. 1998. The European Parliament's Role in EU Closer Integration. New York: St Martin's Press.

Corbett, R. and Mendez de Vivo, I. 2008. Report on the Treaty of Lisbon, European Parliament.

Crum, B. 2013. "Saving the Euro at the cost of democracy?" Journal of Common Market Studies 51: 4, 614-30.

Dehousse, R. (ed.). 2002. Une Constitution pour l'Europe? Paris: Presses de Sciences Po.

Dehousse, R. 2004. "La méthode ouverte de coordination: Quand l'instrument tient lieu de politique." In P. Lascoumes and P. Le Galès (eds), Gouverner par les instruments. Les Presses de Sciences Po.

Dehousse, R. 2006. "The unmaking of a constitution: lessons from the European Referenda." Constellations 13: 2, 151-64.

Delors, J. 2013. "JCMS 50th Anniversary Lecture Economic Governance in the European Union: past, present and future." Journal of Common Market Studies 51: 2, 169-78.

Dietz, M. G. 2002. Turning Operations: Feminisms, Arendt and Politics. New York: Routledge.

Duchêne, F. 1994. Jean Monnet: The First Statesman of Interdependence. New York and London: W.W. Norton and Company.

Duff, A. 2013. "On dealing with Euroscepticism." Journal of Common Market Studies 51: $1,140-52$.

Eriksen. E. O. and Fossum, J. E. 2012. "Representation through deliberation - the European case." Constellations 19: 2, 325-39.

Eriksen. E. O. and Fossum, J. E. (eds). 2000. Democracy in the European Union: Integration through Deliberation? New York: Routledge.

European Council. 2007. Treaty of Lisbon, OJEU, 2007/C 306/10. http:europa.eu/Lisbon treaty/full_text/index_en.htm (accessed November 12, 2010). Original version before "consolidation".

Featherstone, K. 1994. "Jean Monnet and the 'democratic deficit' in the European Union”. Journal of Common Market Studies 32: 2, 149-70.

Fischer, J. 2000. "From Confederacy to Federation - Thoughts on the finality of European integration." May 12, Humboldt University, Berlin. http: www.auswaertiges-amt. de/6_archiv/2/r/r000512c.htm (accessed July 20, 2000).

Fontaine, P. 2000. A New Idea for Europe: The Schuman Declaration, 1950-2000. Luxembourg: Office for Official Publications of the European Communities.

Friedrich, D. 2011. Democratic Participation and Civil Society in the European Union. Manchester, UK: Manchester University Press.

Fultner, B. 2001. "Translator's Introduction." In Habermas, J. On the Pragmatics of Social Interaction: Preliminary Studies in the Theory of Communicative Action, trans. B. Fultner. Cambridge, MA: MIT Press.

Gaffney, J. 1999. "Political rhetoric and the legitimation of the European Union." In Banchoff, T. and Smith, M. P. (eds) Legitimacy and the European Union: The Contested Polity. London and New York: Routledge, pp. 199-211.

Gerth, H. H. and Mills, C.W. (eds) 1973. From Max Weber: Essays in Sociology, Trans. And Introduction by H. H. Gerth and C. W. Mills. New York: Oxford University Press.

Guisan. C. 1999. Lost Treasure? An Arendtian Study of the Ethical Politics of Contemporary European Integration. Ann Arbor, MI: UMI Dissertation Services.

Guisan. C. 2003. Un sens à l'Europe: Gagner la paix. Paris: Odile Jacob. 
Guisan. C. 2012. A Political Theory of Identity in European Integration: Memory and Policies. New York and Oxford: Routledge.

Habermas, J. 1975. Legitimation Crisis, trans. Thomas McCarthy. Boston: Beacon Press.

Habermas, J. 1990. Moral Consciousness and Communicative Action, trans. Christian Lehnhardt and Shierry Weber Nicholsen. Cambridge, MA: The MIT Press.

Habermas, J. 1992. Autonomy and Solidarity, ed. and trans. Peter Dews. London and New York: Verso.

Habermas, J. 1996. Between Facts and Norms: Contribution to a Discourse Theory of Law and Democracy, trans. William Rheg. Cambridge, MA: The MIT Press.

Habermas, J. 1997. A Berlin Republic: Writings on Germany, trans Steven Randall. Lincoln, NE: University of Nebraska Press.

Habermas, J. 2001. On the Pragmatics of Social Interaction: Preliminary Studies in the Theory of Communicative Action, trans. B. Fultner. The MIT Press, Cambridge. MA.

Habermas, J. 2006. Times of Transition, ed. and trans. Ciara Cronin and Max Pensky. Cambridge, UK and Malden, USA: Polity.

Habermas, J. 2009. Europe: The Faltering Project, trans. Ciara Cronin. Cambridge, UK and Malden, USA: Polity.

Habermas, J. 2012a. La constitution de l'Europe, trans. Christian Bouchindhomme. Paris: Gallimard.

Habermas, J. 2012b. The Crisis of the European Union: A Response, trans. Ciaran Cronin. Cambridge, UK: Polity Press.

Hewstone, M. 1986. Understanding Attitudes to the European Community: A SocialPsychological Study in Four Member States. Cambridge, UK: Cambridge University Press.

Hunyadi, M. 1990. "Une morale postmétaphysique, Introduction à la théorie morale de Jürgen Habermas". Revue de théologie et de philosophie 122: 4, 467-83.

Hug, S. 2002. Voices of Europe: Citizens, Referendums and European Integration. Lanham, MD: Rowman and Littlefield.

Joly, M. 2007. Le mythe Jean Monnet: Contribution à une Sociologie Historique de la Construction Européenne. Paris: CNRS Éditions.

Jones, E. 2002. The Politics of Economic and Monetary Union: Integration and Idiosyncrasy. Lanham, MD: Rowman and Littlefield.

Judge, D. and Earnshaw, D. 2008. The European Parliament, 2nd edn. Basingstoke, UK: Palgrave Macmillan.

Kant, I. 1949. Critique of Practical Reason and Other Writings in Moral Philosophy, ed. and trans. Lewis White Beck. Chicago: University of Chicago Press, pp. 346-50.

Machiavelli. 1988. The Prince, ed. Quentin Skinner, trans. Russell Price. Cambridge, UK: Cambridge University Press.

McCormick, J. P. 2007. Weber, Habermas, and Transformations of the European State. Cambridge, UK: Cambridge University Press.

McNamara, K. R. 2011. Historicizing the Unique: Why the EMU has no Fiscal Authority and Why it Matters. Mortara Center Working Paper, September.

Melchionni, M. G. and Ducci, R. (eds). 2007. La Genèse des Traités de Rome: Entretiens inédits avec 18 acteurs et témoins de la négociation. Lausanne: Fondation Jean Monnet pour l'Europe et Paris: Economica.

Mertens. 1996. "Cosmopolitanism and citizenship: Kant against Habermas." European Journal of Philosophy 4: 3.

Monnet, J. 1978. Memoirs, trans. Richard Mayne. New York: Doubleday. 
Nicolaïdis, K. and Howse, R. (eds). 2001. The Federal Vision: Legitimacy and Levels of Governance in the United States and the European Union. Oxford: Oxford University Press.

Niemi, J. I. 2005. "Habermas and Validity Claims." International Journal of Philosophical Studies 13: 2, 227-44.

Rieben, H., Nathusius, M., Nicod, F. and Camperio-Tixier, C. 2000. Un changement d'espérance: La Déclaration du 9 mai 1950 Jean Monnet - Robert Schuman. Lausanne: Fondation Jean Monnet pour l'Europe.

Rittberger, B. 2005. Building Europe's Parliament: Democratic Representation beyond the Nation-State. Oxford: Oxford University Press.

Schuman, R. 1964. Pour l'Europe, Paris: Nagel.

Scheuerman, W. E. 2008a. Frankfurt School Perspectives on Globalization, Democracy and the Law. London and New York: Routledge.

Scheuerman, W. E. 2008b. "Global governance without global government?" Political Theory 6: 3, 133-51.

Spinelli Group. 2013. Manifesto and Current Events. www.spinelligroup.eu.

Schmidt, V. A. 2006. Democracy in Europe: The EU and National Politics. Oxford: Oxford University Press.

Strange, G. 2012. "The Euro, EU social democracy and international monetary power: a critique of new constitutionalism." Globalizations 9: 2, 257-72.

Tavoillot, P.-H. 2013. "Réhabilitons l'exercice de la dispute! Un bon outil pour la morale laïque.” Le Monde April 15.

Varden, H. 2010. "Kant and lying to the murderer at the door.... One more time. Kant's legal philosophy and lies to murderers and Nazis". Journal of Social Philosophy 41: 4, 403-21.

Wood, A. W. 2011. "Kant and the right to lie reviewed essay: On a supposed right to lie from philanthropy, by Immanuel Kant (1797)". Eidos, no. 15, July/Dec. http://rcientificas. uninorte.edu.co/index.php/eidos/issue/view/263.

Zarka, Y. C. 2013. "En avouant, M. Cahuzac a brisé un tabou de la caste politique. La moralization est un leurre, la transparence, un imperative." Le Monde, April 18.

\section{Interviews by the author}

MEP Bourlanges, J.-L. 1999. EP, Strasbourg, April 7.

MEP Corbett, R. 2008. EP, Brussels, March 13.

MEP Duff, A. 2008. EP, December 3.

MEP Leinen, J. 2008. EP, Brussels, December 4.

Rabier, J.-R. 1999. (former collaborator of Jean Monnet), Brussels, March 3.

MEP Rack, R. 2005. EP, Strasbourg, May 14. 


\section{Index}

Abin, Esther 8, 10, 11, 109, 152

Aboulafia, Mitchell 84, 90

accountability $10,13,28,68,73,80,82$, 86, 192, 193

Alexander, Jeffrey 78, 90

Améry, Jean 12, 156, 157, 159, 161, 163-72

anarchic 7

Anderson, Pamela Sue 7, 10, 92, 106, 107, 152

Anderson, Perry 201

Andersson, Staffan 66, 72

Apel, Karl-Otto 72, 176, 186

Aquinas, Thomas 30, 31

Arendt, Hannah 160, 162, 171, 189, 200-2

Aristotle 30, 31, 92, 93, 105, 107

Aristotle: Nicomachean Ethics 31, 93, 107

assertion 9, 17-19, 21, 22, 30, 97-9, 104

Atwell, John 153, 155

Audi, Robert 35, 44

Augustine, Saint 26, 30, 31

Baiasu, Roxana 107

Baiasu, Sorin 8, 11, 139, 153, 155

Baier, Annette 107, 156, 164, 169, 171

Banchoff, Thomas 193, 201, 202

Bartels, Larry 72

Bateson, Gregory 124, 125, 130, 133

Berg-Sørensen, Anders 8, 10, 77

Boda, Zsolt 12, 173, 175, 182, 183, 186

Bohman, James 70, 72

Bok, Sissela 13, 109, 121

Bowler, Shaun 179, 180, 186

Boxer, Philip 131, 133

Boyer, Alain 113, 121

Boylan, Timothy 196, 201

Breitmeier, Helmut 176, 186

Brenner, Joseph 131, 133

Brito, Camargo 191, 192, 200-2
Brudholm, Thomas 170, 171

Buckley-Zistel, Susanne 167, 168

Burns, James 178, 186

Byrd, Sharon 169, 171

Campbell, William 175, 186

candour $1,8,10,12,14,93-6,98-102$, $105,107,148,151,154,172$

care: as a precondition of political trust 12 , 51-3, 70, 156, 164, 165, 168, 170, 175

Carlin, John 166, 167, 171

Carroll, Lewis: Alice in Wonderland 21, 31, 135

Carson, Thomas 12, 13

Cheli, Simone 8, 11, 122-4, 131-4

Chisholm, Roderick 9, 13, 18, 30, 31

Cholbi, Michael 152, 155, 169, 171

Christopher, Christopher 132

Cicero 60

Clinton, President Bill 24, 31, 180, 187

Coady, Anthony 88, 90

Cohen, G.A. 9, 46, 47, 58, 59, 68, 72, 73

collective identity $185,187,197$

Collini, Simone 128, 134

commissive $8,49,56$

communicative action 190-2, 194, 199, 202, 203

community method 198, 201

complex system 131

conflict $66,71,86,111,122,132,133$, $150,157,158,160,164,168,171,178$, 193, 194, 199

Constant, Benjamin 4, 5, 13, 62, 63, 72, $111,121,139-41,152,169-72,189$, 200

constructivism 10, 11, 73, 123, 132-4

contingency $11,109,110,113,114,116$, 117,121

Coomaraswamy, Ananda 132, 134 
Corbett, Richard 196, 202, 204

corruption 2, 3, 7-10, 60, 61, 63, 65-73, $78,90,160,180,185,186,190$; political 8, 9, 60, 61, 63, 65-8, 70-3, 186

cosmopolitanism 72, 90, 157, 160, 162, 170,203

cultural hegemony 128-30, 132

cybernetics $130,133,134$

cynicism $8,10,67,77-81,83-91,122$

deception 8, 9, 12-14, 17-27, 31, 61, 65, 110-12, 122, 132, 139, 143, 145-51, 153-6, 158, 159, 162, 163, 165, 166, 168, 180; political 17, 19, 21, 23, 25, 27, 29,31

defamation 3, 158, 169

Dehousse, Renaud 195, 199, 201, 202

democracy 5, 9, 28, 37, 44, 45, 60-2, 65, $66,68,71-3,78,80-6,88-91,129,133$, $174,175,177,178,186,187,189-94$, 196-8, 201-4

democratic deficit 189, 190, 201, 202

Desmond, William 78, 90

Dietz, Mary 200, 202

Directorate, The 5, 62

Dirty Hands 11, 70, 73, 89-91

discourse ethics 12, 186, 190, 191, 193, 194, 197, 198, 200

discourse of truth $125,127-9$

disillusion $50,77,78,88,89$

dissent 122, 129-32

dissimulation 11, 58, 111, 139, 145, $147-51,154,155$; obligation to 11,151 ; political 11, 139, 146, 151

doubt: and political disagreement 11

Dryzek, John 176, 186

Ducci, Roberto 199, 201, 203

Duchêne, François 193, 202

Duff, Andrew 196, 198, 199, 202, 204

Duke, E.A. 132, 134

duplicity $66,67,73,160$

Dutch and French referenda 190

duty not to lie $12,60,62,63,94,95,97$, 100,104

duty of right: truthfulness as a 2, 4, 5, 145

Ellis, Elisabeth 160, 169-71

Elridge, Michael 84, 90

epistemological closure 130

epistemological doubt 11, 122

Eriksen, Erik 192, 193, 199, 201, 202

ethical cultivation $10,78,86,87$ ethics of conviction 189

European Charter of Fundamental Rights 190, 195

European coal and steel community 192

European Constitution: Convention on the Treaty for 195,198

European institution building 8

European Parliament 190, 195, 202, 203

European Union 185, 189, 196, 199, 201-4

Evans, Mark 8, 9, 46

evil $13,48,57,68,84,88,90,100,101$, $106,169,172$

exceptionalism 4

experimentalism 82,84

faithfulness 8,120

fallibilism 84, 89

Featherstone, Kevin 192, 194, 202

federation 160, 163, 192, 194, 198, 202

Feehan, Thomas 9, 13, 18, 30, 31

Fischer, Joschka 199, 202

Foerster, Heinz 123, 130, 131, 134, 135

Fontaine, Pascal 193, 202

formal and material wrong 158, 160

Fossum, John 192, 193, 199, 201, 202

Foucault, Michel 125, 126, 128, 134

Frankfurt, Harry 111, 121, 204

Fransella, Fay 124, 133, 134

fraudulent contract 3

freedom of expression 3, 169

French Revolution 5, 61, 62

Gaffney, John 190, 202

Gangl, Amy 176, 186

Garsten, Bryan 36, 44

Gaus, Gerald 9, 30-8, 41-4

genocide 52, 156, 160, 166-8, 171

Geuss, Raymond 118, 121

Gilligan, Andrew 28, 30

Gilovic, Thomas 44

Glasersfeld, Ernst von 123, 124, 126, 131, 134

Gourevitch, Philip 167, 171

governing capacity $8,12,173,174,180$, $181,184,185$

Gramsci, Antonio 129, 133, 134

Grice, Paul 30, 31

Griffin, Dale 44

Grillo, Giuseppe 129, 133, 134

Grosskopf, Anke 175, 186

Guisan, Catherine 8, 12, 189, 192, 196, 201-3

Gutmann, Amy 67, 72 
Györffy, Dora 185, 186

Habermas, Jürgen 12, 176, 186, 189-95, 197-204

Harold, Crystal 178, 179, 187

Haslam, Alexander 185-7

Hawdon, James 175, 187

Hay, Colin 170, 171

Hayek, Friedrich 132, 135

Hegel, Georg W.F. 73, 169, 171

help: as a precondition of political trust 12 , $156,165-8,170,185$

Herbert, Maria von 10, 93, 94, 106-8

Hewstone, Miles 194, 203

Heywood, Paul 66, 72

Hibbing, John 187

Hobbes, Thomas 7, 13, 91, 122

Holtz, Brian 178, 179, 187

honesty $60-5,82,94,95,98-100,104$, $105,109,142,152,158,159,161,164$, 169,192

Hruschka, Joachim 108, 169, 171

Humpty Dumpty 21

Hunyadi, Mark 201, 203

hypocrisy 9, 47-9, 91, 94, 103, 104, 169

implicature 18, 21, 23

individuation 131

institutions $6,8,11,37,44,61,64,65$, $67-9,73,78,112,137,139,146,147$, 149-51, 164, 173-87, 189, 193-5, 197, 201

instrumentalisation 9, 10, 179, 200

intelligibility $12,36,37,112,140,141$, $176,190-8,201$

intergovernmental methods 200

intermediate principle 4,13

international relations $7,13,122$

Jacobins 5

Johnston, Michael 66-8, 72

justice $10,12,28,31,33,35,38,44,50$,

$72,73,84,88,89,92,103,130,140$,

$157,160,164,166,169,171,176-8$,

$185-8,192,193,200$

justificatory sincerity 32,33

Kahneman, Daniel 44

Kant, Immanuel 2-14, 30, 31, 60-9, 71-3, 92-108, 113, 116, 119, 121, 139-72,

189, 191, 200, 201, 203, 204;

Categorical Imperative 11, 98, 100, 102, 105, 143, 151, 160, 161, 169;

Groundwork 100-2, 108, 152, 169; imputability 4, 154; lies 'in a jurist's sense' 3, 142-5, 150; moralising politician $5,60,67,115,116$;

'murderer-at-the-door' examples 2, 3, 5, $6,13,14,62-4,139,154,155,158,159$, 163, 169-72, 189, 204; “On a Supposed Right to Lie From Philanthropy" 2, 4, 14, 60, 95, 98, 108, 139, 141, 143, 152, 154, 158, 159, 169; Perpetual Peace 4, $60,62,63,72,157,160,161,169$; the postulate of public right $5,7,8$; the principle of publicity $8,9,63,161,162$, 170; right and politics 4,162 ; the rightful condition 4, 6-8, 11, 12, 61, 63-5, 142, 149-51, 156, 157, 159, 160, 166; truthfulness as a duty to oneself 102 ; untruthfulness as a wrong 'in general' 5

Kantian 2, 7, 8, 10-14, 53, 61, 62, 65, 67, $68,70-3,92-7,99-107,112,139,143$, $151,155,158,170,172,191,200$

Karp, Jeffrey 179, 180, 186

Karvonen, Lauri 179, 187

Kaufman, Zach 167, 168, 171

Keeney, Bradford 128, 130, 135

Kelly, Dr David 28-30, 124-6, 128, 129, $132-5$

Kennedy, John F. 20, 22

Kenny, Vincent 131, 133

Kissinger, Henry 122, 123, 135

Klandermans, Bert 185, 187

Kloppenberg, James 84, 85, 90

Korsgaard, Christine 13, 108, 169, 172

Koven, Steven 180, 187

Kramer, Roderick 178, 187

Krippendorff, Klaus 133, 135

Kunselman, Julie 180, 187

Lacan, Jacques 127, 131, 135

La Caze, Marguerite 8, 12, 152, 156

Langton, Rae 106-8, 152, 155

Laursen, John 78, 90

Leventhal, Gerald 176, 177, 187

Levi, Margaret 174, 179, 180, 187

Levinas, Emmanuel 124, 135

Littvay, Levente 187

Loriaux, Sylvie 6, 13, 169

Lottman, Herbert 170, 172

lying $1-6,8-10,12-14,18-21,23,24,28$, $60,62-5,72,73,93-102,104-6,108$, $111,121,132,139,141-6,148,149$, $152-5,158,159,169,172,173,176$, 180, 189, 200, 204; and deception 13, 139, 146; international 7, 13 
McCormick, John 201, 203

Macedo, Stephen 38, 43, 44

Machiavelli, Niccolo 57, 111, 121, 123, 189, 203; The Prince 121, 122, 203

McNamara, Kathleen 198, 203

Mahon, James 3, 12, 14, 143, 144, 152, $153,155,169,172$

making sense 105, 109, 110, 112, 114, $116,117,119$

Maturana, Humberto 124, 135

Mazella, David 78, 90

meaning $8,9,11,21,25,26,30,51,54$, $61,66,68,73,77-81,89,94,115,118$, $122-5,127-9,131,141,157,169,176$, 177, 191; accepted communicative 9

Medve-Bálint, Gergo 174, 175, 182, 183, 184

Melchionni, Maria 199, 201, 203

mendacity (see lying) 8, 18, 28, 189

Mendez de Vigo, Inigo 196, 202

Mertens, Thomas 152, 155, 189, 203

Miller, Gary 174, 187

money $39,54,64,68,70,153,159,186$

Monnet, Jean 192-4, 199, 201-4

moral criticism 8, 9, 47, 49-53, 55, 57

moral imagination $77,78,82,84,85,88$, 89

motivation 5, 61, 65, 67-73, 94, 116, 173, $174,178,179,186,188$

Murphy, Kristina 176, 187

Nagel, Thomas 32, 33, 44, 204

Navot, Doron 8-10, 60, 152

Nazism 14, 39, 94, 95, 155, 163-5, 172 , 192, 204

Newey, Glen 8, 9, 17, 30, 31, 152

Newman, Saul 127, 135

Nicod, Françoise 192, 204

Nicolaïdis; Kalypso 201, 204

Nicolovius 108

Niemi, Jari 201, 204

normativity $11,17,21,61,70,71,78,113$, 115-17, 141, 153, 155, 159, 175-7, 179, $185,189,191,192,199,201,203$

Obama, President Barack 10, 77-91 opportunism: political 5, 26, 78, 111 ordinary vices $10,59,77-9,85,86,89,91$ Orwell, George 91, 122, 126, 134

Patocka, Jan 124, 135

Paton, Herbert 13, 14, 62, 63, 72

peace $7,72,83,84,88,90,111,156,160$, $161,163,168,170,192,193,202$ persuasion $32,36,44,92-7,99,105,190$, 193

Pharr, Susan 175, 186, 187

Piaget, Jean 123, 130, 134, 135, 199

Plato 51, 123, 132, 134, 194p; Cratylus 123; Thaetetus 123

political efficacy 200

political liberalism $38-45,73$

political power 10,32 ; misuse 65

power: system of 125,128

pragmatism 68, 83-5, 87, 89-91

Preez, Peter du 125, 134

Prigogine, Ilya 131, 133, 135

Prime Minister (Tony Blair) 29, 30

private gain $62,65,67-70,71,80$

provisional state $157,161,168$

prudence $4,102,108$

publicity $8-10,15,60-5,67,69,71,73$, 161,162

public power: abuse $62,67,71,72,78,92$, 112,121

public reason: 'consensus' model 38, 42, 44; 'convergence' model 9, 35

quasi-Platonic 52

quasi-Weberian 58

Quong, Jonathan 9, 32-45

Rawls, John 28, 31-3, 35, 37-40, 43-5, 73

Raz, Joseph 3, 14

reason: practical 45, 102, 112-16, 120 , 121, 191, 203; public 8, 9, 32-5, 37-9, 41-5, 96

reasonableness $9,17,21,23,25-9,33-43$, $60,112,163,170,192$; interpretative 25

respect $12,51-3,56,61,67,69,114,152$, $156,158,159,162,164,165,168,170$, 193

reticence $10,14,95,98,99,101-3,105$, $152,154,172$

revolution $5,61,62,162-4,184$

rights $2-8,13,14,19,22,46,51-3,56,58$, 60-3, 65, 69-73, 95, 98, 108, 139-41, $143-5,149,154,155,157-64,169-72$, 176, 196, 204; civil 79, 81, 149, 156, 162, 164, 169, 187; public 5, 7, 8, 65, $161,162,170$

right-speaking 12, 189, 190, 192-201, 203

Ripstein, Arthur 73

Rittberger, Berthold 192, 193, 201, 204

Ronzoni, Miriam 73

Rorty, Richard 88, 90, 118, 121, 172 
Rose, Richard 174, 175, 187

Rousseau, Jean-Jacques 73, 110, 121

Runciman, David 77, 91

Russell, Bertrand 133, 136, 203

Rwanda 12, 157, 166-8, 170, 171

Sandel, Michael 85, 91

Sanna, Manuela 132, 135

Saxonhouse, Arlene 68, 73

Scheuerman, William 201, 204

Schmidt, Vivien 190, 201, 204

Schmitt, Carl 197

Schneewind, Jerome 31, 155

Scholl, Inge 163, 172

Schultz, Bart 84, 91

Schuman, Robert 192-4, 199, 202, 204

Schwartzman, Micah 32, 34, 44, 45

Schweer, Martin 174, 187

Seawright, Jason 72

secrecy $63,65,73,98,111,159-62,180$, 184, 194, 201

self-defence 7

Shea, Louisa 78, 91

Shklar, Judith 10, 47, 59, 77-9, 85-9, 91

Siebers, Tobin 169,172

silencing 9, 46-55, 57, 58, 142, 143, 145, 147,152

Simondon, Gilbert 131, 135

sincerity: political communication 12 , 179,180 ; political rhetoric $10,77-81$, $83-5,87,89,91,202$; as procedural fairness norm 12, 173, 175-9, 184; and publicity $60,61,63,65,67,69,71,73$; and rhetoric $8,10,92-7,99-105,194$; and trust $107,156,157,159,161,163$, $165,167,169,171$

Sloterdijk, Peter 89, 91

Smith, Kevin 175, 177-9, 187, 193, 201, 202

Socrate 124, 135

speaker-intention 26

Spinelli 196, 198, 199, 204

Spinoza, Baruch 112, 119-21

Starobinsky, Jean 110, 121

Starr, Kenneth 23, 30, 31

statement 1-2, 12, 18, 20, 28, 34, 50, 117, $125,128,129,141-5,149,153,157$. $158,163,189,192,195,198$

Stokes, Susan 178, 186

Stokker, Laura 174, 187

Sunstein, Cass 70, 71, 73

Sverdlik, Steven 69, 73

Szasz, Thomas 126, 135 target-belief of the speaker 9, 24, 26, 27

Tebbit, Sir Kevin 29, 30

technocracy 12, 190, 193

temporality 109, 119-21, 200

tendency standard 71

Thomassen, Lasse 169, 170, 172

Thompson, Dennis 9, 61, 63, 66-8, 70-3

Thoreau, Henry D. 124, 135

tradition, american political 80-5, 89, 90

transparency $10,11,77,80,82,110$, 195-7, 201

Treaty of Lisbon 190, 195-7, 201, 202

trust $6-8,12,13,64,71,73,77,79,80,82$, 107, 113, 156-71, 173-87, 190, 191, 201; between states 7, 168; political 8, $12,156,157,159,161,163-5,167-9$, 171, 187; public $6,77,80,82,175,184$

truth: as normative standard 11

truthfulness: and candour 12, 101; in politics $2,5,7,10-12,28,61,71,92-4$, 96, 97, 100, 101, 105, 109-12, 117, $120,121,125,126,139,150,171,172$, 180, 189-91, 200, 201; as a principle of 'the strict kind' $8,11,32,38,43,139$, $146,153,161$; sincerity as $1,92,94,96$, 105

truth-speaking 166

truth-telling $12,28,63,95,103,104,159$, 176, 189-95, 197, 199-201, 203

untruthfulness $1,2,5-8,143,145,153$, 176

uprightness 93, 94, 99, 101, 103, 105, 107

Valentini, Laura 73

Vallier, Kevin 35, 44

Varden, Helga 6, 14, 152, 155, 159, 163 , $169,172,189,204$

Varela, Francisco 124, 130, 131, 135, 136

Velicogna, Francesco 123, 134

vices $10,33,36,48,59,77-8,85-7,89$, 91,120

Vico, Giambattista 123, 134

Vries, Hent de 88, 91

Vuillemin, Jules 170, 172

war $7,12,28,77,81,84,87,88,111,122$, $156,157,160,161,163,165,167,170$, $180,190,197$

war: civil 12, 156, 160; right to wage 7

Warren, Mark 9, 61, 66, 67, 70, 73

Watzlawick, Paul 130, 136

Weber, Max 58, 59, 117, 189, 200, 202, 203 
210 Index

Williams, Bernard 11, 12, 14, 64, 73, 105, 106, 108-21, 152, 155

Zarka, Yves 189, 204

Young, Oran 176, 186

Zoffoli, Enrico 8, 9, 32, 44, 45

Zolkos, Magdalena 170, 172

Zürn, Michael 176, 186 